\title{
Molecular mechanisms of beta-carotene action in the lung
}

Citation for published version (APA):

van Helden, Y. G. J. (2010). Molecular mechanisms of beta-carotene action in the lung. [Doctoral Thesis, Maastricht University]. https://doi.org/10.26481/dis.20100701yv

Document status and date:

Published: 01/01/2010

DOI:

10.26481/dis.20100701yv

Document Version:

Publisher's PDF, also known as Version of record

\section{Please check the document version of this publication:}

- A submitted manuscript is the version of the article upon submission and before peer-review. There can be important differences between the submitted version and the official published version of record.

People interested in the research are advised to contact the author for the final version of the publication, or visit the DOI to the publisher's website.

- The final author version and the galley proof are versions of the publication after peer review.

- The final published version features the final layout of the paper including the volume, issue and page numbers.

Link to publication

\footnotetext{
General rights rights.

- You may freely distribute the URL identifying the publication in the public portal. please follow below link for the End User Agreement:

www.umlib.nl/taverne-license

Take down policy

If you believe that this document breaches copyright please contact us at:

repository@maastrichtuniversity.nl

providing details and we will investigate your claim.
}

Copyright and moral rights for the publications made accessible in the public portal are retained by the authors and/or other copyright owners and it is a condition of accessing publications that users recognise and abide by the legal requirements associated with these

- Users may download and print one copy of any publication from the public portal for the purpose of private study or research.

- You may not further distribute the material or use it for any profit-making activity or commercial gain

If the publication is distributed under the terms of Article $25 \mathrm{fa}$ of the Dutch Copyright Act, indicated by the "Taverne" license above, 


\title{
Molecular Mechanisms of Beta-Carotene Action in the Lung
}

\author{
Yvonne G.J. van Helden
}


(C) 2010 Yvonne G.J. van Helden

ISBN: 978-90-6464-398-9

Cover design: $\quad$ Yvonne van Helden

Lay-out:

Yvonne van Helden

Production:

GVO drukkers \& vormgevers B.V. | Ponsen \& Looijen
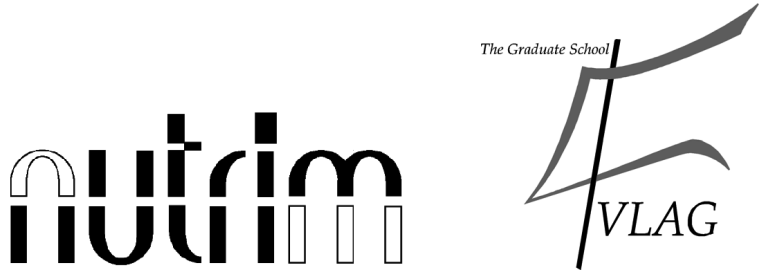

The study presented in this thesis was performed within NUTRIM School for Nutrition, Toxicology and Metabolism which participates in the Graduate School VLAG (Food Technology, Agrobiotechnology, Nutrition and Health Sciences), accredited by the Royal Netherlands Academy of Arts and Sciences. 


\section{Molecular Mechanisms of Beta-Carotene Action in the Lung}

\section{PROEFSCHRIFT}

ter verkrijging van de graad van doctor aan de Universiteit Maastricht, op gezag van Rector Magnificus, Prof. Mr. G.P.M.F. Mols, volgens het besluit van het College van Decanen, in het openbaar te verdedigen op donderdag 1 juli 2010 om 14.00 uur

door

Yvonne Gerarda Jacoba van Helden

Geboren op 31 mei 1981 te Grubbenvorst 


\section{Promotores:}

Prof. dr. F.J. van Schooten

Prof. dr. ir. J. Keijer (Wageningen Universiteit)

\section{Copromotor:}

Dr. R.W.L. Godschalk

\section{Beoordelingscommissie:}

Prof. dr. E.C.M. Mariman (voorzitter)

Prof. dr. A. Bast

Dr. R.M. Elliott (Institute of Food Research, Norwich, UK)

Prof. dr. R.A. Woutersen (Wageningen Universiteit, Wageningen/TNO, Zeist)

Prof. dr. E.F.M. Wouters 


\section{Contents}

\section{Chapter 1}

Introduction

Chapter 2 34

Beta-carotene affects oxidative stress-related DNA damage in lung epithelial cells and in ferret lung.

Chapter 3 54

Beta-carotene metabolites enhance inflammation-induced oxidative DNA damage in lung epithelial cells.

Chapter 4 70

Transcriptome analysis in benefit-risk assessment of micronutrients and bioactive food components.

Chapter 5

Knockout of the Bcmol gene results in an inflammatory response in female lung, which is suppressed by dietary beta-carotene.

Chapter 6

Down regulation of $\mathrm{Fzd} 6$ and $C$ thrc 1 and up regulation of olfactory receptors and protocadherins by dietary beta-carotene in lungs of $\mathrm{Bcmo1}^{-/}$- mice

Chapter 7

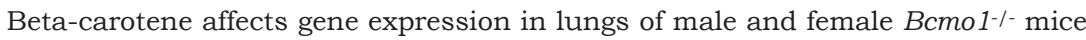
in opposite directions.

Chapter 8 160

Global gene expression response of mouse lung, liver and white adipose tissue to beta-carotene supplementation, knockout of Bcmo1 and gender

Chapter 9 178

Organ specificity of beta-carotene induced lung gene expression changes in Bcmo 1\% mice

Chapter 10

Summary and general discussion 
(1)

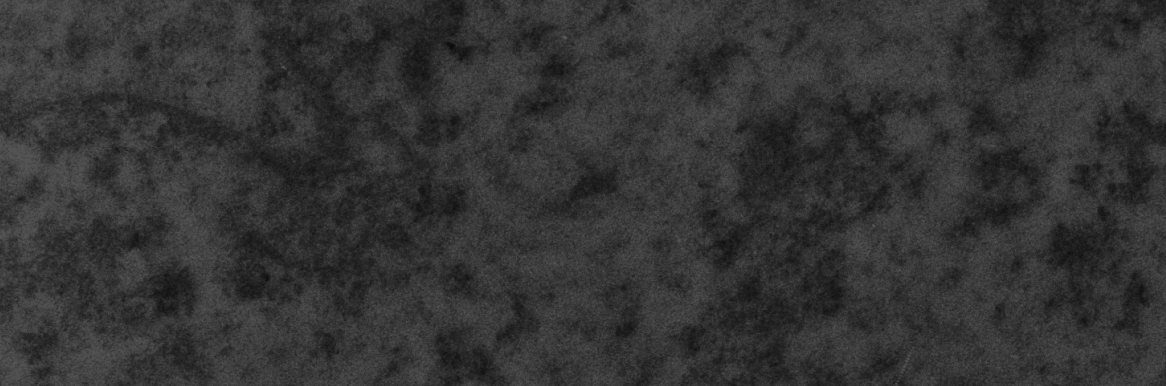

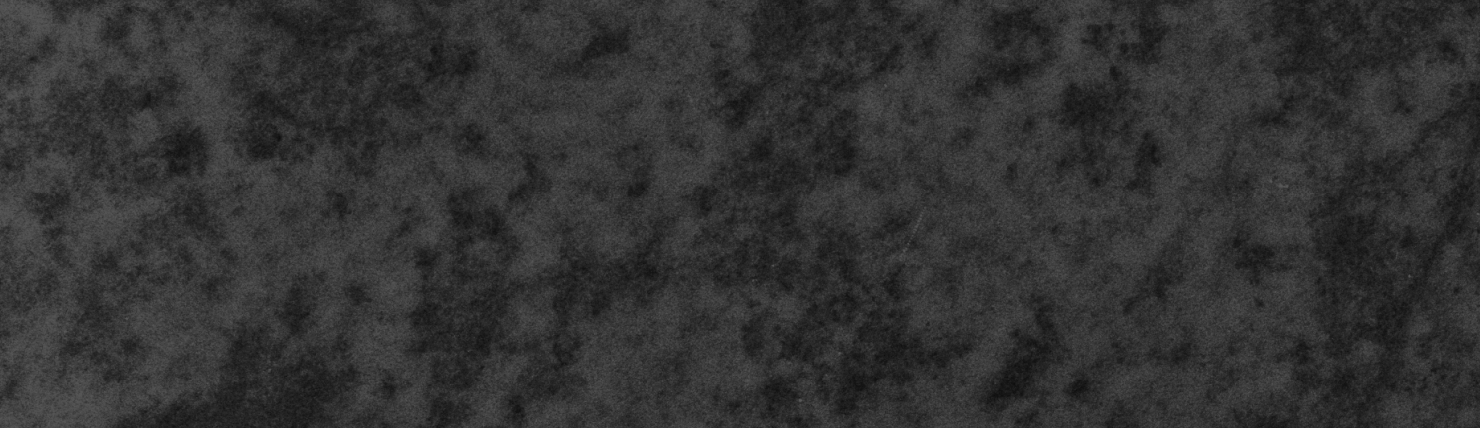

4

4. 3

$(3)$

(3)

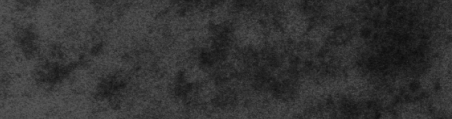

3)

x.

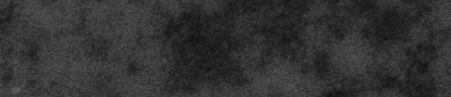

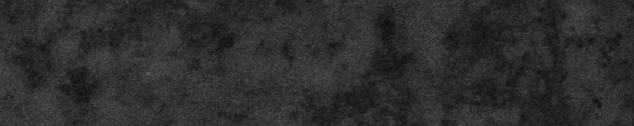

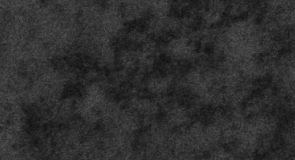

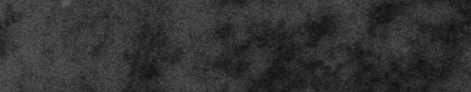

(2.)

(1)

(1)

(2)

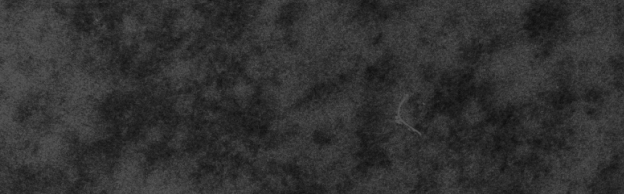

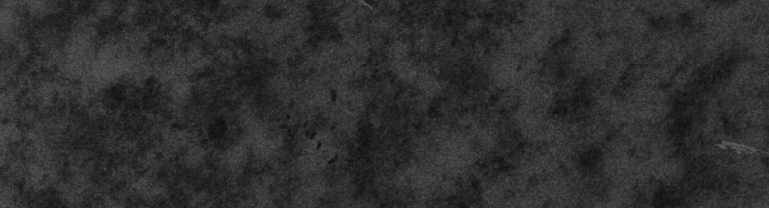

1.7.

(3)

8.

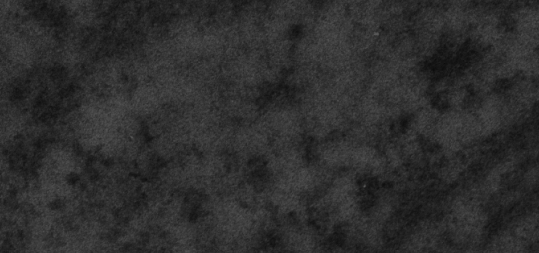

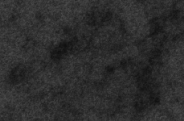

the

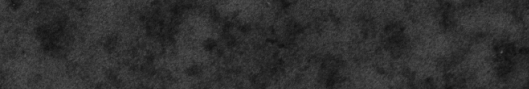

3.

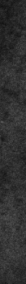




\section{Introduction}




\section{Background}

When in 1996 the awaited results of the Alpha-Tocopherol and Beta-Carotene Cancer prevention trial (ATBC) and the Carotenoid and Retinol efficacy Trial (CARET) were published, researchers were surprised about the unexpected outcome; beta-carotene (BC) supplementation resulted in an increased lung cancer risk in smokers or asbestos exposed subjects, rather than the hypothesized decreased lung cancer risk $[2,3]$. Both studies had a double blind placebo control design and involved 29,133 (ATBC) and 18,314 (CARET) subjects, respectively [4,5]. Since both studies had a similar outcome, the ATBC and CARET study are regarded as important evidence for an increased lung cancer risk in smokers and asbestos exposed subjects due to high supplemental intake of BC.

Although the results of the ATBC study and the CARET trial were published already more than a decade ago, the mechanism how $\mathrm{BC}$ can increase lung cancer risk in at risk subjects is still unknown. Moreover other questions remain such as; "what is the maximal safe level of BC intake?" do these effects only apply to BC or also to its metabolites?" and "are only smokers and asbestos exposed subjects at risk?" The answer to these questions is of importance from a scientific, but also societal point of view, because BC is highly used in the food industry, mainly as a coloring agent and in supplements to correct for vitamin A deficiency. To answer these questions, more insight in mechanisms of $\mathrm{BC}$ action is necessary, and therefore, mechanistic research is needed using adequate methodologies. However, there is one important drawback in BC research, which is the selection of a suitable model that can be used to study possible detrimental effects of $\mathrm{BC}$ on lung cancer risk. Human subjects would, of course, be the best "model" to address these questions, but lung tissue is hard to obtain and BC cannot be supplemented in high doses for ethical reasons. The use of in vivo laboratory animal models would be a good alternative, but frequently used animal models, such as rodents, have large limitations due to different $\mathrm{BC}$ metabolizing pathways compared to humans [6]. Although other animal models have been proposed as being a good model for human BC research such as ferrets [7], Mongolian gerbils [8] and preruminant calves $[9,10]$, there is a lack of molecular knowledge and tools for these animal models, which makes mechanistic research a time-consuming expedition. Although the number of studies on $\mathrm{BC}$ is still increasing, the percentage of $\mathrm{BC}$ related research as compared to the total of scientific publications is declining (Fig.1), in part due to the absence of an appropriate animal model to reliably perform $\mathrm{BC}$ research. 


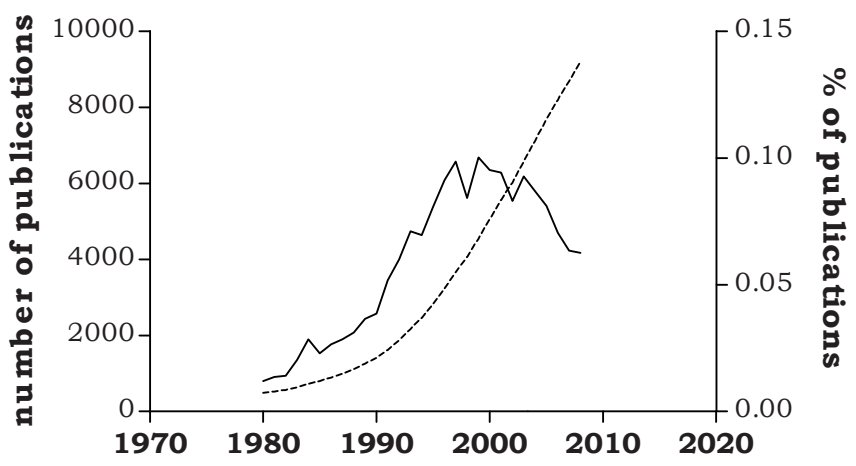

Figure 1: Percentage (solid line) and number (dashed line) of publications indexed in PubMed [11] containing the keyword "beta-carotene" per publication year.

This PhD-thesis aims at elucidating biological pathways altered by BC supplementation to provide mechanistic understanding of the effects induced by dietary $\mathrm{BC}$, using innovative approaches to overcome current problems in $\mathrm{BC}$ research.

\section{Beta-carotene}

\section{Occurrence}

Beta-carotene (Fig. 2) is a lipophilic, orange colored chemical, belonging to the group of carotenoids. Carotenoids are a group of chemically related compounds, derived from 8 isoprene molecules, and thus contain 40 carbon atoms [12]. Carotenoids are produced in certain plants, fungi and bacteria, but not in species of animal origin [12]. The function of carotenoids in plants is to support photosynthesis and to quench the highly reactive singlet oxygen $[13,14]$. Carotenoids are symmetrical molecules and contain a set of conjugated bonds [14], which give $\mathrm{BC}$ its orange color and its ability to scavenge radicals [14]. Of all carotenoids, it is believed that $B C$ is the most important in human nutrition, mainly because of its provitamin A activity [15]. Since species of animal origin are not able to produce $\mathrm{BC}$ de novo, the presence of $\mathrm{BC}$ in the human body is entirely dependent on intake, absorption and to what extend the intact $\mathrm{BC}$ is metabolized [15]. 


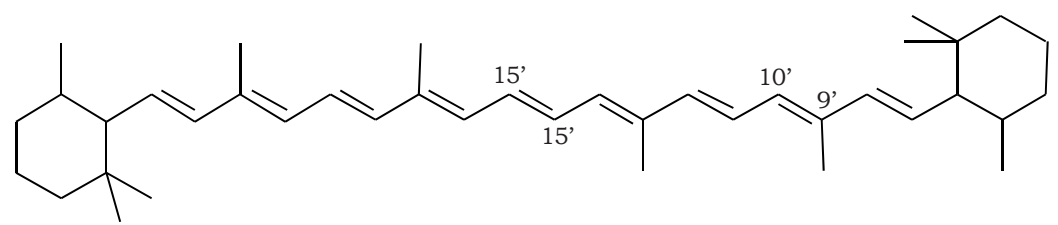

Figure 2: Chemical structure of beta-carotene.

\section{Intake}

The intake of $\mathrm{BC}$ depends on the amount of $\mathrm{BC}$ present in the food. The amount of $\mathrm{BC}$ can vary greatly between different fruits and vegetables. Generally, yellow and orange colored fruits and vegetables such as carrots and mango's and dark green leafy vegetables such as spinach contain relatively high amounts of $\mathrm{BC}[16,17]$. Besides the occurrence of $\mathrm{BC}$ in many natural food sources, $\mathrm{BC}$ is also used as a coloring agent (E160a) to give food products a yellow or orange color and it is added as food supplements to correct for vitamin A deficiency [18]. There are large variations in the daily intake of BC. The estimated average daily intake of $\mathrm{BC}$ in Europe, depending on the location and dietary habits, generally lies around $2800 \mu \mathrm{g} /$ day for an adult person [23].

\section{Absorption and distribution}

The bioavailability of $\mathrm{BC}$ from the diet is highly dependent on the food matrix and ranges from a few percent for raw fruits and vegetables to over $50 \%$ for oily solutions containing BC $[24,25]$. BC is partly absorbed by a mechanism involving passive diffusion and partly via receptor mediated uptake such as scavenger receptor class B, type I (SR-BI), in enterocytes [26]. After absorption, BC is partly metabolized and esterified by enterocytes in human [13], while it is almost entirely cleaved into BC metabolites in rodents $[27,28]$. Intact $\mathrm{BC}$ and $\mathrm{BC}$ metabolites are thereafter incorporated in chylomicrons to be further distributed throughout the body [15].

In humans, around $30 \%$ of the absorbed $\mathrm{BC}$ enters the lymphatic duct intact, while the remainder is effectively metabolized in the enterocytes mainly into retinyl esters $[29,30]$. The absorbed intact $\mathrm{BC}$ can accumulate in several tissues, with white adipose tissue and liver being the main $\mathrm{BC}$ storage tissues [31,32]. Chylomicrons, containing $\mathrm{BC}$ and $\mathrm{BC}$ metabolites, are transported from the digestive tract to the lymph into the blood stream near the heart. From thereon chylomicrons are subsequently transported to the heart followed by the lungs. Therefore, the lungs are the first microvascular tissue exposed to $\mathrm{BC}$ containing chylomicrons before they reach the liver, where $\mathrm{BC}$ is further metabolized. Around $70 \%$ of the chylomicrons containing BC or BC metabolites are absorbed by the liver, while the remainder is absorbed by extrahepatic tissue [33]. The 
liver and white adipose tissue are important for the storage of $\mathrm{BC}$ and $\mathrm{BC}$ metabolites and effectively regulate the levels of retinol (vitamin A), an important BC metabolite, in the blood [31,32]. Both organs are known to produce Retinol Binding Protein 4 (RBP4), which binds to retinol in combination with transthyretin (TTR) with the function to transport stored retinol to other tissues [34-37]. Other tissues are able to absorb the circulating retinol from the RBP-TTR-retinol complex by a specific RBP4 receptor: Stimulated by retinoic acid receptor 6 (STRA6) [38]. After absorption of retinol by the cell, retinol is bound to intracellular retinol binding protein 1 and 2, depending on the tissue $[15,39]$. Another BC metabolite; retinoic acid, is also bound to the intracellular binding proteins cellular retinoic acid binding protein 1 and/or 2 (CRABP1 and 2) [39].

\section{BC metabolism}

$\mathrm{BC}$ can be stored and degraded in several downstream BC metabolizing steps (Fig. 3 and Table 1). The first step in BC metabolism in animals involves the enzyme betacarotene 15,15'-monooxygenase (BCMO1, EC.1.14.15.6) [40,41]. BCMO1 cleaves BC centrally at the 15,15 ' double bond to generate two molecules of retinal. The expression and activity of Bcmo1 are highest in intestine and liver while there is only limited activity in lung tissue [42-44]. BCMO1 is an enzyme containing non-heme ferrous iron as a co-factor [45] and has monooxygenase activity thereby requiring one molecule of oxygen $\left(\mathrm{O}_{2}\right)$ to generate two molecules of retinal from one molecule BC [46].

After this first key step in BC metabolism, retinal can be further metabolized and reversibly stored as retinyl esters or irreversibly metabolized into the bioactive molecule retinoic acid (RA) $[47,48]$. A surplus of RA is primarily metabolized by cytochrome P450 family 26 (Cyp26) to primarily form 4-hydroxy-retinoic acid [49], which can be further degraded. Although Cyp26 isoforms are induced by retinoid acid [50] and are the main enzymes involved in the inactivation of retinoic acid, many other CYPs are known to metabolize RA, although to a much lesser extent [51]. There are many different enzymes which can convert downstream BC metabolites, and the exact metabolizing pathway is dependent on many different factors such as species, catalytic activity of the enzymes, tissue specificity of enzyme expression and exogenous factors inducing these enzymes. Enzymes known to be involved in downstream BC metabolism are listed in Table 1.

Besides $\mathrm{BCMO} 1$, which catalyses the first step in $\mathrm{BC}$ metabolism and is responsible for at least $95 \%$ of the $\mathrm{BC}$ cleavage products $[29,52]$, another $\mathrm{BC}$ metabolizing pathway has been described. This pathway involves the enzyme beta-carotene oxygenase 2 (BCO2; E.C.: 1.14.99.n2), which is present in many cell types that also express BCMO1 [53]. $\mathrm{BCO} 2$ cleaves $\mathrm{BC}$ excentrally at the 9',10', bond to generate one molecule of $\beta$-ionone and one molecule of $\beta$-apo-10'-carotenal [6]. $\beta$-apo-10'-carotenal can be reduced stepwise to generate RA in a $\beta$-oxidation like process $[54,55]$. At this moment, the exact mechanism of this alternative RA producing process involving $\mathrm{BCO} 2$ is still elusive [56]. 
Another possible important step in the degradation of $\mathrm{BC}$, is the formation of oxidation products without involvement of any enzymes, such as in auto-oxidation processes by exposure to tobacco smoke [57], which mainly have been described in vitro $[58,59]$.

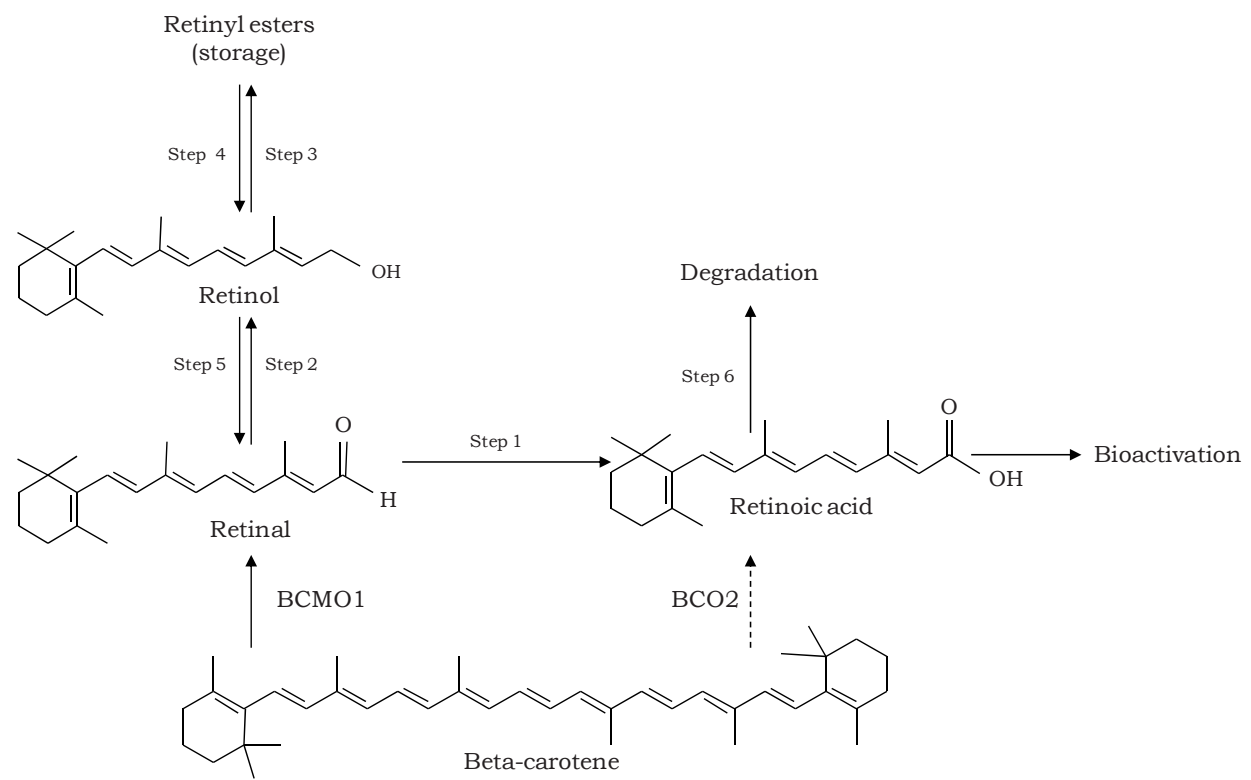

Figure 3: BC metabolism (enzymes involved in the different conversion steps are displayed in Table 1), modified from [60-62].

There are large inter-species differences in BC metabolism. These difference are mainly attributed to differences in Bcmol activity, with rodents having a more active Bcmo1 variant than man, which results in an almost complete conversion of all absorbed $\mathrm{BC}$ in rodents compared to an average of $70 \%$ in human $[44,63,64]$. Consequently BC supplementation to rodents, results in an almost complete conversion of all absorbed $\mathrm{BC}$ and therefore in an accumulation of $\mathrm{BC}$ metabolites in the body, while human absorb and accumulate intact $\mathrm{BC}[6]$. As a result, rodents are not a suitable model for investigating effects of intact BC. Other animal models have been proposed as being a good model for human BC research, such as ferrets [7], Mongolian gerbils [8] and preruminant calves $[9,10]$. Of these animal models, ferrets have been used most for BC research especially regarding questions related to the effect of $\mathrm{BC}$ on lung tissue, since lung physiology and lung pathology induced by cigarette smoke is also very similar to that of humans $[65,66]$. 
Table 1: Enzymes involved in conversion steps (Figure 3) of downstream BC metabolism. Modified from [60-62]

\begin{tabular}{|c|c|c|c|}
\hline \multirow[t]{2}{*}{ name } & \multirow[t]{2}{*}{ abbreviation } & \multicolumn{2}{|l|}{ accession number } \\
\hline & & human & mouse \\
\hline \multicolumn{4}{|l|}{ step1: conversion of retinal into retinoic acid } \\
\hline aldehyde dehydrogenase 1 family, member A1 & ALDH1A1 & NM_000689 & NM_013467 \\
\hline aldehyde dehydrogenase 1 family, member A2 & ALDH1A2 & NM_003888 & NM_009022 \\
\hline aldehyde dehydrogenase 1 family, member A3 & ALDH1A3 & NM_000693 & NM_053080 \\
\hline aldehyde dehydrogenase 2 family (mitochondrial)a & ALDH2 & NM_000690.2 & NM_009656.3 \\
\hline \multicolumn{4}{|l|}{ step 2: conversion of retinal into retinol } \\
\hline retinol dehydrogenase type 1 & Rdh1 & not identified & NM_080436 \\
\hline dehydrogenase/reductase (SDR family) member 3 & DHRS3 & NM_004753 & NM_011303 \\
\hline \multicolumn{4}{|l|}{ step 3: conversion of retinol to store } \\
\hline $\begin{array}{l}\text { lecithin-retinol acyltransferase (phosphatidylcho- } \\
\text { line-retinol-O-acyltransferase) }\end{array}$ & LRAT & NM_00744 & NM_023624 \\
\hline \multicolumn{4}{|l|}{$\begin{array}{l}\text { step 4: conversion of stored retinol into reti- } \\
\text { nol }\end{array}$} \\
\hline $\begin{array}{l}\text { Enzymes with retinyl ester hydrolase activity } \\
\text { patatin-like phospholipase domain containing } 4\end{array}$ & PNPLA4 & $\begin{array}{l}\text { NM_001142389, } \\
\text { NM_004650 }\end{array}$ & not identified \\
\hline \multicolumn{4}{|l|}{ step 5: conversion of retinol into retinal } \\
\hline alcohol dehydrogenase 1 (class I) & Adh1 & not identified & NM_007409 \\
\hline $\begin{array}{l}\text { alcohol dehydrogenase } 1 \mathrm{~A} \text { (class I), alpha poly- } \\
\text { peptide }\end{array}$ & $\mathrm{ADH} 1 \mathrm{~A}$ & NM_000667 & not identified \\
\hline $\begin{array}{l}\text { alcohol dehydrogenase 1B (class I), beta polypep- } \\
\text { tide }\end{array}$ & ADH1B & NM_000668 & not identified \\
\hline $\begin{array}{l}\text { alcohol dehydrogenase } 1 \mathrm{C} \text { (class I), gamma poly- } \\
\text { peptide }\end{array}$ & $\mathrm{ADH} 1 \mathrm{C}$ & NM_000669 & not identified \\
\hline alcohol dehydrogenase (class II), pi polypeptide & ADH4 & NM_000670 & NM_011996 \\
\hline $\begin{array}{l}\text { alcohol dehydrogenase (class IV), mu or sigma } \\
\text { polypeptide }\end{array}$ & ADH 7 & NM_000673 & NM_009626 \\
\hline retinol dehydrogenase 16 (all-trans) & RDH16 & NM_003708 & not identified \\
\hline retinol dehydrogenase 5 & RDH5 & NM_002905 & NM_134006 \\
\hline retinol dehydrogenase 16 & RDH16 & NM_003708 & NM_009040 \\
\hline \multicolumn{4}{|l|}{ step 6: degradation of retinoic acid } \\
\hline aldehyde dehydrogenase 1 family, member A1 & ALDH1A1 & NM_000689 & NM_013467 \\
\hline aldehyde dehydrogenase 1 family, member A2 & ALDH1A2 & NM_003888 & NM_009022 \\
\hline $\begin{array}{l}\text { aldehyde dehydrogenase family } 1 \text {, subfamily A } 7 \\
\text { followed by several cytochrome P450's families } \\
\text { such as: }\end{array}$ & Aldh1A7 & not identified & NM_011921 \\
\hline CYP26, CYP1a, Сур2, Сур3а, Сур4а & & & \\
\hline
\end{tabular}

aonly low retinal activity in mouse, and no retinal activity in human 
Besides high inter-species differences in BC conversion, there are also high interindividual differences in $\mathrm{BC}$ conversion activity. Previously performed $\mathrm{BC}$ intervention studies have demonstrated that $\mathrm{BC}$ supplementation resulted in a low response to this $\mathrm{BC}$ supplementation in part of the subjects, while other subjects had a high increase in serum BC levels. These different responses to BC in different subjects has resulted in the definition of so-called "low responders" and "low converters" [67]; around 25-45\% of the population are classified as being low converters and have a 10-fold lower BC conversion ability than low responders [68-70]. There are several genetic polymorphisms known to be related to these differences in $\mathrm{BC}$ response, which were mainly found in genes that encode for proteins involved in lipid transport and uptake, which is also important for transport of the lipophilic molecule BC. These polymorphisms are reported to be present in for example the apolipoprotein $B(A P O B)$ promoter, lipase member $C$ (LIPC) promoter and in the coding region of lipoprotein lipase $(L P L)$ and scavenger receptor type BI (SCARB1) [71-73]. Moreover, polymorphisms in the key BC metabolizing enzyme $B C M O 1$ have also been related to the reported differences in $\mathrm{BC}$ absorption $[20,74,75]$. One of these studies was a case study performed in one patient with excessive yellowness of the skin and resulted in the finding of a polymorphism in the BCMO1 coding region that reduced $\mathrm{BC}$ conversion with $90 \%$. However, this polymorphism is probably very rare in the Caucasian population [74]. Another study, of wider impact, found two other genetic variants in the $B C M O 1$ gene which occurred with frequencies of $24 \%$ and $42 \%$. Carriers of both variants had a $57 \%$ decrease in $\mathrm{BC}$ conversion resulting in high $\mathrm{BC}$ accumulation, while the most frequent variant alone results in $13 \%$ decrease in $\mathrm{BC}$ accumulation [20].

\section{Beta-carotene as a bioactive ingredient}

Although a high intake of $\mathrm{BC}$ as supplement has been reported to increase lung cancer risk in smokers and asbestos exposed subjects, there are also many known health promoting effects of BC intake. For example, a high dietary intake of BC has been associated with a decreased risks for the development of cardiovascular diseases [76] and decreased risk for the development of several types of cancer [77,78]. BC is also an effective antioxidant thereby preventing macromolecular damage [79]. Moreover, $\mathrm{BC}$ is an important vitamin A precursor, contributing to up to $80 \%$ of the dietary source of vitamin A [17] and can thus correct for or prevent vitamin A deficiency. Vitamin A deficiency is a serious health problem worldwide, with predominantly people in the undeveloped world suffering [80]. The ability of BC to correct for vitamin A deficiency has also resulted in the engineering of the so-called "golden rice", which contains high quantities of $\mathrm{BC}$ and was planned to be used for correcting vitamin A deficiency in the undeveloped world in which white rice is often the main food source [19]. Despite of the humanitarian perspective of "golden rice", this genetically engineered rice variant is not available for human consumption at this moment, due to critical concerns regarding genetically modified organisms. Vitamin A deficiency is also still a problem in Western 
populations. Vitamin A deficiency has been reported for $15 \%$ of young individuals aged 19-24 years in the United Kingdom [20], and almost half of American postmenopausal women may experience vitamin A deficiency [21]. Moreover, pregnant and lactating women are at risk for the development of vitamin A deficiency due to the discouragement of the intake of foods containing high quantities of vitamin A, such as liver, in combination with their increased requirements for vitamin A [81,22]. Smokers are also at risk for the development of vitamin A deficiency, since smoking causes vitamin A depletion [82,83]. Vitamin A deficiency results in a wide variety of clinical manifestations, such as night blindness, Xeropthalmia which is a condition where the eye is unable to produce tears, impaired growth, and a reduced resistance to infections. Many trials have demonstrated that vitamin A supplementation to people with vitamin A deficiency results in a less severe manifestation of infections such as measles and diarrhea, and supplementation reduced the mortality rate due to infectious disease $[84,85]$.

The molecular basis of these health effects of BC are mainly attributed to RA, which is an important bioactive derivative of $\mathrm{BC}$. RA is able to bind to a specific class of transcription factors. The function of these transcription factors is to regulate DNA transcription by their binding to the DNA [86]. There are three classes of transcription factors to which RA can bind; the first class of receptors are the retinoic acid receptors (RARs), which consist of three isoforms RARa, RAR $\beta$ and RARy. 9-Cis retinoic acid (9cRA) as well as its all-trans isomer (atRA), are able to bind to RAR [87-89]. The second class of receptors are the retinoic $\mathrm{x}$ receptors (RXRs) which consist, like RAR, of three isoforms; RXRa, RXRß and RXRY [90]. RAR can form heterodimers with RXR (RAR/RXR) to jointly bind to the retinoic acid responsive elements (RARE) in the promoter region of target genes. When the RAR/RXR complex is bound to the DNA together with several repressor proteins, gene expression is repressed. Upon RA binding to RAR and RXR, the heterodimer undergoes major conformational changes which results in the release of the repressor proteins and the recruitment of mediators and additional transcription proteins which result in active gene transcription (Fig. 4A and 4B). RARs can form heterodimers only with RXR to regulate target gene transcription. RXR however, can also form homodimers and heterodimers with several other transcription factors, such as peroxisome proliferator-activated receptors PPARs, and therefore, RXR can regulate a broader range of target genes. Related to RAR and RXR, there are also the RAR-related orphan receptors (ROR)s; RORa, $-\beta$, and $-\gamma$, which bind as monomers to the ROR responsive elements to modulate gene-transcription in a variety of physiological processes. Several retinoids including all-trans retinoic acid are able to bind reversibly to ROR $\beta$ and RORY thereby, in contrast to the heterodimer RAR/RXR, inhibiting transcription [91,92] (Fig. 4C and 4D). 
A)

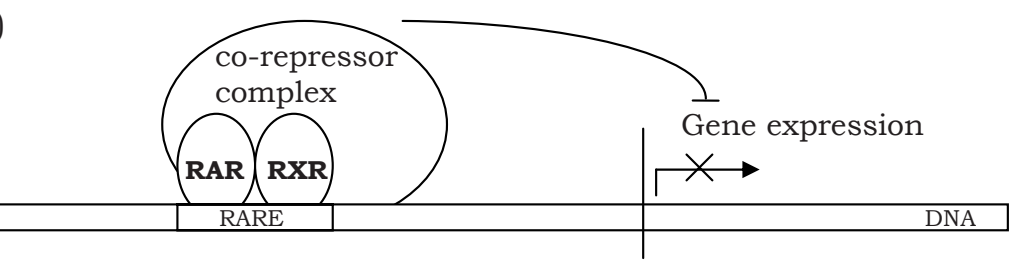

B)

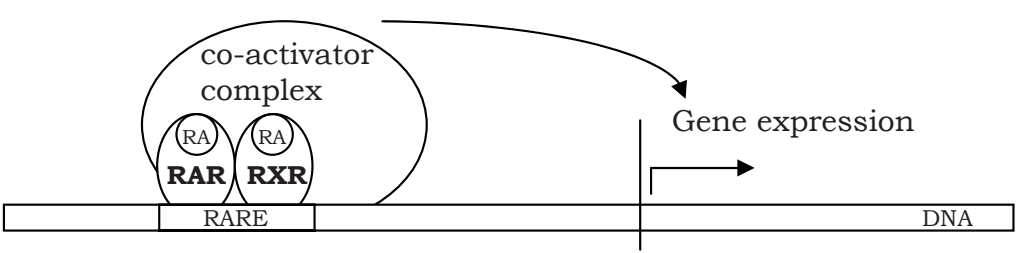

C)

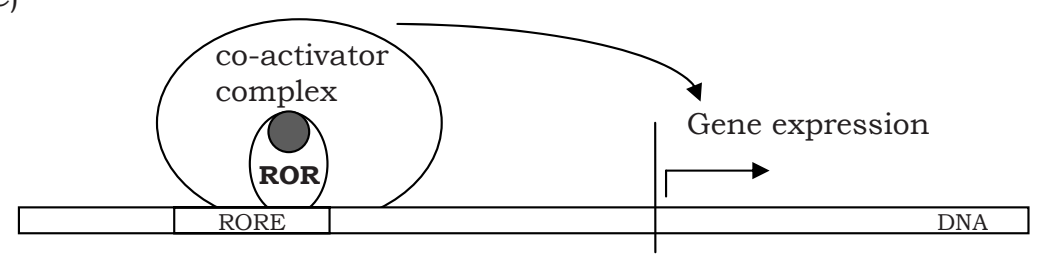

D)

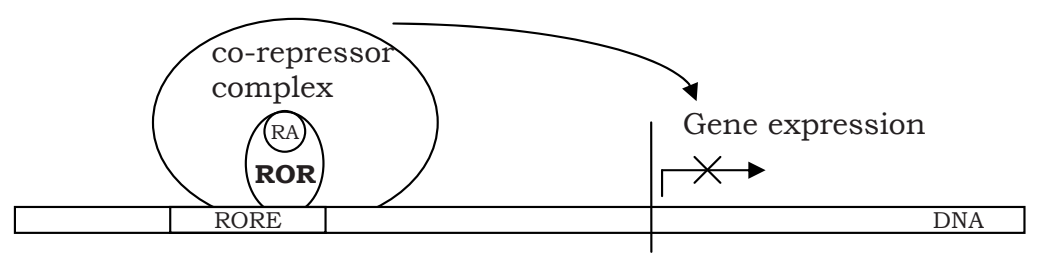

Figure 4: Mechanisms of retinoic acid action. The transcription factors retinoic acid receptor (RAR) and retinoid $\mathrm{X}$ receptor (RXR) bind as heterodimers to the retinoic acid responsive element, present in the DNA (A and B). Without the binding of a ligand, the heterodimer complex interacts with the corepressor complex, thereby inhibiting gene expression (A). Retinoic acid can bind to RAR and RXR, thereby inducing a conformational change of RAR and RXR and the induction of the interaction with the co-activator complex. Consequently gene expression is induced (B). Also RXR/RXR homodimers exist, able to regulate gene transcription in a similar manner [87-89]. The retinoid-related orphan receptor (ROR) binds as a monomer to the retinoid-related orphan receptor element (RORE). Ligands can bind (grey) to ROR to induce a conformation change thereby inducing gene expression (C). RA however, binds to ROR and induces a conformational change that recruits the co-repressor complex, thereby silencing gene expression (D). The effects of ROR have predominantly been demonstrated in vitro [91]. 


\section{Beta-carotene and lung cancer}

\section{Lung cancer risk after BC supplementation}

$\mathrm{BC}$ was thought to be an effective antioxidant which has led to the hypothesis that $\mathrm{BC}$ would protect against smoke and asbestos induced carcinogenesis. Indeed many epidemiological studies suggest that a high dietary intake of $\mathrm{BC}$ reduces the risk for several types of cancer, including lung cancer [78,93]. Smokers and asbestos exposed subjects have an increased lung cancer risk [94], in combination with a lower BC status [95]. Therefore it was hypothesized that $\mathrm{BC}$ had the ability to decrease lung cancer risk especially in smokers and asbestos exposed subjects. This hypothesis was tested in the ATBC and CARET trials where smokers (ATBC and CARET) and asbestos exposed subjects (CARET) were supplemented with $\mathrm{BC}$ alone $(20 \mathrm{mg} /$ day) or in combination with vitamin $\mathrm{E}(50 \mathrm{mg} /$ day) (ATBC) and in combination with retinyl palmitate $(25,000$ IU/day) (CARET). The CARET study was performed with 18,314 participants with a median duration of 3.7 years, resulting in an unknown increase in BC plasma concentration and the ATBC study was performed in 29,133 participant with a median duration of 6.1 years [96], resulting in an average BC concentration of $5.59 \mathrm{uM} \mathrm{BC}$ in blood after 3 years of intervention [96]. The CARET and the ATBC study, where smokers and asbestos exposed subjects were supplemented with high amounts of $\mathrm{BC}$, resulted in an increased lung cancer risk (Fig. 5) [2,3]. The ATBC study also reported other detrimental effects such as an increased risk for cardiovascular diseases [98] and the CARET study reported an increased mortality due to coronary heart disease after BC supplementation [99]. In a study with 22,071 male physicians, subjects were supplemented with $\mathrm{BC}(50 \mathrm{mg} /$ alternating day) resulting in a concentration of $2.24 \mathrm{uM} \mathrm{BC}$ in the blood. In contrast to the ATBC study and the CARET study, these volunteers were mainly non-smoking subjects. Interestingly, in this study BC supplementation did not result in any observed detrimental effects [97].

Although the ATBC study and the Physicians' health study were performed in male volunteers only, the CARET study also included female volunteers. In 2004, differences in female and male relative lung cancer risks were reported [1]. Notably, BC supplementation to female and male volunteers resulted in differences in relative lung cancer risk, especially after the trial had stopped. The relative lung cancer risk in BC supplemented male volunteers was reduced to levels as observed in the placebo group shortly after the intervention, while female volunteers did have a prolonged increased lung cancer risk even four years after the intervention had stopped (Fig. 6). 
A)

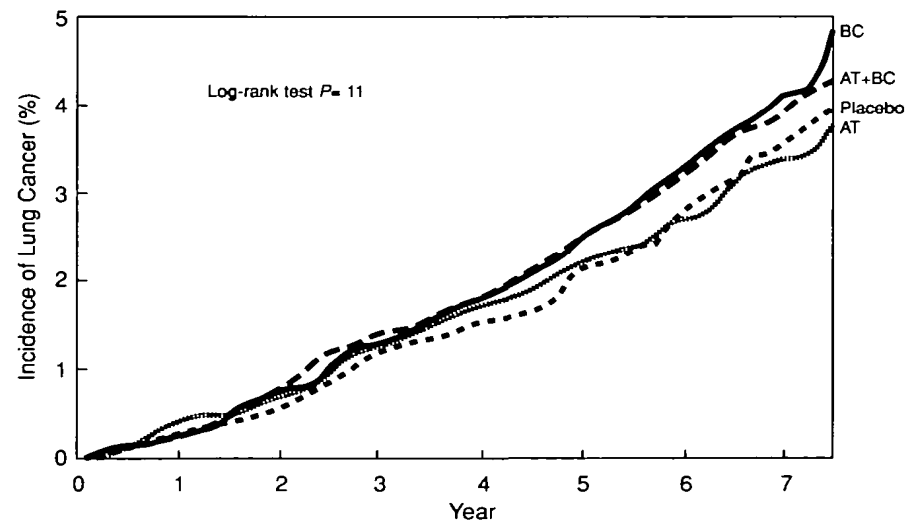

B)

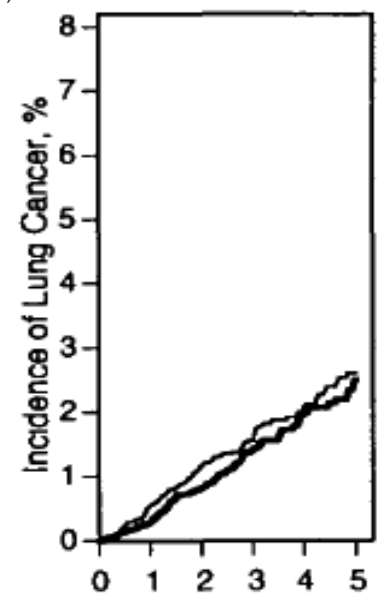

C)

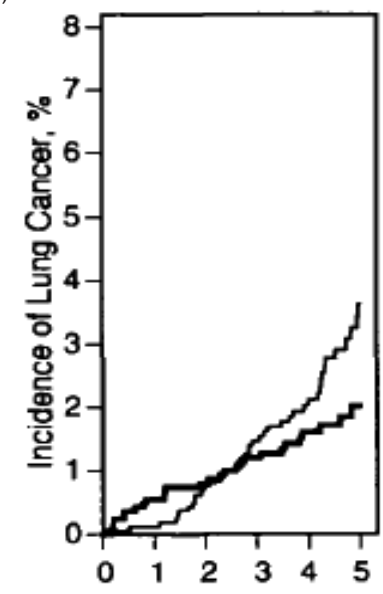

Figure 5: Lung cancer risk in smokers of the ATBC study (A), in smokers of the CARET study (B) and in asbestos exposed subjects of the CARET study (C). In Figure A the thick solid line indicates BC supplemented volunteers and the thin dashed line indicates the placebo arm of the trial. In Figure B and $\mathrm{C}$, the thick line represents the placebo group and the thin line the $\mathrm{BC}$ supplemented group $[2,3]$. 

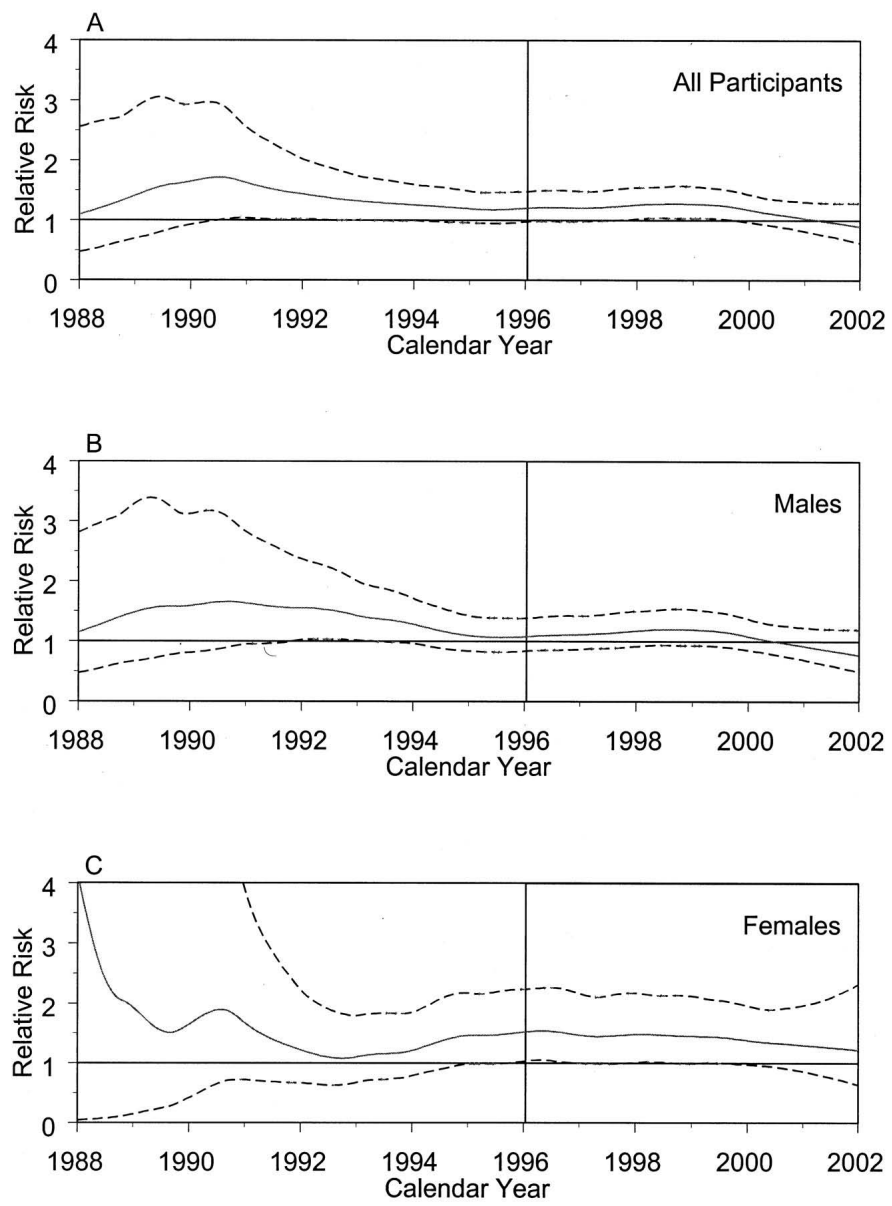

Figure 6: Lung cancer incidence relative risks (solid lines) and pointwise 95\% confidence intervals (dashed lines) by calendar time for all participants (A), males (B), and females (C) from the CARET study. Vertical line indicates the end of the CARET intervention period on January 11, 1996. ([1]).

This effect of $\mathrm{BC}$ on lung cancer risk in combination with smoke or asbestos exposure has been further investigated using ferrets as an animal model. However, BC related mechanistic research is difficult in ferrets and therefore has revealed only few possible mechanisms of $\mathrm{BC}$ action. In these studies, high but physiological $(0.43 \mathrm{mg} / \mathrm{kg}$ body weight/day) $\mathrm{BC}$ concentrations increased retinoic acid concentrations in smoke exposed ferrets while pharmacological concentrations $(2.4 \mathrm{mg} / \mathrm{kg}$ bodyweight/day) decreased retinoic acid concentrations and RAR $\beta$ protein [100]. Part of this effect has been explained by smoke induced BC oxidation. Moreover, there were higher protein levels of phosphorylated JNK, p38, and c-Jun, in groups exposed to smoke with a pharmacologi- 
cal dose of BC compared to smoke exposed ferrets alone. High but physiological doses of $\mathrm{BC}$ to smoke exposed ferrets decreased phosphorylated levels of JNK, p38, and cJun. Jun N-terminal kinase (JNK) and p38, members of the mitogen-activated protein kinase (MAPK) family, mediated cellular responses to cytokines and environmental stress and may play an important role in carcinogenesis [101]. Vitamin E and C have been shown to decrease oxidative $\mathrm{BC}$ breakdown and $\mathrm{BC}$ supplementation in combination with these vitamins resulted in higher RA acid concentrations than after BC supplementation alone [102].

Altogether these studies show that mechanistic studies are possible, but possibilities for these are limited since almost no commercial tools, such as antibodies or DNA microarrays, are available and there is very limited knowledge regarding gene and protein sequences.

\section{Smoke and asbestos induced carcinogenesis}

BC supplementation has been described to result in an increased lung cancer risk, only in smokers or asbestos exposed subjects that are at risk for lung cancer. Smoking is by far the main contributor to the occurrence of lung cancer, causing around $90 \%$ of all cases. Tobacco smoking results in the exposure to a complex mixture of carcinogens, including benzo[a]pyrene $(\mathrm{B}[\mathrm{a}] \mathrm{P})$, which is one of the best studied chemical carcinogens. $\mathrm{B}[\mathrm{a}] \mathrm{P}$ requires metabolic activation to exert its carcinogenic effect [103]. The major metabolic activation pathway of $\mathrm{B}[\mathrm{a}] \mathrm{P}$ is conversion to its 7,8-diol-9,10-epoxide (BPDE), which is highly reactive with DNA thereby forming BPDE-DNA adducts [104]. Studies indeed link the formation of BPDE-DNA adducts to specific mutations found in lung cancer [105]. Another important contributor to the remainder lung cancer cases is asbestos [106], which is a fibrous silicate material which was used in a wide variety of products. Although there are many differences between the cancer initiation mechanisms of asbestos and smoke induced lung cancer, there are also some commonalities in their etiology. When small asbestos fibers or smoke is inhaled for a long period of time, a chronic inflammatory state of the lungs is initiated [107-110], and inflammation is thought to be involved in the onset and progression of carcinogenesis [111-113]. Reversibly, the intake of non-steroid anti-inflammatory drugs (NSAIDs) in subjects with a chronic inflammation in the lungs has been associated with decreased lung cancer risk $[111,112]$. The process in the inflammation driven development of smoke and asbestos induced cancer is depicted in Fig. 7 . BC is possibly able to modulate this process at several steps. 


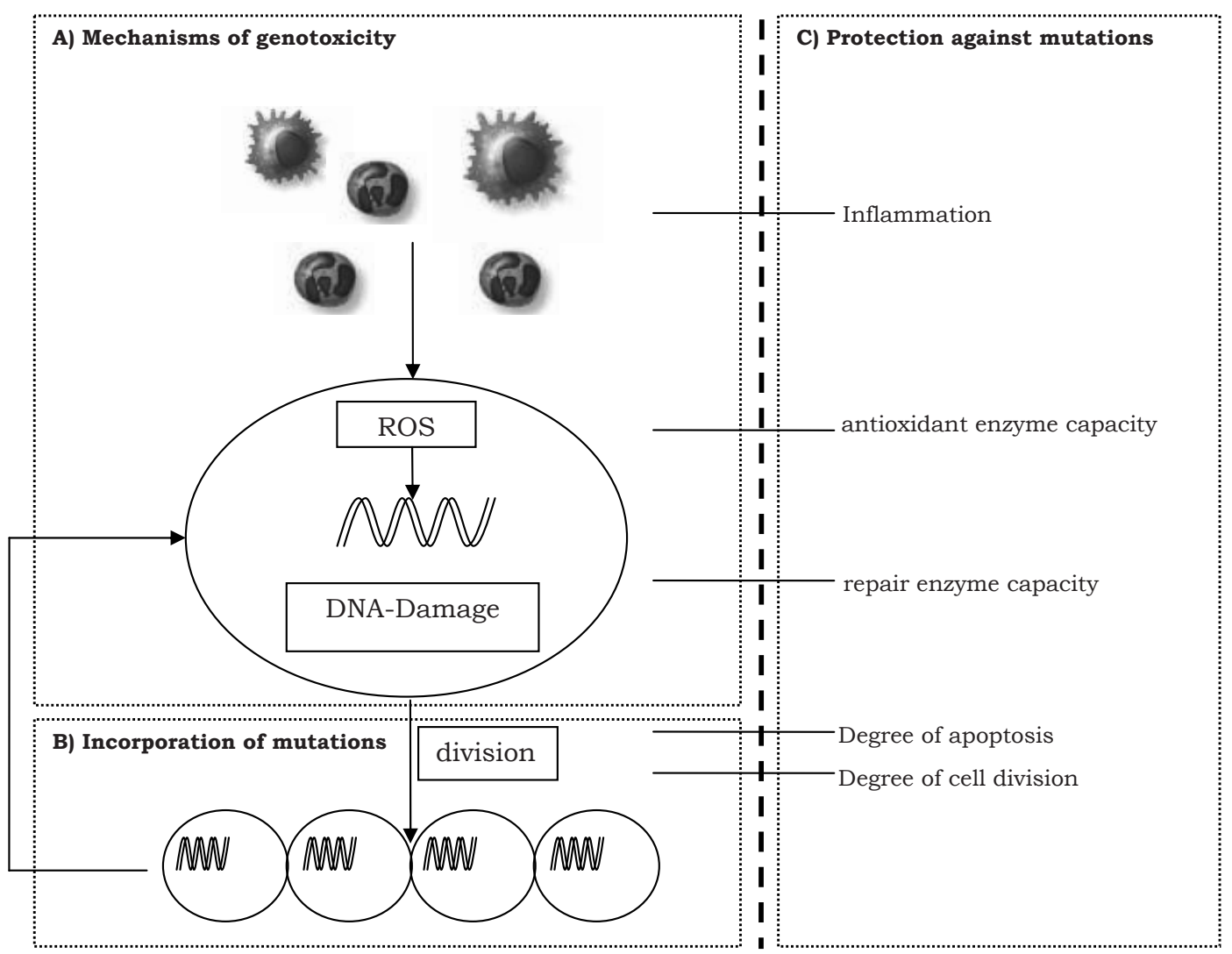

Figure 7: Common mechanism in smoke and asbestos induced carcinogenesis potentially modulated by BC. Both smoking and asbestos exposure induce an inflammatory reaction in the lungs which is characterized by the infiltration of neutrophils. Neutrophils produce large quantities of ROS which can result in DNA damage (A). During cell division, DNA is duplicated and when DNA-damage is not recognized, misincorporation of nucleotides opposite the damaged site can occur. Cells are continuously exposed to ROS which might thus result in the introduction of multiple mutations (B). There are also mechanisms that help to protect against inflammation induced mutations. The cells contain many antioxidant enzymes that help to scavenge ROS. When DNA damage is present, enzymes recognize and repair damage to protect against the formation of mutations. When there is too much damage, a cell can go into apoptosis or prevent cell division (C). All these mechanisms contribute to the carcinogenic process and are possibly influenced by dietary BC. Moreover dietary BC itself might act as an anti- or pro- oxidant to modulate ROS induced genotoxicity.

\section{Inflammation}

Typical for the inflammatory response in the lungs is the infiltration of neutrophils [114]. Activated neutrophils produce reactive oxygen species (ROS), in a reaction called the "respiratory burst" [115], during which oxygen is consumed to produce superoxide, 
mediated by enzymes such as nicotinamide adenine dinucleotide phosphate (NADPH) oxidase [116]. Superoxide dismutases spontaneously or through catalysis by superoxide dismutase, into hydrogen peroxide $\left(\mathrm{H}_{2} \mathrm{O}_{2}\right)$. Specific for neutrophils is that they contain the green heme containing enzyme meyeloperoxidase (MPO), which is released upon neutrophilic activation and can convert $\mathrm{H}_{2} \mathrm{O}_{2}$ into hypochlorous acid (HOCl) [116]. $\mathrm{H}_{2} \mathrm{O}_{2}$ is -in contrast to free radical species- relatively stable. $\mathrm{H}_{2} \mathrm{O}_{2}$ can therefore diffuse into the cell's nucleus where it can react with DNA-bound transition metals to induce DNA damage (Fig. 8). The presence of neutrophils is typical for a pulmonary inflammation since the concentration of neutrophils in the capillary system of the lungs is 20-60 times higher than in large vessels [117]. Neutrophils are effective antibacterial agents due to the production of ROS, but activated neutrophils are possibly also involved in the initiation of carcinogenesis, since the radicals produced are also able to induce macromolecular damage in lung cells. Thus neutrophils theoretically posses the ability to induce macromolecular damage and consequently mutations [118]. Both smoke and asbestos cause an inflammatory response in the lung.

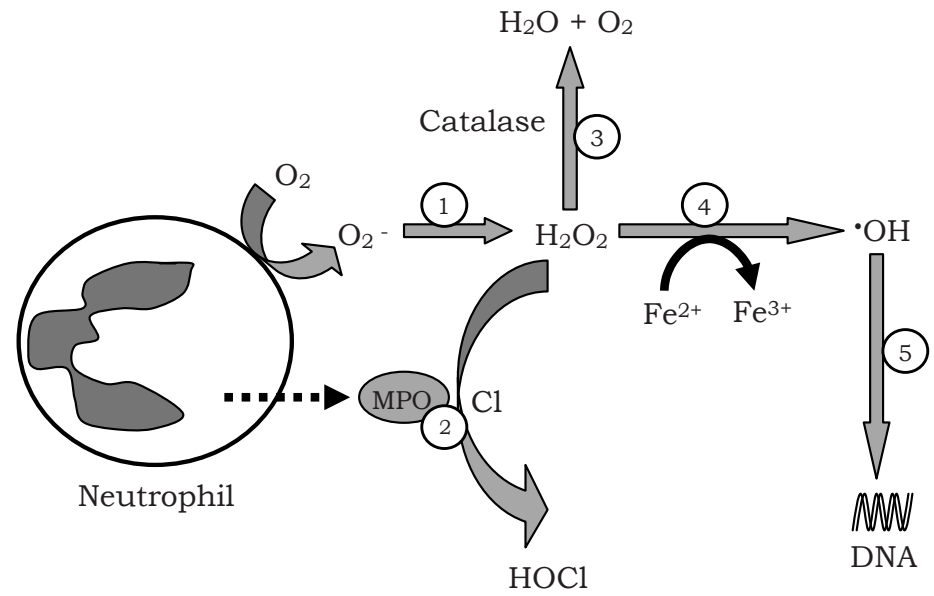

Figure 8: Mechanism of neutrophil induced genotoxicity. When neutrophils are activated, the respiratory burst is initiated thereby consuming oxygen to generate superoxide radicals. Superoxide dismutase converts superoxide into hydrogenperoxide (step1). Hydrogen peroxide can be converted into $\mathrm{HOCl}$ by the heme containing enzyme MPO, which is also released by the activated neutrophil (step 2). $\mathrm{H}_{2} \mathrm{O}_{2}$ can also be converted into water and oxygen by antioxidant enzymes such as catalase (step 3). When iron is present, $\mathrm{H}_{2} \mathrm{O}_{2}$ can be converted into the highly reactive hydroxyl radicals (step 4), which can subsequently directly or indirectly damage the DNA (step 5). 


\section{ROS induced genotoxicity}

ROS produced by inflammatory cells are very reactive and able to damage the DNA. One of the most abundant, highly mutagenic, ROS induced DNA lesions is the oxidation of guanosine to form 8-oxo-7,8-dihydro-2'-deoxyguanosine (8-oxo-dG) [119,120]. Because of its high occurrence and its known mutagenic capacity, it is considered to be a good marker for ROS induced genotoxicity $[119,121]$. Besides the direct ability of ROS to react with the DNA, ROS can also indirectly damage the DNA; ROS can react with several intracellular macromolecular structures such as polyunsaturated fatty acids, to result in carbon centered radicals. These carbon centered radicals are again highly reactive resulting in the degradation of polyunsaturated fatty acids [122].

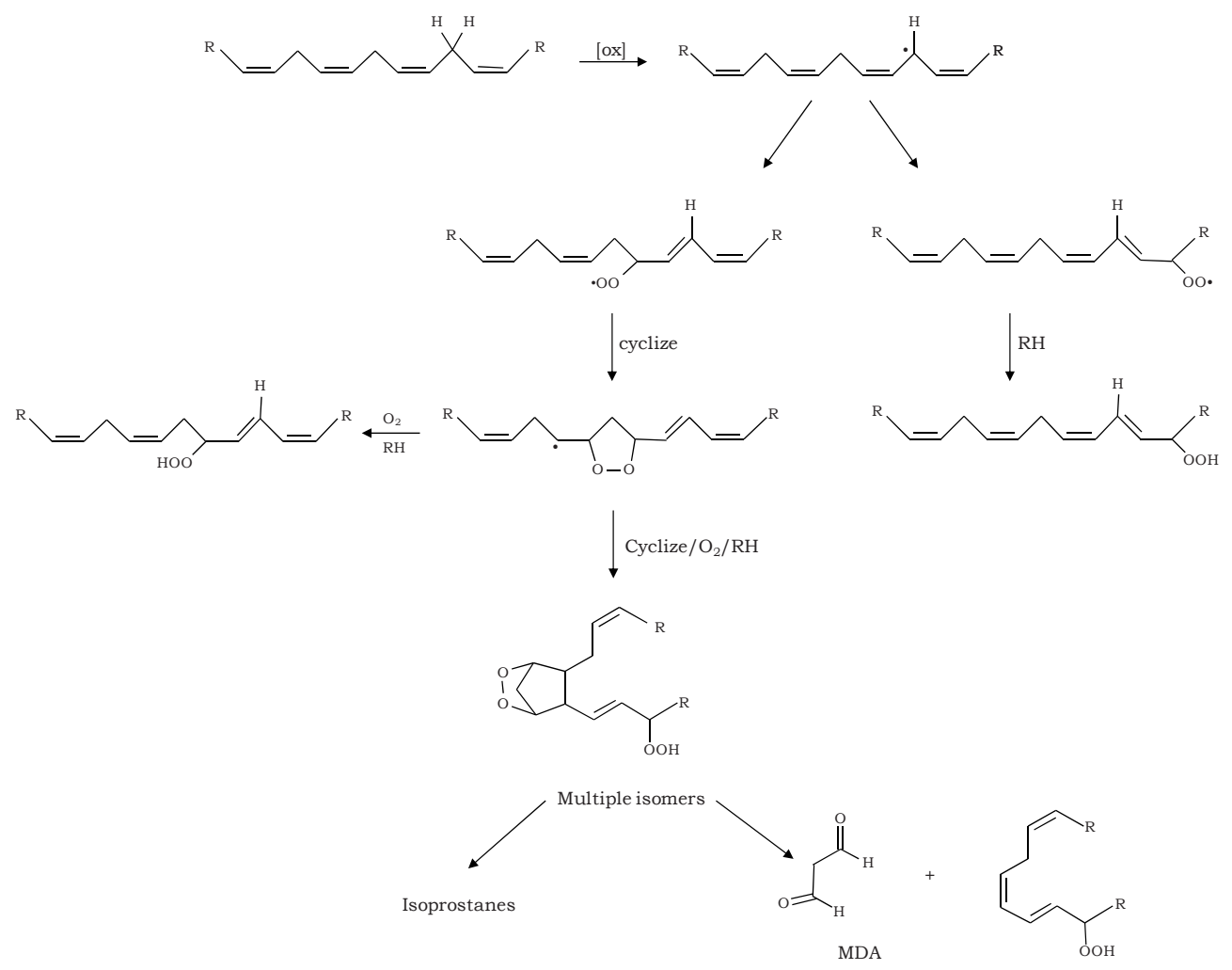

Figure 9: Pathways of lipid peroxidation. Ultimately, the genotoxic lipid peroxidation product MDA is formed [122].

This process of lipid peroxidation results in a wide range of different degradation products as can be seen in Fig. 9. Malondialdehyde (MDA) is one of these degradation products, which appears to be a mutagenic product of lipid peroxidation [123]. MDA is able 
to react with the DNA to form MDA-DNA adducts, with the major adduct form being 3(2-deoxy- $\beta$-D-erythro-pentafuranosyl)pyrimido[1,2- $\alpha]$ purin-10(3H)-one deoxyguanosine $\left(\mathrm{M}_{1} \mathrm{dG}\right)$ [124]. Because of its abundance and mutagenic character, $\mathrm{M}_{1} \mathrm{dG}$ can be considered as an important marker for ROS induced genotoxicity, with carbon centered radicals as important intermediates.

When the DNA strand is duplicated, nucleotides at the side of the altered nucleotide might be recognized incorrectly which results in the incorporation of a wrong nucleotide in the DNA. In general it is believed that several mutations in regulatory or coding regions of genes are necessary for the initiation of a cancer cell [125].

\section{Pathways involved in the prevention of carcinogenesis}

Although inflammation induced ROS might be an important contributor to the carcinogenic process, a cell has several enzymes and pathways to prevent a cell to become cancerous. Several antioxidant enzymes are available to scavenge the inflammation induced ROS [126]. Moreover, the ROS induced DNA damage can be recognized and repaired by specific DNA repair enzymes. These repair mechanism are highly specific for each type of DNA damage. The main repair mechanism involved in the repair of ROS induced DNA lesions is the base excision repair (BER) mechanism which specifically recognizes oxidized base lesions such as 8-oxo-dG [127].

Because of the repair mechanisms, the chemical alteration of nucleotides/bases in a DNA strand is a reversible process and DNA damage will not necessarily result in permanent DNA mutations. Nonetheless, the degree of DNA damage is thought to be positively correlated with the risk for the development of mutations $[128,129]$ and there are some studies that demonstrate the ability for BC to increase DNA damage, such as single strand breaks in DNA of beta-carotene supplemented volunteers [130].

\section{Lung cancer}

Ultimately, the accumulation of mutations can result in cancer. Lung cancer is the uncontrolled growth of cells originating from lung tissue. There are several types of lung cancer, each originating from a different cell type. The clinical histological characterization mainly subdivides lung cancer into two major subtypes; the small cell lung carcinoma (17\%) and non small cell lung carcinoma (80\%) [131]. Non small cell lung carcinomas are again subdivided into 3 main classes; large cell lung carcinoma, squamous cell lung carcinoma and large cell lung carcinoma. Adenocarcinoma is mainly defined as a neoplasm derived from lung glandular cells [132], whereas squamous cell carcinoma is mainly derived from epithelial cells. Additionally, small cell lung carcinoma's as well as a significant part of large cell carcinomas are derived from neuroendocrine cells and account together for approximately $20 \%$ of all lung cancers [133]. Both small cell lung 
carcinoma and large cell lung carcinomas originating from neuroendocrine cells are strongly related with tobacco use $[133,134]$ and are both associated with the worst prognosis [135-137]. An exact classification of all subtypes is provided by the world health organization [138].

\section{Benefit-risk analysis of BC}

Altogether, many health promoting effects have been observed for dietary BC intake, but also adverse effects have been reported when smokers or asbestos exposed subjects were supplemented with high amounts of BC. Many regulatory authorities have difficulties in the evaluation of the safety of BC use, mainly because of a lack of available data concerning modes of action. In toxicology, safety is often assessed using NOAELS (no observed adverse effect level) in animals to extrapolate to human safe intakes [139]. In this extrapolation "safety factors" are being used, which often include a factor 10 for interspecies differences and a factor 10 for inter-individual differences in susceptibility and metabolism [139]. When applying this concept to the use of BC, than in the ATBC and CARET study, adverse effects were already reported for a BC intake of $30 \mathrm{mg} /$ day (CARET) in smokers. When applying a safety factor of 10 for inter-individual differences in susceptibility and metabolism, than a BC intake of just above the average intake of $2.8 \mathrm{mg} /$ day, would not be safe to use. However, no adverse effects have been observed in non-smoking humans when supplemented with high concentrations of BC (50 mg/ 2-days) [97] and high dietary BC intakes have been correlated with many health promoting effects [140]. To properly assess benefits and risks of BC, it is necessary to weigh benefits and risks and a schematic presentation of benefit-risk is depicted in Fig. 10 [141]. To properly assess risks and benefits for BC intake, knowledge concerning BC action and the characterization of possible susceptible groups, is necessary.

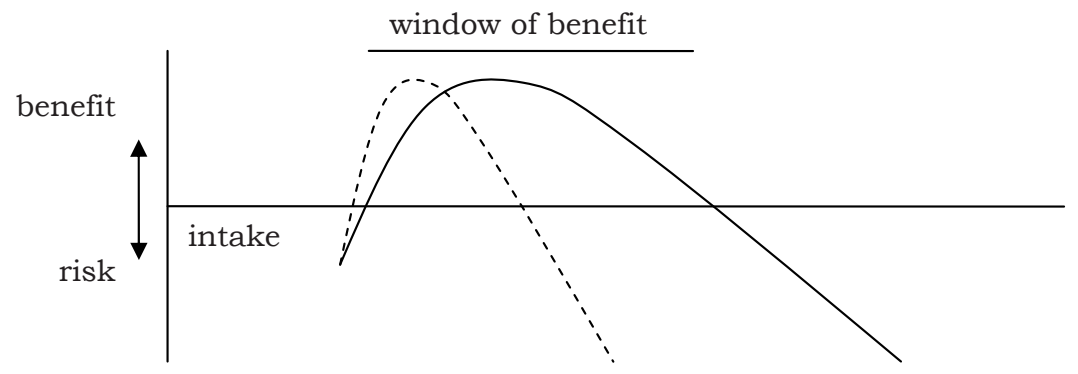

Figure 10: Schematic presentation of the "window of benefit". An increase in the intake of a food or food component will result in the change from an adverse to a beneficial condition, to an optimal condition and at higher concentrations again to an adverse condition (solid line). The window of benefit is not fixed, but is dependent on age, genotype, gender and lifestyle. When using the nutrient BC, there may be more susceptible groups such as smokers or asbestos exposed subjects, but also unknown others (dashed line) [141]. 


\section{AIMS and OUTLINE of this thesis}

In this thesis we aim to provide more insight in mechanisms of $\mathrm{BC}$ action in the lung, which can ultimately contribute to improved benefit-risk assessment of BC. Since BC was shown to increase lung cancer risk in smokers and asbestos exposed subjects, and not in non-smoking subjects we hypothesize that BC, or one of its metabolites specifically increases neutrophil induced genotoxicity. Therefore, the aim of the first part of this thesis is to study the effect of BC on molecular mechanisms involved in genotoxicity and in particular in inflammation induced genotoxicity. There are studies that show that $\mathrm{BC}$ is an antioxidant, able to scavenge radicals and prevents radical induced genotoxicity, but $\mathrm{BC}$ might become a pro-oxidant under certain conditions. Indeed, there are studies indicating that $\mathrm{BC}$ can act as an antioxidant or as a pro-oxidant dependent on the condition such as $\mathrm{BC}$ concentration, oxygen tensions $\left(\mathrm{pO}_{2}\right)[142,143]$ and the presence of other antioxidants, such as vitamin C and E, to allow for redox cycling [144,145] or no effects have been reported [146]. These theories have mainly been tested in cell systems, but only partly contribute to the mechanism involved. In Chapter 2 we investigate the effects of $\mathrm{BC}$ on mechanisms involved in $\mathrm{B}[\mathrm{a}] \mathrm{P}$ and inflammation induced genotoxicity to further explain the previously found increase in lung cancer risk by $\mathrm{BC}$ supplementation in smokers. We used in vitro lung epithelial cells to investigate the effect of $\mathrm{BC}$ on $\mathrm{H}_{2} \mathrm{O}_{2}$ and $\mathrm{B}[\mathrm{a}] \mathrm{P}$ induced $\mathrm{M}_{1} \mathrm{dG}$ and 8-oxo-dG. Moreover, we supplemented ferrets with $\mathrm{BC}$, in combination with or without $\mathrm{B}[\mathrm{a}] \mathrm{P}$ and investigated the effects on 8 oxo-dG and $\mathrm{M}_{1} \mathrm{dG}$ in vivo. Ferrets have the advantage of a similar $\mathrm{BC}$ metabolism and lung physiology as humans [147].

Smoking and asbestos exposure have in common that they result in an inflammation in the lungs. This inflammation is mainly characterized by a neutrophilic influx in the lungs able to cause genotoxicity. In Chapter $\mathbf{3}$ we investigated the effects of $\mathrm{BC}$ on neutrophil induced genotoxicity. Therefore we investigated the effect of $\mathrm{BC}$ or its metabolites on individual steps involved in neutrophil induced ROS production and the subsequent genotoxic effects.

There is a lack in knowledge concerning gene expression changes induced by BC supplementation in the lung. In previous mechanistic $\mathrm{BC}$ research, the main drawback was the lack of an animal model resembling human BC metabolism with the advantage of the availability of tools and knowledge to perform sophisticated molecular research. In the second part of this thesis we used a mouse model with a knockout for Bcmo1, the key enzyme in BC metabolism [64], which accumulates, like humans intact BC with the advantage of the accessibility to many molecular tools and knowledge. We supplemented female and male, wildtype $\left(\mathrm{Bcmo1}^{+/+}\right)$and $\mathrm{Bcmol}$ knockout mice $\left(\mathrm{Bcmo1}^{-/}\right)$with $\mathrm{BC}$. We hypothesized that by using these animals, the effects from BC could be dissected from effects induced by $\mathrm{BC}$ metabolites and that control diet fed $\mathrm{Bcmo} 1 \%$ mice and control diet fed $\mathrm{Bcmol}^{+/+}$mice showed similar gene expression patterns. 
To study effects of $\mathrm{BC}$ on gene expression, we used whole genome microarray analysis. In Chapter 4 we describe the advantages and the drawbacks of animal models in nutritional research using microarray analysis.

Only the CARET study investigated the effect of BC in both male as well as in female volunteers and found remarkable differences. The relative risk appeared to be higher in females than in males and the increased lung cancer risk remained after the BC intervention only in female smokers while this was not the case in male volunteers [1]. This indicates that females and males respond differently to $\mathrm{BC}$ supplementation. Therefore we investigated the mechanisms of BC action in females in Chapter $\mathbf{5}$ and for males in Chapter 6. Since we were also interested in the question which mechanisms of BC were similar in male and female mice, we analyzed the genes and processes that were regulated by $\mathrm{BC}$ in both male and in female $\mathrm{BCmo1}^{-/-}$mice in Chapter $\mathbf{7}$.

Since we used a $2 \times 2 \times 2$ factorial design involving two genders (male and female mice), two different genotypes ( $\mathrm{Bcmo1}^{+/+}$and $\mathrm{Bcmo1} 1^{--}$mice) and two different diets (control diet and $\mathrm{BC}$ supplemented diet), we were able to investigate interactions between these factors and differences in responses in lungs, liver and white adipose tissue (iWAT). BC accumulation occurs mainly in white adipose tissue [31] and liver and metabolism occurs mainly in liver [148]. In Chapter 8 we aimed to gain more insight in three different questions: "how weigh gene expression responses of nutritional intake to effects induced by differences in genetic background or gender and do they interact", "Do tissues differ in response to a nutritional intervention" and finally "Do female and male mice respond similar to a dietary intervention?" We therefore quantitatively analyzed effects in lung, liver and iWAT. Further insight in these different research questions are of general biological importance, but also contributes to benefit-risk assessment by providing insight in the more systemic effects of BC.

Since we analyzed the pathways changed by BC supplementations in lungs of male and female mice, we aimed to elucidate whether these pathways were also altered in iWAT and liver, as described in Chapter 9. This analysis contributes to our understanding of the role and importance of the effects observed in the lung.

The Discussion, the final chapter of this thesis summarizes and discusses all findings in this thesis and concludes with recommendations for future research. 


\section{References}

[1] G.E. Goodman, M.D. Thornquist, J. Balmes, M.R. Cullen, F.L. Meyskens, Jr., G.S. Omenn, B. Valanis and J.H. Williams, Jr. The Beta-Carotene and Retinol Efficacy Trial: incidence of lung cancer and cardiovascular disease mortality during 6-year follow-up after stopping beta-carotene and retinol supplements, J Natl Cancer Inst 96 (2004) 1743-1750.

[2] D. Albanes, O.P. Heinonen, P.R. Taylor, J. Virtamo, B.K. Edwards, M. Rautalahti, A.M. Hartman, J. Palmgren, L.S. Freedman, J. Haapakoski, M.J. Barrett, P. Pietinen, N. Malila, E. Tala, K. Liippo, E.R. Salomaa, J.A. Tangrea, L. Teppo, F.B. Askin, E. Taskinen, Y. Erozan, P. Greenwald and J.K. Huttunen AlphaTocopherol and beta-carotene supplements and lung cancer incidence in the alpha-tocopherol, betacarotene cancer prevention study: effects of base-line characteristics and study compliance, J Natl Cancer Inst 88 (1996) 1560-1570.

[3] G.S. Omenn, G.E. Goodman, M.D. Thornquist, J. Balmes, M.R. Cullen, A. Glass, J.P. Keogh, F.L. Meyskens, Jr., B. Valanis, J.H. Williams, Jr., S. Barnhart, M.G. Cherniack, C.A. Brodkin and S. Hammar Risk factors for lung cancer and for intervention effects in CARET, the Beta-Carotene and Retinol Efficacy Trial, J Natl Cancer Inst 88 (1996) 1550-1559.

[4] The alpha-tocopherol, beta-carotene lung cancer prevention study: design, methods, participant characteristics, and compliance. The ATBC Cancer Prevention Study Group, Ann Epidemiol 4 (1994) 1-10.

[5] G.S. Omenn, G. Goodman, M. Thornquist, J. Grizzle, L. Rosenstock, S. Barnhart, J. Balmes, M.G. Cherniack, M.R. Cullen, A. Glass and et al. The beta-carotene and retinol efficacy trial (CARET) for chemoprevention of lung cancer in high risk populations: smokers and asbestos-exposed workers, Cancer Res 54 (1994) 2038s-2043s.

[6] C. Kiefer, S. Hessel, J.M. Lampert, K. Vogt, M.O. Lederer, D.E. Breithaupt and J. von Lintig Identification and characterization of a mammalian enzyme catalyzing the asymmetric oxidative cleavage of provitamin A, J Biol Chem 276 (2001) 14110-14116.

[7] X.D. Wang Review: absorption and metabolism of beta-carotene, J Am Coll Nutr 13 (1994) 314-325.

[8] C.M. Lee, J.D. Lederman, N.E. Hofmann and J.W. Erdman The mongolian gerbil (Meriones unguiculatus) is an appropriate animal model for evaluation of the conversion of beta-carotene to vitamin A, J Nutr 128 (1998) 280-286.

[9] T.L. Bierer, N.R. Merchen and J.W. Erdman, Jr. Comparative absorption and transport of five common carotenoids in preruminant calves, J Nutr 125 (1995) 1569-1577.

[10] C.L. Poor, T.L. Bierer, N.R. Merchen, G.C. Fahey, Jr., M.R. Murphy and J.W. Erdman, Jr. Evaluation of the preruminant calf as a model for the study of human carotenoid metabolism, J Nutr 122 (1992) 262-268.

[11] http://www.ncbi.nlm.nih.gov.

[12] G.A. Armstrong and J.E. Hearst Carotenoids 2: Genetics and molecular biology of carotenoid pigment biosynthesis, Faseb J 10 (1996) 228-237.

[13] R.S. Parker Absorption, metabolism, and transport of carotenoids, Faseb J 10 (1996) 542-551.

[14] G.E. Bartley and P.A. Scolnik Plant carotenoids: pigments for photoprotection, visual attraction, and human health, Plant Cell 7 (1995) 1027-1038.

[15] H.K. Biesalski, G.R. Chichili, J. Frank, J. von Lintig and D. Nohr Conversion of beta-carotene to retinal pigment, Vitam Horm 75 (2007) 117-130.

[16] USDA National Nutrient Database for Standard Reference, Release 21.

[17] C.E. West Meeting requirements for vitamin A, Nutr Rev 58 (2000) 341-345.

[18] www.voedingscentrum.nl.

[19] X. Ye, S. Al-Babili, A. Kloti, J. Zhang, P. Lucca, P. Beyer and I. Potrykus Engineering the provitamin A (beta-carotene) biosynthetic pathway into (carotenoid-free) rice endosperm, Science 287 (2000) 303-305.

[20] W.C. Leung, S. Hessel, C. Meplan, J. Flint, V. Oberhauser, F. Tourniaire, J.E. Hesketh, J. von Lintig and G. Lietz Two common single nucleotide polymorphisms in the gene encoding beta-carotene 15, 15'monoxygenase alter beta-carotene metabolism in female volunteers, Faseb J 23 (2009) 1041-1053.

[21] D. Feskanich, V. Singh, W.C. Willett and G.A. Colditz Vitamin A intake and hip fractures among postmenopausal women, Jama 287 (2002) 47-54.

[22] M. Strobel, J. Tinz and H.K. Biesalski The importance of beta-carotene as a source of vitamin A with special regard to pregnant and breastfeeding women, Eur J Nutr 46 Suppl 1 (2007) I1-20. 
[23] M. Jenab, S. Salvini, C.H. van Gils, M. Brustad, S. Shakya-Shrestha, B. Buijsse, H. Verhagen, M. Touvier, C. Biessy, P. Wallstrom, K. Bouckaert, E. Lund, M. Waaseth, N. Roswall, A.M. Joensen, J. Linseisen, H. Boeing, E. Vasilopoulou, V. Dilis, S. Sieri, C. Sacerdote, P. Ferrari, J. Manjer, S. Nilsson, A.A. Welch, R. Travis, M.C. Boutron-Ruault, M. Niravong, H.B. Bueno-de-Mesquita, Y.T. van der Schouw, M.J. Tormo, A. Barricarte, E. Riboli, S. Bingham and N. Slimani Dietary intakes of retinol, beta-carotene, vitamin D and vitamin E in the European Prospective Investigation into Cancer and Nutrition cohort, Eur J Clin Nutr 63 Suppl 4 (2009) S150-178.

[24] K.H. van Het Hof, C.E. West, J.A. Weststrate and J.G. Hautvast Dietary factors that affect the bioavailability of carotenoids, J Nutr 130 (2000) 503-506.

[25] K.J. Yeum and R.M. Russell Carotenoid bioavailability and bioconversion, Annu Rev Nutr 22 (2002) 483504.

[26] A. van Bennekum, M. Werder, S.T. Thuahnai, C.H. Han, P. Duong, D.L. Williams, P. Wettstein, G. Schulthess, M.C. Phillips and H. Hauser Class B scavenger receptor-mediated intestinal absorption of dietary beta-carotene and cholesterol, Biochemistry 44 (2005) 4517-4525.

[27] H.S. Huang and D.S. Goodman Vitamin a and Carotenoids. I. Intestinal Absorption and Metabolism of 14cLabelled Vitamin a Alcohol and Beta-Carotene in the Rat, J Biol Chem 240 (1965) 2839-2844.

[28] N.I. Krinsky, M.M. Mathews-Roth, S. Welankiwar, P.K. Sehgal, N.C. Lausen and M. Russett The metabolism of [14C]beta-carotene and the presence of other carotenoids in rats and monkeys, J Nutr 120 (1990) 81-87.

[29] D.S. Goodman, R. Blomstrand, B. Werner, H.S. Huang and T. Shiratori The intestinal absorption and metabolism of vitamin A and beta-carotene in man, J Clin Invest 45 (1966) 1615-1623.

[30] T. van Vliet, W.H. Schreurs and H. van den Berg Intestinal beta-carotene absorption and cleavage in men: response of beta-carotene and retinyl esters in the triglyceride-rich lipoprotein fraction after a single oral dose of beta-carotene, Am J Clin Nutr 62 (1995) 110-116.

[31] L.A. Kaplan, J.M. Lau and E.A. Stein Carotenoid composition, concentrations, and relationships in various human organs, Clin Physiol Biochem 8 (1990) 1-10.

[32] H. Senoo, N. Kojima and M. Sato Vitamin A-storing cells (stellate cells), Vitam Horm 75 (2007) 131-159.

[33] D.S. Goodman and H.S. Huang Biosynthesis of Vitamin a with Rat Intestinal Enzymes, Science 149 (1965) 879-880.

[34] F.R. Smith and D.S. Goodman The effects of diseases of the liver, thyroid, and kidneys on the transport of vitamin A in human plasma, J Clin Invest 50 (1971) 2426-2436.

[35] H.K. Biesalski and D. Nohr New aspects in vitamin a metabolism: the role of retinyl esters as systemic and local sources for retinol in mucous epithelia, J Nutr 134 (2004) 3453S-3457S.

[36] A. Makover, D.R. Soprano, M.L. Wyatt and D.S. Goodman Localization of retinol-binding protein messenger RNA in the rat kidney and in perinephric fat tissue, J Lipid Res 30 (1989) 171-180.

[37] C. Tsutsumi, M. Okuno, L. Tannous, R. Piantedosi, M. Allan, D.S. Goodman and W.S. Blaner Retinoids and retinoid-binding protein expression in rat adipocytes, J Biol Chem 267 (1992) 1805-1810.

[38] G. Wolf Identification of a membrane receptor for retinol-binding protein functioning in the cellular uptake of retinol, Nutr Rev 65 (2007) 385-388.

[39] E. Li and A.W. Norris Structure/function of cytoplasmic vitamin A-binding proteins, Annu Rev Nutr 16 (1996) 205-234.

[40] T.M. Redmond, S. Gentleman, T. Duncan, S. Yu, B. Wiggert, E. Gantt and F.X. Cunningham, Jr. Identification, expression, and substrate specificity of a mammalian beta-carotene 15,15'-dioxygenase, J Biol Chem 276 (2001) 6560-6565.

[41] W. Yan, G.F. Jang, F. Haeseleer, N. Esumi, J. Chang, M. Kerrigan, M. Campochiaro, P. Campochiaro, K. Palczewski and D.J. Zack Cloning and characterization of a human beta, beta-carotene-15,15'-dioxygenase that is highly expressed in the retinal pigment epithelium, Genomics 72 (2001) 193-202.

[42] A. During, A. Nagao, C. Hoshino and J. Terao Assay of beta-carotene 15,15'-dioxygenase activity by reverse-phase high-pressure liquid chromatography, Anal Biochem 241 (1996) 199-205.

[43] A. Lindqvist and S. Andersson Cell type-specific expression of beta-carotene 15,15'-mono-oxygenase in human tissues, J Histochem Cytochem 52 (2004) 491-499.

[44] A. Wyss Carotene oxygenases: a new family of double bond cleavage enzymes, J Nutr 134 (2004) 246S250S.

[45] M.R. Lakshmanan, H. Chansang and J.A. Olson Purification and properties of carotene 15,15'-dioxygenase of rabbit intestine, J Lipid Res 13 (1972) 477-482. 
[46] M.G. Leuenberger, C. Engeloch-Jarret and W.D. Woggon The Reaction Mechanism of the EnzymeCatalyzed Central Cleavage of beta-Carotene to Retinal This research was supported by F. Hoffmann-La Roche AG and the Swiss National Science Foundation. We are grateful to F. Hoffmann-La Roche AG for a generous gift of carotenoids and Dr. Claus Bornemann for preliminary experiments, Angew Chem Int Ed Engl 40 (2001) 2613-2617.

[47] J. von Lintig and A. Wyss Molecular analysis of vitamin A formation: cloning and characterization of betacarotene 15,15'-dioxygenases, Arch Biochem Biophys 385 (2001) 47-52.

[48] F. Tourniaire, E. Gouranton, J. von Lintig, J. Keijer, M. Luisa Bonet, J. Amengual, G. Lietz and J.F. Landrier beta-Carotene conversion products and their effects on adipose tissue, Genes Nutr 4 (2009) 179-187.

[49] J.A. White, B. Beckett-Jones, Y.D. Guo, F.J. Dilworth, J. Bonasoro, G. Jones and M. Petkovich cDNA cloning of human retinoic acid-metabolizing enzyme (hP450RAI) identifies a novel family of cytochromes P450, J Biol Chem 272 (1997) 18538-18541.

[50] O. Loudig, C. Babichuk, J. White, S. Abu-Abed, C. Mueller and M. Petkovich Cytochrome P450RAI(CYP26) promoter: a distinct composite retinoic acid response element underlies the complex regulation of retinoic acid metabolism, Mol Endocrinol 14 (2000) 1483-1497.

[51] J.E. Thatcher and N. Isoherranen The role of CYP26 enzymes in retinoic acid clearance, Expert Opin Drug Metab Toxicol 5 (2009) 875-886.

[52] A.B. Barua and J.A. Olson beta-carotene is converted primarily to retinoids in rats in vivo, J Nutr 130 (2000) 1996-2001.

[53] A. Lindqvist, Y.G. He and S. Andersson Cell type-specific expression of beta-carotene 9',10'-monooxygenase in human tissues, J Histochem Cytochem 53 (2005) 1403-1412.

[54] R.V. Sharma, S.N. Mathur and J. Ganguly Studies on the relative biopotencies and intestinal absorption of different apo-beta-carotenoids in rats and chickens, Biochem J 158 (1976) 377-383.

[55] X.D. Wang, R.M. Russell, C. Liu, F. Stickel, D.E. Smith and N.I. Krinsky Beta-oxidation in rabbit liver in vitro and in the perfused ferret liver contributes to retinoic acid biosynthesis from beta-apocarotenoic acids, J Biol Chem 271 (1996) 26490-26498.

[56] J. von Lintig, S. Hessel, A. Isken, C. Kiefer, J.M. Lampert, O. Voolstra and K. Vogt Towards a better understanding of carotenoid metabolism in animals, Biochim Biophys Acta 1740 (2005) 122-131.

[57] J.S. Hurst, J.E. Contreras, W.G. Siems and F.J. Van Kuijk Oxidation of carotenoids by heat and tobacco smoke, Biofactors 20 (2004) 23-35.

[58] W. Siems, O. Sommerburg, L. Schild, W. Augustin, C.D. Langhans and I. Wiswedel Beta-carotene cleavage products induce oxidative stress in vitro by impairing mitochondrial respiration, Faseb J 16 (2002) 12891291.

[59] W.G. Siems, O. Sommerburg, J.S. Hurst and F.J. van Kuijk Carotenoid oxidative degradation products inhibit Na+-K+-ATPase, Free Radic Res 33 (2000) 427-435.

[60] G. Duester Families of retinoid dehydrogenases regulating vitamin A function: production of visual pigment and retinoic acid, Eur J Biochem 267 (2000) 4315-4324.

[61] G. Duester Genetic dissection of retinoid dehydrogenases, Chem Biol Interact 130-132 (2001) 469-480.

[62] http://www.genome.jp/kegg/pathway/map/map00830.html Retinol metabolism pathway.

[63] Y. Fierce, M. de Morais Vieira, R. Piantedosi, A. Wyss, W.S. Blaner and J. Paik In vitro and in vivo characterization of retinoid synthesis from beta-carotene, Arch Biochem Biophys 472 (2008) 126-138.

[64] S. Hessel, A. Eichinger, A. Isken, J. Amengual, S. Hunzelmann, U. Hoeller, V. Elste, W. Hunziker, R. Goralczyk, V. Oberhauser, J. von Lintig and A. Wyss CMO1 deficiency abolishes vitamin A production from beta-carotene and alters lipid metabolism in mice, J Biol Chem 282 (2007) 33553-33561.

[65] R.K. Sindhu, R.E. Rasmussen and Y. Kikkawa Exposure to environmental tobacco smoke results in an increased production of $(+)$-anti-benzo[a]pyrene-7,8-dihydrodiol-9,10-epoxide in juvenile ferret lung homogenates, J Toxicol Environ Health 47 (1996) 523-534.

[66] A. Vinegar, E.E. Sinnett, P.C. Kosch and M.L. Miller Pulmonary physiology of the ferret and its potential as a model for inhalation toxicology, Lab Anim Sci 35 (1985) 246-250.

[67] P. Borel, P. Grolier, N. Mekki, Y. Boirie, Y. Rochette, B. Le Roy, M.C. Alexandre-Gouabau, D. Lairon and V. Azais-Braesco Low and high responders to pharmacological doses of beta-carotene: proportion in the population, mechanisms involved and consequences on beta-carotene metabolism, J Lipid Res 39 (1998) 22502260.

[68] S.J. Hickenbottom, J.R. Follett, Y. Lin, S.R. Dueker, B.J. Burri, T.R. Neidlinger and A.J. Clifford Variability in conversion of beta-carotene to vitamin A in men as measured by using a double-tracer study design, Am J Clin Nutr 75 (2002) 900-907.

[69] Y. Lin, S.R. Dueker, B.J. Burri, T.R. Neidlinger and A.J. Clifford Variability of the conversion of betacarotene to vitamin A in women measured by using a double-tracer study design, Am J Clin Nutr 71 (2000) 1545-1554. 
[70] Z. Wang, S. Yin, X. Zhao, R.M. Russell and G. Tang beta-Carotene-vitamin A equivalence in Chinese adults assessed by an isotope dilution technique, Br J Nutr 91 (2004) 121-131.

[71] P. Borel, M. Moussa, E. Reboul, B. Lyan, C. Defoort, S. Vincent-Baudry, M. Maillot, M. Gastaldi, M. Darmon, H. Portugal, D. Lairon and R. Planells Human fasting plasma concentrations of vitamin E and carotenoids, and their association with genetic variants in apo C-III, cholesteryl ester transfer protein, hepatic lipase, intestinal fatty acid binding protein and microsomal triacylglycerol transfer protein, $\mathrm{Br} \mathrm{J}$ Nutr 101 (2009) 680-687.

[72] P. Borel, M. Moussa, E. Reboul, B. Lyan, C. Defoort, S. Vincent-Baudry, M. Maillot, M. Gastaldi, M. Darmon, H. Portugal, R. Planells and D. Lairon Human plasma levels of vitamin E and carotenoids are associated with genetic polymorphisms in genes involved in lipid metabolism, J Nutr 137 (2007) 2653-2659.

[73] B. Herbeth, S. Gueguen, P. Leroy, G. Siest and S. Visvikis-Siest The lipoprotein lipase serine 447 stop polymorphism is associated with altered serum carotenoid concentrations in the Stanislas Family Study, J Am Coll Nutr 26 (2007) 655-662.

[74] A. Lindqvist, J. Sharvill, D.E. Sharvill and S. Andersson Loss-of-function mutation in carotenoid 15,15'monooxygenase identified in a patient with hypercarotenemia and hypovitaminosis A, J Nutr 137 (2007) 2346-2350.

[75] L. Ferrucci, J.R. Perry, A. Matteini, M. Perola, T. Tanaka, K. Silander, N. Rice, D. Melzer, A. Murray, C. Cluett, L.P. Fried, D. Albanes, A.M. Corsi, A. Cherubini, J. Guralnik, S. Bandinelli, A. Singleton, J. Virtamo, J. Walston, R.D. Semba and T.M. Frayling Common variation in the beta-carotene 15, 15'monooxygenase 1 gene affects circulating levels of carotenoids: a genome-wide association study, Am J Hum Genet 84 (2009) 123-133.

[76] S. Voutilainen, T. Nurmi, J. Mursu and T.H. Rissanen Carotenoids and cardiovascular health, Am J Clin Nutr 83 (2006) 1265-1271.

[77] G. van Poppel Epidemiological evidence for beta-carotene in prevention of cancer and cardiovascular disease, Eur J Clin Nutr 50 Suppl 3 (1996) S57-61.

[78] R.G. Ziegler Vegetables, fruits, and carotenoids and the risk of cancer, Am J Clin Nutr 53 (1991) 251S259S.

[79] N.I. Krinsky Carotenoids as chemopreventive agents, Prev Med 18 (1989) 592-602.

[80] WHO Countries categorized by degree of public health importance of vitamin A deficiency, www.who.int (1995).

[81] E.S. Strobel, E. Fritschka, A. Schmitt-Graff and H.H. Peter An unusual case of systemic lupus erythematosus, lupus nephritis, and transient monoclonal gammopathy, Rheumatol Int 19 (2000) 235-241.

[82] T.E. Edes and D.S. Gysbers Carcinogen-induced tissue vitamin A depletion. Potential protective advantages of beta-carotene, Ann N Y Acad Sci 686 (1993) 203-211; discussion 211-202.

[83] C.A. Northrop-Clewes and D.I. Thurnham Monitoring micronutrients in cigarette smokers, Clin Chim Acta 377 (2007) 14-38.

[84] P.P. Glasziou and D.E. Mackerras Vitamin A supplementation in infectious diseases: a meta-analysis, Bmj 306 (1993) 366-370.

[85] A. Sommer Vitamin a deficiency and clinical disease: an historical overview, J Nutr 138 (2008) 1835-1839.

[86] T. Maniatis, S. Goodbourn and J.A. Fischer Regulation of inducible and tissue-specific gene expression, Science 236 (1987) 1237-1245.

[87] J. Bastien and C. Rochette-Egly Nuclear retinoid receptors and the transcription of retinoid-target genes, Gene 328 (2004) 1-16.

[88] A.D. Weston, B. Blumberg and T.M. Underhill Active repression by unliganded retinoid receptors in development: less is sometimes more, J Cell Biol 161 (2003) 223-228.

[89] O. Ziouzenkova and J. Plutzky Retinoid metabolism and nuclear receptor responses: New insights into coordinated regulation of the PPAR-RXR complex, FEBS Lett 582 (2008) 32-38.

[90] B. Desvergne RXR: from partnership to leadership in metabolic regulations, Vitam Horm 75 (2007) 1-32.

[91] A.M. Jetten Retinoid-related orphan receptors (RORs): critical roles in development, immunity, circadian rhythm, and cellular metabolism, Nucl Recept Signal 7 (2009) e003.

[92] C. Stehlin-Gaon, D. Willmann, D. Zeyer, S. Sanglier, A. Van Dorsselaer, J.P. Renaud, D. Moras and R. Schule All-trans retinoic acid is a ligand for the orphan nuclear receptor ROR beta, Nat Struct Biol 10 (2003) 820-825.

[93] R. Peto, R. Doll, J.D. Buckley and M.B. Sporn Can dietary beta-carotene materially reduce human cancer rates?, Nature 290 (1981) 201-208.

[94] I. Bruske-Hohlfeld Environmental and occupational risk factors for lung cancer, Methods Mol Biol 472 (2009) 3-23. 
[95] V.L. Van Antwerpen, A.J. Theron, G.A. Richards, C.A. Van der Merwe, E. Viljoen, R. Van der Walt and R. Anderson Plasma levels of beta-carotene are inversely correlated with circulating neutrophil counts in young male cigarette smokers, Inflammation 19 (1995) 405-414.

[96] D. Albanes, O.P. Heinonen, J.K. Huttunen, P.R. Taylor, J. Virtamo, B.K. Edwards, J. Haapakoski, M. Rautalahti, A.M. Hartman, J. Palmgren and et al. Effects of alpha-tocopherol and beta-carotene supplements on cancer incidence in the Alpha-Tocopherol Beta-Carotene Cancer Prevention Study, Am J Clin Nutr 62 (1995) 1427S-1430S.

[97] C.H. Hennekens, J.E. Buring, J.E. Manson, M. Stampfer, B. Rosner, N.R. Cook, C. Belanger, F. LaMotte, J.M. Gaziano, P.M. Ridker, W. Willett and R. Peto Lack of effect of long-term supplementation with beta carotene on the incidence of malignant neoplasms and cardiovascular disease, N Engl J Med 334 (1996) 1145-1149.

[98] J.M. Rapola, J. Virtamo, S. Ripatti, J.K. Huttunen, D. Albanes, P.R. Taylor and O.P. Heinonen Randomised trial of alpha-tocopherol and beta-carotene supplements on incidence of major coronary events in men with previous myocardial infarction, Lancet 349 (1997) 1715-1720.

[99] G.S. Omenn, G.E. Goodman, M.D. Thornquist, J. Balmes, M.R. Cullen, A. Glass, J.P. Keogh, F.L. Meyskens, B. Valanis, J.H. Williams, S. Barnhart and S. Hammar Effects of a combination of beta carotene and vitamin A on lung cancer and cardiovascular disease, N Engl J Med 334 (1996) 1150-1155.

[100] C. Liu, R.M. Russell and X.D. Wang Exposing ferrets to cigarette smoke and a pharmacological dose of beta-carotene supplementation enhance in vitro retinoic acid catabolism in lungs via induction of cytochrome P450 enzymes, J Nutr 133 (2003) 173-179.

[101] R.J. Davis Signal transduction by the JNK group of MAP kinases, Cell 103 (2000) 239-252.

[102] C. Liu, R.M. Russell and X.D. Wang Alpha-tocopherol and ascorbic acid decrease the production of betaapo-carotenals and increase the formation of retinoids from beta-carotene in the lung tissues of cigarette smoke-exposed ferrets in vitro, J Nutr 134 (2004) 426-430.

[103] H.V. Gelboin Benzo[alpha]pyrene metabolism, activation and carcinogenesis: role and regulation of mixedfunction oxidases and related enzymes, Physiol Rev 60 (1980) 1107-1166.

[104] S.S. Hecht Tobacco smoke carcinogens and lung cancer, J Natl Cancer Inst 91 (1999) 1194-1210.

[105] M.F. Denissenko, A. Pao, M. Tang and G.P. Pfeifer Preferential formation of benzo[a]pyrene adducts at lung cancer mutational hotspots in P53, Science 274 (1996) 430-432.

[106] W.J. Nicholson Cancer following occupational exposure to asbestos and vinyl chloride, Cancer 39 (1977) 1792-1801.

[107] G. Lee, T.C. Walser and S.M. Dubinett Chronic inflammation, chronic obstructive pulmonary disease, and lung cancer, Curr Opin Pulm Med 15 (2009) 303-307.

[108] R. Robledo and B. Mossman Cellular and molecular mechanisms of asbestos-induced fibrosis, J Cell Physiol 180 (1999) 158-166.

[109] J.S. Brody and A. Spira State of the art. Chronic obstructive pulmonary disease, inflammation, and lung cancer, Proc Am Thorac Soc 3 (2006) 535-537.

[110] A.G. Schwartz, G.M. Prysak, C.H. Bock and M.L. Cote The molecular epidemiology of lung cancer, Carcinogenesis 28 (2007) 507-518.

[111] R.E. Harris, J. Beebe-Donk and H.M. Schuller Chemoprevention of lung cancer by non-steroidal antiinflammatory drugs among cigarette smokers, Oncol Rep 9 (2002) 693-695.

[112] J.E. Muscat, S.Q. Chen, J.P. Richie, Jr., N.K. Altorki, M. Citron, S. Olson, A.I. Neugut and S.D. Stellman Risk of lung carcinoma among users of nonsteroidal antiinflammatory drugs, Cancer 97 (2003) 1732-1736.

[113] S.S. Hecht Progress and challenges in selected areas of tobacco carcinogenesis, Chem Res Toxicol 21 (2008) 160-171.

[114] R. O'Donnell, D. Breen, S. Wilson and R. Djukanovic Inflammatory cells in the airways in COPD, Thorax 61 (2006) 448-454.

[115] L. Fialkow, Y. Wang and G.P. Downey Reactive oxygen and nitrogen species as signaling molecules regulating neutrophil function, Free Radic Biol Med 42 (2007) 153-164.

[116] H.S. Park, S.R. Kim and Y.C. Lee Impact of oxidative stress on lung diseases, Respirology 14 (2009) 27-38.

[117] C.M. Doerschuk Leukocyte trafficking in alveoli and airway passages, Respir Res 1 (2000) 136-140.

[118] A.M. Knaapen, N. Gungor, R.P. Schins, P.J. Borm and F.J. Van Schooten Neutrophils and respiratory tract DNA damage and mutagenesis: a review, Mutagenesis 21 (2006) 225-236.

[119] S. Loft and H.E. Poulsen Cancer risk and oxidative DNA damage in man, J Mol Med 74 (1996) 297-312.

[120] J. Retel, B. Hoebee, J.E. Braun, J.T. Lutgerink, E. van den Akker, A.H. Wanamarta, H. Joenje and M.V. Lafleur Mutational specificity of oxidative DNA damage, Mutat Res 299 (1993) 165-182.

[121] R.A. Floyd The role of 8-hydroxyguanine in carcinogenesis, Carcinogenesis 11 (1990) 1447-1450. 
[122] L.J. Marnett Lipid peroxidation-DNA damage by malondialdehyde, Mutat Res 424 (1999) 83-95.

[123] H. Esterbauer, P. Eckl and A. Ortner Possible mutagens derived from lipids and lipid precursors, Mutat Res 238 (1990) 223-233.

[124] A.K. Chaudhary, G.R. Reddy, I.A. Blair and L.J. Marnett Characterization of an N6-oxopropenyl-2'deoxyadenosine adduct in malondialdehyde-modified DNA using liquid chromatography/electrospray ionization tandem mass spectrometry, Carcinogenesis 17 (1996) 1167-1170.

[125] K. Dixon and E. Kopras Genetic alterations and DNA repair in human carcinogenesis, Semin Cancer Biol 14 (2004) 441-448.

[126] I. Rahman, S.K. Biswas and A. Kode Oxidant and antioxidant balance in the airways and airway diseases, Eur J Pharmacol 533 (2006) 222-239.

[127] S. Maynard, S.H. Schurman, C. Harboe, N.C. de Souza-Pinto and V.A. Bohr Base excision repair of oxidative DNA damage and association with cancer and aging, Carcinogenesis 30 (2009) 2-10.

[128] H. Ellinger-Ziegelbauer, J. Aubrecht, J.C. Kleinjans and H.J. Ahr Application of toxicogenomics to study mechanisms of genotoxicity and carcinogenicity, Toxicol Lett 186 (2009) 36-44.

[129] G.M. Williams Mechanisms of chemical carcinogenesis and application to human cancer risk assessment, Toxicology 166 (2001) 3-10.

[130] S.B. Astley, D.A. Hughes, A.J. Wright, R.M. Elliott and S. Southon DNA damage and susceptibility to oxidative damage in lymphocytes: effects of carotenoids in vitro and in vivo, Br J Nutr 91 (2004) 53-61.

[131] W.D. Travis, L.B. Travis and S.S. Devesa Lung cancer, Cancer 75 (1995) 191-202.

[132] C.A. Moran Pulmonary adenocarcinoma: the expanding spectrum of histologic variants, Arch Pathol Lab Med 130 (2006) 958-962.

[133] B.I. Gustafsson, M. Kidd, A. Chan, M.V. Malfertheiner and I.M. Modlin Bronchopulmonary neuroendocrine tumors, Cancer 113 (2008) 5-21.

[134] R. Govindan, N. Page, D. Morgensztern, W. Read, R. Tierney, A. Vlahiotis, E.L. Spitznagel and J. Piccirillo Changing epidemiology of small-cell lung cancer in the United States over the last 30 years: analysis of the surveillance, epidemiologic, and end results database, J Clin Oncol 24 (2006) 4539-4544.

[135] F.G. Fernandez and R.J. Battafarano Large-cell neuroendocrine carcinoma of the lung: an aggressive neuroendocrine lung cancer, Semin Thorac Cardiovasc Surg 18 (2006) 206-210.

[136] F.G. Fernandez and R.J. Battafarano Large-cell neuroendocrine carcinoma of the lung, Cancer Control 13 (2006) 270-275.

[137] M. Garcia-Yuste, J.M. Matilla and F. Gonzalez-Aragoneses Neuroendocrine tumors of the lung, Curr Opin Oncol 20 (2008) 148-154.

[138] E. Brambilla, W.D. Travis, T.V. Colby, B. Corrin and Y. Shimosato The new World Health Organization classification of lung tumours, Eur Respir J 18 (2001) 1059-1068.

[139] J.L. Dorne Impact of inter-individual differences in drug metabolism and pharmacokinetics on safety evaluation, Fundam Clin Pharmacol 18 (2004) 609-620.

[140] J. Keijer, A. Bunschoten, A. Palou and N.L. Franssen-van Hal Beta-carotene and the application of transcriptomics in risk-benefit evaluation of natural dietary components, Biochim Biophys Acta 1740 (2005) 139-146.

[141] A. Palou, C. Pico and J. Keijer Integration of risk and benefit analysis-the window of benefit as a new tool?, Crit Rev Food Sci Nutr 49 (2009) 670-680.

[142] A.J. Alija, N. Bresgen, O. Sommerburg, C.D. Langhans, W. Siems and P.M. Eckl Cyto- and genotoxic potential of beta-carotene and cleavage products under oxidative stress, Biofactors 24 (2005) 159-163.

[143] P. Palozza, G. Calviello and G.M. Bartoli Prooxidant activity of beta-carotene under 100\% oxygen pressure in rat liver microsomes, Free Radic Biol Med 19 (1995) 887-892.

[144] P. Zhang and S.T. Omaye Beta-carotene and protein oxidation: effects of ascorbic acid and alphatocopherol, Toxicology 146 (2000) 37-47.

[145] P. Zhang and S.T. Omaye Antioxidant and prooxidant roles for beta-carotene, alpha-tocopherol and ascorbic acid in human lung cells, Toxicol In Vitro 15 (2001) 13-24.

[146] A. Bast, R.M. van der Plas, H. van den Berg and G.R. Haenen Beta-carotene as antioxidant, Eur J Clin Nutr 50 Suppl 3 (1996) S54-56.

[147] C.M. Lee, A.C. Boileau, T.W. Boileau, A.W. Williams, K.S. Swanson, K.A. Heintz and J.W. Erdman, Jr. Review of animal models in carotenoid research, J Nutr 129 (1999) 2271-2277.

[148] R.S. Parker Carotenoids in human blood and tissues, J Nutr 119 (1989) 101-104. 
Beta-carotene $(\mathrm{BC})$ was found to enhance lung cancer risk in smokers. This adverse effect was unexpected because BC was thought to act as an antioxidant against cigarette smoke-derived radicals. These radicals can directly or indirectly damage DNA, leading to the formation of promutagenic DNA lesions such as 8-oxo-7,8-dihydro-2'-deoxyguanosine (8-oxo-dG) and 3-(2-deoxy-beta-D-erythro-pentafuranosyl)pyrimido[1,2alpha]purin-10(3H)-one deoxyguanosine $\left(\mathrm{M}_{1} \mathrm{dG}\right)$. Later, it was suggested that high concentrations of $\mathrm{BC}$ could also result in pro-oxidant effects. Therefore, we investigated whether high but physiologically feasible concentrations of BC were able to alter (i) the formation of radicals in vitro assessed by electron spin resonance spectroscopy, (ii) the levels of 8-oxo-dG and $\mathrm{M}_{1} \mathrm{dG}$ in vitro in lung epithelial cells after incubation with hydrogen peroxide $\left(\mathrm{H}_{2} \mathrm{O}_{2}\right)$ and the smoke-derived carcinogen benzo[a]pyrene (B[a]P) and (iii) the levels of 8-oxo-dG and $\mathrm{M}_{1} \mathrm{dG}$ in vivo in ferrets' lung after chronic exposure to $\mathrm{B}[\mathrm{a}] \mathrm{P}$. BC increased in vitro hydroxyl radical formation in the Fenton reaction but inhibited the formation of carbon-centered radicals. Similarly, BC was able to enhance 8-oxo-dG in vitro in lung epithelial cells. On the other hand, BC significantly inhibited $M_{1} d G$ formation in lung epithelial cells, especially after induction of $\mathrm{M}_{1} \mathrm{dG}$ by $\mathrm{H}_{2} \mathrm{O}_{2}$ or $\mathrm{B}[\mathrm{a}] \mathrm{P}$. Finally, $\mathrm{BC}$ supplementation of ferrets also resulted in a significant decrease in $\mathrm{M}_{1} \mathrm{dG}$, but in contrast to the in vitro experiments, no effect was observed on 8-oxo-dG levels, probably because of increased base excision repair capacities as assessed by a modified comet assay. These data indicate that the fate of $\mathrm{BC}$ being a pro- or antioxidant strongly depends on the type of radical involved. 


\section{Beta-carotene affects oxidative stress related DNA damage in lung epithelial cells and in ferret lung}

\section{Carcinogenesis}

Yvonne G.J. van Helden, Jaap Keijer, Sandra G. Heil, Catalina Picó, Andreu Palou, Paula Oliver, Armelle Munnia, Jacob J. Briedé, Marco Peluso, Nicole Franssen-van Hal, Frederik J. van Schooten, Roger W. L. Godschalk 


\section{Introduction}

The consumption of high concentrations of beta-carotene $(\mathrm{BC})$, predominantly present in fruits and vegetables, is associated with a lower incidence of cardiovascular diseases and several types of cancers [1]. This was attributed to the antioxidant properties of BC [2]. However, two human intervention trials unexpectedly demonstrated that BC supplementation alone, Alpha-Tocopherol Beta-Carotene Cancer prevention study (ATBC), or in combination with vitamin A, Carotene and Retinol Efficacy Trial (CARET), had adverse effects including an increased lung cancer risk in smokers, suggesting that a high $\mathrm{BC}$ intake can enhance smoke-induced carcinogenesis $[3,4]$. The mechanism behind this increased lung cancer risk upon $\mathrm{BC}$ supplementation is still not elucidated, but an interaction of $\mathrm{BC}$ with cigarette smoke-induced processes or constituents is likely, because no detrimental effects of $\mathrm{BC}$ were observed in non-smokers [5].

Cigarette smoke contains many genotoxic compounds, including benzo[a]pyrene (B[a]P), one of the best studied chemical carcinogens [6]. Although the formation of B[a]Prelated DNA adducts is an important contributor to the carcinogenicity of cigarette smoke [7], other types of DNA lesions may also contribute to this mechanism. For instance, cigarette smoke contains many free radicals and oxidants (1014 per puff), capable of damaging the DNA [8]. Further, inhalation of cigarette smoke results in an inflammatory response in the lung, and a role for chronic inflammation in lung carcinogenesis has been demonstrated by studies in which the use of anti-inflammatory drugs resulted in a reduction in the relative risk of lung cancer in smokers $[9,10]$. During inflammation, large amounts of reactive oxygen species (ROS) are produced that can directly interact with DNA to form pro-mutagenic DNA lesions, with the most studied lesion being 8-oxo-7,8-dihydro-2'-deoxyguanosine (8-oxo-dG) [11]. ROS can also indirectly damage DNA by reacting with lipids first, causing lipid peroxidation (LPO), and a subsequent binding of these LPO products to the DNA. An important LPO product is malondialdehyde (MDA), able to form the pro-mutagenic MDA-derived DNA adduct 3-(2-deoxy$\beta$-D-erythro-pentafuranosyl)pyrimido[1,2- $\alpha$ purin-10(3H)-one deoxyguanosine $\left(\mathrm{M}_{1} \mathrm{dG}\right)[12]$. DNA adducts can result in mutations and are considered to be an important first step in carcinogenesis. Antioxidants have the potential to neutralize both ROS and LPO, thereby decreasing the formation of genotoxic DNA lesions. BC is also regarded as an antioxidant, but an increasing number of studies show that $\mathrm{BC}$ can also act as a pro-oxidant [reviewed in ref. [13]], able to enhance DNA lesion formation. Repair enzymes have the ability to restore these lesions; nucleotide excision repair enzymes specifically recognize bulky DNA adducts such as $\mathrm{M}_{1} \mathrm{dG}$, whereas base excision repair (BER) enzymes remove small lesions such as oxidized DNA bases like 8-oxo-dG. The modulation of DNA repair enzyme capacities can thus also result in altered levels of 
smoke-induced DNA lesions, ultimately leading to increased or decreased protection against DNA mutations [14,15].

The aim of this study was to assess the pro- and antioxidant properties of $\mathrm{BC}$ in vitro and in vivo to get more insight in the unexpected increase of lung cancer incidence in smokers who were supplemented with BC. We studied the modulating effect of BC supplementation on two major types of DNA lesions that are thought to be involved in smoke and oxidative stress-induced lung carcinogenesis: 8-oxo- $\mathrm{dG}$ and $\mathrm{M}_{1} \mathrm{dG}$, in vitro and in vivo. Therefore, we exposed human lung epithelial cells to $\mathrm{BC}$ at a concentration of $5 \mu \mathrm{M}$, which was equal to the BC serum concentration in the ATBC and CARET study at the end of the interventions, in combination with the smoke-derived ROS generating $\mathrm{B}$ [a]P or hydrogen peroxide $\left(\mathrm{H}_{2} \mathrm{O}_{2}\right)$. To validate in vitro results, ferrets (Mustela putorius furo) were exposed to $\mathrm{BC}$ (based on the $\mathrm{BC}$ intake in the human intervention trials) in combination with or without B[a]P. Ferrets were used since they absorb and metabolize $\mathrm{BC}$ more comparable with humans than rodents and display increasing $\mathrm{BC}$ serum concentration with increasing $\mathrm{BC}$ intake, rather than increasing $\mathrm{BC}$ metabolite concentrations $[16,17]$.

\section{Materials \& Methods}

\section{BC stock solutions}

The $\mathrm{BC}$ concentration $(5 \mu \mathrm{M})$ that was used in the in vitro studies was based on serum concentrations observed in the CARET and ATBC study after 3 years of daily vitamin intake [18]. Stock solutions of BC (15 mM) (Sigma-Aldrich, Zwijndrecht, The Netherlands) with or without B[a]P $(30 \mathrm{mM})$ and $\mathrm{B}[\mathrm{a}] \mathrm{P}$ alone $(30 \mathrm{mM})$ (Sigma-Aldrich) were prepared in deperoxidized tetrahydrofuran (THF) and stored, including the THF control, in amber vials under argon at $-80^{\circ} \mathrm{C}$ until use. THF was deperoxidized over an ALOX column (aluminium oxide-90 active basic, Merck, Darmstadt, Germany). Stock solutions were diluted 1:30 in heat-inactivated fetal calf serum (Gibco, Invitrogen, Breda, The Netherlands) to make BC better soluble in hydrophilic solutions. This solution was further diluted 1:100 in medium or water.

\section{Pro- and antioxidant effects of $\mathrm{BC}$ assessed by electron spin resonance spectroscopy}

Iron sulphate $\left(\mathrm{FeSO}_{4}\right), \mathrm{H}_{2} \mathrm{O}_{2}$ and the spin traps: a-(4-pyridyl 1-oxide)- $N$-tert-butylnitrone (POBN) and 5,5-dimethyl-1-pyrolline $N$-oxide (DMPO) were purchased from SigmaAldrich. DMPO was dissolved in nitrogen-flushed water and purified by charcoal treatment. Concentrations of DMPO stocks were determined spectrophotometrically $(\varepsilon=$ $7700 / \mathrm{M} / \mathrm{cm}, 234 \mathrm{~nm}$ ). Electron spin resonance (ESR) spectra were recorded at room 
temperature in glass capillaries (100 $\mu$, Brand AG, Wertheim, Germany) in a Bruker EMX 1273 spectrometer equipped with an ER 4119HS high-sensitivity cavity and $12 \mathrm{~kW}$ power supply operating at $\mathrm{X}$ band frequencies. The modulation frequency of the spectrometer was $100 \mathrm{kHz}$. Instrumental conditions for the recorded spectra were as follows: magnetic field, $3490 \mathrm{G}$; scan range, $60 \mathrm{G}$; modulation amplitude, $1 \mathrm{G}$; receiver gain, $1 \mathrm{x}$ 105; microwave frequency, $9.85 \mathrm{GHz}$; power, $50 \mathrm{~mW}$; time constant, $40.96 \mathrm{~ms}$; scan time, $20.97 \mathrm{~s}$; number of scans, 10 when using the spin-trap DMPO and 20 when using the spin-trap POBN. Surface area and hyperfine coupling constants of the peaks were calculated using the WIN-EPR spectrum manipulation program (Bruker, Billerica, MA). To assess the formation of hydroxyl radicals $\left({ }^{\circ} \mathrm{OH}\right)$ or carbon-centered radicals $\left({ }^{\circ} \mathrm{C}\right), \mathrm{Fe}-$ $\mathrm{SO}_{4}(20 \mu \mathrm{M})$ was mixed with the spin-trap DMPO $(100 \mathrm{mM})$ or POBN $(100 \mathrm{mM})$, respectively, and solvent (control) with or without $\mathrm{BC}(5 \mu \mathrm{M}) . \mathrm{H}_{2} \mathrm{O}_{2}(100 \mu \mathrm{M})$ was added to start the reaction. Exactly $2 \mathrm{~min}$ after the addition of $\mathrm{H}_{2} \mathrm{O}_{2}$, the spectrum was recorded and every condition was tested in triplicate.

\section{DNA damage in lung epithelial cells}

Pro- and antioxidant effects of $\mathrm{BC}$ on $\mathrm{H}_{2} \mathrm{O}_{2}$ - or $\mathrm{B}[\mathrm{a}] \mathrm{P}$-induced genotoxicity in $\mathrm{A} 549$ and BEAS-2B lung epithelial cells were studied. For this, the human epithelial lung carcinoma cell line A549 was cultured in Dulbecco's modified Eagle's medium supplemented with 10\% heat-inactivated fetal calf serum (Life Technologies, Invitrogen, Breda, The Netherlands), $1 \%$ penicillin and 1\% streptomycin (Sigma-Aldrich) and the human SV40 transformed lung cell line BEAS-2B was cultured in RPMI 1640 containing L-glutamine (Sigma) and supplemented with $5 \%$ fetal calf serum, 1\% penicillin, 1\% streptomycin, $1 \mathrm{x}$ non-essential amino acids and $10 \mathrm{mM} \mathrm{N}$-2-hydroxyethylpiperazine- $N$-2-ethanesulfonic acid (Gibco). Both cell lines were cultured at $37^{\circ} \mathrm{C}$ in a $5 \% \mathrm{CO}_{2}$ atmosphere. Cells were cultured in T75 flasks and $48 \mathrm{~h}$ prior to $\mathrm{H}_{2} \mathrm{O}_{2}$ or $\mathrm{B}[\mathrm{a}] \mathrm{P}$ exposure, medium supplemented with or without $5 \mu \mathrm{M} \mathrm{BC}$ was refreshed daily to ensure the presence of intact $\mathrm{BC}$ in the cells [19]. After 48 h, 80\% confluent cells were exposed to fresh medium with or without $\mathrm{B}[\mathrm{a}] \mathrm{P}(10 \mu \mathrm{M})$ or $\mathrm{H}_{2} \mathrm{O}_{2}(100 \mu \mathrm{M})$ in combination with or without $\mathrm{BC}(5 \mu \mathrm{M})$. Experiments were performed in quadruplet and $1 \mathrm{~h}$ after $\mathrm{H}_{2} \mathrm{O}_{2}$ exposure and $16 \mathrm{~h}$ after B[a]P exposure cells were harvested. From the cells, DNA was isolated and assayed for 8-oxo-dG and $\mathrm{M}_{1} \mathrm{dG}$ (see below).

\section{Ferret housing, treatment and lung collection}

The calculation of the ferret equivalent of $\mathrm{BC}$ doses as used in the human ATBC and CARET intervention trials ( 30 mg/day in a $70 \mathrm{~kg}$ person) was based on previous reports $[17,20]$ and was based on total absorption of intact BC. Ferrets were housed and treated as described by Fuster et al. [21]. Briefly, female 7-week-old ferrets (Exopet AB, Glommen, Sweden) were fed ad libitum (Friskies). After 1 week of adaptation, ferrets were randomly assigned in five groups of six animals receiving the following diets: con- 
trol formulation (Co); $0.8 \mathrm{mg} \mathrm{BC} / \mathrm{kg} /$ day $(\mathrm{BC} 0.8$ ) which is equivalent to $\sim 10 \mathrm{mg} \mathrm{BC} /$ day in a $70 \mathrm{~kg}$ person; $3.2 \mathrm{mg} \mathrm{BC} / \mathrm{kg} /$ day $(\mathrm{BC} 3.2$ ) which is equivalent to $40 \mathrm{mg} \mathrm{BC} /$ day; control formulation in combination with exposure to $8 \mathrm{mg} \mathrm{B}[\mathrm{a}] \mathrm{P} / \mathrm{kg}$ three times a week for 10 weeks by oral gavage $(\mathrm{B}[\mathrm{a}] \mathrm{P})$ and $0.8 \mathrm{mg} \mathrm{BC} / \mathrm{kg} /$ day in combination with exposure to $8 \mathrm{mg} \mathrm{B}[\mathrm{a}] \mathrm{P} / \mathrm{kg}$ three times a week for 10 weeks by oral gavage $(\mathrm{BCB}[\mathrm{a}] \mathrm{P})$. BC was provided every morning for 6 months as a water-soluble formulation by DSM Nutritional Products Ltd (Basel, Switzerland), which contained crystalline BC, DL-alpha-tocopherol, ascorbyl palmitate, corn oil, fish gelatine, sucrose and corn starch. B[a]P treatment started 1 week after beginning the treatment with BC. Formulations with or without BC were dissolved in $200 \mu \mathrm{l}$ water and given to the animals. After the 6 months treatment, ferrets were anesthetized using $10 \mathrm{mg} / \mathrm{kg}$ ketamine hydrochloride (Imalgène 1000, Merial Laboratorios SA, Lyon, France) and $80 \mu \mathrm{g} / \mathrm{kg}$ medetomidine (Domtor, Orion Pharma, Espoo, Finland). Arterial blood was collected. Animals were killed by exsanguinations; lung tissue was collected, snap frozen in liquid nitrogen and stored at $-80^{\circ} \mathrm{C}$ until analysis.

\section{DNA isolation for $M_{1} \mathrm{dG}$ and 8-oxo-dG measurement}

Lung was cut into small pieces in a solution containing $100 \mathrm{mM} \mathrm{NaCl}, 20 \mathrm{mM}$ ethylenediaminetetraacetic acid, $50 \mathrm{mM}$ Tris- $\mathrm{HCl}, 25 \mathrm{mM}$ 2,2,6,6-tetramethylpiperidine-1oxyl and $0.5 \%$ sodium dodecyl sulfate. RNase A $(0.1 \mathrm{mg} / \mathrm{ml})$ and RNase T1 $(1000 \mathrm{U} / \mathrm{ml})$ were added and samples were incubated at $37^{\circ} \mathrm{C}$ for $1 \mathrm{~h}$. Thereafter, proteinase $\mathrm{K}$ was added $(1 \mathrm{mg} / \mathrm{ml})$ and incubation was continued overnight at $37^{\circ} \mathrm{C}$. The aqueous phase was successively extracted with equal volumes of phenol:chloroform:isoamyl alcohol (25:24:1) containing 8-hydroxyquinoline and chloroform:isoamyl alcohol (24:1). The DNA was then precipitated using 2 vols of ice-cold ethanol after addition of 1 /30 vols sodium acetate $(3 \mathrm{M})$ and washed with $70 \%$ ethanol. DNA was dried under nitrogen and dissolved in $2 \mathrm{mM}$ Tris $(\mathrm{pH} 7.4)$ at a concentration of $0.5 \mathrm{mg} / \mathrm{ml}$. 2,2,6,6Tetramethylpiperidine-1-oxyl and 8-hydroxyquinoline were added to prevent artificial formation of 8-oxo-dG. All DNA samples had an A260/A280 > 1.8 and an A230/A260 $\sim 0.45$, indicating the purity of the DNA.

\section{Preparation of the reference $\mathbf{M}_{1} \mathrm{dG}$ standards}

Reference adduct standards were used for the optimization of the ${ }^{32} \mathrm{P}-\mathrm{DNA}$ post-labeling procedure. We prepared the reference adduct standards by treating calf thymus (CT) DNA with $10 \mathrm{mM}$ MDA according to published condition [22], yielding $\mathrm{M}_{1} \mathrm{dG}$ [22-24]. MDA-treated CT-DNA was then diluted with untreated CT-DNA to obtain decreasing levels of the reference adduct standard to generate a calibration curve $\left(R^{2}=0.99\right)$. 


\section{${ }^{32} P$-DNA post-labeling of $M_{1} \mathrm{dG}$}

The analysis of $\mathrm{M}_{1} \mathrm{dG}$ by ${ }^{32} \mathrm{P}-\mathrm{DNA}$ post-labeling was performed as described by Munnia et al. [25] with minor modifications. $\mathrm{M}_{1} \mathrm{dG}$ standards were prepared according to published conditions [22] in which CT-DNA $(1 \mathrm{mg} / \mathrm{ml})$ was incubated in vitro with $10 \mathrm{mM}$ MDA. DNA was digested by micrococcal nuclease and spleen phosphodiesterase [26]. Hydrolyzed samples were subsequently treated with $2.5 \mu \mathrm{g}$ of nuclease P1 for $30 \mathrm{~min}$ at $37^{\circ} \mathrm{C}$. The nuclease P1-resistant nucleotides were incubated with $15-25 \mu \mathrm{Ci}$ of $\left[\gamma^{-32} \mathrm{P}\right]-$ ATP $(3000 \mathrm{Ci} / \mathrm{mmol})$ and $\mathrm{T} 4$-polynucleotide $(0.75 \mathrm{U} / \mu \mathrm{l})$ to generate ${ }^{32} \mathrm{P}-$ labeled $\mathrm{M}_{1} \mathrm{dG}$, which were subsequently separated by thin layer chromatography [25] 32P-labeled products were applied to the origin of chromatograms and developed with $0.35 \mathrm{MgCl}_{2}$ up to $2.0 \mathrm{~cm}$ filter paper wick. Plates were developed in the opposite direction with $2.1 \mathrm{M}$ lithium formate, $3.75 \mathrm{M}$ urea, $\mathrm{pH} 3.75$, and then run at the right angle to the previous development with $0.24 \mathrm{M}$ sodium phosphate, $2.4 \mathrm{M}$ urea, $\mathrm{pH}$ 6.4.

Detection and quantification of $\mathrm{M}_{1} \mathrm{dG}$ and total nucleotides was obtained by storage phosphor imaging technique employing intensifying screens from Molecular Dynamics (Sunnyvale, CA) for 0.20-48 h. The screens were scanned using a Typhoon 9210 (Amersham, Buckinghamshire, UK). Software used to process the data was ImageQuant (Molecular Dynamics). After background subtraction, the levels of $\mathrm{M}_{1} \mathrm{dG}$ were expressed as relative adduct labeling $=$ screen pixel in adducted nucleotides/screen pixel in total nucleotides. To calculate the levels of total nucleotides, aliquots of hydrolyzed DNA were appropriately diluted and reacted in the same mixtures used for $\mathrm{M}_{1} \mathrm{dG}$ labeling. The obtained ${ }^{32} \mathrm{P}-\mathrm{labeled}$ total nucleotides were separated on Merck polyethyleneiminecellulose thin layer chromatography plates using $280 \mathrm{mM}\left(\mathrm{NH}_{4}\right)_{2} \mathrm{SO}_{4}$ and $50 \mathrm{mM}$ $\mathrm{NaH}_{2} \mathrm{PO}_{4}$. The values measured for $\mathrm{M}_{1} \mathrm{dG}$ were corrected across experiments based on the recovery of standard $\mathrm{M}_{1} \mathrm{dG}$ after the ${ }^{32} \mathrm{P}-\mathrm{DNA}$ post-labeling assay.

\section{High-performance liquid chromatography/electrochemical detection anal- ysis of 8-oxo-dG}

Oxidative damage in DNA was evaluated as described previously [27] and was expressed as the ratio of 8-oxo-dG to deoxyguanosine. In short, DNA was digested into deoxyribonucleosides by treatment with nuclease $\mathrm{P} 1(0.02 \mathrm{U} / \mu \mathrm{l})$ and alkaline phosphatase $(0.014$ $\mathrm{U} / \mu 1$ ). The digest was then injected into a Gynkotek 480 isocratic pump (Gynkotek, Bremen, Germany) coupled with a Midas injector (Spark Holland, Hendrik Ido Ambacht, The Netherlands) and connected to a SupelcosilTM LC-18S column (250 x $4.6 \mathrm{~mm}$ ) (Supelco Park, Bellefonte, PA) and an electrochemical detector (Antec, Leiden, The Netherlands). The mobile phase consisted of $10 \%$ aqueous methanol containing $94 \mathrm{mM}$ $\mathrm{KH}_{2} \mathrm{PO}_{4}, 13 \mathrm{mM} \mathrm{K}_{2} \mathrm{HPO}_{4}, 26 \mathrm{mM} \mathrm{NaCl}$ and $0.5 \mathrm{mM}$ ethylenediaminetetraacetic acid. Elution was performed at a flow rate of $1.0 \mathrm{ml} / \mathrm{min}$ with a lower detection limit of 40 
fmol absolute for 8-oxo-dG or 1.5 residues/106 2'-deoxyguanosine. Deoxyguanosine was simultaneously monitored at $260 \mathrm{~nm}$.

\section{BER assay}

BER capacity was measured as described previously [28], with some minor modifications. Pairs of gels containing $\sim 5 \times 10^{4}$ A549 substrate cells [exposed to $1 \mathrm{mM}$ Ro 198022 (Roche, Basel, Switzerland) and irradiated $5 \mathrm{~min}, 33 \mathrm{~cm}$ from a $500 \mathrm{~W}$ halogen lamp] in $100 \mu \mathrm{l}$ of $1 \%$ low-melting point agarose (Invitrogen Life Technologies) were placed on glass microscope slides pre-coated with $1.5 \%$ normal melting point agarose. The gels were covered with glass cover slips and allowed to solidify for $30 \mathrm{~min}$ at $4{ }^{\circ} \mathrm{C}$, after which they were lysed overnight in $2.5 \mathrm{M} \mathrm{NaCl}, 0.1 \mathrm{M}$ ethylenediaminetetraacetic acid (EDTA), $10 \mathrm{mM}$ Tris, $1 \%$ Triton X-100 and 10\% dimethyl sulfoxide, $\mathrm{pH} \mathrm{10}$, at $4^{\circ} \mathrm{C}$. Slides were washed $3 \times 5$ min with reaction buffer. Forty-five microliters of lung protein extract $(1 \mathrm{mg} / \mathrm{ml})$ was added to each gel, covered with a cover slip and incubated for 10 min at $37^{\circ} \mathrm{C}$. As a negative control, reaction buffer alone was used and as a positive control $2.5 \mu \mathrm{g} / \mathrm{ml}$ formamidopyrimidine DNA glycosylase (FPG, kindly provided by Bernd Epe, University of Mainz, Mainz, Germany). After incubation, slides were immediately processed according to the conventional comet assay [29] to measure the DNA breaks introduced by repair enzymes in the protein extract.

\section{Statistics}

Statistical analyses were performed in SPSS (version 15.0) for windows using a Student's $t$-test to test for differences between control samples and BC in the ESR experiments. For the in vitro tests, we used $2 \times 2 \times 2$ factorial univariate analysis of variance (ANOVA) to test for differences between BC treatment, exposure and cell type. For the in vivo experiments, we used $2 \times 2$ factorial univariate analysis of variance to test for diet and exposure differences. Statistical tests were performed two tailed and $\mathrm{p}<0.05$ was considered statistically significant.

\section{Results}

\section{$\mathrm{BC}$ affects hydroxyl radical $(\cdot \mathrm{OH})$ and carbon centered radical $(\cdot \mathrm{C})$ formation in vitro}

The DMPO-trapped $\cdot \mathrm{OH}\left(\mathrm{DMPO} /{ }^{\circ} \mathrm{OH}\right)$ signal was predominant [coupling constants: $a(\mathrm{~N})$ $=14.86 \mathrm{G}, a(\beta-\mathrm{H})=14.71 \mathrm{G}]($ Fig. $1 \mathrm{~A})$ in an acellular $\mathrm{Fe}^{2+} / \mathrm{H}_{2} \mathrm{O}_{2}$ system but also included other small DMPO-trapped radical signals including possible ${ }^{\circ} \mathrm{C}\left(\mathrm{DMPO} /{ }^{\circ} \mathrm{C}\right)$ peaks, most probably derived from THF. BC $(5 \mu \mathrm{M})$ increased the DMPO/ $/ \mathrm{OH}$ signal by 
$43 \%$, as was published before [29], whereas the $\mathrm{DMPO} /{ }^{\circ} \mathrm{C}$ peaks completely disappeared (Fig. 1B and C).
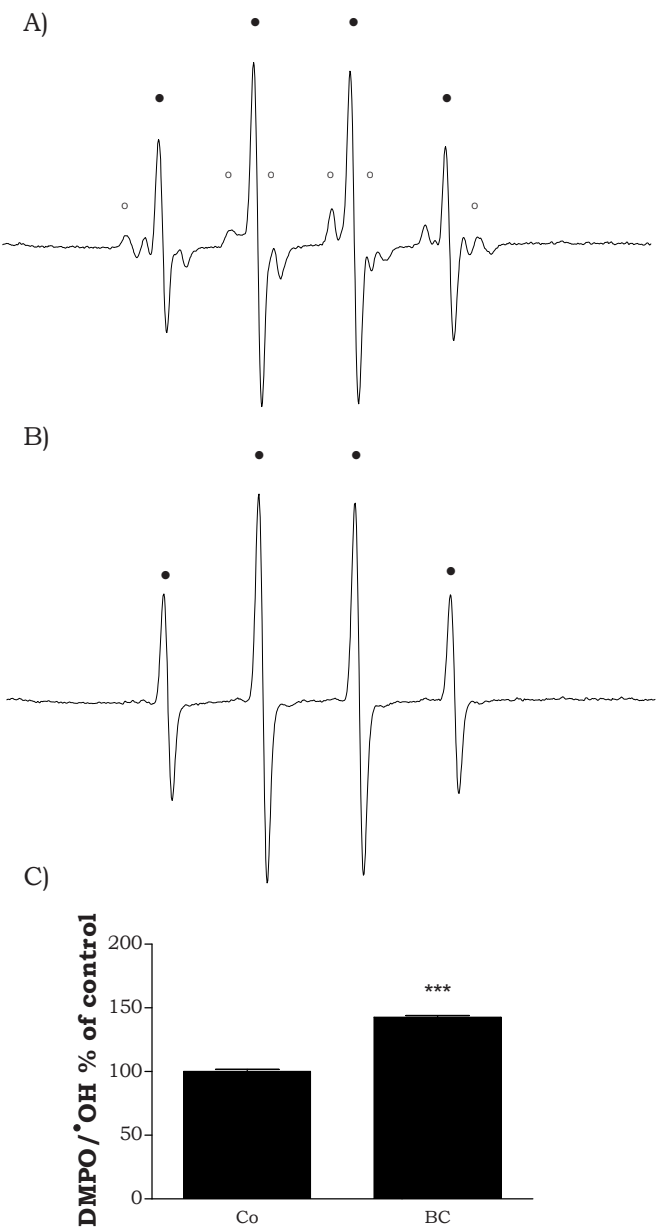

Figure 1: ESR spectrum of an $\mathrm{Fe}^{2+} / \mathrm{H}_{2} \mathrm{O}_{2}$ reaction containing DMPO $(100 \mathrm{mM}), \mathrm{FeSO}_{4}(20 \mu \mathrm{M})$ and $\mathrm{H}_{2} \mathrm{O}_{2}(100 \mu \mathrm{M})$ in $(\mathrm{A})$ solvent or $(\mathrm{B})$ with $\mathrm{BC}(5 \mu \mathrm{M})$. Solid dots indicate the DMPO/.OH adduct signal and open circles indicate the DMPO $/{ }^{\circ} \mathrm{C}$ adduct signal. Surface area of the DMPO/ $/{ }^{\circ} \mathrm{OH}$ peaks was calculated and expressed as percentage of the control incubations (Co) (C). BC increased DMPO/.OH formation. Data are expressed as mean \pm standard error of the mean. ${ }^{* * *} \mathrm{p}<0.001$.

Therefore, the inhibition of ${ }^{\circ} \mathrm{C}$ by $\mathrm{BC}$ was further studied by ESR spectroscopy combined with the spin-trap $\mathrm{POBN}$, which is more specific for ${ }^{\circ} \mathrm{C}$ [30]. The $\mathrm{Fe}^{2+} / \mathrm{H}_{2} \mathrm{O}_{2}$ system gen- 
erated POBN-trapped radicals resulting in peaks [coupling constants: $a(\mathrm{~N})=15.66 \mathrm{G}$, $a(\beta-\mathrm{H})=2.62 \mathrm{G}$ ] only in organic solvent controls (Fig. $2 \mathrm{~A}$ ), but not in water controls, indicative for the generation of $\mathrm{POBN} /{ }^{\circ} \mathrm{C}$ rather than $\mathrm{POBN} /{ }^{\circ} \mathrm{OH}$. BC reduced the intensity of the $\mathrm{POBN} / \cdot \mathrm{C}$ signal (Fig. 2B) by $93 \%$ (Fig. 2C).

A)

B)
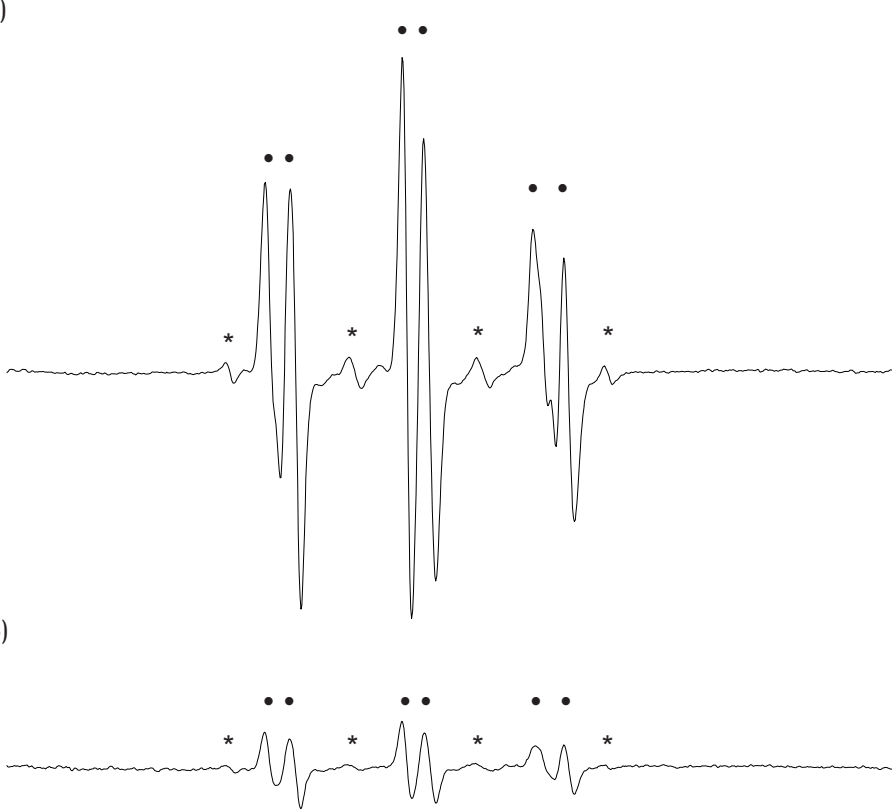

C)

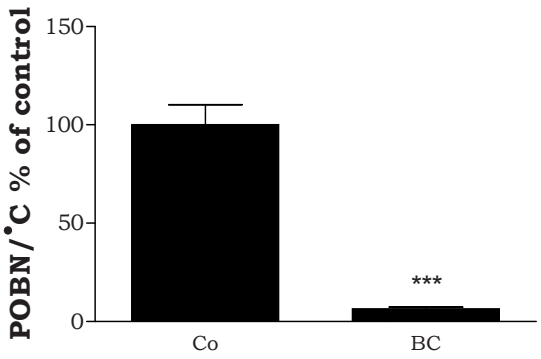

Figure: 2: ESR spectrum of an $\mathrm{Fe}^{2+} / \mathrm{H}_{2} \mathrm{O}_{2}$ reaction containing POBN $(100 \mathrm{mM}), \mathrm{FeSO}_{4}(20 \mu \mathrm{M})$ and $\mathrm{H}_{2} \mathrm{O}_{2}(100 \mu \mathrm{M})$ in (A) solvent or with (B) BC $(5 \mu \mathrm{M})$. Solid dots indicate the POBN $/{ }^{\circ} \mathrm{C}$ adduct signal. POBN can hydrolyze into 2-methyl-2-nitrosopropane [31] and stars indicate 2-methyl-2nitrosopropane $/ \cdot \mathrm{H}$ adducts $[a(\mathrm{~N})=a(\mathrm{H})=14.27 \mathrm{G}]$. Surface area of the POBN $/{ }^{\circ} \mathrm{C}$ peaks were calculated and expressed as percentage of the control incubations (Co) (C). BC decreased POBN $/{ }^{\circ} \mathrm{C}$ formation. Data are expressed as mean \pm standard error of the mean, ${ }^{* * *} \mathrm{p}<0.001$. 


\section{$\mathrm{H}_{2} \mathrm{O}_{2}$ - and $\mathrm{B}[\mathrm{a}] \mathrm{P}$-induced genotoxicity is modulated by $\mathrm{BC}$ in lung epithelial cells}

BC supplementation to A549 and BEAS-2B lung epithelial cells resulted in a significant increase in 8-oxo-dG. In fact, $\mathrm{BC}$ supplementation increased the production of 8-oxo$\mathrm{dG}$, independently of $\mathrm{H}_{2} \mathrm{O}_{2}$ or $\mathrm{B}[\mathrm{a}] \mathrm{P}$ exposure (Fig. 3).

A)

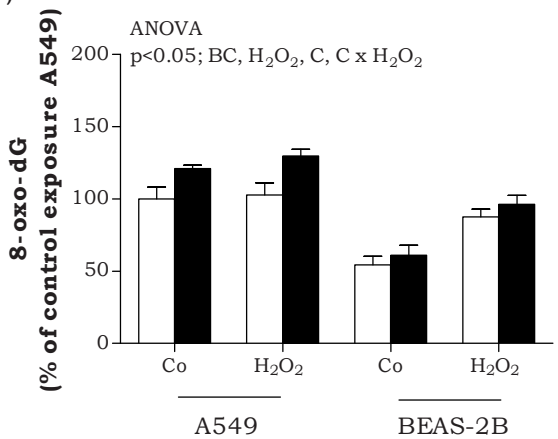

B)

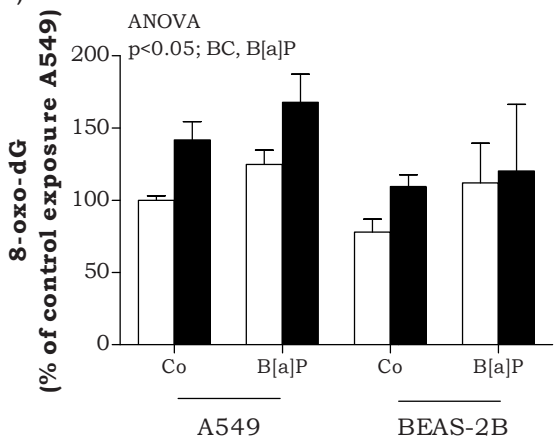

Figure 3: 8-Oxo-dG levels in A549 and BEAS-2B lung epithelial cells exposed to (A) $\mathrm{H}_{2} \mathrm{O}_{2}$ or (B) $\mathrm{B}[\mathrm{a}] \mathrm{P}$ in combination with $\mathrm{BC}$ (black bars) or solvent control (white bars) starting $48 \mathrm{~h}$ prior to the $\mathrm{H}_{2} \mathrm{O}_{2}$ or $\mathrm{B}[\mathrm{a}] \mathrm{P}$ incubation. Data are expressed as mean \pm standard error of the mean, significance was tested using analysis of variance (ANOVA) and considered significant at $p<0.05$. Statistically significant effects were found for (A) BC treatment $(B C), \mathrm{H}_{2} \mathrm{O}_{2}$ exposure $\left(\mathrm{H}_{2} \mathrm{O}_{2}\right)$, cell line (C) and the interaction between cell line and $\mathrm{H}_{2} \mathrm{O}_{2}$ exposure $\left(\mathrm{H}_{2} \mathrm{O}_{2} \times \mathrm{C}\right)$ and $(\mathrm{B}) \mathrm{BC}(\mathrm{BC})$ treatment and $\mathrm{B}[\mathrm{a}] \mathrm{P}$ exposure $(\mathrm{B}[\mathrm{a}] \mathrm{P})$.

$\mathrm{M}_{1} \mathrm{dG}$ was quantified using ${ }^{32} \mathrm{P}-\mathrm{DNA}$ post-labeling by measuring the intensity of the specific $\mathrm{M}_{1} \mathrm{dG}$ spots (Fig. 4).
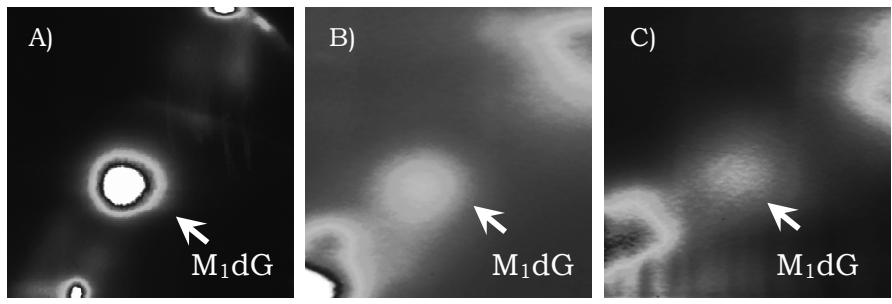

Figure 4: ${ }^{32} \mathrm{P}-\mathrm{DNA}$ post-labeling chromatograms. ${ }^{32} \mathrm{P}-\mathrm{DNA}$ post-labeling chromatograms showing patterns of $\mathrm{M}_{1} \mathrm{dG}$ in (A) MDA-treated CT-DNA, (B) $\mathrm{H}_{2} \mathrm{O}_{2}$-treated cells and (C) $\mathrm{H}_{2} \mathrm{O}_{2}$ in combination with $\mathrm{BC}$-treated cells. For color figure see Color Figures section. 
In contrast to the effect of $\mathrm{BC}$ supplementation on 8-oxo-dG formation, $\mathrm{BC}$ supplementation significantly reduced $\mathrm{M}_{1} \mathrm{dG}$ and $\mathrm{BC}$ had the tendency to reduce $\mathrm{H}_{2} \mathrm{O}_{2}(P=0.06)$ and reduced $\mathrm{B}[\mathrm{a}] \mathrm{P}(\mathrm{p}<0.001)$-induced $\mathrm{M}_{1} \mathrm{dG}$ levels in lung epithelial cells (Fig. 5).

A)

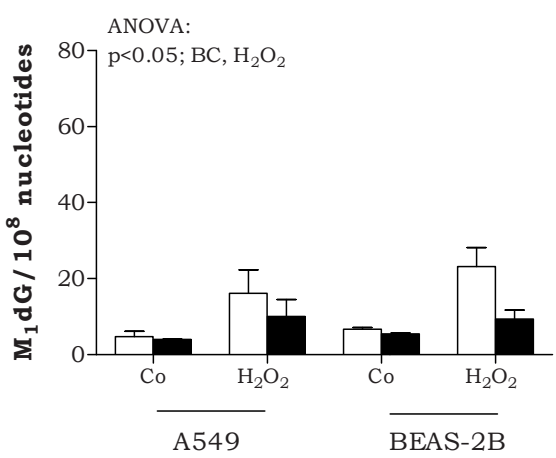

B)

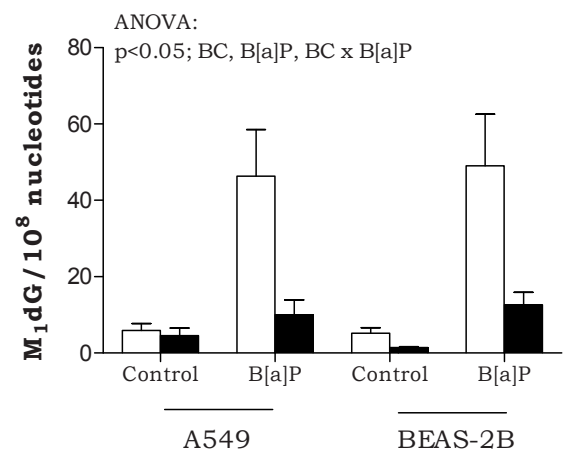

Figure 5: $\mathrm{M}_{1} \mathrm{dG}$ levels in A549 and BEAS-2B lung epithelial cells exposed to (A) $\mathrm{H}_{2} \mathrm{O}_{2}$ or (B) B[a]P in combination with $\mathrm{BC}$ (black bars) or solvent control (white bars) starting $48 \mathrm{~h}$ prior to the $\mathrm{H}_{2} \mathrm{O}_{2}$ or $\mathrm{B}[\mathrm{a}] \mathrm{P}$ incubation. Data are expressed as mean \pm standard error of the mean; significance was tested using analysis of variance and considered significant at $p<0.05$. Statistically significant effects were found for $(\mathrm{A}) \mathrm{BC}$ treatment $(\mathrm{BC}), \mathrm{H}_{2} \mathrm{O}_{2}$ exposure $\left(\mathrm{H}_{2} \mathrm{O}_{2}\right)$ and $(\mathrm{B}) \mathrm{BC}$ treatment $(\mathrm{BC}), \mathrm{B}[\mathrm{a}] \mathrm{P}$ exposure $(\mathrm{B}[\mathrm{a}] \mathrm{P})$ and the interaction between $\mathrm{B}[\mathrm{a}] \mathrm{P}$ exposure and $\mathrm{BC}$ treatment $(\mathrm{B}[\mathrm{a}] \mathrm{P} \times \mathrm{BC})$.

\section{BC supplementation modulates $\mathrm{B}[\mathrm{a}] \mathrm{P}$-induced genotoxicity in ferrets}

$\mathrm{BC}$ supplementation resulted in increased $\mathrm{BC}$ plasma concentrations compared with ferrets that were not supplemented with $\mathrm{BC}$, as was published previously [21]. BC supplementation did not lead to altered levels of 8-oxo-dG in ferret lung DNA compared to the controls (Fig. 6A), whereas $\mathrm{B}[\mathrm{a}] \mathrm{P}$ exposure, in contrast to the in vitro experiments, reduced 8-oxo-dG in ferret lung DNA $(\mathrm{p}<0.01)$. Moreover, BC supplemented ferrets had significantly reduced $\mathrm{M}_{1} \mathrm{dG}$ levels $(\mathrm{p}<0.05)$ compared to non-supplemented ferrets (Fig. $6 \mathrm{~B})$. There was no effect of $\mathrm{B}[\mathrm{a}] \mathrm{P}$ exposure on $\mathrm{M}_{1} \mathrm{dG}$ levels in vivo in ferrets.

Two contradictions were observed between in vitro and in vivo experiments. First, in vivo BC supplementation did not increase 8-oxo-dG levels as was observed in vitro. Second, $\mathrm{B}[\mathrm{a}] \mathrm{P}$ exposure increased 8-oxo-dG levels in vitro in lung epithelial cells but significantly decreased 8-oxo-dG levels in vivo. Both contradictions might be explained by repair of oxidative DNA damage by BER, and therefore, effects of $\mathrm{BC}$ and $\mathrm{B}[\mathrm{a}] \mathrm{P}$ exposures on $\mathrm{BER}$ capacities in ferret's lung were further investigated by a modified comet assay. BC exposure led to an increased BER capacity, but this did not reach statistical significance $(P=$ 
0.08). On the other hand, B[a]P exposure significantly increased BER capacity in ferret lung $(\mathrm{p}<0.001)$ as can be seen in (Fig. 6C).

A)

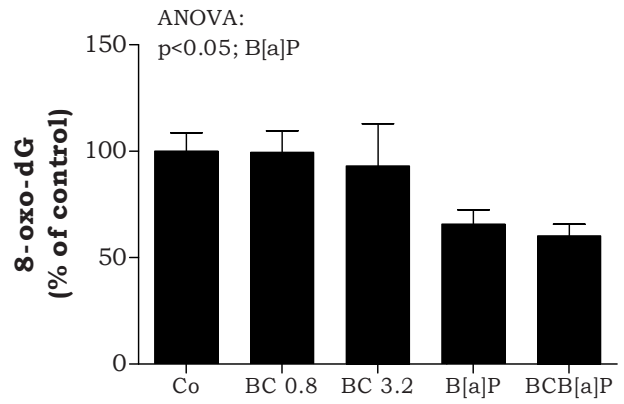

B)

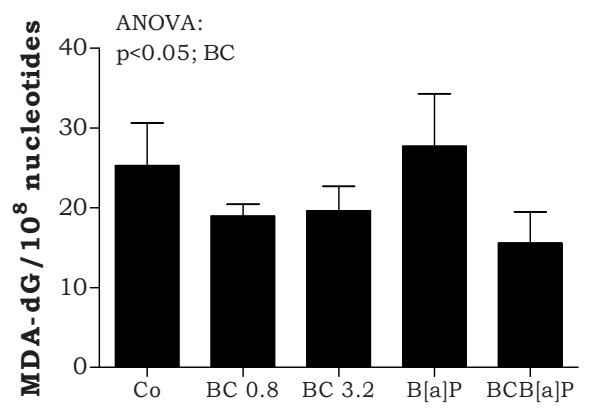

C)

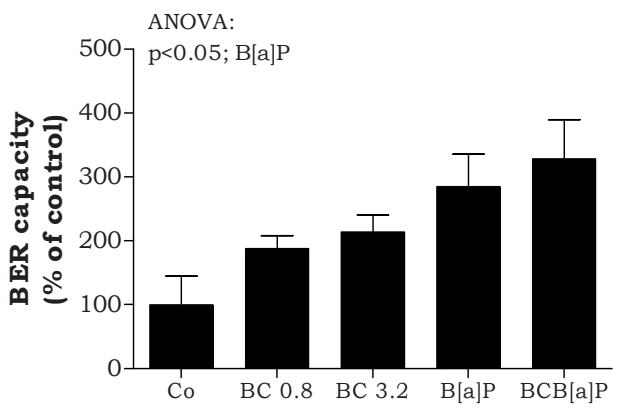

Figure 6: 8-Oxo-dG levels (A), $\mathrm{M}_{1} \mathrm{dG}$ levels (B) and BER capacity $(\mathrm{C})$ in ferret lung. Data are expressed as mean \pm standard error of the mean (SEM), significance was tested using analysis of variance (ANO$\mathrm{VA}$ ) and considered significant at $\mathrm{p}<0.05$. Statistically significant effects were found for (A) $\mathrm{B}[\mathrm{a}] \mathrm{P}$ exposure $(\mathrm{B}[\mathrm{a}] \mathrm{P}),(\mathrm{B}) \mathrm{BC}$ treatment $(\mathrm{BC})$ and $(\mathrm{C}) \mathrm{B}[\mathrm{a}] \mathrm{P}$ exposure. 


\section{Discussion}

We investigated the in vitro and in vivo anti- and pro-oxidant properties of $\mathrm{BC}$ in relation to DNA-damaging effects in lung epithelial cells in vitro and in vivo in lung tissue of ferrets. Although we found no antioxidant properties of $\mathrm{BC}$ against ROS, BC did have strong antioxidant properties toward ${ }^{\circ} \mathrm{C}$. These ${ }^{\circ} \mathrm{C}$ are important intermediates in LPO, which in turn are capable of inducing DNA damage [12]. Indeed, we observed lower levels of the LPO-derived $\mathrm{M}_{1} \mathrm{dG}$ adducts in vitro as well as in vivo after BC supplementation. On the other hand, $\mathrm{BC}$ acted as a pro-oxidant with regard to ${ }^{\circ} \mathrm{OH}$ formation in the Fenton reaction and consequently $\mathrm{BC}$ supplementation in vitro to lung epithelial cells increased oxidation of DNA, measured as the pro-mutagenic lesion 8-oxo-dG. In vivo in ferret lung, however, BC supplementation did not increase 8-oxo-dG levels, probably because of improved BER capacities to counteract the formation of 8-oxo-dG.

We show in this study that a high but physiologically relevant $\mathrm{BC}$ concentration can exert a dual role; being an effective antioxidant on one hand for ${ }^{\circ} \mathrm{C}$ and on the other hand being a pro-oxidant in the iron-dependent Fenton reaction that generates $\cdot \mathrm{OH}$. Although both pro- and antioxidant properties of $\mathrm{BC}$ are also suggested in other studies $[32,33]$, this study designates the fate of $\mathrm{BC}$ being a pro-oxidant or antioxidant to be dependent on the type of radical. Indeed, previous studies focusing on LPO products mainly designate $\mathrm{BC}$ as being an antioxidant. For example, Shih et al. [34] found that $\mathrm{BC}$ was able to decrease cholesterol-induced LPO in liver and plasma of rats. Although LPO products can be considered to be important markers in carcinogenesis, no study thus far focused on the influence of BC on LPO-induced DNA adducts. We show in this study that BC can reduce LPO-induced genotoxicity in vitro and in vivo. In contrast, most studies that appoint $\mathrm{BC}$ as a pro-oxidant are performed under conditions where oxygen seems to be an important mediator. For example, Alija et al. [35] demonstrated that $\mathrm{BC}$ enhanced genotoxicity of oxidative stress after re-oxygenation of hypoxic rat hepatocytes. In another study, BC was not able to scavenge ROS generated by a xanthine/xanthine oxidase system. However, physiologically irrelevant concentrations of BC were used in that study [36]. Moreover, we showed previously that BC metabolites were able to increase oxidative DNA damage during a co-culture experiment with activated neutrophils and A549 lung epithelial cells [29]. In this study, we observed a pro-oxidant effect of BC in our acellular ESR experiments when ${ }^{\circ} \mathrm{OH}$ were involved and in vitro on 8 oxo-dG levels. This pro-oxidant effect in vitro was independent of additional exposure to $\mathrm{H}_{2} \mathrm{O}_{2}$ or $\mathrm{B}[\mathrm{a}] \mathrm{P}$, which indicates that $\mathrm{BC}$ was able to increase endogenously generated ROS. Important ROS-producing organelles are mitochondria, and previously Siems et al. $[37,38]$ found that $\mathrm{BC}$ cleavage products were able to impair mitochondrial functioning, which possibly leads to an increased formation of 8-oxo-dG and might explain our in vitro results with epithelial cells. 
We were interested in the effects of $\mathrm{BC}$ on ${ }^{\circ} \mathrm{C}$ radical formation and ultimately on the level of MDA-derived DNA adducts $\left(\mathrm{M}_{1} \mathrm{dG}\right)$. MDA is a natural product of LPO and several studies show significant correlations between $\mathrm{M}_{1} \mathrm{dG}$ formation and LPO products [39]. For example, high levels of $\omega-6$ polyunsaturated fatty acids in the diet have been associated with increased levels of $\mathrm{M}_{1} \mathrm{dG}$ [40,41]. Furthermore, levels of $\mathrm{M}_{1} \mathrm{dG}$ significantly correlate with etheno-DNA adducts, which are induced by LPO by-products such as acrolein, croton aldehyde and trans-4-hydroxy-2-nonenal [41]. Besides these studies that imply an important role for LPO in $\mathrm{M}_{1} \mathrm{dG}$ formation, Dedon et al. proposed a mechanism in which $\mathrm{M}_{1} \mathrm{dG}$ can also be formed directly upon $\mathrm{H}_{2} \mathrm{O}_{2}$ exposure to isolated DNA through the formation of base propenal [42,43]. Although this direct route might also be important in the formation of $\mathrm{M}_{1} \mathrm{dG}$, these results are mainly based on experiments using naked DNA. Jeong et al. [44] found that fatty acids decrease the direct formation of $\mathrm{M}_{1} \mathrm{dG}$ and the amount of $\mathrm{M}_{1} \mathrm{dG}$ formed is dependent on the saturation of the fatty acids, indicating that the ability of fatty acids to form LPO is still important in the formation of $\mathrm{M}_{1} \mathrm{dG}$. The presence of fatty acids is physiologically more relevant than a system without fatty acids. Although there might be some debate on the exact mechanism of $\mathrm{M}_{1} \mathrm{dG}$ formation, $\mathrm{LPO}$ is, at least in part, involved in the formation of $\mathrm{M}_{1} \mathrm{dG}$ and - $\mathrm{C}$ radicals are also important intermediates in the direct $\mathrm{M}_{1} \mathrm{dG}$ formation. We showed that $\mathrm{BC}$ was able to scavenge ${ }^{\circ} \mathrm{C}$ radicals and not ${ }^{\circ} \mathrm{OH}$ or $\mathrm{O}_{2}{ }^{-}-$[as shown previously [29]] radicals. Therefore, these results are in line with the hypothesis that $\mathrm{BC}$ is able to scavenge ${ }^{\circ} \mathrm{C}$ radicals and thereby is able to decrease $\mathrm{M}_{1} \mathrm{dG}$.

When investigating effects of $\mathrm{BC}$ in humans, it is important to use in vitro and in vivo models that represent physiological conditions as much as possible. In humans, around $30-40 \%$ of all ingested BC is absorbed intact. Therefore, an increase in BC intake has been shown to result in increased plasma BC levels. A total of $60-70 \%$ of the ingested $\mathrm{BC}$ is converted into retinal, which subsequently can be further metabolized into retinol and retinol derivatives [45]. To investigate effects of $\mathrm{BC}$, the in vitro and in vivo model systems should both have the property to take up intact BC and to metabolize BC comparable with the human situation. Several human colon and lung cell lines were previously tested, including BEAS-2B, on the intracellular levels of $\mathrm{BC}$ and $\mathrm{BC}$ metabolites after exposure to $1 \mu \mathrm{M} \mathrm{BC}$ for $2 \mathrm{~h}$ up to 3 weeks. All cell lines were able to accumulate intact BC [19]. We exposed cells for 59 or $64 \mathrm{~h}$, which was an exposure time required for a stable BC concentration in cell culture experiments. Moreover, all cell lines previously tested, including BEAS-2B, were able to metabolize BC. However, the type and exact concentration of $\mathrm{BC}$ metabolites in the cells differed between cell lines. Moreover, various cell lines are expected to express antioxidant enzymes differently. To circumvent a strong bias due to cell line used, we used both BEAS-2B and A549 lung epithelial cells and we used an animal model to further validate our results. The often used laboratory animal models, which are mainly rodents, have the disadvantage that $\mathrm{BC}$ is entirely cleaved and $\mathrm{BC}$ research is therefore virtually impossible [17]. Ferrets are known to possess a $\mathrm{BC}$ metabolism more comparable with humans, with an increase in both $\mathrm{BC}$ and 
$\mathrm{BC}$ metabolites upon an increased $\mathrm{BC}$ intake [17]. We have taken $\mathrm{BC}$ metabolism as well as $\mathrm{BC}$ concentration into account in our experiments aiming to be as close as possible to known human physiological conditions.

We used ESR, in vitro as well as in vivo models, to assess the effect of $\mathrm{BC}$ on oxidative DNA damage. Whether there was a significant effect of BC on 8-oxo-dG formation was mainly dependent on the experimental models that were used. We showed with these methods that $\mathrm{BC}$ was able to decrease ${ }^{\circ} \mathrm{C}$ in the $\mathrm{ESR}$ and $\mathrm{M}_{1} \mathrm{dG}$ formation in vitro as well as in vivo. Although these results demonstrate similar effects, there were some differences regarding the extent of the effects. There are some potentially confounding factors when performing in vitro experiments with $\mathrm{BC}$, which have been discussed and reviewed previously [46]. For example, BC is highly lipophilic and THF was used to dissolve BC into the medium and medium sometimes contains relatively high concentrations of certain vitamins. These differences in vitamin concentrations and the use of a solvent might be an additional factor, which can cause differences in the induction of 8-oxo-dG and the extend of the effect on $\mathrm{M}_{1} \mathrm{dG}$. Moreover, it should be noted that the $\mathrm{BC}$ used in our in vivo experiment was a water-soluble formulation, containing DL-alpha-tocopherol and ascorbyl palmitate as stabilizers, while this was not the case in the in vitro experiments. The BC formulation might thus have influenced our end points in vivo. Effects of BC supplementation may be more pronounced, when supplemented without alphatocopherol. Palozza et al. [47] demonstrated previously that increased formation of peroxidation products in lung microsomal membranes by $\mathrm{BC}$ upon an increase in $\mathrm{pO}_{2}$ was partly reduced by alpha-tocopherol. Moreover, two different studies exposed ferrets to low and high $\mathrm{BC}$ concentrations but used different formulations of BC; Liu et al. [20] used a formulation of $\mathrm{BC}$ in corn oil, whereas Fuster et al. [21] used the same formulation as in this experiment containing DL-alpha-tocopherol and ascorbyl palmitate as stabilizers. Relative expression of the same cell cycle and proliferation enzymes varied between both studies and were more pronounced in the study using corn oil. A possible explanation for this effect is that radical cycling between alpha-tocopherol, ascorbyl palmitate and $\mathrm{BC}$ occurs and that therefore radical-induced effects are inhibited by a protective effect of alpha-tocopherol and ascorbyl palmitate as has been reviewed by Palozza [48] and Krinsky et al. [49].

Although it is thought that $\mathrm{B}[\mathrm{a}] \mathrm{P}$ metabolism results in enhanced formation of ROS and 8-oxo-dG in vitro, $\mathrm{B}[\mathrm{a}] \mathrm{P}$ exposure resulted in decreased levels of 8-oxo-dG in ferret lung DNA, which was very persistent since $\mathrm{B}[\mathrm{a}] \mathrm{P}$ exposure stopped 13 weeks before the animals were sacrificed. Decreased levels of 8-oxo-dG could possibly be explained by an induction of antioxidant or repair enzymes in vivo after B[a]P exposure. Briedé et al. [50] already suggested a potential role for induced repair of 8-oxo-dG by $\mathrm{B}[\mathrm{a}] \mathrm{P}$, since $\mathrm{B}[\mathrm{a}] \mathrm{P}$ exposure reduced 8-oxo-dG in rat lung, accompanied by an increase in urinary excretion of 8-oxo-dG/8-oxo-Gua. Here, we demonstrated that BER capacities were indeed improved upon $\mathrm{B}[\mathrm{a}] \mathrm{P}$ exposure. This finding might also indicate that toxins are able to trigger defense systems even long after the last dosage and that exposure to toxins 
might trigger endogenous protection systems. This is in accordance with a theory that mutagens do not necessarily act in a dose-response manner but that mutagens can induce the endogenous protection systems when occasionally consumed [51].

Many studies indicating possible pro-oxidant activities of $\mathrm{BC}$, including this study, are performed in vitro. Studies focusing on pro-oxidant effects of $\mathrm{BC}$ in vivo are largely lacking. Therefore, we investigated the effect of $\mathrm{BC}$ on the formation of 8-oxo-dG, an important genotoxic marker induced by oxidative stress in vivo in ferrets. There was no difference between steady-state levels of 8-oxo-dG in BC-supplemented groups compared with control groups, whereas BER capacity tended to be increased by BC supplementation. This suggests that a potential increase in oxidative stress was counterbalanced by an enhanced removal of lesions due to an increased BER capacity, restoring the steady state. Therefore, genotoxicity of $\mathrm{BC}$ might become important in conditions when simultaneously oxidative stress is induced and BER capacity is impaired. Smoking is such a situation where oxidative stress is increased and there are indications that repair is decreased [52,53].

In summary, we demonstrate that the fate of $\mathrm{BC}$, being a pro-oxidant or an antioxidant, is dependent on the type of radicals involved. $\mathrm{BC}$ is an antioxidant regarding ${ }^{\circ} \mathrm{C}$, able to significantly reduce $\mathrm{M}_{1} \mathrm{dG}$ levels in vitro as well as in vivo. On the other hand, $\mathrm{BC}$ has no ability to scavenge $\cdot \mathrm{OH}$ and even results in an increased ROS production and subsequent formation of 8-oxo-dG in lung epithelial cells.

\section{Acknowledgements}

We gratefully acknowledge DSM Neutraceutical products, in particular Dr Regina Goralczyk, for providing the $\mathrm{BC}$ formulation for the ferret study. Centro de Investigación Biomédica en Red de Fisiopatología de la Obesidad y Nutricion is an initiative of the Instituto de Salud Carlos III. J.K. and A.P. are members of Mitofood.

\section{References}

[1] S.T. Mayne Beta-carotene, carotenoids, and disease prevention in humans, Faseb J 10 (1996) 690-701.

[2] L.J. Machlin and A. Bendich Free radical tissue damage: protective role of antioxidant nutrients, Faseb J 1 (1987) 441-445. 
D. Albanes, O.P. Heinonen, P.R. Taylor, J. Virtamo, B.K. Edwards, M. Rautalahti, A.M. Hartman, J. Palmgren, L.S. Freedman, J. Haapakoski, M.J. Barrett, P. Pietinen, N. Malila, E. Tala, K. Liippo, E.R. Salomaa, J.A. Tangrea, L. Teppo, F.B. Askin, E. Taskinen, Y. Erozan, P. Greenwald and J.K. Huttunen AlphaTocopherol and beta-carotene supplements and lung cancer incidence in the alpha-tocopherol, betacarotene cancer prevention study: effects of base-line characteristics and study compliance, J Natl Cancer Inst 88 (1996) 1560-1570.

[4] G.S. Omenn, G.E. Goodman, M.D. Thornquist, J. Balmes, M.R. Cullen, A. Glass, J.P. Keogh, F.L. Meyskens, Jr., B. Valanis, J.H. Williams, Jr., S. Barnhart, M.G. Cherniack, C.A. Brodkin and S. Hammar Risk factors for lung cancer and for intervention effects in CARET, the Beta-Carotene and Retinol Efficacy Trial, J Natl Cancer Inst 88 (1996) 1550-1559.

[5] C.H. Hennekens, J.E. Buring, J.E. Manson, M. Stampfer, B. Rosner, N.R. Cook, C. Belanger, F. LaMotte, J.M. Gaziano, P.M. Ridker, W. Willett and R. Peto Lack of effect of long-term supplementation with beta carotene on the incidence of malignant neoplasms and cardiovascular disease, N Engl J Med 334 (1996) 1145-1149.

[6] R. Singh, R.J. Sram, B. Binkova, I. Kalina, T.A. Popov, T. Georgieva, S. Garte, E. Taioli and P.B. Farmer The relationship between biomarkers of oxidative DNA damage, polycyclic aromatic hydrocarbon DNA adducts, antioxidant status and genetic susceptibility following exposure to environmental air pollution in humans, Mutat Res 620 (2007) 83-92.

[7] M.F. Denissenko, A. Pao, M. Tang and G.P. Pfeifer Preferential formation of benzo[a]pyrene adducts at lung cancer mutational hotspots in P53, Science 274 (1996) 430-432.

[8] W.A. Pryor and K. Stone Oxidants in cigarette smoke. Radicals, hydrogen peroxide, peroxynitrate, and peroxynitrite, Ann N Y Acad Sci 686 (1993) 12-27; discussion 27-18.

[9] R.E. Harris, J. Beebe-Donk and H.M. Schuller Chemoprevention of lung cancer by non-steroidal antiinflammatory drugs among cigarette smokers, Oncol Rep 9 (2002) 693-695.

[10] J.E. Muscat, S.Q. Chen, J.P. Richie, Jr., N.K. Altorki, M. Citron, S. Olson, A.I. Neugut and S.D. Stellman Risk of lung carcinoma among users of nonsteroidal antiinflammatory drugs, Cancer 97 (2003) 1732-1736.

[11] S. Loft, P. Moller, M.S. Cooke, R. Rozalski and R. Olinski Antioxidant vitamins and cancer risk: is oxidative damage to DNA a relevant biomarker?, Eur J Nutr 47 Suppl 2 (2008) 19-28.

[12] L.J. Marnett Oxy radicals, lipid peroxidation and DNA damage, Toxicology 181-182 (2002) 219-222.

[13] P. Palozza, S. Serini, F. Di Nicuolo, E. Piccioni and G. Calviello Prooxidant effects of beta-carotene in cultured cells, Mol Aspects Med 24 (2003) 353-362.

[14] V. Gorbunova, A. Seluanov, Z. Mao and C. Hine Changes in DNA repair during aging, Nucleic Acids Res 35 (2007) 7466-7474.

[15] L.J. Niedernhofer, J.S. Daniels, C.A. Rouzer, R.E. Greene and L.J. Marnett Malondialdehyde, a product of lipid peroxidation, is mutagenic in human cells, J Biol Chem 278 (2003) 31426-31433.

[16] E.T. Gugger, T.L. Bierer, T.M. Henze, W.S. White and J.W. Erdman, Jr. Beta-carotene uptake and tissue distribution in ferrets (Mustela putorius furo), J Nutr 122 (1992) 115-119.

[17] X.D. Wang, N.I. Krinsky, R.P. Marini, G. Tang, J. Yu, R. Hurley, J.G. Fox and R.M. Russell Intestinal uptake and lymphatic absorption of beta-carotene in ferrets: a model for human beta-carotene metabolism, Am J Physiol 263 (1992) G480-486.

[18] D. Albanes, N. Malila, P.R. Taylor, J.K. Huttunen, J. Virtamo, B.K. Edwards, M. Rautalahti, A.M. Hartman, M.J. Barrett, P. Pietinen, T.J. Hartman, P. Sipponen, K. Lewin, L. Teerenhovi, P. Hietanen, J.A. Tangrea, M. Virtanen and O.P. Heinonen Effects of supplemental alpha-tocopherol and beta-carotene on colorectal cancer: results from a controlled trial (Finland), Cancer Causes Control 11 (2000) 197-205.

[19] N.L. Franssen-van Hal, J.E. Bunschoten, D.P. Venema, P.C. Hollman, G. Riss and J. Keijer Human intestinal and lung cell lines exposed to beta-carotene show a large variation in intracellular levels of betacarotene and its metabolites, Arch Biochem Biophys 439 (2005) 32-41.

[20] C. Liu, X.D. Wang, R.T. Bronson, D.E. Smith, N.I. Krinsky and R.M. Russell Effects of physiological versus pharmacological beta-carotene supplementation on cell proliferation and histopathological changes in the lungs of cigarette smoke-exposed ferrets, Carcinogenesis 21 (2000) 2245-2253.

[21] A. Fuster, C. Pico, J. Sanchez, P. Oliver, M.C. Zingaretti, I. Murano, M. Morroni, U. Hoeller, R. Goralczyk, S. Cinti and A. Palou Effects of 6-month daily supplementation with oral beta-carotene in combination or not with benzo[a]pyrene on cell-cycle markers in the lung of ferrets, J Nutr Biochem 19 (2008) 295-304.

[22] X. Sun, J. Nair and H. Bartsch A modified immuno-enriched 32P-postlabeling method for analyzing the malondialdehyde-deoxyguanosine adduct, 3-(2-deoxy-beta-D-erythro-pentofuranosyl)- pyrimido[1,2alpha]purin-10(3H)one in human tissue samples, Chem Res Toxicol 17 (2004) 268-272.

[23] C. Leuratti, R. Singh, C. Lagneau, P.B. Farmer, J.P. Plastaras, L.J. Marnett and D.E. Shuker Determination of malondialdehyde-induced DNA damage in human tissues using an immunoslot blot assay, Carcinogenesis 19 (1998) 1919-1924. 


\section{Chapter 2}

[24] C.E. Vaca, P. Vodicka and K. Hemminki Determination of malonaldehyde-modified 2'-deoxyguanosine-3'monophosphate and DNA by 32P-postlabelling, Carcinogenesis 13 (1992) 593-599.

[25] A. Munnia, S. Bonassi, A. Verna, R. Quaglia, D. Pelucco, M. Ceppi, M. Neri, M. Buratti, E. Taioli, S. Garte and M. Peluso Bronchial malondialdehyde DNA adducts, tobacco smoking, and lung cancer, Free Radic Biol Med 41 (2006) 1499-1505.

[26] A. Munnia, F. Saletta, A. Allione, S. Piro, M. Confortini, G. Matullo and M. Peluso 32P-Post-labelling method improvements for aromatic compound-related molecular epidemiology studies, Mutagenesis 22 (2007) 381-385.

[27] P.J. Borm, A.M. Knaapen, R.P. Schins, R.W. Godschalk and F.J. Schooten Neutrophils amplify the formation of DNA adducts by benzo[a]pyrene in lung target cells, Environ Health Perspect 105 Suppl 5 (1997) 1089-1093.

[28] I. Gaivao, A. Piasek, A. Brevik, S. Shaposhnikov and A.R. Collins Comet assay-based methods for measuring DNA repair in vitro; estimates of inter- and intra-individual variation, Cell Biol Toxicol (2007).

[29] Y.G. van Helden, J. Keijer, A.M. Knaapen, S.G. Heil, J.J. Briede, F.J. van Schooten and R.W. Godschalk Beta-carotene metabolites enhance inflammation-induced oxidative DNA damage in lung epithelial cells, Free Radic Biol Med 46 (2009) 299-304.

[30] S. Yue Qian, K.B. Tomer, G.H. Yue, Q. Guo, M.B. Kadiiska and R.P. Mason Characterization of the initial carbon-centered pentadienyl radical and subsequent radicals in lipid peroxidation: identification via online high performance liquid chromatography/electron spin resonance and mass spectrometry, Free Radic Biol Med 33 (2002) 998-1009.

[31] B.E. Britigan, S. Pou, G.M. Rosen, D.M. Lilleg and G.R. Buettner Hydroxyl radical is not a product of the reaction of xanthine oxidase and xanthine. The confounding problem of adventitious iron bound to xanthine oxidase, J Biol Chem 265 (1990) 17533-17538.

[32] S.T. Omaye, N.I. Krinsky, V.E. Kagan, S.T. Mayne, D.C. Liebler and W.R. Bidlack beta-carotene: friend or foe?, Fundam Appl Toxicol 40 (1997) 163-174.

[33] A.J. Young and G.M. Lowe Antioxidant and prooxidant properties of carotenoids, Arch Biochem Biophys 385 (2001) 20-27.

[34] C.K. Shih, J.H. Chang, S.H. Yang, T.W. Chou and H.H. Cheng beta-Carotene and canthaxanthin alter the pro-oxidation and antioxidation balance in rats fed a high-cholesterol and high-fat diet, $\mathrm{Br} \mathrm{J}$ Nutr 99 (2008) 59-66.

[35] A.J. Alija, N. Bresgen, O. Sommerburg, C.D. Langhans, W. Siems and P.M. Eckl Cyto- and genotoxic potential of beta-carotene and cleavage products under oxidative stress, Biofactors 24 (2005) 159-163.

[36] G.M. Lowe, L.A. Booth, A.J. Young and R.F. Bilton Lycopene and beta-carotene protect against oxidative damage in HT29 cells at low concentrations but rapidly lose this capacity at higher doses, Free Radic Res 30 (1999) 141-151.

[37] W. Siems, O. Sommerburg, L. Schild, W. Augustin, C.D. Langhans and I. Wiswedel Beta-carotene cleavage products induce oxidative stress in vitro by impairing mitochondrial respiration, Faseb J 16 (2002) 12891291

[38] W. Siems, I. Wiswedel, C. Salerno, C. Crifo, W. Augustin, L. Schild, C.D. Langhans and O. Sommerburg Beta-carotene breakdown products may impair mitochondrial functions--potential side effects of high-dose beta-carotene supplementation, J Nutr Biochem 16 (2005) 385-397.

[39] L.J. Marnett Oxyradicals and DNA damage, Carcinogenesis 21 (2000) 361-370.

[40] J.L. Fang, C.E. Vaca, L.M. Valsta and M. Mutanen Determination of DNA adducts of malonaldehyde in humans: effects of dietary fatty acid composition, Carcinogenesis 17 (1996) 1035-1040.

[41] J. Nair, C.E. Vaca, I. Velic, M. Mutanen, L.M. Valsta and H. Bartsch High dietary omega-6 polyunsaturated fatty acids drastically increase the formation of etheno-DNA base adducts in white blood cells of female subjects, Cancer Epidemiol Biomarkers Prev 6 (1997) 597-601.

[42] P.C. Dedon, J.P. Plastaras, C.A. Rouzer and L.J. Marnett Indirect mutagenesis by oxidative DNA damage: formation of the pyrimidopurinone adduct of deoxyguanosine by base propenal, Proc Natl Acad Sci U S A 95 (1998) 11113-11116.

[43] X. Zhou, K. Taghizadeh and P.C. Dedon Chemical and biological evidence for base propenals as the major source of the endogenous M1dG adduct in cellular DNA, J Biol Chem 280 (2005) 25377-25382.

[44] Y.C. Jeong and J.A. Swenberg Formation of M1G-dR from endogenous and exogenous ROS-inducing chemicals, Free Radic Biol Med 39 (2005) 1021-1029.

[45] R.S. Parker Absorption, metabolism, and transport of carotenoids, Faseb J 10 (1996) 542-551.

[46] P. Palozza Can beta-carotene regulate cell growth by a redox mechanism? An answer from cultured cells, Biochim Biophys Acta 1740 (2005) 215-221. 
[47] P. Palozza, S. Serini, S. Trombino, L. Lauriola, F.O. Ranelletti and G. Calviello Dual role of beta-carotene in combination with cigarette smoke aqueous extract on the formation of mutagenic lipid peroxidation products in lung membranes: dependence on pO2, Carcinogenesis 27 (2006) 2383-2391.

[48] P. Palozza Prooxidant actions of carotenoids in biologic systems, Nutr Rev 56 (1998) 257-265.

[49] N.I. Krinsky and K.J. Yeum Carotenoid-radical interactions, Biochem Biophys Res Commun 305 (2003) 754-760.

[50] J.J. Briede, R.W. Godschalk, M.T. Emans, T.M. De Kok, E. Van Agen, J. Van Maanen, F.J. Van Schooten and J.C. Kleinjans In vitro and in vivo studies on oxygen free radical and DNA adduct formation in rat lung and liver during benzo[a]pyrene metabolism, Free Radic Res 38 (2004) 995-1002.

[51] B.N. Ames, M. Profet and L.S. Gold Nature's chemicals and synthetic chemicals: comparative toxicology, Proc Natl Acad Sci U S A 87 (1990) 7782-7786.

[52] A. Cebulska-Wasilewska, A. Wiechec, A. Panek, B. Binkova, R.J. Sram and P.B. Farmer Influence of environmental exposure to PAHs on the susceptibility of lymphocytes to DNA-damage induction and on their repair capacity, Mutat Res 588 (2005) 73-81.

[53] M.E. Fracasso, D. Doria, P. Franceschetti, L. Perbellini and L. Romeo DNA damage and repair capacity by comet assay in lymphocytes of white-collar active smokers and passive smokers (non- and ex-smokers) at workplace, Toxicol Lett 167 (2006) 131-141. 
Beta-carotene $(\mathrm{BC})$ intake has been shown to enhance lung cancer risk in smokers and asbestos exposed subjects (according to the ATBC and CARET studies), but the mechanism behind this pro-carcinogenic effect of $\mathrm{BC}$ is unclear. Both smoking and asbestos exposure induce an influx of inflammatory neutrophils into the airways, which results in an increased production of reactive oxygen species (ROS) and formation of promutagenic DNA lesions. Therefore, the aim of our study is to investigate the effects of $\mathrm{BC}$ and its metabolites (BCM) on neutrophil induced genotoxicity. We observed that the BCM; vitamin A (Vit A) and retinoic acid (RA) inhibited the $\mathrm{H}_{2} \mathrm{O}_{2}$ utilizing enzyme myeloperoxidase, which is released by neutrophils, thereby reducing $\mathrm{H}_{2} \mathrm{O}_{2}$ conversion. Moreover, $\mathrm{BC}$ and $\mathrm{BCM}$ were able to increase $\cdot \mathrm{OH}$ formation from $\mathrm{H}_{2} \mathrm{O}_{2}$ in the Fenton reaction (determined by electron spin resonance (ESR) spectroscopy). Addition of Vit A and RA to lung epithelial cells that were coincubated with activated neutrophils, resulted in a significant increase in the level of oxidized purines assessed by the formamidopyrimidine DNA glycosylase (FPG)-modified comet assay. These data indicate that BCM can enhance neutrophil induced genotoxicity by inhibition of MPO in combination with subsequent increased formation of hydroxyl radicals. 


\section{Beta-carotene metabolites enhance inflammation induced oxidative DNA damage in lung epithelial cells}

Free Radical Biology \& Medicine

Yvonne G.J. van Helden, Jaap Keijer, Ad M. Knaapen, Sandra G. Heil, Jacob J. Briedé, Frederik J. van Schooten, Roger W.L. Godschalk 


\section{Introduction}

Beta-carotene $(\mathrm{BC})$ is a naturally occurring orange coloured phytochemical, widely used as colouring agent in food products and added to vitamin supplements. BC is considered to be an effective antioxidant and thought to decrease cancer risk, especially lung cancer $[1,2]$. Two large scale intervention trials, the Alpha-Tocopherol Beta-Carotene Cancer prevention study (ATBC study) and Carotene and Retinol Efficacy Trial (CARET study), investigated the effect of BC supplementation alone (ATBC) or in combination with vitamin A (CARET) in subjects at risk for lung cancer. The effect of vitamin E (Vit E) was also explored in the ATBC study. Unexpectedly, BC supplementation increased lung cancer incidence in both the ATBC and the CARET study, while vitamin E (Vit E) supplementation did not show any effect $[3,4]$. The mechanism leading to this increased lung cancer risk is not known and remains to be elucidated.

Different mechanisms are involved in the carcinogenicity of asbestos and smoking, but both exposures cause an inflammatory response in the lungs and are associated with the onset and progression of carcinogenesis [5-9]. A role for chronic inflammation in lung carcinogenesis is demonstrated by studies in which the use of anti-inflammatory drugs for at least one year resulted in a reduction in the relative risk of lung cancer in smokers $[10,11]$. Typical for lung inflammation is the influx of neutrophils into the airways $[12,13]$.

Activated neutrophils display a respiratory burst, generating reactive oxygen species (ROS); superoxide anions $\left(\mathrm{O}_{2}{ }^{--}\right)$are formed which can be converted into hydrogen peroxide $\left(\mathrm{H}_{2} \mathrm{O}_{2}\right)$ [13]. Subsequently, $\mathrm{H}_{2} \mathrm{O}_{2}$ can either be converted into hypochloric acid ( $\left.\mathrm{HOCl}\right)$ by myeloperoxidase (MPO), an enzyme released by activated neutrophils, or it can react with transition metals to form highly reactive hydroxyl radicals $(\cdot \mathrm{OH})$ via the Fenton reaction. Both $\mathrm{HOCl}$ and $\cdot \mathrm{OH}$ are highly reactive and are able to peroxidize proteins and lipids and to react with DNA. However, due to their high reactivity it is unlikely that they diffuse into the nucleus when generated extracellularly [14-16]. In contrast, $\mathrm{H}_{2} \mathrm{O}_{2}$ is relatively stable and able to diffuse into the nucleus where it can react with DNAassociated transition metals to form $\cdot \mathrm{OH}$ causing a variety of DNA lesions, including single strand DNA breaks (ssDNA) and oxidized DNA bases [17]. Moreover, $\mathrm{H}_{2} \mathrm{O}_{2}$ has probably a greater genotoxic potential than $\mathrm{HOCl}$ since inhibition of MPO led to an increase in ssDNA breaks in RLE lung epithelial cells co-incubated with neutrophils [18]. Oxidatively damaged DNA is known to be promutagenic and is therefore an important marker for carcinogenesis. In this respect, catalase is considered to be an important antioxidant enzyme in alveolar cells since it converts $\mathrm{H}_{2} \mathrm{O}_{2}$ into water and oxygen, thereby preventing $\mathrm{H}_{2} \mathrm{O}_{2}$ induced damage [19]. 
High $\mathrm{BC}$ intake was associated with increased lung cancer risk in smokers and asbestos exposed subjects. Both asbestos exposure and smoking cause a neutrophilic influx which is suggested to be a mediating factor in lung cancer development [13]. To examine a possible role for $\mathrm{BC}$ in neutrophil mediated carcinogenesis, we investigated the effect of BC on neutrophil induced oxidative DNA damage in A549 type II lung epithelial cells. The effect of $\mathrm{BC}$ on the generation of $\mathrm{O}_{2}{ }^{--}$and ${ }^{\cdot} \mathrm{OH}$ was tested in vitro using electron spin resonance (ESR) spectroscopy in combination with the spin trapping technique. Subsequently, the effects of BC on MPO and catalase activity were measured. As $\mathrm{BC}$ can be metabolized in the human body [20], the $\mathrm{BC}$ metabolites $(\mathrm{BCM})$; retinoic acid (RA), retinal (RAL) and vitamin A (Vit A) were also included. Vit E was used to test the specificity of the observed effects because Vit $\mathrm{E}$ is a lipophilic vitamin, like BC, but no effect on lung cancer incidence was observed in the ATBC study.

\section{Materials \& Methods}

\section{Preparation of vitamin solutions}

To study the effects of BC supplementation on lung carcinogenesis in smokers, vitamin concentrations were based on serum concentrations that were observed in the CARET and ATBC study after 3 years of daily vitamin intake [21]. Analogous to BC serum concentrations in these studies, $5 \mu \mathrm{M}$ BC was used in our in vitro experiments. Corresponding to this $\mathrm{BC}$ concentration, $10 \mu \mathrm{M} \mathrm{BCM}$ were used in our in vitro experiments since $\mathrm{BC}$ can be metabolized and cleaved in two molecules retinal (RAL) which can subsequently be metabolized into vitamin A (Vit A) or retinoic acid (RA). Based on Vit E serum concentrations after 3 years of daily Vit E intake (ATBC) [21], $40 \mu \mathrm{M}$ Vit E was used in the in vitro experiments. Stock solutions of all-trans-beta-carotene $(15 \mathrm{mM})$, retinol $(30 \mathrm{mM})$, retinal $(30 \mathrm{mM})$, retinoic acid $(30 \mathrm{mM})$ and a-tocopherol $(120 \mathrm{mM})$ (all from Sigma-Aldrich) were prepared in deperoxidized tetrahydrofuran (THF) and stored in amber vials under argon at $-80^{\circ} \mathrm{C}$ until use. THF was deperoxidized over an ALOXcolumn (aluminium oxide-90 active basic, Merck). Stock solutions were diluted 1:30 in heat inactivated fetal calf serum (FCS, Gibco) to make the vitamins better soluble in hydrophilic solutions. Solvent containing $0.033 \%$ THF and $1 \%$ FCS was used as control (Co).

\section{Radical measurement by electron spin resonance (ESR) spectroscopy}

Phenazine methosulfate (PMS), $\beta$-nicotinamide adenine dinucleotide (NADH, reduced form), iron sulfate $\left(\mathrm{FeSO}_{4}\right)$, hydrogenperoxide $\left(\mathrm{H}_{2} \mathrm{O}_{2}\right)$ and the spin trap 5,5-dimethyl-1pyrolline $N$-oxide (DMPO) were purchased from Sigma-Aldrich. DMPO was dissolved in nitrogen flushed water and purified by charcoal treatment. Concentrations of DMPO 
stocks were determined spectrophotometrically $\left(\varepsilon=7700 \mathrm{M}^{-1} \mathrm{~cm}^{-1}, 234 \mathrm{~nm}\right)$. ESR spectra were recorded at room temperature in glass capillaries (100 $\mu 1$, Brand AG) on a Bruker EMX 1273 spectrometer equipped with an ER 4119HS high sensitivity cavity and $12 \mathrm{~kW}$ power supply operating at $\mathrm{X}$ band frequencies. The modulation frequency of the spectrometer was $100 \mathrm{kHz}$. Instrumental conditions for the recorded spectra were: magnetic field: $3490 \mathrm{G}$; scan range: $60 \mathrm{G}$; modulation amplitude: 1 G; receiver gain: 1x105; microwave frequency: $9.85 \mathrm{GHz}$; power: $50 \mathrm{~mW}$; time constant: $40.96 \mathrm{~ms}$; scan time: $20.97 \mathrm{~s}$; number of scans: 10. Surface area and hyperfine coupling constants of the peaks were calculated using the WIN-EPR spectrum manipulation program (Bruker, Germany).

To assess $\cdot \mathrm{OH}$ formation, $\mathrm{FeSO}_{4}(20 \mu \mathrm{M})$ was mixed with DMPO $(100 \mathrm{mM})$ and solvent with or without $\mathrm{BC}, \mathrm{BCM}$ or Vit $\mathrm{E} . \mathrm{H}_{2} \mathrm{O}_{2}(100 \mu \mathrm{M})$ was added to start the reaction. The measurement of $\mathrm{O}_{2}{ }^{-}$- formation was accomplished by a reaction containing PMS (3.3 $\mu \mathrm{M})$ mixed with DMPO $(100 \mathrm{mM})$ and solvent with or without $\mathrm{BC}, \mathrm{BCM}$ or Vit E. Addition of $\mathrm{NADH}(50 \mu \mathrm{M})$ started the generation of $\mathrm{O}_{2}{ }^{-\cdots}$. In the ESR spectrum DMPO trapped $\mathrm{O}_{2} \cdot-(\mathrm{DMPO} / \cdot \mathrm{OOH})$ and $\mathrm{DMPO}$ trapped $\cdot \mathrm{OH}(\mathrm{DMPO} / \cdot \mathrm{OH})$ signals arise. Wilms et al. previously demonstrated that the PMS/NADH system solely generates $\mathrm{O}_{2}{ }^{*}$ - since complete inhibition of the radical signals is established upon treatment by superoxide dismutase (SOD). The DMPO/ $\cdot \mathrm{OH}$ signal is generated because $\mathrm{DMPO} / \cdot \mathrm{OOH}$ decomposes into DMPO/ ${ }^{\circ} \mathrm{OH}$ [22]. Exactly 2 minutes after the addition of $\mathrm{H}_{2} \mathrm{O}_{2}$ or $\mathrm{NADH}$ the spectrum was recorded. Experiments were performed in triplicates.

\section{Neutrophil isolation}

Polymorphonuclear neutrophils (PMN) consist of basophilic, eosinophilics as well as neutrophilic granulocytes. Since the neutrophilic granulocytes are the most abundant fraction, we refer to PMN as neutrophils throughout the paper. Blood of healthy, non smoking, human donors was obtained by venapuncture and 1:1 diluted with Hanks' balanced salt solution (HBSS, Gibco). Lymphocytes were removed by gradient centrifugation and subsequently erythrocytes were lysed by adding 2 volumes of cold lysis buffer $\left(155 \mathrm{mM} \mathrm{NH} 4 \mathrm{Cl}, 10 \mathrm{mM} \mathrm{KHCO}_{3}\right.$ and $10 \mathrm{mM}$ EDTA, $\mathrm{pH}$ 7.4). Neutrophils were washed and resuspended in HBSS, counted and viability was determined by Trypan Blue exclusion. Neutrophil viability was always $>95 \%$. Solutions and neutrophils were kept on ice during the whole procedure.

\section{MPO activity measurement}

Neutrophils $\left(1 \times 10^{7}\right)$ were dissolved in $10 \mathrm{ml}$ HBSS and incubated for 15 minutes at $37^{\circ} \mathrm{C}$ in a $75 \mathrm{~cm}^{2}$ culturing flask. Thereafter, phorbol 12-mystrate 13-acetate (PMA, Sigma-Aldrich) was added $(100 \mathrm{ng} / \mathrm{ml})$ and the incubation was continued for another hour at $37^{\circ} \mathrm{C}$. MPO activity in the supernatant was immediately determined in a 96 -well 
plate based on the method described by Klebanoff et al. [23] with some modifications: $40 \mu \mathrm{l}$ supernatant was mixed with $20 \mu \mathrm{l}$ solvent, BC, BCM or Vit E and $140 \mu 1$ assay solution (containing $10 \mathrm{mM}$ sodium phosphate buffer, $0.33 \mathrm{mM} \mathrm{H}_{2} \mathrm{O}_{2}$ and $11 \%$ guaiacol). The generation of tetra-guaiacol is a measure for MPO activity and was assessed spectrophotometrically at $470 \mathrm{~nm}$. MPO activity was calculated with the formula: $\mathrm{U} / \mathrm{ml}$ $=\Delta \mathrm{OD} / \min \times 1.203$, as $\%$ of control.

The whole procedure was also performed without the presence of neutrophils to examine the effect of solvent, $\mathrm{BC}, \mathrm{BCM}$ and Vit $\mathrm{E}$ on the formation of tetraguaiacol as such. No effect of the vitamins on the formation of tetraguaiacol was observed.

\section{Co-culture with neutrophils}

The human epithelial lung carcinoma cell line A549 was cultured in DMEM (SigmaAldrich) supplemented with $10 \%$ heat inactivated FCS (Life Technologies, Invitrogen) and $1 \%$ penicillin and $1 \%$ streptomycin (Sigma-Aldrich) at $37^{\circ} \mathrm{C}$ in a $5 \% \mathrm{CO}_{2}$ atmosphere. Co-culture experiments were performed, as described by Knaapen et al. [24]. A549 cells were cultured in a 6-well plate in medium containing solvent, BC, BCM or Vit E, starting 24 hours prior to the co-incubation. One confluent well contained approximately $1 \times 10^{6}$ cells. Cells were washed with HBSS and thereafter neutrophils $\left(1 \times 10^{6}\right.$ cells) in HBSS containing solvent (Co), BC, BCM or Vit E were added to the wells in a total volume of $400 \mu \mathrm{l}$ and incubated at $37^{\circ} \mathrm{C}$ for 15 minutes. Thereafter PMA was added $(100 \mathrm{ng} / \mathrm{ml})$ and cells were incubated for 1 hour at $37^{\circ} \mathrm{C}$. After incubation cells were washed with HBSS without calcium chloride, magnesium chloride or magnesium sulfate to remove the neutrophils. Epithelial cells were harvested and resuspended in HBSS at a concentration of $2 \times 10^{6}$ cells $/ \mathrm{ml}$.

\section{FPG modified comet assay}

Twenty five $\mu \mathrm{l}$ cell suspension $\left(2 \times 10^{6}\right.$ cells $\left./ \mathrm{ml}\right)$ was mixed with $75 \mu$ low melting point agarose $(0.65 \%$ in PBS). $75 \mu$ suspension was transferred to a coated $(1.5 \%$ normal agarose in PBS) microscopic slide, covered with a coverslip and stored at $4^{\circ} \mathrm{C}$ to solidify the low melting point agarose. Slides were subsequently lysed $(16 \mathrm{~h})$ at $4^{\circ} \mathrm{C}$ in lysisbuffer (2.5 M NaCl, $100 \mathrm{mM}$ EDTA, $10 \mathrm{mM}$ Tris, $250 \mathrm{mM} \mathrm{NaOH}, 10 \%$ DMSO and 1\% triton X100). After lysis, slides were washed 3 times in $40 \mathrm{mM}$ HEPES, $0.1 \mathrm{M} \mathrm{KCl}, 0.5 \mathrm{mM}$ EDTA, $0.2 \mathrm{mg} / \mathrm{ml} \mathrm{BSA}, \mathrm{pH}$ 8.0. Slides were incubated for 10 minutes at $37^{\circ} \mathrm{C}$ with $50 \mu 1$ FPG $(2.5 \mu \mathrm{g} / \mathrm{ml}$, kindly provided by Bernd Epe, University of Mainz, Germany) and subsequently placed on ice to stop the reaction. FPG specifically recognizes and cuts oxidized purines. Slides were incubated in $300 \mathrm{mM} \mathrm{NaOH}$ and $1 \mathrm{mM}$ EDTA for 20 minutes to unwind and denature DNA. Thereafter electrophoresis was performed for 20 minutes at $300 \mathrm{~mA}$ and $25 \mathrm{~V}$. Slides were rinsed 3 times in cold $0.4 \mathrm{M}$ Tris solution and rinsed 3 times with $100 \%$ ethanol. Dry slides were stained with ethidium bromide $(10 \mu \mathrm{g} / \mathrm{ml})$ 
and 50 cells per slides were blindly scored using the comet assay III (Perceptive instruments) program and the $\Delta$ (FPG treated-untreated) median tail moment was used for the level of oxidized purines in the DNA.

\section{Catalase activity measurement}

Catalase activity was measured spectrophotometrically in triplicates as described by Morikawa et al. [25]. Briefly, $100 \mu \mathrm{l}$ assay buffer containing $3 \mathrm{mU} / \mathrm{ml}$ catalase and vitamins was mixed with $75 \mu \mathrm{l}$ Purpald (Sigma-Aldrich) $(25 \mathrm{mM}$ in $2 \mathrm{M}$ potassium hydroxide). The reaction was stopped after 2 minutes by adding $25 \mu$ of potassium periodate $(65.2 \mathrm{mM})$ and absorbance was recorded at $540 \mathrm{~nm}$. Catalase activity was measured as $\%$ of control. The whole procedure was also performed without catalase to examine the effect of solvent, BC, BCM and Vit E on the oxidation of Purpald. No effect of the vitamins on the formation of the purple colour was observed.

\section{Statistics}

Each measurement was performed at least in triplicate for each subject $(\mathrm{N}=6)$. Triplicates were averaged for each subject and results are presented as mean \pm SEM. Statistical analysis was performed in SPSS (version 15.0) for windows using ANOVA and subsequent Student's $t$-tests to compare incubation of $\mathrm{BC}, \mathrm{BCM}$ or Vit $\mathrm{E}$ versus control (Co). Trend analysis was performed using linear regression analysis on dose response relationships. Differences were considered to be statistically significant at $\mathrm{p}<0.05$.

\section{Results}

\section{Effect of vitamins on ROS formation}

During neutrophil induced oxidative stress, $\mathrm{O}_{2}{ }^{--}$are formed and converted into $\mathrm{H}_{2} \mathrm{O}_{2}$, which subsequently can react with transition metals to form ${ }^{\circ} \mathrm{OH}$. The effect of $\mathrm{BC}, \mathrm{BCM}$ or Vit $\mathrm{E}$ on $\mathrm{O}_{2}{ }^{\cdot-}$ and ${ }^{\circ} \mathrm{OH}$ formation was assessed by ESR spectroscopy [22].

The DMPO/ $\cdot \mathrm{OH}$ signal was predominant in the $\mathrm{Fe}^{2+} / \mathrm{H}_{2} \mathrm{O}_{2}$ system (coupling constants: $a(\mathrm{~N})=14.86 \mathrm{G}, a(\beta-\mathrm{H})=14.71 \mathrm{G})($ Fig. $1 \mathrm{~A})$. A significant increase of approximately $40 \%$ in $\cdot \mathrm{OH}$ formation $(\mathrm{p}<0.001)$ by $\mathrm{BC}, \mathrm{BCM}$ and Vit $\mathrm{E}$ was observed in the $\mathrm{Fe}^{2+} / \mathrm{H}_{2} \mathrm{O}_{2}$ system (Fig. 1B). 
A)

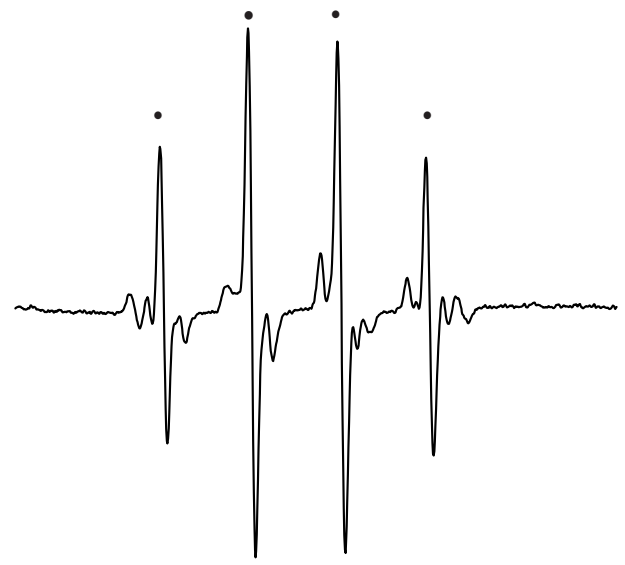

B)

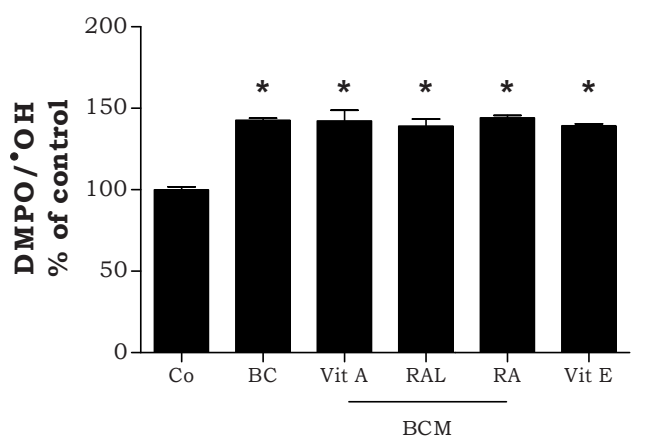

Figure 1: (A) ESR spectrum of an $\mathrm{Fe}^{2+} / \mathrm{H}_{2} \mathrm{O}_{2}$ reaction containing DMPO (100 mM), $\mathrm{FeSO}_{4}(20 \mu \mathrm{M})$, and $\mathrm{H}_{2} \mathrm{O}_{2}(100 \mu \mathrm{M})$ in solvent. Dots indicate the DMPO/.OH adduct signal. (B) Surface area of the $\mathrm{DMPO} /{ }^{\circ} \mathrm{OH}$ peaks in the absence $(\mathrm{Co})$ or presence of BC $(5 \mu \mathrm{M})$, BCM $(10 \mu \mathrm{M})$, or Vit $\mathrm{E}(40 \mu \mathrm{M})$ was recorded and is expressed as \% of control. BC $(5 \mu \mathrm{M})$, BCM $(10 \mu \mathrm{M})$, and Vit $\mathrm{E}(40 \mu \mathrm{M})$ increased the $\mathrm{DMPO} / \cdot \mathrm{OH}$ radical formation significantly. ${ }^{*} p<0.001$; error bars indicate SEM.

The $\mathrm{O}_{2}{ }^{\cdot-}$ generated in the PMS/NADH system was measured as a sum of DMPO/•OH and $\mathrm{DMPO} / \cdot \mathrm{OOH}$ (coupling constants: $a(\mathrm{~N})=14.10 \mathrm{G}, a(\beta-\mathrm{H})=11.05 \mathrm{G}$ and $a(\gamma-\mathrm{H})=$ $1.18 \mathrm{G}$ for the $\mathrm{DMPO} / \cdot \mathrm{OOH}$ signal) (Fig. 2A). Equal amounts of $\mathrm{DMPO} / \cdot \mathrm{OOH}+$ $\mathrm{DMPO} / \cdot \mathrm{OH}$ were formed in the presence of $\mathrm{BC}, \mathrm{BCM}$ and Vit $\mathrm{E}$ as compared to the control (Fig. 2B). 
A)

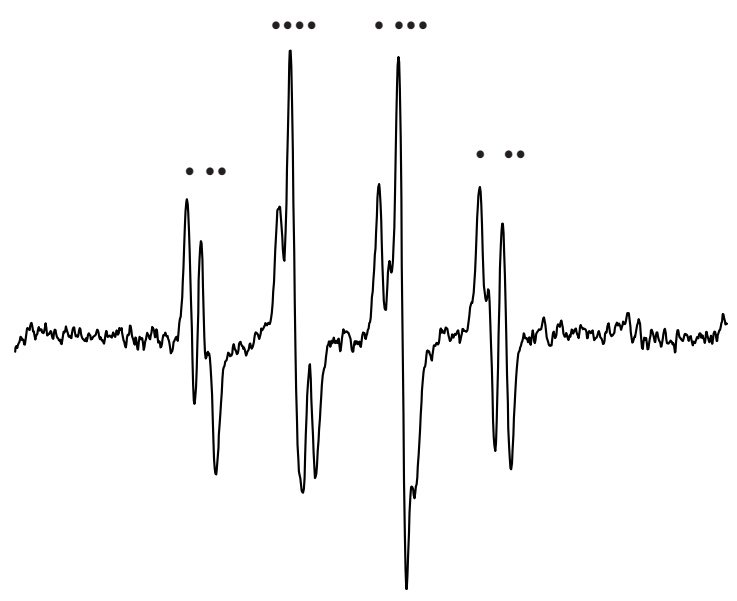

B)

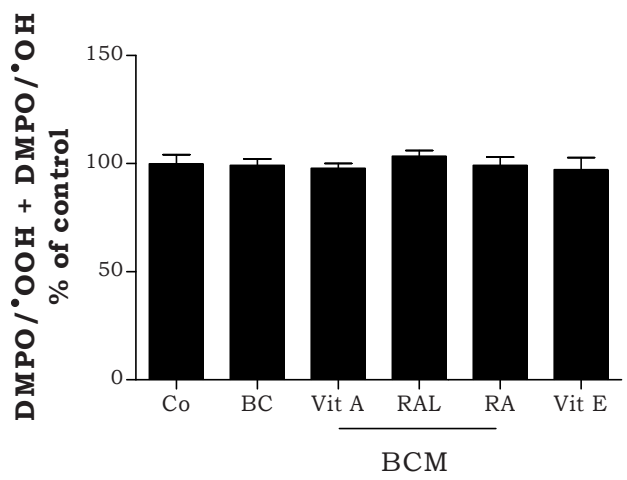

Figure 2: (A) ESR spectrum of a PMS/NADH reaction containing DMPO (100 mM), PMS (3.3 $\mu \mathrm{M})$, and NADH $(50 \mu \mathrm{M})$ in solvent. Dots indicate the combined DMPO $/ \cdot \mathrm{OH}$ and $\mathrm{DMPO} / \cdot \mathrm{OOH}$ adduct signal. (B) Surface area of the $\mathrm{DMPO} / \cdot \mathrm{OH}+\mathrm{DMPO} / \cdot \mathrm{OOH}$ peaks in the absence $(\mathrm{Co})$ or presence of $\mathrm{BC}(5 \mu \mathrm{M})$, $\mathrm{BCM}(10 \mu \mathrm{M})$, or Vit $\mathrm{E}(40 \mu \mathrm{M})$ was recorded and is expressed as \% of control. There were no differences in total $\mathrm{DMPO} / \cdot \mathrm{OH}+\mathrm{DMPO} / \cdot \mathrm{OOH}$ radical formation between Co and $\mathrm{BC}, \mathrm{BCM}$, or Vit E. Error bars indicate SEM.

\section{Effect of vitamins on $\mathrm{H}_{2} \mathrm{O}_{2}$ consuming enzymes: MPO and catalase}

MPO activity was measured in the supernatant of PMA activated neutrophils of 6 healthy non-smoking human donors (2 females, 4 males, age: 25-50 years). Vit A and RA effectively inhibited MPO activity by $31 \%$ and $21 \%$ respectively (Fig. 3). BC, RAL and Vit E did not affect MPO activity. 


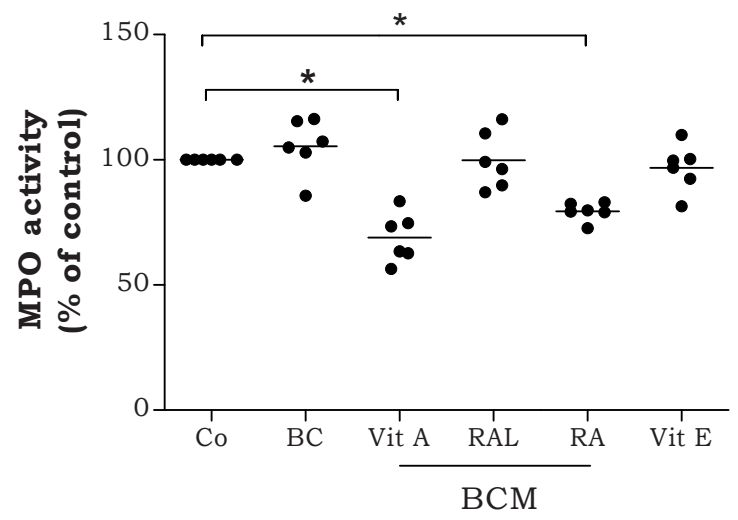

Figure 3: MPO activity in the supernatant of PMA-activated neutrophils from six volunteers, measured in the absence $(\mathrm{Co})$ or presence of BC $(5 \mu \mathrm{M})$, BCM $(10 \mu \mathrm{M})$, or Vit $\mathrm{E}(40 \mu \mathrm{M})$. Data are expressed as $\%$ of control. RA $(10 \mu \mathrm{M})$ and Vit $A(10 \mu \mathrm{M})$ decreased MPO activity significantly. ${ }^{* *} \mathrm{p}<0.05$; error bars indicate SEM.

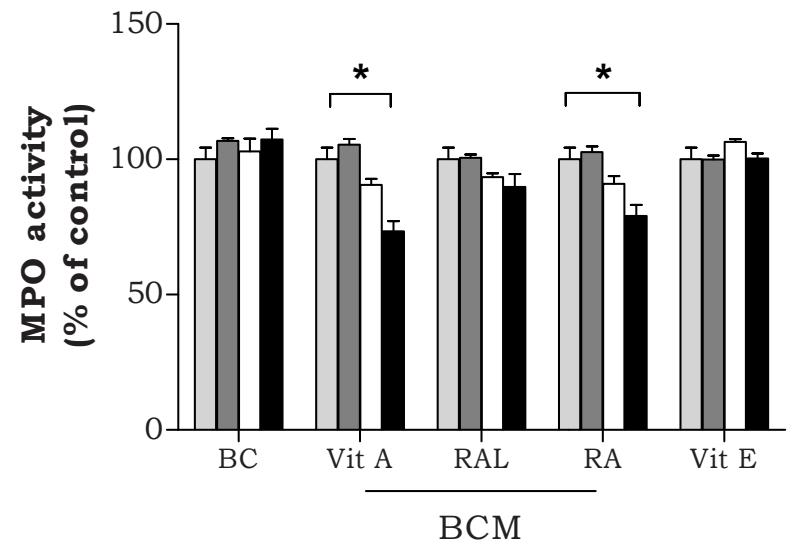

Figure 4: MPO activity in the supernatant of PMA-activated neutrophils, measured in the absence (Co; $0 \%$ ) (light gray bars) or presence of $4 \%$ (dark gray bars), 20\% (white bars), or 100\% (black bars) BC $(5 \mu \mathrm{M}), \mathrm{BCM}(10 \mu \mathrm{M})$, or Vit $\mathrm{E}(40 \mu \mathrm{M})$ and expressed as $\%$ of control. There was a significant dosedependent inhibition of MPO activity by RA and Vit A. " $p$ for trend $<0.001$; error bars indicate SEM. 
There was a dose-dependent ( $\mathrm{p}$ for trend $<0.001$ ) inhibition of MPO activity by Vit A and RA (Fig. 4). Catalase activity was not affected by BC, BCM or Vit E.

\section{The effect of BC, BCM and vitamin $\mathrm{E}$ on the level of oxidized purines in the DNA of epithelial cells, induced by co-cultured neutrophils}

Supplementation with Vit A and RA, resulted in a 4-fold and 3-fold increase in neutrophil induced oxidative DNA damage respectively, while there was no significant increase in the level of oxidized DNA when cells were exposed to BC, RAL or Vit E (Fig. 5). The potency of the vitamins to enhance FPG labile sites correlated significantly with their capacity to inhibit MPO activity $(\mathrm{r}=-0.82, \mathrm{p}<0.05)$.

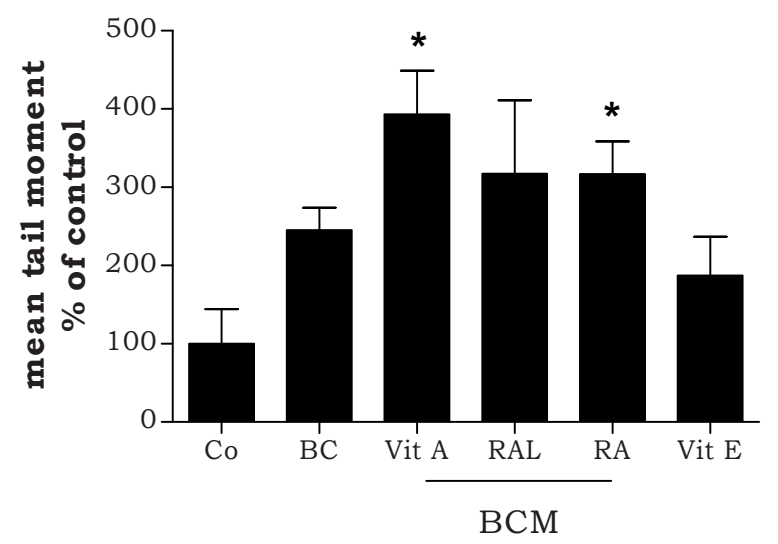

Figure 5: Level of oxidized purines (\% of control) in A549 epithelial cells after co-incubation with PMAactivated neutrophils in the absence $(\mathrm{Co})$ or presence of $\mathrm{BC}(5 \mu \mathrm{M}), \mathrm{BCM}(10 \mu \mathrm{M})$, or Vit E $(40 \mu \mathrm{M})$, as measured by the FPG-modified comet assay. Vit A and RA increased mean tail moment compared to the control. ${ }^{*} \mathrm{p}<0.05$; error bars indicate SEM.

\section{Discussion}

We examined the effect of $\mathrm{BC}$ and $\mathrm{BCM}$ on neutrophil induced genotoxicity as a possible mechanism to explain the adverse health effects of BC supplementation that have been observed in smokers and asbestos exposed subjects. Here, we demonstrate that the BCM; RA and Vit A, significantly increase the level of oxidized purines in DNA of A549 lung epithelial cells that were co-incubated with neutrophils. We show that this increase is, at least in part, due to an increased formation of ${ }^{\circ} \mathrm{OH}$ and decreased MPO ac- 
tivity. Our proposed mechanism is depicted in Fig. 6. Active MPO normally converts 40$70 \%$ of all neutrophil-generated hydrogen peroxide $\left(\mathrm{H}_{2} \mathrm{O}_{2}\right)$ (Fig. 6, step 1) to generate HOCl (Fig. 6, step 2) [26]. We demonstrate that Vit A and RA are able to decrease MPO activity thereby increasing the production of genotoxic ${ }^{\circ} \mathrm{OH}$ radicals (Fig. 6 , step 3 ) that form pro-mutagenic DNA lesions.

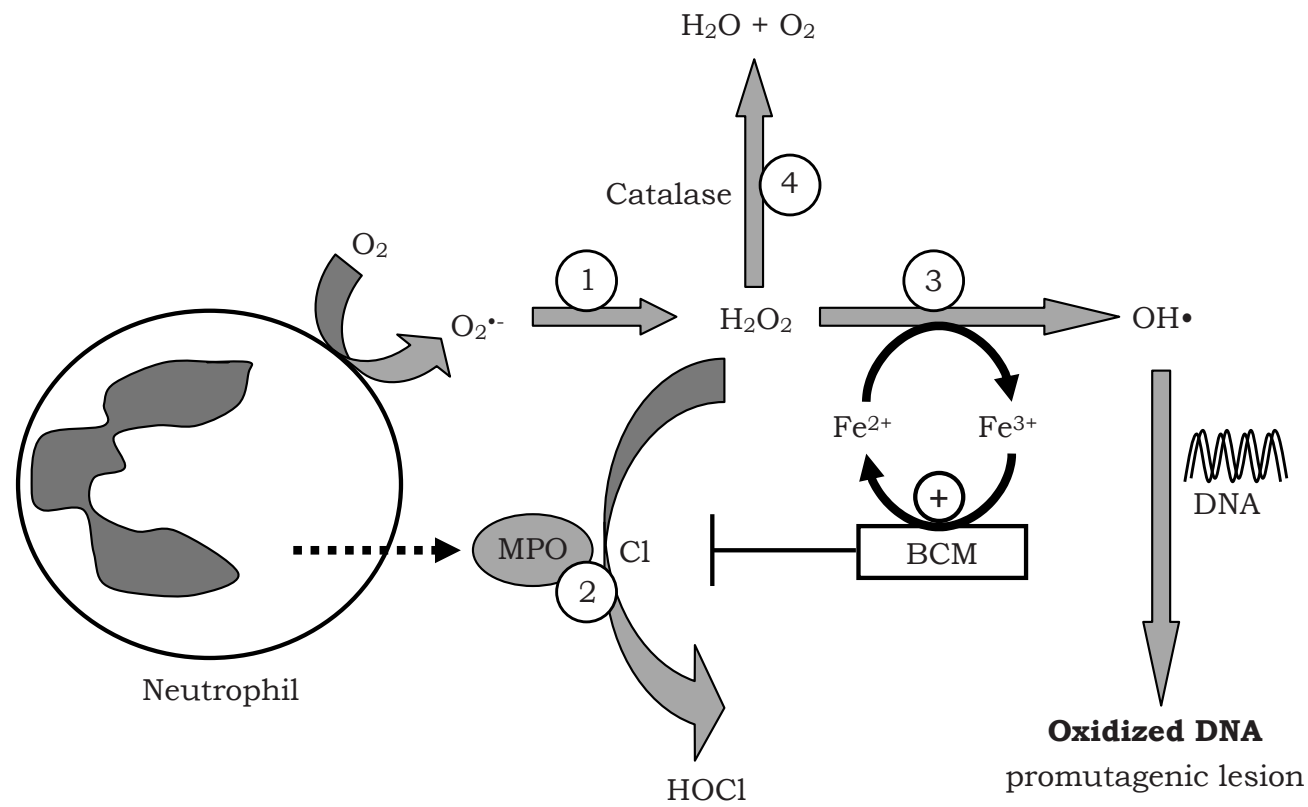

Figure 6: Proposed mechanism of the effects of BCM on inflammation-induced oxidation of DNA in lung epithelial cells. During the respiratory burst $\mathrm{O}_{2} \cdot$ - is generated and converted into $\mathrm{H}_{2} \mathrm{O}_{2}$ (step 1). $\mathrm{H}_{2} \mathrm{O}_{2}$ can be converted to $\mathrm{HOCl}$ by MPO, which is released by activated neutrophils (step 2), or it can react with transition metals to form ${ }^{\circ} \mathrm{OH}$ (step 3), which is able to oxidize DNA. The BCM Vit A and RA decrease MPO activity (step 2). This will yield higher local concentrations of $\mathrm{H}_{2} \mathrm{O}_{2}$ at the site of inflammation, which is subsequently converted to ${ }^{\circ} \mathrm{OH}$ in the Fenton reaction (step 3). The Fenton reaction is more efficient in the presence of $\mathrm{BCM}$, thereby increasing the level of $\cdot \mathrm{OH}$ and DNA oxidation. Alternatively, $\mathrm{H}_{2} \mathrm{O}_{2}$ can be converted into water and oxygen by catalase (step 4), but catalase activity was not affected by any of the vitamins.

A relation between MPO activity and lung cancer risk was studied before; the $-436 \mathrm{G}>\mathrm{A}$ polymorphism in the $M P O$ promoter region was assessed in a number of epidemiological studies on lung cancer. The A-allele, which is related to reduced MPO transcriptional activity [27] and lower MPO activity [28], was in some [29,30], but not all studies [31] associated with reduced rather than increased lung cancer risk. This seems to contra- 
dict our hypothesis. However, we would like to stress that most of these studies focused on subjects with a normal diet without additional intake of BC. In fact, one of the studies that failed to demonstrate a reduced lung cancer risk for carriers of the A allele was nested within the ATBC study and included subjects with relatively high BC and Vit E levels due to the intervention [31]. The relatively high vitamin status in half of the subjects could counteract the protective effect of the A allele. Moreover, epidemiological studies are often unable to fully characterize the level of inflammation by actual measurements of MPO and factors that modulate its activity. For instance, the study by Van Schooten et al. (2004) found large inter-individual variations in MPO activity, even between subjects with the same $M P O$ genotype and similar levels of exposure to cigarette smoke. Our study indicates that it is important to correct for possible confounding factors such as BC intake in studying the relationship between MPO and lung cancer risk in smokers and asbestos exposed subjects [28].

Iron is an important constituent of smoke and asbestos, and iron concentrations are indeed elevated in lungs of smokers and subjects exposed to asbestos [32,33]. Intracellular concentrations of iron are important in neutrophil induced DNA damage since most neutrophil-derived $\mathrm{H}_{2} \mathrm{O}_{2}$ is generated outside the activated neutrophils during the respiratory burst [34], which than diffuses into the nucleus and reacts with DNAassociated iron to form highly genotoxic hydroxyl radicals. In vitro experiments show that $\mathrm{BC}$ is able to increase iron uptake [35], making more iron available in the cells to react with $\mathrm{H}_{2} \mathrm{O}_{2}$. Moreover, $\mathrm{BC}$ and $\mathrm{BCM}$ seem to accumulate in the crude nuclei of NCIH69 cells [36], being able to specifically react with DNA-associated transition metals to form ${ }^{\circ} \mathrm{OH}$ at the proximity of the DNA. The formation of ${ }^{\cdot} \mathrm{OH}$ in a reaction of $\mathrm{H}_{2} \mathrm{O}_{2}$ with $\mathrm{Fe}^{2+}$ was indeed increased by BC, BCM and Vit E (Fig. 6, step 3). which might be attributed to the ability of $\mathrm{BC}, \mathrm{BCM}$ and Vit $\mathrm{E}$ to reduce iron from $\mathrm{Fe}^{3+}$ to $\mathrm{Fe}^{2+}$, making it better available for electron transfer with $\mathrm{H}_{2} \mathrm{O}_{2}$ [37].

We observed an inverse correlation between MPO activity and the level of oxidized purines, suggesting that decreased MPO activity leads to increased $\mathrm{H}_{2} \mathrm{O}_{2}$ and thus to increased formation of oxidized purines. Since $\mathrm{H}_{2} \mathrm{O}_{2}$ plays a crucial role in the formation of neutrophil induced oxidized DNA, it would be interesting to measure the actual $\mathrm{H}_{2} \mathrm{O}_{2}$ concentration. Unfortunately, most described methods to measure $\mathrm{H}_{2} \mathrm{O}_{2}$ use iron or iron containing enzymes like horse radish peroxidase (HRP), which are affected by BC (data not shown), making these methods unsuitable for the measurement of $\mathrm{H}_{2} \mathrm{O}_{2}$ in systems containing $\mathrm{BC}$. For that reason, no $\mathrm{H}_{2} \mathrm{O}_{2}$ was assessed in the present study.

$\mathrm{BC}$ concentrations that were used in our study were high but physiologically achievable, because similar $\mathrm{BC}$ serum concentrations were accomplished after three years of daily BC intake, based on the ATBC and CARET studies. In the CARET study, the average serum Vit A level was $2.2 \mu \mathrm{M}$, both in the placebo as well as the intervention group [38]. However, Vit A levels in serum are highly regulated. On the other hand, Vit A levels in lung are less well regulated and do not correlate with serum Vit A levels [39], but 
they do correlate with the concentrations observed in bronchoalveolar lavages (BAL). Vit A levels in BAL were assessed in a study using 5 CARET participants (4 intervention and 1 placebo) and 21 additional subjects participating in a study performed like the CARET, but with an intervention period of only 6 months. The additional intervention study indicated a slight increase in Vit A levels in BAL after 6 months of intervention from 0.5 to $0.7 \mu \mathrm{M}$, while the BAL Vit A level in CARET participants after 5 years of intervention was $1.9 \mu \mathrm{M}[39,40]$. These data indicate that Vit A increases in lung cells upon supplementation, which is also supported by data in the mouse [41]. RA concentrations were not measured in the ATBC and CARET study. The highest used concentration of RA may be physiologically high, since RA concentrations in plasma are in the nanomolar range [42] However, higher levels of RA are usually found in tissues by endogenous oxidation of Vit A [43], especially in the lung [44]. Overall, the BCM $(10 \mu \mathrm{M})$ concentrations that we used in our in vitro experiments are relatively high but physiological relevant.

Besides BCM investigated in our study, other $\mathrm{BC}$ derived products are known, which are generated by various mechanisms such as auto-oxidation and radical reactions [45]. Siems et al. demonstrated an important role for stimulated neutrophils in oxidative BC breakdown [46]. These BCM may have, similar to Vit A and RA, inhibitory effects on MPO activity. As a follow up on our study, it would be of interest to further examine other BCM, possibly also Vit E metabolites and interactions between different antioxidant vitamins and their breakdown products $[47,48]$.

In conclusion, we demonstrate a role for BCM in neutrophil induced genotoxicity. The $\mathrm{BCM}$; Vit A and RA were able to decrease MPO activity and enhance $\cdot \mathrm{OH}$ radical formation in the Fenton reaction. This ultimately led to an increase in the level of oxidized purines in the DNA of lung epithelial cells when co-cultured with freshly isolated activated neutrophils. Further research is needed to verify the relevance of these effects for neutrophil-induced genotoxicity in the lung in vivo.

\section{Acknowledgements}

This study was supported by the European Network of Excellence (NoE) "Environmental cancer, nutrition and individual susceptibility" (ECNIS), operating within European Union sixth Framework Programme (FP6), Priority 5: "Food Quality and Safety", FOOD-CT2005-513943. Sandra G. Heil and Jaap Keijer were supported by the Dutch Ministry of Agriculture, Nature and Food Quality. 


\section{References}

[1] G. van Poppel Epidemiological evidence for beta-carotene in prevention of cancer and cardiovascular disease, Eur J Clin Nutr 50 Suppl 3 (1996) S57-61.

[2] R.G. Ziegler A review of epidemiologic evidence that carotenoids reduce the risk of cancer, J Nutr 119 (1989) 116-122.

[3] G.S. Omenn, G.E. Goodman, M.D. Thornquist, J. Balmes, M.R. Cullen, A. Glass, J.P. Keogh, F.L. Meyskens, Jr., B. Valanis, J.H. Williams, Jr., S. Barnhart, M.G. Cherniack, C.A. Brodkin and S. Hammar Risk factors for lung cancer and for intervention effects in CARET, the Beta-Carotene and Retinol Efficacy Trial, J Natl Cancer Inst 88 (1996) 1550-1559.

[4] D. Albanes, O.P. Heinonen, P.R. Taylor, et al. Alpha-Tocopherol and beta-carotene supplements and lung cancer incidence in the alpha-tocopherol, beta-carotene cancer prevention study: effects of base-line characteristics and study compliance, J Natl Cancer Inst 88 (1996) 1560-1570.

[5] J.A. Baron and R.S. Sandler Nonsteroidal anti-inflammatory drugs and cancer prevention, Annu Rev Med 51 (2000) 511-523.

[6] D. Pereg and M. Lishner Non-steroidal anti-inflammatory drugs for the prevention and treatment of cancer, J Intern Med 258 (2005) 115-123.

[7] M.J. Thun, S.J. Henley and C. Patrono Nonsteroidal anti-inflammatory drugs as anticancer agents: mechanistic, pharmacologic, and clinical issues, J Natl Cancer Inst 94 (2002) 252-266.

[8] A.G. Schwartz, G.M. Prysak, C.H. Bock and M.L. Cote The molecular epidemiology of lung cancer, Carcinogenesis 28 (2007) 507-518.

[9] J.S. Brody and A. Spira State of the art. Chronic obstructive pulmonary disease, inflammation, and lung cancer, Proc Am Thorac Soc 3 (2006) 535-537.

[10] R.E. Harris, J. Beebe-Donk and H.M. Schuller Chemoprevention of lung cancer by non-steroidal antiinflammatory drugs among cigarette smokers, Oncol Rep 9 (2002) 693-695.

[11] J.E. Muscat, S.Q. Chen, J.P. Richie, Jr., N.K. Altorki, M. Citron, S. Olson, A.I. Neugut and S.D. Stellman Risk of lung carcinoma among users of nonsteroidal antiinflammatory drugs, Cancer 97 (2003) 1732-1736.

[12] C.M. Doerschuk Mechanisms of leukocyte sequestration in inflamed lungs, Microcirculation 8 (2001) 71 88.

[13] A.M. Knaapen, N. Gungor, R.P. Schins, P.J. Borm and F.J. Van Schooten Neutrophils and respiratory tract DNA damage and mutagenesis: a review, Mutagenesis 21 (2006) 225-236.

[14] J.H. Jackson, E. Gajewski, I.U. Schraufstatter, P.A. Hyslop, A.F. Fuciarelli, C.G. Cochrane and M. Dizdaroglu Damage to the bases in DNA induced by stimulated human neutrophils, J Clin Invest 84 (1989) 16441649.

[15] J.P. Spencer, M. Whiteman, A. Jenner and B. Halliwell Nitrite-induced deamination and hypochloriteinduced oxidation of DNA in intact human respiratory tract epithelial cells, Free Radic Biol Med 28 (2000) 1039-1050.

[16] J.M. Gutteridge and B. Halliwell Free radicals and antioxidants in the year 2000. A historical look to the future, Ann N Y Acad Sci 899 (2000) 136-147.

[17] I. Schraufstatter, P.A. Hyslop, J.H. Jackson and C.G. Cochrane Oxidant-induced DNA damage of target cells, J Clin Invest 82 (1988) 1040-1050.

[18] A.M. Knaapen, R.P. Schins, P.J. Borm and F.J. van Schooten Nitrite enhances neutrophil-induced DNA strand breakage in pulmonary epithelial cells by inhibition of myeloperoxidase, Carcinogenesis 26 (2005) 1642-1648.

[19] I. Rahman, S.K. Biswas and A. Kode Oxidant and antioxidant balance in the airways and airway diseases, Eur J Pharmacol 533 (2006) 222-239.

[20] J. von Lintig, S. Hessel, A. Isken, C. Kiefer, J.M. Lampert, O. Voolstra and K. Vogt Towards a better understanding of carotenoid metabolism in animals, Biochim Biophys Acta 1740 (2005) 122-131.

[21] D. Albanes, N. Malila, P.R. Taylor, J.K. Huttunen, J. Virtamo, B.K. Edwards, M. Rautalahti, A.M. Hartman, M.J. Barrett, P. Pietinen, T.J. Hartman, P. Sipponen, K. Lewin, L. Teerenhovi, P. Hietanen, J.A. Tangrea, M. Virtanen and O.P. Heinonen Effects of supplemental alpha-tocopherol and beta-carotene on colorectal cancer: results from a controlled trial (Finland), Cancer Causes Control 11 (2000) 197-205.

[22] L.C. Wilms, J.C. Kleinjans, E.J. Moonen and J.J. Briede Discriminative protection against hydroxyl and superoxide anion radicals by quercetin in human leucocytes in vitro, Toxicol In Vitro 22 (2008) 301-307.

[23] S.J. Klebanoff, A.M. Waltersdorph and H. Rosen Antimicrobial activity of myeloperoxidase, Methods Enzymol 105 (1984) 399-403. 
[24] A.M. Knaapen, F. Seiler, P.A. Schilderman, P. Nehls, J. Bruch, R.P. Schins and P.J. Borm Neutrophils cause oxidative DNA damage in alveolar epithelial cells, Free Radic Biol Med 27 (1999) 234-240.

[25] K. Morikawa, H. Shimokawa, T. Matoba, H. Kubota, T. Akaike, M.A. Talukder, M. Hatanaka, T. Fujiki, H. Maeda, S. Takahashi and A. Takeshita Pivotal role of $\mathrm{Cu}, \mathrm{Zn}$-superoxide dismutase in endotheliumdependent hyperpolarization, J Clin Invest 112 (2003) 1871-1879.

[26] S.J. Klebanoff Myeloperoxidase, Proc Assoc Am Physicians 111 (1999) 383-389.

[27] F.J. Piedrafita, R.B. Molander, G. Vansant, E.A. Orlova, M. Pfahl and W.F. Reynolds An Alu element in the myeloperoxidase promoter contains a composite SP1-thyroid hormone-retinoic acid response element, J Biol Chem 271 (1996) 14412-14420.

[28] F.J. Van Schooten, A.W. Boots, A.M. Knaapen, R.W. Godschalk, L.M. Maas, P.J. Borm, M. Drent and J.A. Jacobs Myeloperoxidase (MPO) -463G->A reduces MPO activity and DNA adduct levels in bronchoalveolar lavages of smokers, Cancer Epidemiol Biomarkers Prev 13 (2004) 828-833.

[29] W. Lu, J. Qi, D. Xing, W. Tan, X. Miao, W. Su, M. Wu and D. Lin [Lung cancer risk associated with genetic polymorphism in myeloperoxidase $(-463 \mathrm{G} / \mathrm{A})$ in a Chinese population], Zhonghua Zhong Liu Za Zhi 24 (2002) 250-253.

[30] M.B. Schabath, M.R. Spitz, X. Zhang, G.L. Delclos and X. Wu Genetic variants of myeloperoxidase and lung cancer risk, Carcinogenesis 21 (2000) 1163-1166.

[31] R.R. Misra, J.A. Tangrea, J. Virtamo, D. Ratnasinghe, M.R. Andersen, M. Barrett, P.R. Taylor and D. Albanes Variation in the promoter region of the myeloperoxidase gene is not directly related to lung cancer risk among male smokers in Finland, Cancer Lett 164 (2001) 161-167.

[32] F. Mateos, J.H. Brock and J.L. Perez-Arellano Iron metabolism in the lower respiratory tract, Thorax 53 (1998) 594-600.

[33] D. Upadhyay and D.W. Kamp Asbestos-induced pulmonary toxicity: role of DNA damage and apoptosis, Exp Biol Med (Maywood) 228 (2003) 650-659.

[34] M.B. Hampton, A.J. Kettle and C.C. Winterbourn Inside the neutrophil phagosome: oxidants, myeloperoxidase, and bacterial killing, Blood 92 (1998) 3007-3017.

[35] M.N. Garcia-Casal, I. Leets and M. Layrisse Beta-carotene and inhibitors of iron absorption modify iron uptake by Caco-2 cells, J Nutr 130 (2000) 5-9.

[36] P. Prakash, C.L. Jackson and L.E. Gerber Subcellular accumulation of beta-carotene and retinoids in growth-inhibited NCI-H69 small cell lung cancer cells, Nutr Cancer 34 (1999) 76-82.

[37] N.E. Polyakov, T.V. Leshina, T.A. Konovalova and L.D. Kispert Carotenoids as scavengers of free radicals in a Fenton reaction: antioxidants or pro-oxidants? Free Radic Biol Med 31 (2001) 398-404.

[38] C.A. Redlich, J.S. Chung, M.R. Cullen, W.S. Blaner, A.M. Van Bennekum and L. Berglund Effect of longterm beta-carotene and vitamin A on serum cholesterol and triglyceride levels among participants in the Carotene and Retinol Efficacy Trial (CARET), Atherosclerosis 145 (1999) 425-432.

[39] C.A. Redlich, W.S. Blaner, A.M. Van Bennekum, J.S. Chung, S.L. Clever, C.T. Holm and M.R. Cullen Effect of supplementation with beta-carotene and vitamin A on lung nutrient levels, Cancer Epidemiol Biomarkers Prev 7 (1998) 211-214.

[40] N.L. Franssen-van Hal, J.E. Bunschoten, D.P. Venema, P.C. Hollman, G. Riss and J. Keijer Human intestinal and lung cell lines exposed to beta-carotene show a large variation in intracellular levels of betacarotene and its metabolites, Arch Biochem Biophys 439 (2005) 32-41.

[41] R. Goralczyk, K. Wertz, B. Lenz, G. Riss, P. Buchwald Hunziker, B. Geatrix, C.P. Aebischer and H. Bachmann Beta-carotene interaction with NNK in the AJ-mouse model: effects on cell proliferation, tumor formation and retinoic acid responsive genes, Biochim Biophys Acta 1740 (2005) 179-188.

[42] J.L. Napoli Quantification of physiological levels of retinoic acid, Methods Enzymol 123 (1986) 112-124.

[43] S.B. Kurlandsky, M.V. Gamble, R. Ramakrishnan and W.S. Blaner Plasma delivery of retinoic acid to tissues in the rat, J Biol Chem 270 (1995) 17850-17857.

[44] A.C. Ross On the sources of retinoic acid in the lung: understanding the local conversion of retinol to retinoic acid, Am J Physiol Lung Cell Mol Physiol 286 (2004) L247-248.

[45] W. Siems, I. Wiswedel, C. Salerno, C. Crifo, W. Augustin, L. Schild, C.D. Langhans and O. Sommerburg Beta-carotene breakdown products may impair mitochondrial functions--potential side effects of high-dose beta-carotene supplementation, J Nutr Biochem 16 (2005) 385-397.

[46] O. Sommerburg, C.D. Langhans, J. Arnhold, M. Leichsenring, C. Salerno, C. Crifo, G.F. Hoffmann, K.M. Debatin and W.G. Siems Beta-carotene cleavage products after oxidation mediated by hypochlorous acid--a model for neutrophil-derived degradation, Free Radic Biol Med 35 (2003) 1480-1490.

[47] N.I. Krinsky and K.J. Yeum Carotenoid-radical interactions, Biochem Biophys Res Commun 305 (2003) 754-760.

[48] P. Palozza, S. Serini, F. Di Nicuolo, E. Piccioni and G. Calviello Prooxidant effects of beta-carotene in cultured cells, Mol Aspects Med 24 (2003) 353-362. 
The establishment of functional effects due to variation in concentrations of micronutrients in our diet is difficult since they are often not immediately recognized as being healthy or unhealthy. Indeed, effects induced by micronutrients are hard to identify and therefore the establishment of the recommended daily intake, the optimal intake and the upper limit pose a challenge. For bioactive food components this is even more complicated. Whole-genome transcriptome analysis is highly suitable to obtain unbiased information on potential affected biological processes on a whole-genome level. Here, we will describe and discuss several aspects of transcriptome analysis in benefit-risk assessment, including effect size, sensitivity and statistical power, that have to be taken into account to faithfully identify functional effects of micronutrients and bioactive food components. 


\section{Transcriptome analysis in benefit- risk assessment of micronutrients and bioactive food components}

Molecular Nutrition \& Food Research

Jaap Keijer, Yvonne G. J. van Helden, Annelies Bunschoten, Evert M. van Schothorst 


\section{Introduction}

It is well established that different intakes of micronutrients affect our health. How they do this over a range of concentrations is less clear. This information is important for determining optimal intakes and for the application of micronutrients in dietary strategies to increase a healthy life span. Clearly, deficient as well as excessive intakes of micronutrients can result in physiological changes and ultimately in pathological effects. Between these extremes, many physiological effects over a range of concentrations can occur, with a certain optimal beneficial intake. Benefit-risk assessment means to establish the borders where shortage changes into enough, defined as the recommended daily intake (RDI), and where enough changes into too much, defined as the upper limit (UL), as well as the establishment of the optimal beneficial intake (Fig. 1, [1]). The RDI is established based on the minimal intake that is needed to avoid deficiency symptoms in $97 \%$ of the population. While in some cases this is already difficult to establish, it is even more difficult to determine the optimal beneficial concentration, supporting maximal health over a lifetime. Indeed for most micronutrients this is not known. To be able to assess this properly, an overview of all possible effects is needed and functional genomic technologies are potentially suitable to obtain such an overview. What is true for micronutrients is also true for bioactive food components with claimed beneficial health effects as a consequence of habitual intake, such as polyphenols and carotenoids. Of course, for bioactive food components functionality has to be established first.

The question can be raised whether a slightly higher intake than the RDI can be of additional functional importance. That this may be true has been shown for the micronutrient selenium, which, to our knowledge, is the only example available at present. It is well known that (severe) selenium deficiency results in Keshan disease, Kashin-Beck disease, and even symptoms of hypothyroidism due to its function in thyroid metabolism (reviewed by [2]), whereas an excess intake results in toxicity known as selenosis [3]. Although epidemiological studies showed positive health effects of high selenium intake, the underlying mechanisms were not clear, making it difficult to causally link intake to effect. Gene expression analysis of human lymphocytes showed an increase in the protein translation machinery when the selenium status was increased from just below to a level just above the RDI [4]. The same result, an increase in the protein translation machinery, was also found when gene expression in the colon of wildtype C57BL/6J mice on marginal deficient and adequate selenium diets were compared [5], thereby validating the observations made in humans. At present it is not clear whether the effect on the protein translation machinery is related to the main physiological effects associated with deficiency (e.g. Keshan disease), but its identification allows to establish not only this causality, but also the minimal, and possibly optimal, required 
selenium intake for optimal protein translation capacity, making it a potential biomarker.

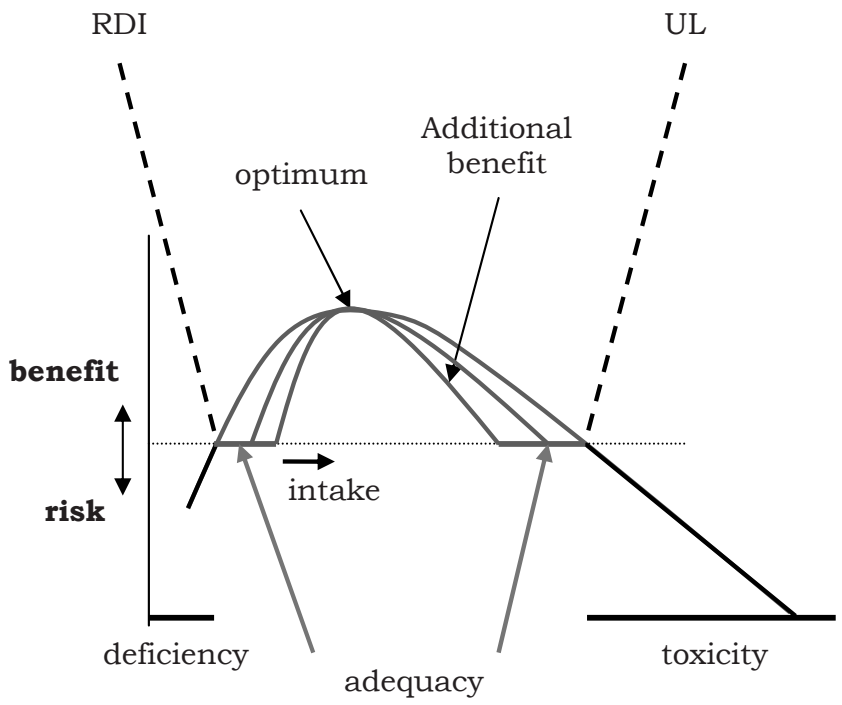

Figure 1: The RDI and the UL border the window of benefit [35]. Deficiency occurs below the RDI and toxicity above the UL. Between these borders the amount of a micronutrient can be adequate to support physiological performance, but additive benefit may occur at certain concentrations or under certain conditions (from [1]).

This example indicates that understanding the mechanisms of nutrient-induced functional effects is important, since they may affect fitness, well-being and healthy aging. Moreover, understanding the mode of action will help to define susceptible population groups. By definition, no overt pathology is involved at micronutrient intakes between the RDI and UL and we are thus faced with the task to identify small functional and molecular effects. This poses constraints on the experimental setup and on the analysis techniques. Furthermore, we do not know which effects will occur and the use of an initial unbiased approach is essential. Whole-genome transcriptome analysis is highly suited for this. In this review we describe this technique and several technical as well as experimental considerations with regard to its application in nutritional studies in general and in benefit-risk assessment in more detail. 


\section{Whole-genome transcriptome analysis as a tool for benefit- risk analysis}

A highly suitable tool toward the identification of mechanisms underlying nutrientinduced functional effects is whole-genome expression profiling (also known as wholegenome DNA microarray analysis). This is a highly comprehensive profiling technique, able to screen for differences in gene expression between (groups of) individuals. This technique has become robust over the past years, and is able to detect small differences between individuals and thus suitable as a first phase screen in benefit-risk analysis.

In transcriptome profiling, global gene expression in one condition is compared with another condition. There are several different microarray platforms, of which those by Affymetrix and Agilent are mostly used. To determine global gene mRNA expression, both systems use a linear amplification and labeling procedure to obtain cRNA, which is hybridized to the microarray. Affymetrix uses statistical ranking of the binding of cRNA to multiple sense versus missense probes per probe set, with each probe being 25 bases in length. In contrast Agilent probes are 60 bases in length, but only one or a limited number of probes are used to represent an expression product. A second difference is that the Affymetrix platform uses a single dye to label an experimental sample, and normalization is fully statistical, whereas Agilent arrays can hybridize and detect two or even more dyes, for example one for the experimental sample and one for a reference sample. Both types of arrays have become highly robust and allow generation of high quality data [6]. More details are given below. The Agilent platform is used as an example in this paper.

Agilent whole-genome microarrays contain roughly 44,000 probes, including positive and negative controls, which represent over 40,000 different annotations. Since some annotations represent the same gene, the arrays allow to screen for differences in expression of over at least 25,000 unique genes, plus around 1400 annotations of unassigned genes. Since generally two dyes are used, direct comparison of two different experimental samples is possible, although this approach has two major disadvantages. The first disadvantage is that a dye swap is necessary, since the two dyes give rise to different results, due to chemical differences in the labeling procedure. The second disadvantage is that only pre-defined comparisons can be analyzed and experiments comparing more experimental groups require highly intricate designs. To circumvent these disadvantages a reference pool design can be used. A reference pool design allows for post hoc selection of the experimental groups to be compared and a dye swap is not necessary. In a reference pool design, each experimental sample is individually labeled with a fluorescent dye (e.g. Cy5-cRNA) and hybridized to a microarray together with the same amount of a mixed sample, ideally containing an equal molar mixture of all experimental samples, labeled with a second dye (e.g. Cy3-cRNA) [7][8]. Five hundred nanogram of total input RNA suffices in the amplification and labeling reaction [8]. After 
hybridization, the microarrays are washed and scanned. The fluorescent intensity for each probe on the array is then integrated and represents a quantitative measure for the amount of the corresponding mRNA in the sample. The microarrays first pass a quality control pipeline that controls labeling and hybridization. Since values close to the background may give aberrant fold changes between groups, these are generally discarded for further analysis. We normally discard all signal values that are on average below two times the local background values for both the samples and the reference pool, although with present day microarray reproducibility lower cut-offs are possible. In general, at least $50-60 \%$ of the probes are being expressed two times above background in any tissue analyzed.

In the next step, expressed probe intensities are normalized by correcting the signals relative to the reference sample probe signals [7]. The use of the reference sample facilitates experimental normalization and, compared with single dye experiments, is less sensitive to technical variation such as hybridization conditions and microarray quality. The use of a method that is low in technical variation for benefit-risk assessment is crucial, since changes in gene expression are small and the used method has to be sensitive enough to separate these changes from the technical noise. In the end, a fluorescent normalized log intensity value is obtained for each of the expressed probes on the array, for each experimental sample. This results in a datasheet that is used for downstream applications, such as statistical analyses, pathway overrepresentation analysis, cluster analysis, and other methods that facilitate data interpretation.

\section{Data-confirmation by Q-PCR}

Changes in gene expression identified using whole-genome microarrays are usually confirmed by real-time quantitative PCR (Q-PCR). In Q-PCR, specific mRNA's are amplified using intron-spanning primers and amplification is monitored in real time allowing mRNA quantification. To normalize for possible variation in the amount and quality of RNA between different samples, the level of a target gene is compared and expressed relative to that of one or more reference genes. Therefore, Q-PCR has a semiquantitative character and the choice of reference genes is particularly important for the validity of the results. The reference genes should be stably expressed over all the conditions that are analyzed. For example, Glyceraldehyde-3-phosphate dehydrogenase, historically used as a reference gene in mRNA Northern blot quantification, shows 1.5 to 3 -fold changes in many dietary interventions (Table 1). It is therefore generally not suitable as a reference gene, especially since changes of around 1.3-fold are often encountered as being physiologically relevant in nutritional studies. Other reference gene candidates such as $18 \mathrm{~S}$ rRNA, general transcription factor II and microarray identified stable expressed genes are better suited as reference candidates. Nevertheless, testing the stability of the expression of different reference genes for the experimental condi- 
tions examined remains a sometimes difficult prerequisite and it has therefore been proposed to use the geometrical mean of multiple reference genes instead of using a single reference gene [9].

As for microarray analysis, Q-PCR analysis needs to meet up to several qualitative important thresholds. We and others use normally a standard curve for each primer pair which should result by linear regression analysis in a $\mathrm{R}^{2}$ of $>0.99$ (preferably: $>0.995$ ) and a PCR efficiency of $100 \pm 10 \%$. More Q-PCR details and thresholds are recently put forward to be included in analysis and publications (MIQE) similar to the MIAME compliant strategy for microarray analysis [10].

Table 1. Differential gene expression of glyceraldehyde 3-phosphate dehydrogenase (Gapdh) in adipose tissue of wildtype C57BL/6J male adult mice following nutritional intervention ( $n=12$ per group) as analyzed by DNA microarray analysis (for details see text and legend of Fig. 2).

\begin{tabular}{lcccccc}
\hline \multirow{2}{*}{ Gene name } & \multicolumn{2}{c}{ CR versus C } & \multicolumn{2}{c}{ LF versus C } & \multicolumn{2}{c}{ E versus C } \\
& Ratio & p-Value & Ratio & p-Value & Ratio & p-Value \\
\hline Gapdh & 3.32 & $5.4 \times 10^{-9}$ & 1.46 & 0.001 & -1.02 & 0.69 \\
\hline
\end{tabular}

$\mathrm{C}=$ control, a purified $30 \mathrm{en} \%$ high fat diet; $\mathrm{CR}=30 \%$ caloric restriction of $\mathrm{C}$; $\mathrm{LF}=\mathrm{a}$ purified low fat diet (10en\% fat, fat substituted by starch); E=C plus $0.5 \% \mathrm{EGCg}$

Initially, Q-PCR validation of microarray results was an absolute necessity, because microarray analysis was insufficiently robust. Present day microarray platforms in the hands of experienced groups are highly robust and technical validation is more a matter of making sure, than of necessity. Indeed, recent experiments in our lab and others have given identical results in a quantitative and qualitative manner, provided that microarray selected reference genes were used in Q-PCR. It can be argued that data obtained using microarrays are more dependable, rather than less, compared with Q-PCR, which is particularly important when small differences in gene expression are considered.

The microarray whole-genome transcriptome profiling technique is a powerful tool to measure differences in mRNA quantity. Differences in mRNA expression are of interest, but are only of relevance if they match to functional biology, and thus are linked to changes in either protein or metabolite levels, or to the predicted physiological changes. Differences at protein level can be confirmed using Western blotting [11] or flow meter based multiplex analysis [12], which both provide quantitative information. Moreover, immunohistochemistry [13] can be used to provide positional information. However, these methods can be difficult or even impossible to perform when a specific and wellcharacterized antibody is lacking or when protein concentrations are low. Another technique that can be used is 2-D electrophoreses coupled to mass spectrometry [14]. Using this technique, proteins are separated by their isoelectric point in the first dimension and by the size of protein in the second dimension. Thereafter proteins are stained and 
quantified using image analysis software. Differentially expressed proteins can be cut from the gel to be identified by MS. This thus allows for simultaneous analysis of many proteins in one sample, which is referred to as proteome analysis. Proteomics has the advantage over transcriptome analysis that it directly assesses at a functional biochemical level. The diverse characteristics of proteins, including variation in size, hydrophobicity, abundancy and secondary, tertiary, or quaternary modifications, imply a smaller window of targets that can be analyzed simultaneously. This precludes replacement of transcriptome analysis for genome wide identification of potential functional effects of micronutrients. This will hold true even if robustness and the window of analysis will be improved by implementing other proteomic approaches that are being developed, which include antibody arrays [15] and chromatographical separation [16]. In many ways proteome analysis is complementary to transcriptome analysis, each targeting a different functional level.

\section{Magnitude of micronutrient effects}

As indicated, benefit-risk assessment will inherently deal with small functional effects, because studies will try to capture stable differences in homeostatic conditions in a relatively short time frame, rather than waiting for a life time outcome of these changes. To exemplify the magnitude of the effects that can be expected, the number (and magnitude) of genes that changed expression was assessed for a mouse dietary intervention with three different bioactive food components and compared with a strong nutritional intervention (caloric restriction, $\mathrm{CR}$ ) and a widely examined nutritional intervention (high fat versus low fat). The 30\% CR intervention resulted in 15,041 genes that were significantly $(\mathrm{p}<0.05)$ differentially expressed compared with the control high fat diet. The gene expression response of a low fat diet was approximately three times less $(5,603$ regulated genes, $p<0.05)$, whereas a diet supplemented with one of three polyphenols again showed a more than threefold lower differential expression using the same cut-off $(\mathrm{p}<0.05) .1,650$ genes changed expression by chronic supplementation with $0.5 \%$ epigallocatechingallate (EGCg; E), 1683 by supplementation with an equimolar amount of resveratrol (R) and 977 by supplementation with an equimolar amount of quercetin (Q). This shows that effects of bioactive food components are relatively small (Fig. 2), both in terms of the number of differentially regulated genes (Fig. 2A) and in terms of the fold changes observed (Fig. 2B) when compared with a high versus low fat diet and especially when compared with CR. It should be realized that a high versus low fat diet intervention already has a mild effect on gene expression when compared with a pharmacological intervention or gene-knockout strategy [17]. 
A)

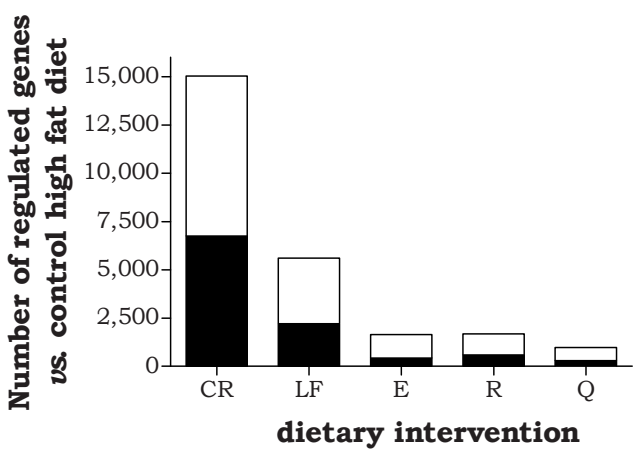

B)

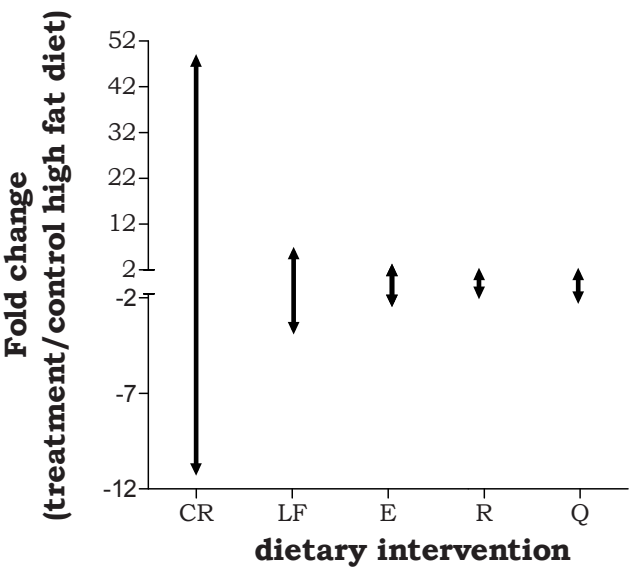

Figure 2: Differential gene regulation by nutritional interventions as analyzed by microarrays. Wildtype C57BL/6J male adult mice ( $n=72)$ received a control purified high fat diet (30 en\% fat) during a $3 \mathrm{wk}$ run-in period, were stratified on body weight, followed by 13 wk dietary intervention with control high fat diet ( $n=12$ ), 30\% caloric restriction (CR, $n=12$ ), a purified low fat diet (10 en $\%$ fat, fat substituted by starch; LF, $n=12)$, a $0.5 \%$ EGCg supplemented high fat diet $(\mathrm{E}, n=12)$ or equimolar resveratrol (R, $n=12)$ or quercetin $(\mathrm{Q}, n=12)$ supplemented high fat diets with dietary groups considered to be independent. The CR diet was adjusted to provide mice with equal micronutrients intake. After the intervention, animals were killed and tissues isolated. All 72 murine epididymal white adipose tissue total RNA samples were analyzed using Agilent 44k whole-genome microarrays as described in the text. Microarray data were normalized and mean gene expression was calculated per dietary group and analyzed versus the control high fat diet group. First, the number of significantly upregulated (white bar) and downregulated (black bar) genes was analyzed $(\mathrm{p}<0.05)(\mathrm{A})$ and the maximal observed fold change range per treatment (treated/control) is shown as double headed (B) (positive numbers: upregulated, negative: downregulated). The animal experiment (DEC2007086) was performed at Wageningen University in The Netherlands fully complying to National and European regulations on animal experimentation. All personnel involved in animal handling have the required experience and certificates. 


\section{Data interpretation}

To determine statistical differences between average quantitative (log) values per expressed probe, different statistical tests can be used depending on the experimental setup and question to be answered. If a pre-defined gene is statistically differentially expressed between two conditions, a Student's $t$-test might be perfectly suitable. In this manner the expression values of a few pre-defined genes can be examined. The data are directly interpreted by the investigator, more or less as an alternative to Q-PCR with an additional advantage that for the normalization thousands of genes are used and signals are therefore more reliable. However, when testing differences in expression levels of thousands of probe sets, a correction for multiple comparisons is needed. For this, the Benjamini-Hochberg false discovery rate is a frequently used statistical method [18]. But, as stated above, benefit-risk assessment deals mostly with small effects and the use of this very strict statistical method will result in a very rapid decrease in sensitivity, ultimately rendering insufficient information for functional interpretation. This decrease in sensitivity can be circumvented in two ways. First, by increasing the number of individuals or samples. This has practical disadvantages, including costs, time and space limitations. In addition, there may be ethical hesitation when laboratory animals are used. The second approach to increase sensitivity in data analysis is by considering the genes at the biological process or pathway level rather than at the individual gene level. In practice this is done by pre-selecting the genes by a conventional statistical method, the Student's $t$-test or a transcriptome focused modification of this test, such as the Limma $t$-test. Thereafter, these genes are grouped using pathway, network, or gene ontology overrepresentation. To consider genes in the context of a process rather than on an individual basis makes biological sense since an orchestrated regulation of the majority of genes within one pathway seems to have more biological relevance than a single gene within the same pathway. As an example, analysis of rat intestinal infection by Salmonella showed consistent upregulation of chemokines in three repetitions of an oral infection experiment. Although a similar number of chemokines were upregulated in these three consecutive experiments, only a minority of chemokines appeared in all three experiments. These results suggest that a response at the process level is more robust than on individual genes ([19]; unpublished results). Identified pathways have to be investigated subsequently to see whether gene expression changes make biological sense, which is unlikely with false-positive genes.

Another method to group genes is by the use of correlation analysis which is performed using statistical programs that examine the correlation in variation between samples [20]. Correlation analysis takes all genes (above threshold) into account and can thus provide information on non-annotated genes. If their behavior is identical to that of annotated genes, in other words when they group together, they are likely to be functionally correlated [21]. Statistical correlation generally provides limited clues on gene 
and/or protein function, because this depends on functional knowledge of the genes present within each group.

Although a selection of significantly regulated genes is often used to group genes and to investigate regulated pathways, functional knowledge can also be gained with pathway analysis programs on a selection of, or even the whole data set. These programs are bioinformatical software programs that examine the overrepresentation of certain pathways/networks/gene ontology terms in the data set (public available tools like GSEA, Ermine J, DAVID/EASE, Pathvisio or commercial tools from Ingenuity or MetaCore, among others; [22][23]). The pathway analysis programs rapidly improve, but still are far from optimal for two main reasons. First, a large number of gene annotations (most) are not recognized neither included in the pathways nor properly translated (e.g. murine gene annotation loaded into a human pathway analysis program) [21]. Second, the pathways are built based on existing knowledge, leading to a bias for well studied pathways and a bias for classic views and questions and against new parts, connections or perspectives. For example, although gastrointestinal hormones can be considered as a common, established denominator of gastrointestinal endocrinology [24], they are not present as an entity in the most frequently used pathway analysis programs. Despite these current drawbacks, pathway analysis programs are an indispensable tool in data interpretation. However, manual inspection of the data and literature mining by the scientist is still required and forms an essential, but time consuming step in the data analysis. It can be envisaged that future analysis will make use of integrated statistical correlation analysis and pathway analysis in a highly structured manner, and a framework of this has been proposed [21].

\section{In vivo and in vitro approaches}

Transcriptomics is a potential powerful tool for unbiased identification of functional effects of nutrients. However, human studies are difficult to control, making it more difficult to identify small effects. Differences in behavior and non-nutritional environmental variation add on to difficulties to faithfully monitor consumption patterns as well as consumption of specific food components. The inability to properly monitor the intake of specific food components is in part being tackled by plasma or urine analysis for specific metabolites that can be considered as biomarkers for intake [25]. Another approach is to perform a fully controlled study, but this has its limitations both in terms of duration as well as in terms of number of subjects that can be analyzed. Another disadvantage is that the human population has a high genetic heterogeneity, thus requiring large numbers of study subjects and higher costs. Another important disadvantage in human studies is that only a few tissues can be easily assessed. These are mainly blood, blood cells, urine, saliva and, with more difficulty, muscle, fat and intestinal biopsies. Indeed, peripheral blood mononuclear cells are increasingly used in nu- 
tritional transcription profiling, both as a target tissue as well as a surrogate tissue $[4,26,27]$.

In vitro approaches, using human immortal cells in culture, can also be used for effect analysis. The main advantages are high-throughput, a well-controlled environment and relatively low costs, as compared with in vivo analysis. One major disadvantage is that most cell models are tumor derived or transformed cells that are physiologically compromised. A second disadvantage is that they do not occur in their natural local environment. Furthermore, nutrient metabolism occurring upon ingestion has to be taken into account. For example, most dietary polyphenols are in vivo metabolized in the intestinal mucosa, with functional consequences [28]. As a result of metabolism in intestinal mucosa and liver, peripheral tissues are hardly, or not at all, in contact with the unmetabolized polyphenols. Nevertheless, many in vitro studies using cell cultures from peripheral origin were performed exposing the cells to these unmetabolized polyphenols, which results in physiologically irrelevant studies. Another, more practical disadvantage is that many physiological and molecular parameters are strongly dependent on the exact cell culture conditions, such as cell density. Transcriptome profiling of in vitro dose-response analysis therefore requires multiple replications and even then the results have to be interpreted with extreme caution. Moreover, an in vitro approach is unable to detect effects due to interactions between different organs, as occurs in vivo. Our own experience trying to confirm new leads that were obtained using in vitro models was highly disappointing, making it more logical to first start in vivo and then, knowing the validity of the target and the response, proceed using in vitro or ex vivo systems that show the relevant response.

\section{Animal models and diets}

Micronutritional benefit-risk studies can also be performed in model animals, with rodents being mostly used. Rodent nutritional studies have the advantage that the environment (temperature, stress), as well as diet and food intake can be highly controlled. Moreover, genetic background can, dependent on the strain, largely be controlled and effects on individual tissues can be assessed in relation to each other. Of importance for benefit-risk assessment is that physiology is largely conserved between rodents and humans [29], although the necessity remains to validate observed effects in humans. An additional advantage of mice is the availability of a large number of strains that lack a specific functional gene (knock-out), either completely, or in a tissue specific or temporal manner. In addition, many transgenic strains exist that express a specific gene at higher level. Both types of strains allow for analysis of the functionality of the gene of interest. For both mice and rats a large number of experimental tools are available, including species-specific gene expression microarrays and many characterized antibodies. Rat and murine genomes are both sequenced [30,31] and are moderately (rat) to 
well (mouse) annotated, and many pathways have been investigated, described and are available in pathway analysis tools. Together, this makes these rodents the preferred species of choice for mechanistic studies. In case of a question that focuses on one specific physiological aspect, other species may have a preference over rodents. For example, ferrets display a carotenoid metabolism that is more similar to humans as compared with rodents. In rodents, beta-carotene, also known as provitamin A, is almost completely cleaved by beta-carotene 15,15 ' monooxygenase 1 (Bcmo1) in the intestine, while less enzyme activity is observed in the ferret and, like in humans, where intact beta-carotene is detected in plasma and peripheral tissues. We have successfully used ferrets to examine effects of beta-carotene in the lung [32], but our molecular analyses were frustrating because of a limited availability of annotated ferret sequences (at present, only 311 nucleotide sequences are available in the NCBI database, of which only 111 are annotated as gene (mRNA) which is only a tiny fraction compared with the 265,635 murine mRNA sequences). Rats clearly have the advantage of the larger amount of tissue that is available for analysis and the higher availability of physiological knowledge compared with the mouse. For this and other reasons, rats have become the species of choice in toxicological and physiological studies. Mice were, and still are, the favorite species of molecular geneticists, because knock-out models were earlier and easily available. Also, mice can be maintained at lower costs. Since many nutritional studies focus on disease prevention, nutritionists adopted the mouse as their model of choice following the medical field. As a consequence, mechanistic benefit-risk studies are being performed in rats as well as in mice, often depending on the background of the laboratory involved.

Many different mouse strains are being used. The inbred strain that is most widely used in nutrigenomics is $\mathrm{C} 57 \mathrm{BL} / 6 \mathrm{~J}$ (black $6 \mathrm{~J}$ ). These mice are obesity prone and are able to develop insulin resistance upon a high fat feeding. Its counterpart is the A/J strain, which is resistant to diet-induced obesity. It should be kept in mind that there are more differences between these strains, for example A/J mice are also sensitive to lung disease. Of course many other strains are being used, dependent on the phenotype that has the interest of the scientist. SV129 is generally encountered, because it provides the usual genetic background in which specific gene knock-outs are generated. Most nutritional toxicology and nutritional studies in rats are being performed using the outbred Wistar strain or the inbred Sprague Dawley strain, and to a lesser extent the Fisher or Brown Norway strains.

In nutritional studies using rodents, attention should be paid to the following two aspects. First, the use of purified diets for all animals, including controls. In many studies chow is used as control and high fat diets are either from different origin or are generated by adding fat. In both cases this will result in many differences apart from the amount of fat and carbohydrate. Chow-based diets should be strongly discouraged, since protein and lipid sources may differ from batch to batch and may result in 1,000fold concentration differences of specific nutrients [33], thus masking specific effects of 
micronutrients or bioactive food components. Therefore, despite higher costs, purified or semi-purified diets of precisely known composition should always be used and described in the materials and methods section. Second, it should be realized that many diets, even purified diets, may contain excessive amounts of certain vitamins and bioactive food components. Generally, vitamin E and beta-carotene are present at high levels, mainly to prevent lipid oxidation, which precludes proper analysis of these and related compounds and may strongly affect the results obtained with, for example, other antioxidant compounds. For example, the vitamin E content in AIN-93G based purified diets is $300 \mathrm{mg} / \mathrm{kg}$, providing mice on average a daily intake of $25 \mathrm{mg} / \mathrm{kg}$ body weight, while for humans the RDI is only $0.131 \mathrm{mg} / \mathrm{kg}$ body weight. It is therefore important to carefully appraise the diet when designing an experiment.

\section{Sensitivity and power}

As shown above, functional effects of micronutritional compounds are small and, although well controlled, in vivo experiments using rodents have variations close to the nutritional effects. In order to obtain as many statistically significantly regulated genes studies need to be sufficiently powered. To get some insight in the effect of the number of animals used ( $\mathrm{n}$ ) on the number of significantly regulated genes in a micronutritional microarray experiment, we determined the number of significantly regulated genes using a smaller number of animals from the data set described above. This was done by random assignment of the desired number of animals ( $n=4$ up to $n=11$ ) out of the group of 12 animals for both the intervention group supplemented with EGCg and the intervention group showing the largest effects (CR) as well as the control group. Since different results can be expected dependent on the specific animals that were randomly assigned to the group, analysis of the number of significantly regulated genes (with a more stringent level of $\mathrm{p}<0.01$ ) for a certain $\mathrm{n}$ was performed 1000 times with randomly drawn groups. As shown in Fig. 3A, the average number of significantly regulated genes of CR versus control group dropped from 12,179 (n=12) to just below 6,000 regulated genes for $n=4$. Examining the effect of the supplementation with $0.5 \%$ of the food bioactive compound EGCg, the average number of significantly regulated genes $(p<0.01)$ was much lower than upon CR and dropped from $490(n=11)$ to $258(n=4)$ regulated genes on average with decreasing group size (Fig. 3B). Most striking in these data sets is the large variation in the number of regulated genes when a small number of animals are used (Fig. 3B). This means, for example, that by using $n=4$ animals 45 regulated genes but also 1500 regulated genes could be identified upon EGCg supplementation, depending on randomly drawn animals in the respective groups. 
A)

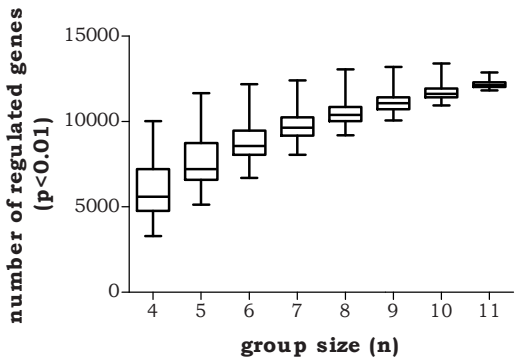

C)

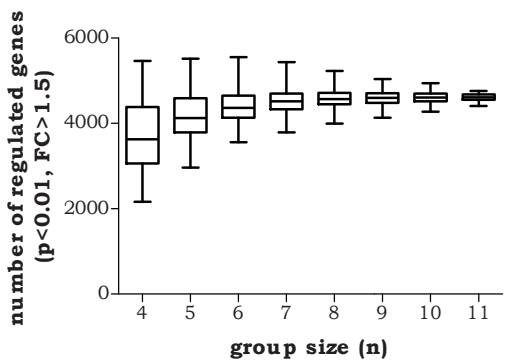

B)

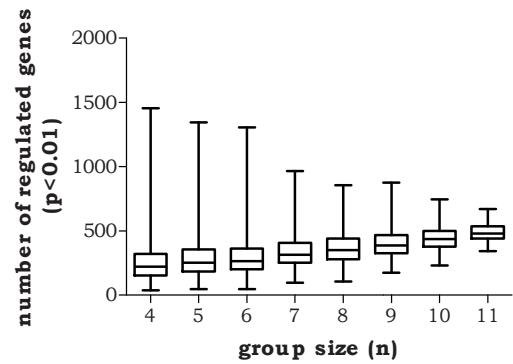

D)

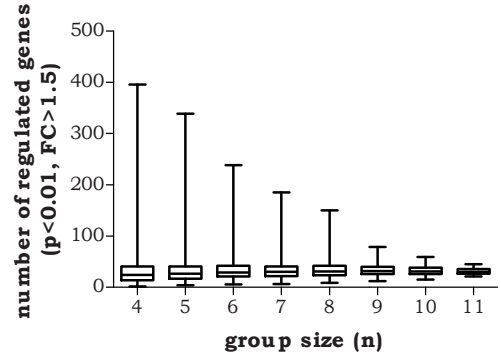

Figure 3: Average number of regulated genes during intervention for different group sizes. Number of regulated genes in a microarray gene expression experiment of mice fed the control diet (C) compared with mice fed the caloric restriction (CR) or EGCg (E) diet for different group sizes. To obtain a different group size, the group size number of animals was randomly drawn from a group of 12 animals on the control diet and compared with a similar randomly drawn intervention group. This was performed 1000 times per group size and the number of significant genes per randomly drawn group comparison was calculated and plotted in whiskers box plots (1-99\%). A gene was considered significantly different when $3 \mathrm{~A}, p<0.01$ for $\mathrm{C}$ versus $\mathrm{CR}$; 3B $p<0.01$ for $\mathrm{C}$ versus $\mathrm{E}$; $3 \mathrm{C}$, an absolute $\mathrm{FC}>1.5$ and $p<0.01$ for $\mathrm{C}$ versus $\mathrm{CR}$ and $3 \mathrm{D}$, an absolute $\mathrm{FC}>1.5$ and $p<0.01$ for $\mathrm{C}$ versus $\mathrm{E}$.

This large variation can result, on the one hand, in a large number of false positives, making it hard to identify real results, or on the other hand, this can result in an underestimation of the actual number of regulated genes, making it hard to perform pathway analysis to interpret the regulated genes in a systems biology manner. In benefitrisk assessment, often an absolute fold change is also used besides the p-value as a cut-off value. We therefore re-analyzed the treatments using an absolute fold change $>1.5$ in addition to a $\mathrm{p}<0.01$. As a result, the average number of regulated genes upon $\mathrm{CR}$ reaches a plateau at $\mathrm{n}>7$ (Fig. $3 \mathrm{C}$ ). The average number of regulated genes upon a dietary supplementation with $0.5 \%$ EGCg did hardly change for $n=4-11$ animals, but the degree of variation between each random taken sample dropped dramatically (Fig. 
3D). Finally, analyzing the $\mathrm{R}$ and $\mathrm{Q}$ supplemented groups using the same procedure showed results similar to those of the EGCg supplemented group (data not shown). Altogether these results imply that a high number of false positives or false negatives may be obtained when a low number of animals are being used. The number of animals that should be used depends not only on the criteria that are chosen, such as significance, fold change, minimal number of genes to perform pathway analysis, but also on the effect that is expected. While in the comparison of caloric restriction versus control no genes are outside the average number of differentially expressed genes plus or minus $25 \%$ when 9 or more animals (in fact: good quality arrays) are used, in the comparison of EGCg supplementation versus control still $60 \%$ of the genes are outside this range when $\mathrm{n}=9$ animals per group are sampled.

\section{Concluding remarks}

In conclusion, micronutrients and bioactive food components may have functional effects that only become apparent in later life, that is, after chronic differences in intake, or under conditions of stress, affecting fitness and wellbeing. While for intake between RDI and UL no overt differences in health can be expected, these differences may be very important for healthy aging and resistance to disease. They may have particular beneficial effects on the overarching processes; metabolic stress, oxidative stress, inflammatory stress and psychological stress [34]. To be able to establish functional health effects of micronutrients and bioactive food components, an overview of mechanistic effects is needed and transcriptome analysis is highly suited as a first step. When applied correctly, it has the power to detect the relatively small differences in gene expression that are induced by micronutrients and food bioactive compounds. It is however not a miracle technique. It takes experience and hard work to use it properly and to generate true and useful data. But when used sensibly, it is highly powerful and will generate data that will contribute to the establishment of functional effects and mechanisms of action of micronutrients and bioactive food components, a prerequisite for their application in health promoting functional foods.

\section{Acknowledgements}

We thank all group members for their efforts over the past years in development of experimental aspects of the application of transcriptome analysis in nutritional intervention studies. We are members of Mitofood and of NuGO. Y. vH. is funded by the graduate school VLAG. The authors have declared no conflict of interest. 


\section{References}

[1] A. Palou, C. Pico and J. Keijer From risk assessment to risk-benefit evaluation: the need for guidelines, concepts and mechanisms, Crit. Rev. Food Sci. Nutr. 49 (2009) 670-680.

[2] S. Chan, B. Gerson and S. Subramaniam The role of copper, molybdenum, selenium, and zinc in nutrition and health, Clin. Lab. Med. 18 (1998) 673-685.

[3] L.D. Koller and J.H. Exon The two faces of selenium-deficiency and toxicity--are similar in animals and man, Can. J. Vet. Res. 50 (1986) 297-306.

[4] V. Pagmantidis, C. Meplan, E.M. van Schothorst, J. Keijer and J.E. Hesketh Supplementation of healthy volunteers with nutritionally relevant amounts of selenium increases the expression of lymphocyte protein biosynthesis genes, Am. J. Clin. Nutr. 87 (2008) 181-189.

[5] A. Kipp, A. Banning, E.M. Van Schothorst, C. Meplan, L. Schomburg, C. Evelo, S. Coort, S. Gaj, J. Keijer, J. Hesketh and R. Brigelius Four selenoproteins, protein biosynthesis, and Wnt signalling are particularly sensitive to selenium intake in mice colon, Mol. Nutr. Food Res. in press (2009).

[6] A. de Reynies, D. Geromin, J.M. Cayuela, F. Petel, P. Dessen, F. Sigaux and D.S. Rickman Comparison of the latest commercial short and long oligonucleotide microarray technologies, BMC Genomics 7 (2006) 51.

[7] L. Pellis, N.L. Franssen-van Hal, J. Burema and J. Keijer The intraclass correlation coefficient applied for evaluation of data correction, labeling methods, and rectal biopsy sampling in DNA microarray experiments, Physiol. Genomics 16 (2003) 99-106.

[8] E.M. van Schothorst, V. Pagmantidis, V.C. de Boer, J. Hesketh and J. Keijer Assessment of reducing RNA input for Agilent oligo microarrays, Anal. Biochem. 363 (2007) 315-317.

[9] J. Vandesompele, K. De Preter, F. Pattyn, B. Poppe, N. Van Roy, A. De Paepe and F. Speleman Accurate normalization of real-time quantitative RT-PCR data by geometric averaging of multiple internal control genes, Genome Biol. 3 (2002) RESEARCH0034.

[10] S.A. Bustin, V. Benes, J.A. Garson, J. Hellemans, J. Huggett, M. Kubista, R. Mueller, T. Nolan, M.W. Pfaffl, G.L. Shipley, J. Vandesompele and C.T. Wittwer The MIQE guidelines: minimum information for publication of quantitative real-time PCR experiments, Clin. Chem. 55 (2009) 611-622.

[11] S.T. Mathews, E.P. Plaisance and T. Kim Imaging systems for westerns: chemiluminescence vs. infrared detection, Methods Mol. Biol. 536 (2009) 499-513.

[12] J.F. Djoba Siawaya, T. Roberts, C. Babb, G. Black, H.J. Golakai, K. Stanley, N.B. Bapela, E. Hoal, S. Parida, P. van Helden and G. Walzl An evaluation of commercial fluorescent bead-based luminex cytokine assays, PLoS One 3 (2008) e2535.

[13] C.A. Sullivan and G.G. Chung Biomarker validation: in situ analysis of protein expression using semiquantitative immunohistochemistry-based techniques, Clin. Colorectal Cancer 7 (2008) 172-177.

[14] T. Bonk and A. Humeny MALDI-TOF-MS analysis of protein and DNA, Neurosci. 7 (2001) 6-12.

[15] D. Zichi, B. Eaton, B. Singer and L. Gold Proteomics and diagnostics: Let's Get Specific, again, Curr. Opin. Chem. Biol. 12 (2008) 78-85.

[16] P. Conrotto and S. Souchelnytskyi Proteomic approaches in biological and medical sciences: principles and applications, Exp. Oncol. 30 (2008) 171-180.

[17] D. Patsouris, J.K. Reddy, M. Muller and S. Kersten Peroxisome proliferator-activated receptor alpha mediates the effects of high-fat diet on hepatic gene expression, Endocrinology 147 (2006) 1508-1516.

[18] Y. Hochberg and Y. Benjamini More powerful procedures for multiple significance testing, Stat. Med. 9 (1990) 811-818.

[19] W. Rodenburg, I.M. Bovee-Oudenhoven, E. Kramer, R. van der Meer and J. Keijer Gene expression response of the rat small intestine following oral Salmonella infection, Physiol Genomics 30 (2007) 123-133.

[20] R. Mansson, P. Tsapogas, M. Akerlund, A. Lagergren, R. Gisler and M. Sigvardsson Pearson correlation analysis of microarray data allows for the identification of genetic targets for early B-cell factor, J. Biol. Chem. 279 (2004) 17905-17913.

[21] W. Rodenburg, A.G. Heidema, J.M. Boer, I.M. Bovee-Oudenhoven, E.J. Feskens, E.C. Mariman and J. Keijer A framework to identify physiological responses in microarray-based gene expression studies: selection and interpretation of biologically relevant genes, Physiol Genomics 33 (2008) 78-90.

[22] T. Werner Bioinformatics applications for pathway analysis of microarray data, Curr. Opin. Biotech. 19 (2008) 50-54.

[23] J.S. Verducci, V.F. Melfi, S. Lin, Z. Wang, S. Roy and C.K. Sen Microarray analysis of gene expression: considerations in data mining and statistical treatment, Physiol. Genomics 25 (2006) 355-363.

[24] M.A. Nauck Unraveling the science of incretin biology, Am. J. Med. 122 (2009) S3-S10.

[25] M.C. Walsh, L. Brennan, E. Pujos-Guillot, J.L. Sebedio, A. Scalbert, A. Fagan, D.G. Higgins and M.J. Gibney Influence of acute phytochemical intake on human urinary metabolomic profiles, Am. J. Clin. Nutr. 86 (2007) 1687-1693. 
[26] L. Afman and M. Muller Nutrigenomics: from molecular nutrition to prevention of disease, J. Am. Diet. Assoc. 106 (2006) 569-576.

[27] J.J. Eady, G.M. Wortley, Y.M. Wormstone, J.C. Hughes, S.B. Astley, R.J. Foxall, J.F. Doleman and R.M. Elliott Variation in gene expression profiles of peripheral blood mononuclear cells from healthy volunteers, Physiol. Genomics 22 (2005) 402-411.

[28] V.C. de Boer, M.C. de Goffau, I.C. Arts, P.C. Hollman and J. Keijer SIRT1 stimulation by polyphenols is affected by their stability and metabolism, Mech. Ageing Dev. 127 (2006) 618-627.

[29] C. Moreno, J. Lazar, H.J. Jacob and A.E. Kwitek Comparative genomics for detecting human disease genes, Adv. Genet. 60 (2008) 655-697.

[30] R.H. Waterston, K. Lindblad-Toh, E. Birney, J. Rogers, J.F. Abril, et al Initial sequencing and comparative analysis of the mouse genome, Nature 420 (2002) 520-562.

[31] R.A. Gibbs, G.M. Weinstock, M.L. Metzker, D.M. Muzny, E.J. Sodergren, et al Genome sequence of the Brown Norway rat yields insights into mammalian evolution, Nature 428 (2004) 493-521.

[32] Y.G. van Helden, J. Keijer, S.G. Heil, C. Pico, A. Palou, P. Oliver, A. Munnia, J.J. Briede, M. Peluso, N.F. Hal, F.J. van Schooten and R.W. Godschalk Beta-carotene affects oxidative stress related DNA damage in lung epithelial cells and in ferret lung, Carcinogenesis (In press) (2009).

[33] H. Wang, S. Tranguch, H. Xie, G. Hanley, S.K. Das and S.K. Dey Variation in commercial rodent diets induces disparate molecular and physiological changes in the mouse uterus, Proc. Natl. Acad. Sci. U.S.A. 102 (2005) 9960-9965.

[34] B. van Ommen, J. Keijer, S.G. Heil and J. Kaput Challenging homeostasis to define biomarkers for nutrition related health, Mol. Nutr. Food Res. 53 (2009) 795-804.

[35] R. Elliott, C. Pico, Y. Dommels, I. Wybranska, J. Hesketh and J. Keijer Nutrigenomic approaches for benefit-risk analysis of foods and food components: defining markers of health, Br. J. Nutr. 98 (2007) 10951100 . 
Beta-carotene $15,15^{\prime}$-mono-oxygenase 1 knockout $\left(B c m o 1^{1 /}\right)$ mice accumulate beta carotene (BC) similarly to humans, whereas wildtype $\left(\mathrm{Bcmo}^{+/+}\right)$mice efficiently cleave BC. Bcmo $1 \%$ mice are therefore suitable to investigate $\mathrm{BC}$ induced alterations in gene expression in lung, assessed by microarray analysis. Bcmo 1\% mice receiving control diet had increased expression of inflammatory genes as compared to BC supplemented $\mathrm{Bcmo} 1^{-}$mice and $\mathrm{Bcmo1}^{+/+}$mice that received either control or BC supplemented diets. Differential gene expression in Bcmo 1\% mice was confirmed by real-time quantitative PCR. Histochemical analysis indeed showed an increase in inflammatory cells in lungs of control $\mathrm{Bcmo}^{-\%}$ mice. Supported by metabolite and gene expression data, we hypothesize that the increased inflammatory response is due to an altered BC metabolism, resulting in an increased vitamin A requirement in Bcmo $1 /$ mice. This suggests that effects of $\mathrm{BC}$ may depend on inter-individual variations in BC metabolizing enzymes, such as the frequently occurring human polymorphisms in BCMO1. 


\section{Knockout of the Bcmol gene results in an inflammatory response in fe- male lung, which is suppressed by dietary beta-carotene}

Cellular and Molecular Life Sciences

Yvonne G.J. van Helden, Sandra. G. Heil, Frederik J. van Schooten, Evelien Kramer, Susanne Hessel, Jaume Amengual, Joan Ribot, Katja Teerds, Adrian Wyss, Georg Lietz, M. Luisa Bonet, Johannes von Lintig, Roger W.L. Godschalk, Jaap Keijer 


\section{Introduction}

Beta-carotene $(\mathrm{BC})$ is an orange colored dietary compound, present in various fruits and vegetables. $\mathrm{BC}$ is regarded as an active antioxidant and is thus able to diminish radicalinduced macromolecular damage [1]. Because of this, a high intake of $\mathrm{BC}$ might be expected to be beneficial and indeed, epidemiological studies have shown that a high dietary intake of $\mathrm{BC}$ is associated with a lower risk for cardiovascular diseases and several types of cancer, including lung cancer $[2,3]$. Moreover, BC can be metabolized into vitamin A, thereby preventing vitamin A deficiency. Vitamin A deficiency can result in a wide variety of clinical manifestations, ranging from night blindness, growth abnormalities, an increased susceptibility for infections and an increased mortality due to infectious diseases $[4,5]$. In Western society, smokers are at risk for vitamin A deficiency in the lung [6,7]. Since dietary BC intake is able to prevent vitamin A deficiency and is associated with a decreased lung cancer risk, it was hypothesized that BC supplementation in smokers would be beneficial and would decrease lung cancer incidence. In contrast to this expectation, BC supplementation alone (ATBC study, [8]) or in combination with vitamin A (CARET study, [9]) resulted in an increased lung cancer risk in smokers and asbestos exposed subjects $[8,9]$. An increased lung cancer risk was predominantly observed in smokers and asbestos exposed subjects and not in former or non-smokers [10,11]. Moreover, six years follow up of the CARET study revealed that females were more at risk for the development of lung cancer upon BC supplementation compared to male volunteers [12]. The underlying mechanisms are not precisely known, although several mechanisms have been suggested. Possibly, BC or BC metabolites can become pro-oxidants at high concentrations [13] or in combination with oxidative stress [14]. There is also evidence that BC supplementation can result in a changed regulation of the transcription factor retinoic acid receptor (RAR) [15]. However, the exact mechanism behind the possible adverse effect of a high $\mathrm{BC}$ intake is still poorly understood.

An important drawback in $\mathrm{BC}$ research is $\mathrm{BC}$ metabolism. First of all, $\mathrm{BC}$ metabolism in humans is highly variable $[16,17]$ and this variability can partly be attributed to differences in enzymatic activity of the beta-carotene 15,15'-monooxygenase 1 enzyme (BCMO1). The 267A $>\mathrm{T}$ and $379 \mathrm{C}>\mathrm{T}$ polymorphisms in the $\mathrm{BCMO1}$ gene are common with variant allele frequencies of $42 \%$ and $24 \%$, respectively in the Caucasian population of the United Kingdom, and result in increased BC and decreased BC metabolite concentrations in plasma $[18,19]$. Secondly, inter-species differences especially in Bcmo1 activity are the cause of the great differences in BC metabolizing activity between humans and regularly used laboratory rodents. Rodents have a more active Bcmo1 enzyme variant than man [20], and therefore BC supplementation to rodents results in a virtually complete conversion of $\mathrm{BC}$ and consequently in a high concentration of $\mathrm{BC}$ metabolites. Previously, a $\mathrm{Bcmo1}$ knock out (Bcmo1/-) mouse was estab- 
lished and characterized, and $\mathrm{BC}$ supplementation to these $\mathrm{Bcmo1} \%$ mice resulted in increased $\mathrm{BC}$ plasma concentrations and $\mathrm{BC}$ accumulation in mouse lung tissue [21]. This $\mathrm{Bcmo1 \%}$ mouse is therefore a unique model to investigate effects of BC itself.

The aim of our study was to investigate $\mathrm{BC}$ induced gene expression differences. Therefore, female $\mathrm{Bcmo1}^{+/+}$and $\mathrm{Bcmo1} \%$ mice, unable to symmetrically cleave $\mathrm{BC}$, were fed for 14 weeks with a vitamin A sufficient diet (1500 IU $/ \mathrm{kg}$ ) without (control) or with supplementation of $\mathrm{BC}(\mathrm{BC}, 150 \mathrm{mg} / \mathrm{kg}$ diet) and microarray analysis was performed (mouse whole genome arrays) on lung copy RNA (cRNA). We specifically chose female animals, because effects of $\mathrm{BC}$ were more pronounced and longer lasting in female volunteers of the CARET study [12]. Moreover, wildtype $\left(\mathrm{Bcmo1}^{+/+}\right)$mice were analyzed to distinguish $\mathrm{BC}$ induced effects from effects due to the knockout of the Bcmo1 gene.

\section{Materials \& Methods}

\section{Animals and treatment}

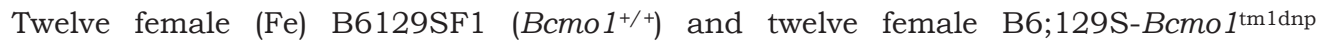
$\left(\mathrm{Bcmo1}^{-/}\right)$mice, previously described by Hessel et al. [21] were used for the experiment. The mouse experiment was conducted in accordance with the German animal protection laws by the guidelines of the local veterinary authorities. During the breeding and weaning periods of the mice, mothers were maintained on KLIBA 3430 chow containing 14000 IU vitamin A/kg diet (Provima Kliba AG, Kaiseraugst, Switzerland). Five-weekold female $\mathrm{Bcmo1}^{+/+}$and $\mathrm{Bcmo1} /$ - mice were caged in groups containing 2 to 4 siblings per group and were maintained under environmentally controlled conditions (temperature $24^{\circ} \mathrm{C}, 12 \mathrm{~h} / 12 \mathrm{~h}$ light/dark cycle). Mice had ad libitum access to feed and water. Basic feed consisted of the palletized diet D12450B (Research Diets Inc, USA) with a fat content of $10 \%$. The diet was modified to contain 1500 IU vitamin A per $\mathrm{kg}$ of diet, which is a vitamin A sufficient diet, and the control diet was supplemented with water soluble vehicle beadlets (DSM Nutritional Products Ltd., Basel, Switzerland) containing DL-alpha-tocopherol and ascorbyl palmitate as stabilizers, as well as carriers such as gelatine, corn oil sucrose and starch. The BC diet was supplemented with identical water soluble beadlets containing 10\% BC (DSM Nutritional Products Ltd., Basel, Switzerland) to generate $150 \mathrm{mg} \mathrm{BC} / \mathrm{kg}$ diet. Beadlets were added by the manufacturer before low temperature pelletting. Feed pellets were color marked and stored at $4^{\circ} \mathrm{C}$ in the dark.

After 14 weeks of dietary intervention, 6 female $\mathrm{Bcmo1}^{+/+}$on the control diet $\left(\mathrm{Bcmo1}^{+/+}\right.$ $\mathrm{Co})$, 6 female $\mathrm{Bcmo1}^{+/+}$on the $\mathrm{BC} \operatorname{diet}\left(\mathrm{Bcmo1}^{+/+} \mathrm{BC}\right), 3$ female $\mathrm{Bcmo1} 1^{-/}$on the control diet $(\mathrm{Bcmo1} / \mathrm{-CO})$ and 3 female $\mathrm{Bcmo1 \%}$ on the $\mathrm{BC}$ diet $(\mathrm{Bcmo1} \% \mathrm{BC})$ were randomly sacrificed during 3 subsequent mornings. Blood was collected from the vena cava after 
isoflurane and ketamin anesthesia. Blood was coagulated for at least 20 minutes at room temperature, cooled to $4^{\circ} \mathrm{C}$ and centrifuged. Lung tissue was removed, rinsed in phosphate buffered saline (PBS) and snap frozen in liquid nitrogen. The lung tissues were stored at $-80^{\circ} \mathrm{C}$. Due to an insufficient number of female $\mathrm{Bcmo1} \%$ mice in the original breeding pool, female $\mathrm{Bcmo1} \%$ mice were used that were born 2 weeks later from an identical experiment, treated identically with 3 mice on the control diet and 3 mice on the $\mathrm{BC}$ diet to generate $\mathrm{n}=6$ per group, and sacrificed 2 weeks after the first group of mice.

\section{HPLC Separation of Retinoids and Carotenoids}

Retinoids and carotenoids were extracted from lung tissues and plasma under dim red safety light $(\lambda \geq 600 \mathrm{~nm})$. Briefly, tissues $(20-40 \mathrm{mg})$ were homogenized in $200 \mu \mathrm{l}$ of $2 \mathrm{M}$ hydroxylamine ( $\mathrm{pH}$ 6.8) and $200 \mu 1$ of methanol with a glass homogenizer. For determination of $\mathrm{BC}$ and vitamin A in serum, $180 \mu \mathrm{l}$ serum was added to $200 \mu \mathrm{l}$ methanol. Then $400 \mu \mathrm{l}$ acetone was added either to these plasma or tissue extracts. Extraction of carotenoids and retinoids was performed with petroleum ether. The extraction was repeated three times, and the collected organic phases were dried under nitrogen and redissolved in HPLC solvent (n-hexane/ethanol, 99.5:0.5). HPLC separation of carotenoids and retinoids and quantification of peak integrals was performed as previously described [22]. Solvents for HPLC and extraction were purchased in HPLC grade from Merck (Darmstadt, Germany).

\section{Serum analysis of inflammation markers}

Serum levels of the inflammatory cytokines; tumor necrosis factor alpha (Tnfa), interleukin-6 (Il-6) and monocyte chemoattractant protein-1 (Mcp-1) were measured using the mouse serum adipokine Lincoplex Kit (Linco Research, Nuclilab, Ede, The Netherlands). Sera were diluted 4x in HPE buffer (Sanquin, Amsterdam, The Netherlands) and measured according to the manufacturer's protocol and as described before [23]. Cytokine levels were measured using the Bio-Plex system (Bio-Rad, Veenendaal, The Netherlands) and using Bio-Plex software (Bio-Rad). All individual samples were analyzed in duplicate and averaged. The detection limit of Mcp- 1 was $60 \mathrm{pg} / \mathrm{ml}$, of Il- 6 was $5 \mathrm{pg} / \mathrm{ml}$ and of Tnfa was $0.3 \mathrm{pg} / \mathrm{ml}$.

\section{Histology of the lung}

Small pieces of upper right lung tissue of 2 randomly selected animals per group were fixed by immersion in $0.1 \mathrm{M}$ sodium phosphate buffer containing $4 \%$ paraformaldehyde (pH 7.4) overnight at $4^{\circ} \mathrm{C}$, thereafter dehydrated, cleared and then paraffin-embedded. Three $\mu \mathrm{m}$-thick sections were cut and stained with Periodic Acid Schiff (PAS) and Mayer's hematoxylin for histological analysis. 


\section{RNA Isolation}

Left lung lobes were homogenized in liquid nitrogen using a cooled mortar and pestle. Total RNA was isolated using TRIzol reagent (Invitrogen, Breda, The Netherlands) followed by purification using RNeasy columns (Qiagen, Venlo, The Netherlands) using the instructions of the manufacturer. RNA concentration and purity were measured using the Nanodrop system (IsoGen Life Science, Maarsen, The Netherlands). Approximately $30 \mu \mathrm{g}$ of total RNA was isolated with A260/A280 ratios above 2 and A260/A230 ratios above 1.9 for all samples, indicating good RNA purity. RNA degradation was checked on the Experion (Bio-Rad, Veenendaal, The Netherlands) using Experion StdSense chips (Bio-Rad). Two samples did not meet RNA quality $\left(\mathrm{Bcmo1}^{1^{++}}\right.$mice, one on $\mathrm{BC}$ diet and one on control diet) and were omitted from the experiment.

\section{Microarray hybridization procedure}

The 4x44k Agilent whole mouse genome microarrays (G4122F, Agilent Technologies, Inc. Santa Clara, CA) were used. Preparation of the sample and the microarray hybridization were carried out according to the manufacturer's protocol with a few exceptions as described previously [23,24]. In brief, cDNA was synthesized from $1 \mu \mathrm{g}$ lung RNA using the Agilent Low RNA Input Fluorescent Linear Amplification Kit for each animal without addition of spikes. Thereafter samples were split in 2 equal amounts, to synthesize Cyanine 3-CTP (Cy3) and Cyanine 5-CTP (Cy5) labeled cRNA using half the amounts per dye as indicated by the manufacturer (Agilent Technologies). Labeled cRNA was purified using RNeasy columns (Qiagen). Yield, A260/A280 ratio and Cy3 or Cy5 activity were examined for every sample using the nanodrop. All samples met the criteria of a cRNA yield higher than $825 \mathrm{ng}$ and a specific activity of at least 8.0 pmol Cy3 or Cy5. 1200 ng of every Cy3 labeled cRNA sample was pooled and used as a common reference pool. Individual 825 ng Cy5-labeled cRNA and 825 ng pooled Cy3-labeled cRNA were fragmented in $1 \mathrm{x}$ fragmentation and $1 \mathrm{x}$ blocking agent (Agilent Technologies) at $60^{\circ} \mathrm{C}$ for 30 minutes and thereafter mixed with GEx Hybridization Buffer HI-RPM (Agilent Technologies) and hybridized in a $1: 1$ ratio at $65^{\circ} \mathrm{C}$ for 17 hours in an Agilent Microarray hybridization Chamber rotating at $4 \mathrm{rpm}$. After hybridization, slides were washed according to the wash protocol with Stabilization and Drying solution (Agilent Technologies). Arrays were scanned with an Agilent scanner with $10 \%$ and $100 \%$ laser power intensities (Agilent Technologies).

\section{Data analyses of microarray results}

Signal intensities for each spot were quantified using Feature Extraction 9.1 (Agilent Technologies). Median density values and background values of each spot were extracted for both the experimental samples (Cy5) and the reference samples (Cy3). 
Quality control for every microarray was performed visually, by using Quality control graphs from Feature extraction and $\mathrm{M}-\mathrm{A}$ plots and boxplots which were made using limmaGUI in R (Bioconductor) [25]. Data were imported into GeneMaths XT 2.0 (Applied Maths, Sint-Martens-Latem, Belgium). Spots with a $\mathrm{Cy} 5$ and $\mathrm{Cy} 3$ signal twice above background were selected and log transformed. The Cy5 signal was normalized against the Cy3 intensity as described before [26]. Supervised principal component analysis and heat mapping were performed using GeneMaths XT. Volcano plots were made using Graphpad Prism 5.0. Pathway analysis was performed using MetaCore (GeneGo), GO overrepresentation analysis (ErmineJ) [27] and literature mining.

\section{Analysis of mRNA expression by real-time quantitative PCR (Q-PCR)}

Real-time quantitative PCR (Q-PCR) was performed on individual samples ( $\mathrm{n}=6$ per group) as described previously [28] to validate the microarray data. One $\mu \mathrm{g}$ of RNA of all individual samples was used for cDNA synthesis using the iScript cDNA synthesis kit (Bio-Rad). Q-PCR reactions were performed with iQ SYBR Green Supermix (Bio-Rad) using the MyIQ single-color real-time PCR detection system (Bio-Rad). Each reaction (25 $\mu 1)$ contained $12.5 \mu \mathrm{l}$ iQ SYBR green supermix, $1 \mu$ forward primer $(10 \mu \mathrm{M}), 1 \mu 1$ reverse primer $(10 \mu \mathrm{M}), 8.5 \mu \mathrm{l}$ RNase-free water and $2 \mu \mathrm{l}$ diluted cDNA. The following cycles were performed: $1 \times 3 \mathrm{~min}$ at $95^{\circ} \mathrm{C}, 40$ amplification cycles $\left(40 \times 15 \mathrm{~s} 95^{\circ} \mathrm{C}, 45 \mathrm{~s}\right.$ optimal annealing temperature, which was followed by $1 \times 1 \min 95^{\circ} \mathrm{C}$ and $1 \times 1 \min 65^{\circ} \mathrm{C}$ and a melting curve was prepared $\left(60 \times 10 \mathrm{~s} 65^{\circ} \mathrm{C}\right.$ with an increase of $0.5^{\circ} \mathrm{C}$ per $\left.10 \mathrm{~s}\right)$. A negative control without cDNA template and a negative control without reverse transcriptase (-RT) were taken along with every assay. Data were normalized against the reference genes syntaxin $5 a(S t x 5 a)$ and ring finger protein 130 (Rnf130) which were chosen based on stable gene expression levels between the mice on the microarray. Primers were designed using Beacon designer 7.00 (Premier Biosoft International, Palo Alto, CA). The following primer sequences were used; reference gene Stx5a forward 5'TTAAAGAACAGGAGGAAACGATTCAGAG-3' and reverse 5'CAGGCAAGGAAGACCACAAAGATG-3' (PCR at $60.0^{\circ} \mathrm{C}$ ), reference gene Rnf130 forward 5'ACAGGAACCAGCGTCGTCTTG-3' and reverse 5'ACCCGAACAACATCATTCTGCTTATAG-3' (PCR at $\left.60.0^{\circ} \mathrm{C}\right)$, interferon, alpha-inducible protein 27 (Ifi27) forward 5'-GCTGCTACCAGGAGGACTCAAC-3' and reverse 5'TGCTGATTGGAGTGTGGCTACC-3' (PCR at 59.2 ${ }^{\circ} \mathrm{C}$ ), tripartite motif protein 12 (Trim12) forward 5'-GGAGAACATCATAGAACGGAGTCATAC-3' and reverse 5'- GGAAGACCCCTAGTAGCGATGAG-3' (PCR at $58.3^{\circ} \mathrm{C}$ ), ISG15 ubiquitin-like modifier (Isg15) forward 5'-TGCAGCAATGGCCTGGGAC-3' and reverse 5'-GCGCTGCTGGAAAGCCG-3' (PCR at $58.3^{\circ} \mathrm{C}$ ), interferon-induced protein 44 (Ifi44) forward 5'- AGACTTGATAAAACATGGCATTCTGC-3' and reverse 5'- CATGGAATGCCTCCAGCTTGG-3' (PCR at $58.3^{\circ} \mathrm{C}$ ). A standard curve for all genes, including reference genes, was generated using serial dilutions of a pooled sample (cDNA from all reactions of the groups analyzed). 
mRNA levels were determined using the $\triangle \triangle \mathrm{CT}$ method (IQ5 software version 2.0 (BioRad). Analysis of individual samples was performed in duplicate.

\section{Statistical analysis}

Fold changes for both microarray gene expression and Q-PCR gene expression were calculated using mean log signal intensities. P-values for differential expressions were calculated between two groups using two tailed Student's $t$-test statistics on log intensity values. Changes were considered statistically different at $p<0.05$. Effects of diet and genotype on concentrations of $\mathrm{BC}$, retinol and retinyl esters in lung and serum were analyzed using 2x2 factorial univariate ANOVA (SPSS version 15.0) and considered statistically significant when $\mathrm{p}<0.05$. Correlations and differences in correlations between $\mathrm{BC}$ concentration and $\mathrm{BC}$ metabolite concentrations in lung were tested (SPSS) and considered significant when $\mathrm{p}<0.05$.

\section{Results}

\section{BC supplementation results in an increased BC concentration in lungs, particularly in $\mathrm{Bcmo} 1 \%$ mice}

$\mathrm{BC}$ supplementation resulted in elevated $\mathrm{BC}$ levels in serum and lung tissue of all mice $(\mathrm{p}<0.05)$, but to a higher extent in $\mathrm{Bcmo1}^{-/}$mice (Fig. $1 \mathrm{~A}$ and $\left.1 \mathrm{~B}, \mathrm{p}<0.05\right)$. Retinol serum levels were not significantly different between the groups (Fig. 1C). Retinol and retinyl ester concentrations in lung were increased in all mice upon BC supplementation $(\mathrm{p}<0.05)$, and as expected, to a higher extend in $\mathrm{Bcmo1}^{+/+}$(Fig. 1D and 1E).

\section{BC supplementation to $\mathrm{Bcmo1} \%$ mice restores differential gene expression to levels as observed in $B c m o 1^{+/+}$mice}

To investigate the effects of $\mathrm{BC}$ on lung gene expression, microarray analysis was performed on cRNA of all mice. Of the 43,379 spots (number of spots on array minus control spots), 31,128 spots had a signal twice above background and were regarded as positive spots and included in the analysis. Supervised principal component analysis (SPCA) showed that animals could be discriminated according to their Bcmo1 genotype and diet (Fig. 2A). BC supplementation resulted in 651 and 1522 differentially expressed genes $(\mathrm{p}<0.05)$ in $\mathrm{Bcmo1}^{+/+}$and $\mathrm{Bcmo1}^{-/}$mice respectively. Of these $\mathrm{BC}$ regulated genes, 32 genes were commonly regulated in $\mathrm{Bcmo1}^{+/+}$and $\mathrm{Bcmo1 \%}$ mice and thus regulated independent of genotype. 
A)

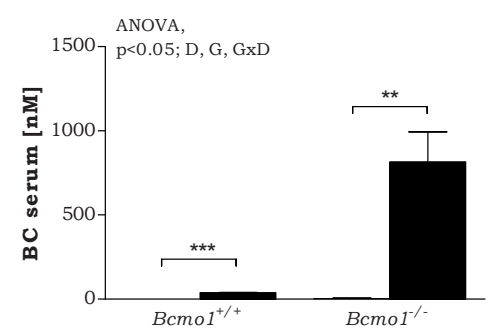

C)

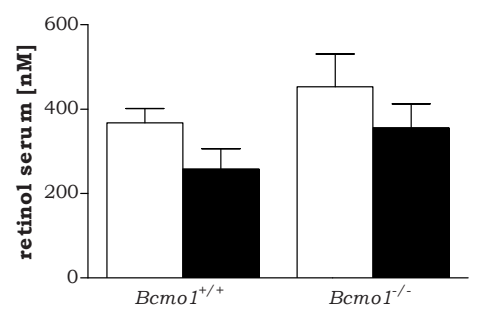

E)

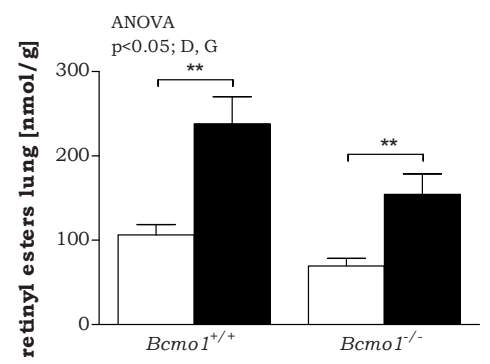

B)

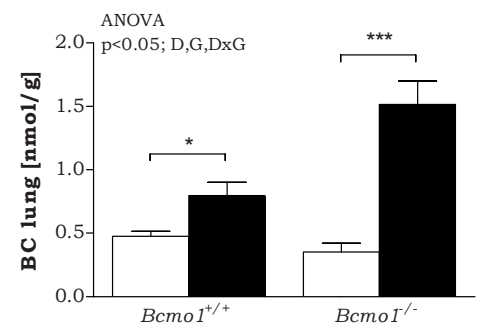

D)

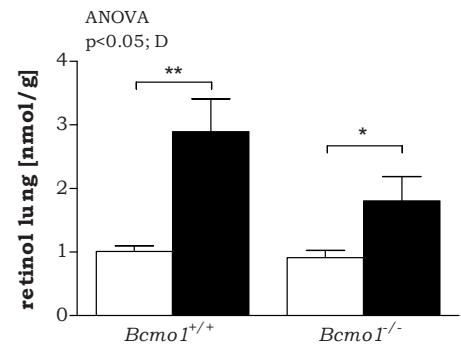

Figure 1: $\mathrm{BC}$ and $\mathrm{BC}$ metabolite concentration in lungs of female Bcmo1/- and $\mathrm{Bcmo1}{ }^{+/+}$mice. Betacarotene $(B C)(A, B)$ and retinol $(C, D)$ concentrations in serum and in lung tissue respectively, and retinyl ester concentrations in lung tissue (E) of female $\mathrm{Bcmo1}^{+/+}$mice and $\mathrm{Bcmo} 1^{1-}$ mice fed a control diet (white bars) or a BC supplemented diet (black bars). Data are expressed as mean \pm SEM, significance was tested using ANOVA and considered significant at $\mathrm{p}<0.05$. D, effect of diet; G, effect of genotype; DxG, interaction between diet and genotype. Student's $t$-test was performed between the BC and control diet and considered significant at $\mathrm{p}<0.05$. ${ }^{*} \mathrm{p}<0.05,{ }^{* *} \mathrm{p}<0.01$ and ${ }^{* * *} \mathrm{p}<0.001$. 
We were interested in effects resulting from $\mathrm{BC}$ accumulation in lung tissue. Since BC levels in lung were higher in $\mathrm{Bcmo1} /-$ mice than in $\mathrm{Bcmo1}^{+/+}$mice and, correspondingly, more genes were regulated in this group after $\mathrm{BC}$ supplementation, we further focused on effects of $\mathrm{BC}$ in $\mathrm{Bcmo1} \%$ mice. Of the $1522 \mathrm{BC}$ regulated genes in Bcmo1\%-mice, 121 genes had an absolute fold change $(\mathrm{FC})>1.5$ fold, with mainly down regulated genes (Fig. 2B).

A)

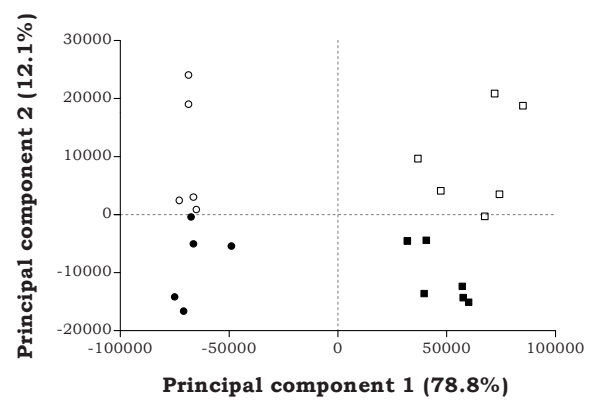

B)

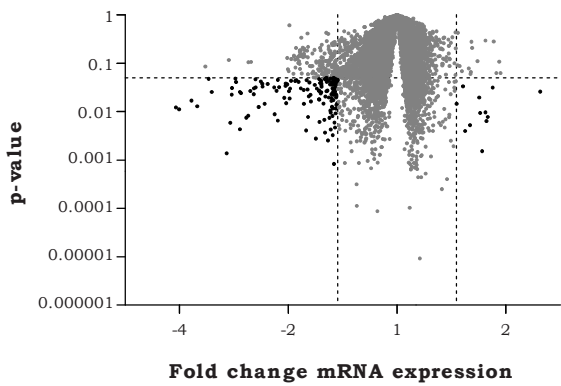

Figure 2: (A) Supervised principal component analysis (SPCA) of the four groups; Bcmo $1^{+/+}$control mice (open circles), $\mathrm{Bcmo} 1^{+/+} \mathrm{BC}$ mice (closed circles), Bcmo1\% control mice (open squares) and $\mathrm{Bcmo} 1^{-}$ /- $\mathrm{BC}$ mice (closed squares). Bcmo $1^{+/+}$mice are separated from $\mathrm{Bcmo1} /$ mice (x-axis) and mice on control diet are separated from mice on the BC diet (y-axis). (B) Volcano plot of the effect of BC supplementation on gene expression in $\mathrm{Bcmol}^{\%}$ mice, showing the fold change on the $\mathrm{x}$-axis and the corresponding Student's $t$-test $\mathrm{p}$-value on the y-axis. In black are all the genes with a p-value $<0.05$ and an absolute fold change $>1.5$. Trim 12 with a FC of 8.75 and $\mathrm{p}<0.05$ is outside the limits of this Figure.

We continued with these $121 \mathrm{BC}$ regulated genes and investigated whether these genes were regulated due to an effect of $\mathrm{BC}$ treatment in $\mathrm{Bcmo} 1 \%$ mice, or due to an effect in the $\mathrm{Bcmo1 \%}$ control mice. Therefore, we evaluated gene expression of these 121 genes in all four groups; $\mathrm{BCmo1}^{+/+}$control mice, $\mathrm{Bcmo1}^{+/+}$mice with supplementation of $\mathrm{BC}$, Bcmo1\% control mice and $\mathrm{Bcmo1 \%}$ mice with $\mathrm{BC}$ supplementation. The absolute expression of each of the 121 genes was set on 1 for the $\mathrm{Bcmo1}^{+/+}$control mice. Cluster analysis of the expression of these genes showed that the $\mathrm{Bcmo1 \%}$ control mice differed most in gene expression compared to the other three groups (Fig. 3A). The expression of these genes was compared to the expression in the $\mathrm{Bcmo1}^{+/+}$control mice and revealed that the average absolute fold-change was significantly different in the $\mathrm{Bcmo} 1 \%$ control mice compared to the $B \mathrm{cmol}^{+/+}$control mice $(\mathrm{p}<0.001)$, while there was no difference between the average expression of these 121 genes between the $\mathrm{BC}$ supplemented $\mathrm{Bcmo1}^{-/}$mice or $\mathrm{Bcmol}^{+/+}$mice and the $\mathrm{Bcmo1}^{+/+}$control mice (Fig. 3B). These data indicate that there was mainly an effect of the knockout of the Bcmo1 gene in the mice fed 
A)
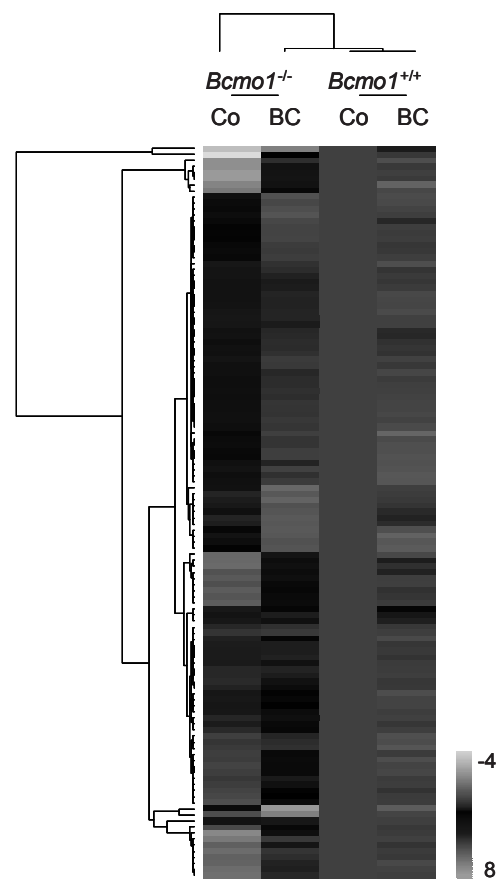

B)

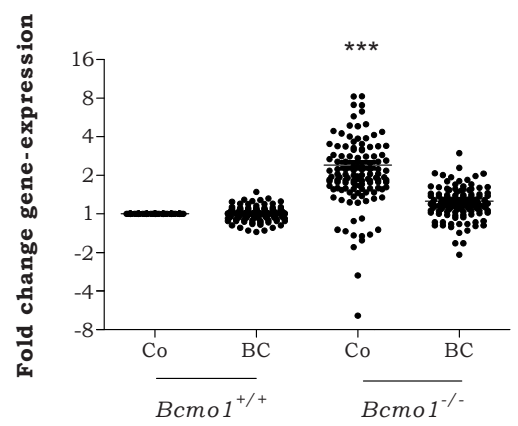

Figure 3: (A) Hierarchical clustering of all experimental groups based on the expression of all genes regulated by $\mathrm{BC}$ in the $\mathrm{Bcmo1} /-$ mice with an absolute $\mathrm{FC}>1.5$ and $\mathrm{p}<0.05$. The expression of every gene is represented relative to the expression in $B c m o 1^{+/+}$control mice, which was set to 1.0. Genes and groups were clustered using Euclidean distance (linear scaled) UPGMA. (B) Graph representing the expression level of all genes regulated by $\mathrm{BC}$ in the Bcmo1\% mice with an absolute $\mathrm{FC}>1.5$ and $\mathrm{p}<0.05$, in all groups. The expression of every genes is represented relative to the expression in $\mathrm{Bcmo1}^{+/+}$control mice, which was set to 1.0. The absolute expression was significantly higher $(\mathrm{p}<0.001)$ in $\mathrm{Bcmo1} /$ - control mice compared to mice in the other groups. There was no significant difference in expression level between the other groups. ${ }^{* * *} \mathrm{p}<0.001$. For color figure see Color Figures section. 
the control diet, which was returned to normal levels as observed in the $\mathrm{Bcmo1}^{+/+}$mice by BC supplementation.

A)

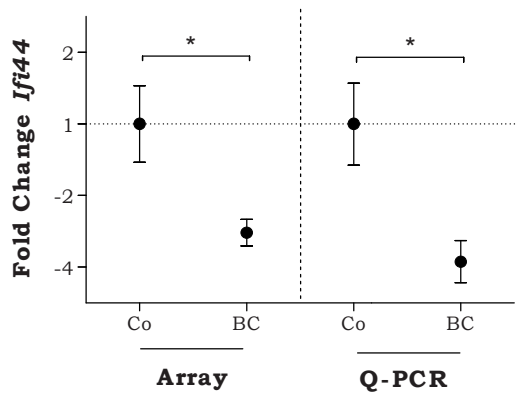

C)

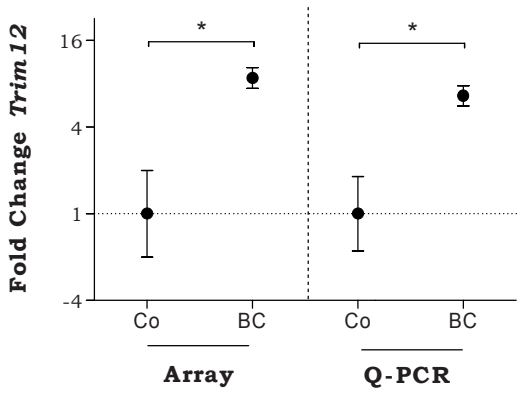

B)

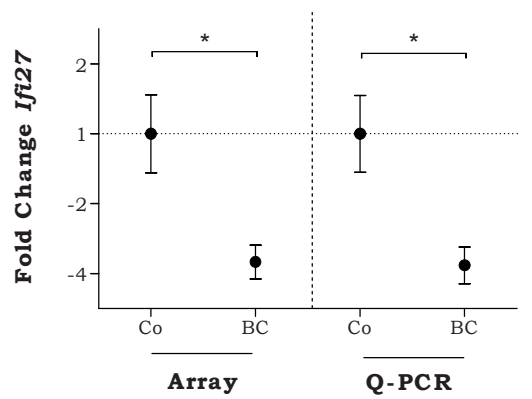

D)

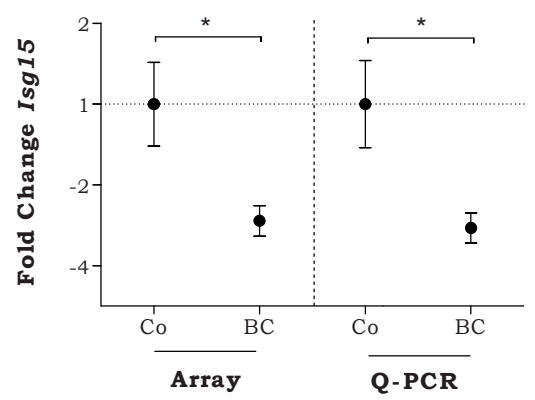

Figure 4: Confirmation of microarray results by Q-PCR. The expression of the genes (A) Ifi44, (B) Ifi27, (C) Trim 12 and (D) Isg15 in Bcmo 1\% mice on a control diet and mice supplemented with BC as analyzed with microarray (left) and as analyzed by Q-PCR (right) using stable reference genes Stx $5 a$ and $R n f 130$. Data represent the average \pm SEM with the average expression of every gene set at 1.0 of mice fed the control diet. * $\mathrm{p}<0.05$ using a Student's $t$-test on the log transformed data.

\section{Confirmation of array results by Q-PCR}

Real-time quantitative PCR (Q-PCR) was used to validate microarray results. Genes with the highest upregulation in Bcmo1\% control mice: interferon-induced protein 44 (Ifi44) (Fig. 4A), and interferon-induced protein 27 (Ifi27) (Fig. 4B); downregulation in Bcmo $1^{-1-}$ control mice: tripartite motif-containing 12 (Trim12) (Fig 4C), and previously demonstrated retinoic acid responsiveness: ISG15 ubiquitin-like modifier (Isg15) [29] (Fig. 4D) were selected for quantification. Microarray results were confirmed by Q-PCR, resulting 
in a virtual identical and significant upregulation of Ifi44, Ifi27, Isg15, and a down regulation of Trim12 in Bcmo 1\% control mice compared to BC supplemented $\mathrm{Bcmo1} \%$ mice in both microarray and Q-PCR analysis.

\section{Gene expression and histology showed an increase in inflammatory re- sponses in lungs of Bcmo1\% control mice}

We further classified the 121 genes that were regulated in $\mathrm{Bcmo1 \%}$ control mice with an absolute $\mathrm{FC}>1.5$ compared to $\mathrm{BC}$ supplemented $\mathrm{Bcmo1 \%}$ mice into general biological process categories (Table 1).

The main affected biological process category was the immune response and in particular direct interferon induced gene response (Fig. 5).

ErmineJ overrepresentation analysis and MetaCore analysis also showed that there was an overrepresentation of the inflammatory response in $\mathrm{Bcmo1 \%}$ control mice compared to BC supplemented Bcmo $1 \%$ mice using the whole dataset (ErmineJ; GO:0006954, Inflammatory response, $\mathrm{p}<10^{-7}$, MetaCore; several maps belonging to the cell process immune response, $\left.\mathrm{p}<2 * 10^{-4}\right)$.

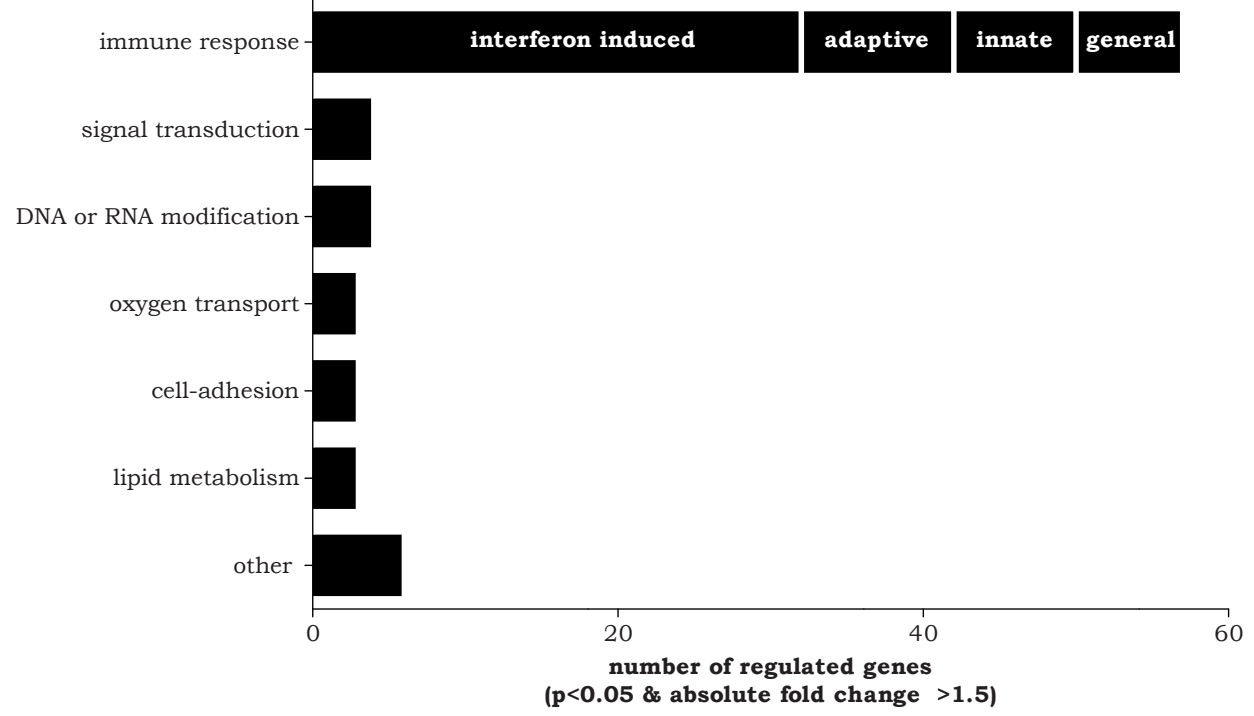

Figure 5: Biological processes affected in $\mathrm{Bcmo1^{-/ }}$ control mice. Graph representing the number of genes differentially expressed in Bcmo1\%- control mice vs Bcmo1-/- BC supplemented mice p $<0.05$ and absolute fold change $>1.5$ per biological processes category. 
$\mathrm{BC}$ restores $\mathrm{Bcmo1 \%}$ dependent lung inflammation

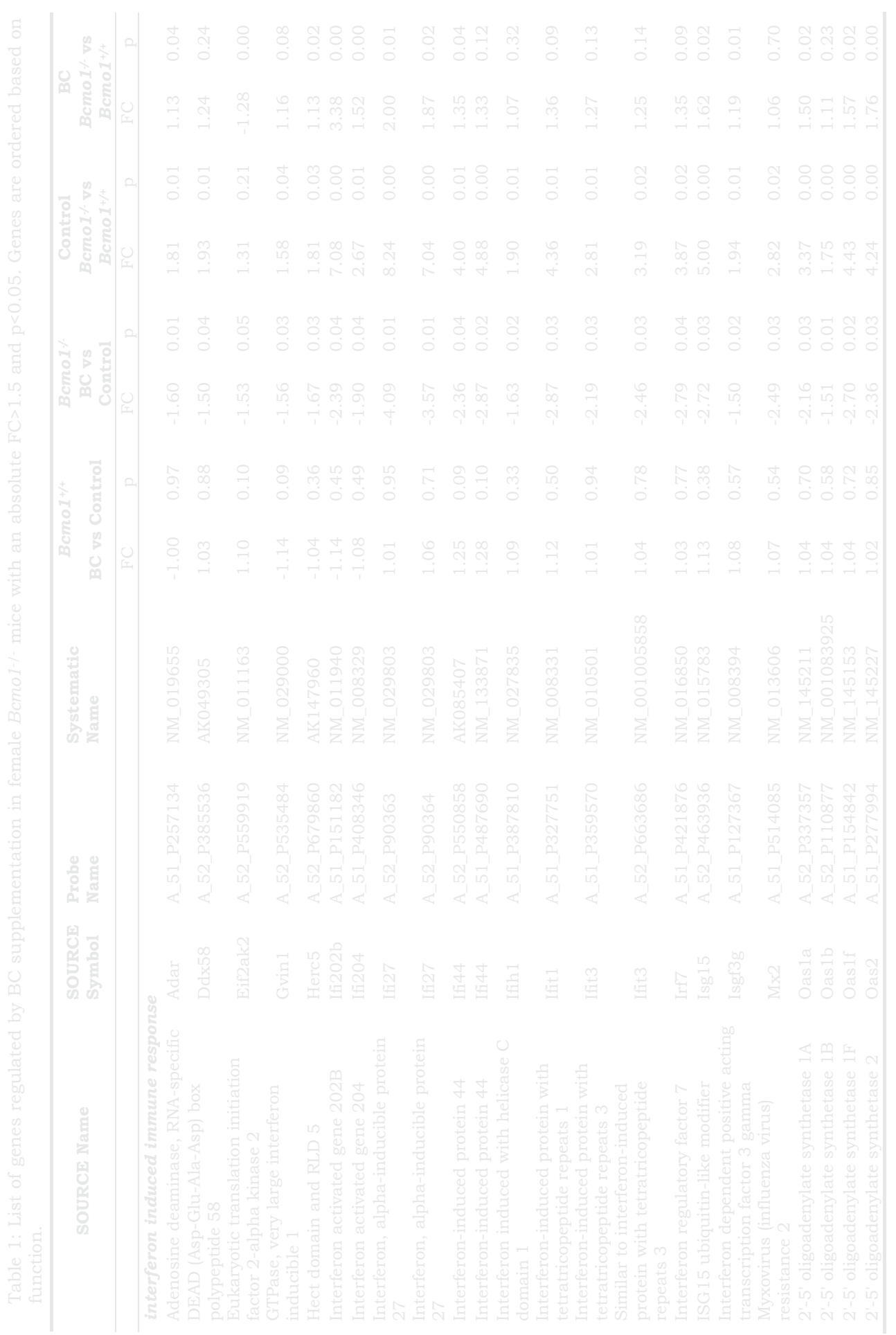


Chapter 5

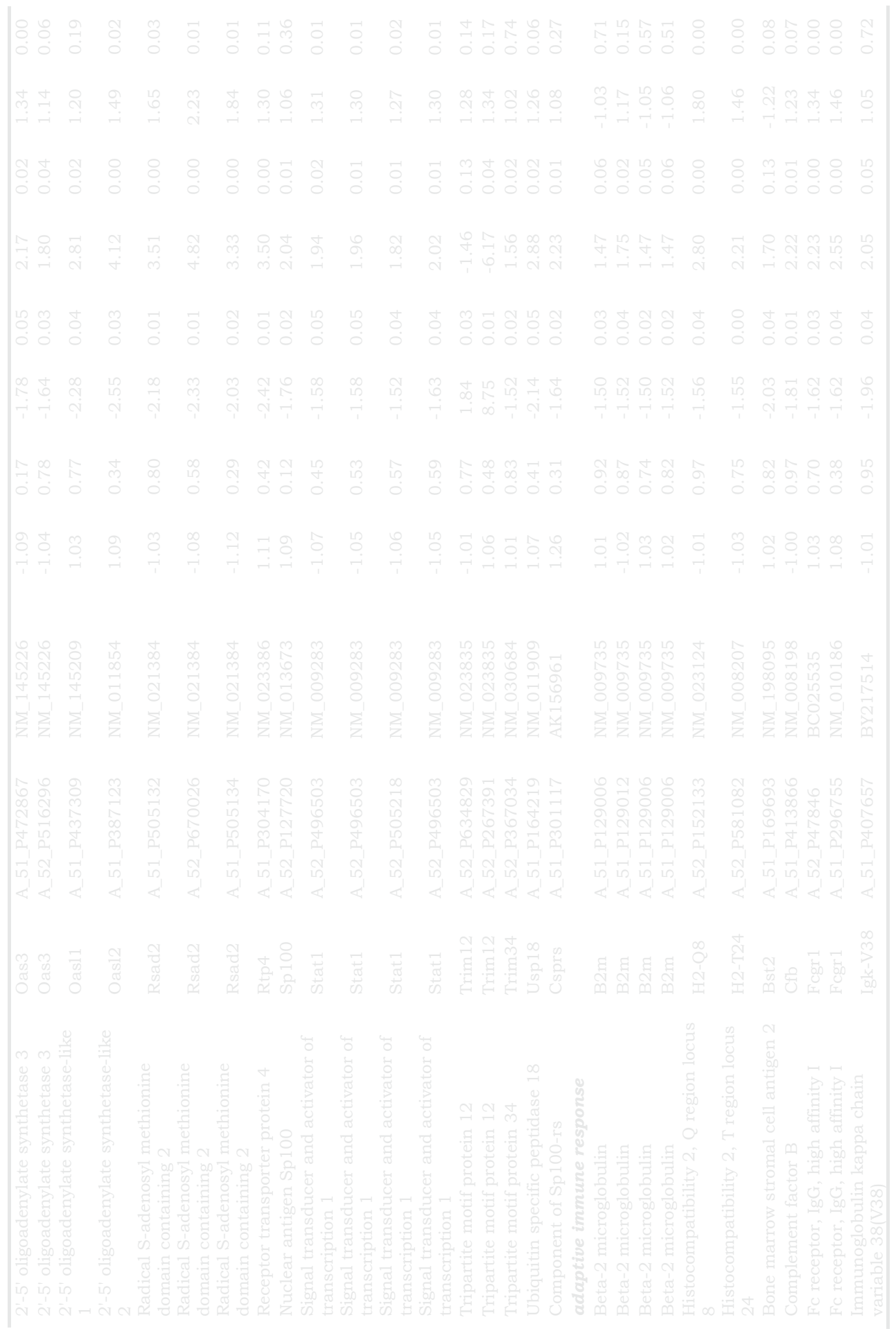


$\mathrm{BC}$ restores $\mathrm{Bcmo} 1 \%$ dependent lung inflammation 
Chapter 5

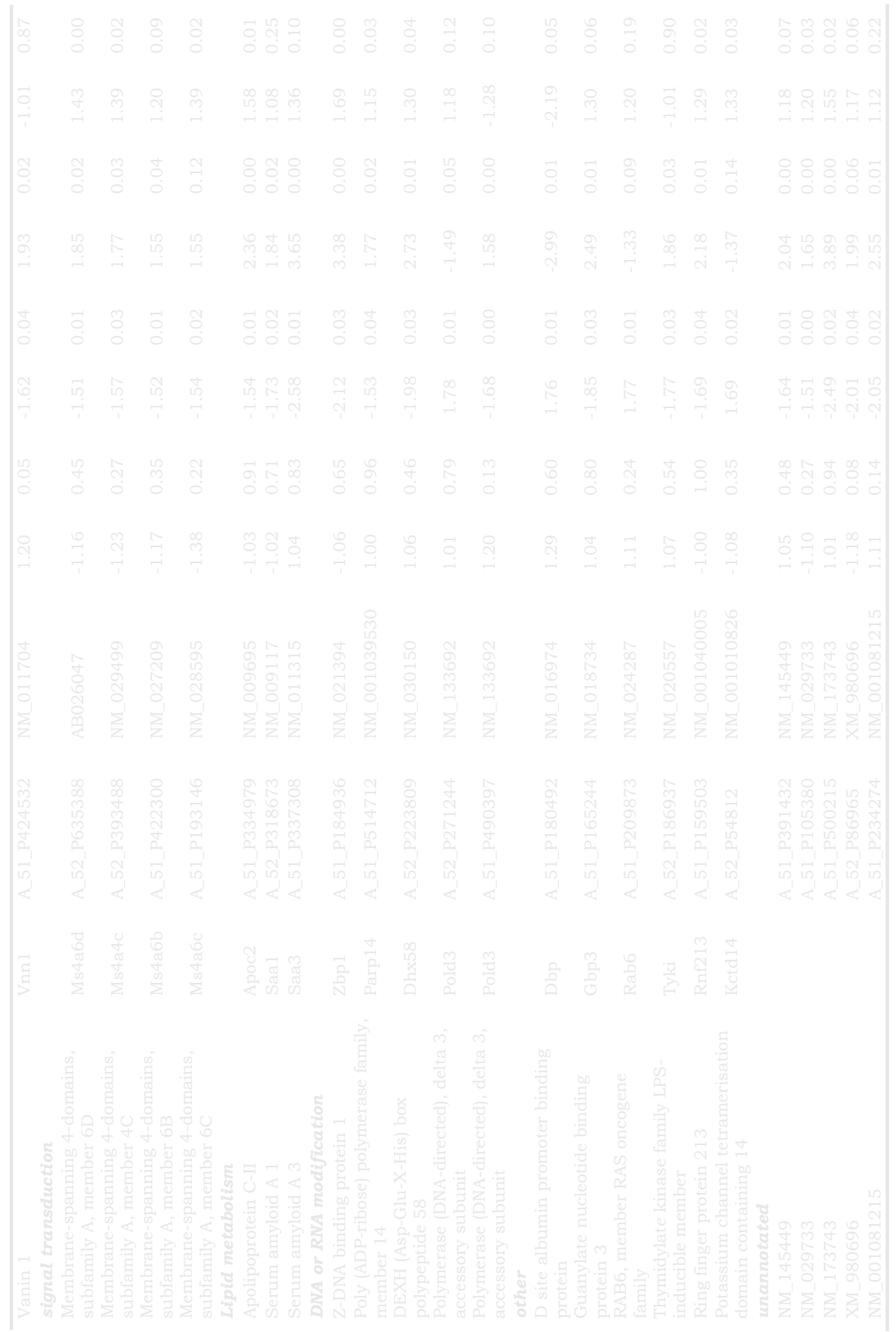


$\mathrm{BC}$ restores $\mathrm{Bcmo} 1 \%$ dependent lung inflammation 


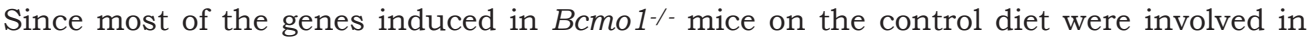
inflammatory responses, we investigated whether the mice had an increased concentration of the inflammation-related cytokines: tumor necrosis factor (Tnfa), interleukin-6 (I1-6) and monocyte chemoattractant protein-1 (Mcp-1). Serum concentrations of all three markers were below the detection limit (data not shown) while pulmonary infections usually would result in detectable serum concentrations of these markers [30].

We had additional material of 2 animals per group available for morphological analysis. Paraffin embedded sections were stained with hematoxylin and PAS and analyzed. Histology showed an overall healthy lung structure in all animals of the groups; $B \mathrm{cmo} 1^{+/+}$ control mice, $\mathrm{Bcmo1}^{+/+}$receiving $\mathrm{BC}$ supplementation and $\mathrm{Bcmo1 \%}$ receiving $\mathrm{BC}$ supplementation (Fig. 6A, 6B and $6 \mathrm{E}$ ). The overall lung histology of the $\mathrm{Bcmo} \%$ control mice was however different from the other groups due to a general increase in the number of inflammatory cell in the lung and occasionally larger inflamed areas (Fig. 6C and 6D), resembling previously described lung histology upon vitamin A deficiency in rats [31].

\section{Expression of genes involved in BC metabolism are shifted towards an in- creased retinyl ester storage in $\mathrm{Bcmo} 1 \%$ mice}

To further investigate whether a lack of $\mathrm{BC}$ or $\mathrm{BC}$ metabolites could explain the transcriptional and histological increased inflammatory response in the Bcmo $1 \%$ control mice, we investigated changes in downstream BC metabolism. First, we evaluated correlations between $\mathrm{BC}$, retinol and retinyl ester concentrations in mouse lung. There was a significant positive correlation between retinyl ester and $\mathrm{BC}$ concentrations in lung tissue of $\mathrm{Bcmo1}^{+/+}$mice $(\mathrm{R}=0.90, \mathrm{p}<0.001)$ (Fig. 7A), with a much lower slope in the Bcmo1/- mice $(\mathrm{R}=0.87, \mathrm{p}<0.001)$. There was no correlation between retinol and $\mathrm{BC}$ concentrations in lung tissue of both $\mathrm{Bcmo1}^{+/+}$as well as in Bcmo1\% mice $(\mathrm{R}=0.46, \mathrm{p}=0.13$ and $\mathrm{R}=0.52$, $\mathrm{p}=0.10$ ) (fig. $7 \mathrm{~B}$ ).

Additionally, the expression of genes involved in downstream $\mathrm{BC}$ metabolism and retinoic acid catabolism in the lungs was analyzed. Four genes involved in BC metabolism were differentially expressed in $\mathrm{Bcmo1} \%$ mice compared to the $\mathrm{Bcmo}^{+/++}$mice (Table 2) with lecithin-retinol acyltransferase (Lrat) and alcohol dehydrogenase 7 class IV (Adh7) having the highest fold change. The expression of Lrat, involved in the esterification of retinol into retinyl esters to store retinol [32], was 2.6 and 3.2 times upregulated in $\mathrm{Bcmo} 1 \%$ mice on the control and $\mathrm{BC}$ supplemented diet respectively, as compared to the $B \mathrm{cmo1} 1^{+/+}$control mice. Moreover, Adh7, the enzyme with the highest affinity and the highest conversion rate in the metabolism of retinol into retinal [33] was 2.7 times lower expressed in the $\mathrm{Bcmo1} /$ mice on a control diet as compared to the $\mathrm{Bcmo} 1^{+/+}$control mice. BC supplementation of Bcmo $1 \%$ mice partly restored this decreased Adh 7 expression. 

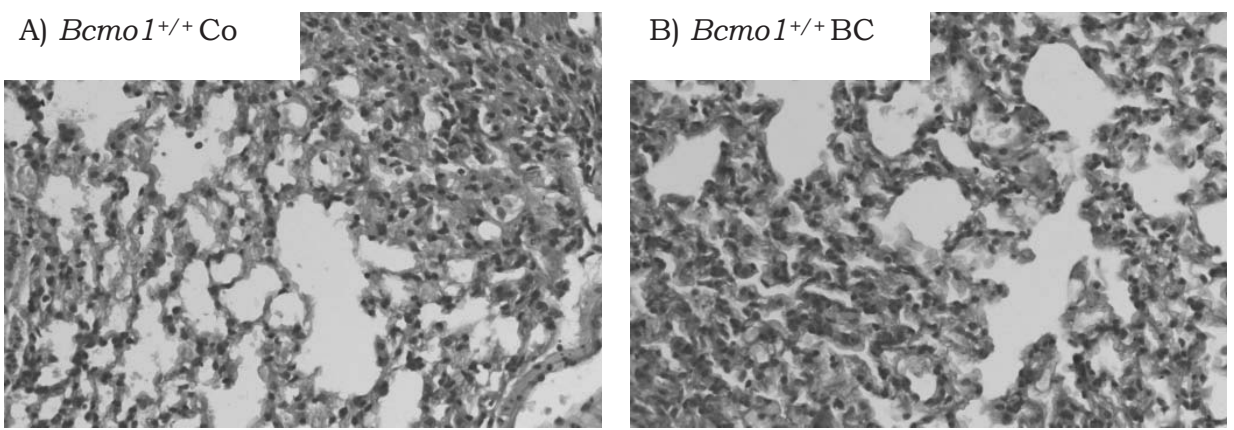

C) $\mathrm{Bcmo1 \%}$ - Co

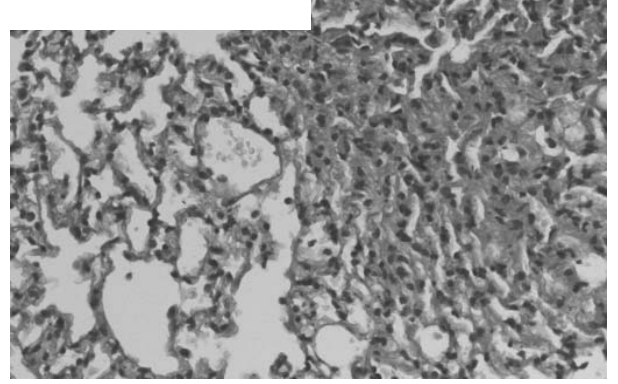

E) $\mathrm{Bcmo1 \% - \textrm {BC }}$

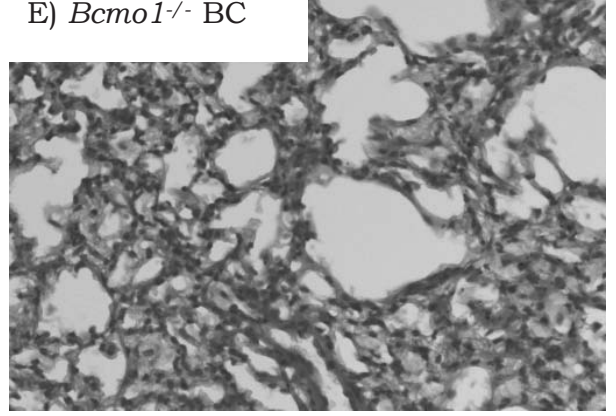

D) $\mathrm{Bcmo1}^{1-} \mathrm{Co}$

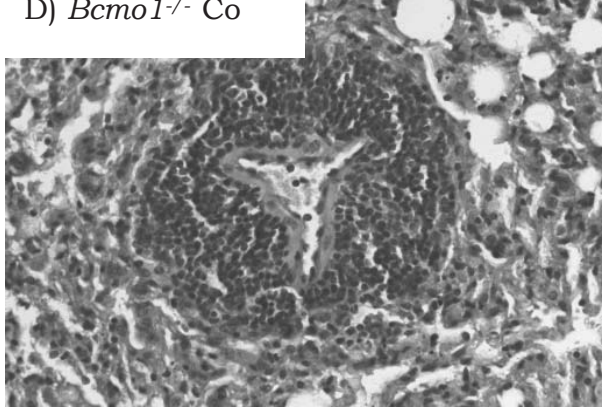

Figure 6: Histological analysis of lung tissue. Representative sections (right upper lobe) of the lung of Bcmo1 $1^{++}$mice $(\mathrm{A}$ and $\mathrm{B})$ and $\mathrm{Bcmo1} \%$ mice $(\mathrm{C}, \mathrm{D}$ and $\mathrm{E})$ on a control diet $(\mathrm{A}, \mathrm{C}, \mathrm{D})$ or a $\mathrm{BC}$ enriched diet (B and $\mathrm{E})$. The lungs of $\mathrm{Bcmo1} \%$ mice receiving the control diet $(\mathrm{C}, \mathrm{D})$ had a different appearance compared to the lungs of the other groups, with an increase in inflammatory cells and occasionally some inflamed area's (D). Magnification: 40 times. For color figures see Color Figures section. 


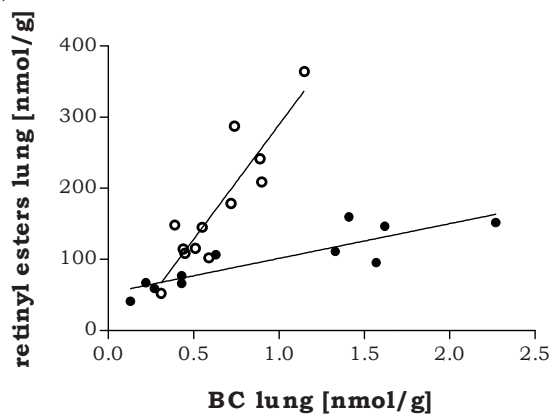

B)

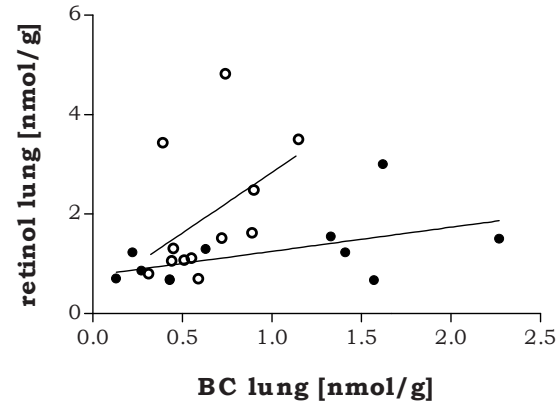

Figure 7: Correlation of $(\mathrm{A}) \mathrm{BC}$ concentration and retinyl ester concentration $\left(B c m o 1^{+/+}: \mathrm{r}=0.90\right.$, $\left.\mathrm{p}<0.001 ; B c m o 1^{-/}: \mathrm{R}=0.87, \mathrm{p}<0.001\right)$ and $(\mathrm{B}) \mathrm{BC}$ concentration and retinol concentration $\left(\mathrm{Bcmo}^{+/+}\right.$:

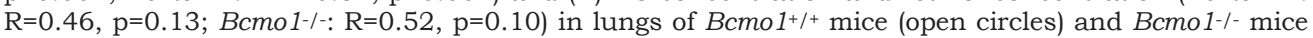
(closed circles).

Table 2: Genes involved in $\mathrm{BC}$ metabolism and retinoic acid catabolism which are significantly regulated by the knockout of Bcmo1.

\begin{tabular}{|c|c|c|c|c|c|}
\hline \multirow[b]{2}{*}{ name } & \multirow[b]{2}{*}{ symbol } & \multicolumn{2}{|c|}{$\mathrm{Bcmo1}^{+/+}$} & \multicolumn{2}{|c|}{$\mathrm{Bcmo}^{1 \%}$} \\
\hline & & Co & BC & Co & BC \\
\hline Aldehyde dehydrogenase family 1 , subfamily A2 & Aldh1a2 & $1 \mathrm{a}$ & $-1.03 a$ & $1.25^{b}$ & $1.20^{\mathrm{b}}$ \\
\hline Aldehyde dehydrogenase family 1 , subfamily A3 & Aldh1a3 & $1^{\mathrm{a}}$ & $-1.25^{b}$ & $-1.43^{c}$ & $-1.41^{c}$ \\
\hline Aldehyde dehydrogenase 2 , mitochondrial & AldH2 & $1^{\mathrm{a}}$ & $1.05^{\mathrm{a}}$ & $-1.18^{b}$ & $-1.01^{\mathrm{a}}$ \\
\hline $\begin{array}{l}\text { Lecithin-retinol acyltransferase (phosphatidyl- } \\
\text { choline-retinol-O-acyltransferase) }\end{array}$ & Lrat & $1 \mathrm{a}$ & $1.58 \mathrm{~b}$ & $2.58^{c}$ & $3.15^{c}$ \\
\hline $\begin{array}{l}\text { Alcohol dehydrogenase } 7 \text { (class IV), mu or sigma } \\
\text { polypeptide }\end{array}$ & Adh7 & $1^{\mathrm{a}}$ & $-1.14^{\mathrm{a}}$ & $-2.67^{b}$ & $-2.16^{c}$ \\
\hline
\end{tabular}

Different letters indicate significant differences (Student's $t$-test, $\mathrm{p}<0.05$ )

\section{Discussion}

In this study we investigated transcriptional pathways that are regulated by $\mathrm{BC}$ in vivo in the lung to obtain insight in possible mechanisms underlying previously found adverse effects of $\mathrm{BC}$ supplementation. For this purpose, we used a $\mathrm{Bcmo1} /$ - mouse model, known to accumulate $\mathrm{BC}$ in serum and lung, as well as $\mathrm{Bcmo1}^{+/+}$mice that have increased $\mathrm{BC}$ metabolite concentrations upon $\mathrm{BC}$ supplementation. Lung gene expression was explored using whole genome microarrays and revealed that mainly genes involved in inflammation were up regulated only in $\mathrm{Bcmo} 1 \%$ control mice. Similarly, histological analysis revealed an increased infiltration of inflammatory cells only in $\mathrm{Bcmo} \mathrm{H}^{\%}$ 
control mice. BC supplementation of $\mathrm{Bcmo1}^{-1-}$ mice restored inflammatory gene expression and decreased the infiltration of inflammatory cells to levels as observed in $\mathrm{Bcmo1}^{+/+}$control mice. An increased inflammatory response in the lungs has previously been observed upon vitamin A deficiency [34] and since BC supplementation could reverse the increase in inflammatory cells and inflammation related gene expression, we hypothesize that these effects are due to increased dietary vitamin A requirement in $\mathrm{Bcmo1}^{1 /}$ mice compared to $\mathrm{Bcmo1}^{+/+}$mice. An explanation for this increased vitamin A requirement could lay in the altered downstream $\mathrm{BC}$ and vitamin $\mathrm{A}$ metabolism in Bcmo1\% mice, resulting in a less efficient conversion of vitamin A into the bioactive form of vitamin A; retinoic acid. $\mathrm{BC}$ supplementation was able to restore these requirements despite of the knockout of Bcmo1.

We observed an increase in inflammatory cells in the lung and an increase in the expression of genes involved in inflammation in $\mathrm{Bcmo1}^{\%}$ control mice, which was restored by $\mathrm{BC}$ supplementation to levels observed in $\mathrm{Bcmo1}^{+/+}$mice. An effect of $\mathrm{BC}$ itself on the inflammatory response has not been reported, whereas vitamin A deficiency has been reported to increase inflammation in rats [31,34]. Moreover, vitamin A supplementation in vitamin A deficient populations reduced the number and severity of infections and decreased the infection induced mortality rate [5]. Since vitamin A levels were approximately similar in lungs of $\mathrm{Bcmo1} \%$ mice fed with a control diet and $\mathrm{Bcmo1}^{+/+}$mice, the increased inflammatory response likely involves the bioactive vitamin A metabolite retinoic acid. Retinoic acid is able to bind to the transcriptional active retinoic acid receptor (RAR) or to the retinoid X receptor (RXR), thereby modulating transcriptional responses. Indeed, effects on the inflammatory response have been shown to be regulated through the transcription factor retinoic acid receptor (RAR) [35,36]. For example Th1/Th2/Th17 balance, involved in the adaptive immune response and important in the onset of autoimmune diseases, asthma and allergic diseases, has been attributed to RAR activity. Interestingly, also interferon stimulated genes, which were predominant in our study, can be RAR regulated [37,38]. Retinoic acid can be present in two isomers; all-trans retinoic acid (atRA) and 9-cis retinoic acid (9cRA), which have different transcriptional activities. Both isomers are able to bind to RAR, while only 9cRA can bind to RXR. Since effects on immunological function have mainly been attributed to RAR functioning, a shift in the balance of atRA and 9cRA is very unlikely to explain our results. We explain the increase in the inflammatory response in lungs of $\mathrm{Bcmo1 \%}$ mice by a more general reduction in available retinoic acid in $\mathrm{Bcmo1 \%}$ control mice due to altered gene expression of downstream BC metabolizing enzymes. The gene expression of Adh7, a key enzyme in the conversion of vitamin A into retinal and an important step before the formation of biologically active retinoic acid [39], was 2.7-fold down regulated in

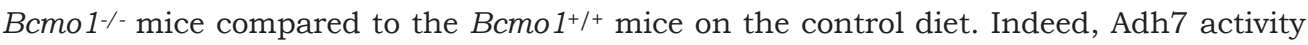
has previously been shown to be inversely associated with the degree of inflammation in the human gastric mucosa [40]. Additionally, an interaction between vitamin A concentration and $A d h 7$ expression was previously reported: a vitamin A deficient diet led to a 
decreased fetal survival in Adh7 knock-out mice compared to wildtype mice, but not on a vitamin A sufficient diet $[33,41]$. The 2.6-fold increase in lecithin-retinol-Oacyltransferase (Lrat) in Bcmo1\% mice was also striking. Lrat is the main enzyme [32] for conversion of retinol to retinylesters, a form in which vitamin A can be stored, indicating that vitamin $\mathrm{A}$ is rather esterified and stored in $\mathrm{Bcmo1} /-$ lungs. Taken together, these findings suggest that an increased inflammatory response in control $\mathrm{Bcmo1} /$ mice may be due to a decreased retinoic acid production. $\mathrm{BC}$ supplementation prevents these effects in the Bcmo1\% mice, possibly because BC can substitute for retinoic acid production in a pathway dependent on beta-carotene oxygenase 2 (Bco2), an enzyme with the ability to asymmetrically cleave $\mathrm{BC}$, thereby generating $\beta$-apocarotenal and $\beta$ ionone [42] which can subsequently be further metabolized into retinoic acid [43]. Altogether, the altered gene expression of key enzymes for vitamin A metabolism may result in a changed dietary vitamin A requirement in $\mathrm{Bcmo} 1^{--}$mice, which changes the vitamin A sufficient control diet for $\mathrm{Bcmo1}^{+/+}$mice, into a mildly vitamin A deficient diet for the $\mathrm{Bcmo1}^{-/}$mice.

We demonstrated an altered $\mathrm{BC}$ metabolism in the $\mathrm{Bcmo1} /$ mice, which resulted, as intended in an increased $\mathrm{BC}$ accumulation in lung and serum of the $\mathrm{Bcmo} 1^{\%}$ mice. We also observed some interesting differences in the gene expression of downstream $\mathrm{BC}$ metabolizing enzymes. This changed metabolism might be important to understand and investigate physiological effects of $\mathrm{BC}$ in lung functioning, especially since there are large inter-human variations in BCMO1 activity due to polymorphisms in this gene. There were some interesting, unexpected changes in $\mathrm{BC}$ metabolite levels upon $\mathrm{BC}$ supplementation in $\mathrm{Bcmo1}^{\%}$ mice. First of all, there was an increase in retinol in lung upon $\mathrm{BC}$ supplementation in $\mathrm{Bcmo1^{-/ }}$ mice. This increase in retinol is unlikely originating from metabolized $\mathrm{BC}$. As far as known, only Bco2 can serve as a partial alternative to $\mathrm{Bcmo} 1$ in $\mathrm{BC}$ metabolism. Bco2 asymmetrically cleaves $\mathrm{BC}$, thereby generating an increase in apocarotenals and ultimately into retinoic acid, which can be degraded by members of the Cytochrome P450 (Cyp) family and in particular Cyp26 [44,45]. Retinol is probably not an intermediate in this alternative $\mathrm{BC}$ metabolism pathway. An increased retinol absorption in the lung, in combination with the (non-significant) decrease in retinol in plasma could theoretically clarify this observation. However, stimulated by retinoic acid 6 (Stra6) which is identified as receptor for the blood retinol carrier; retinol binding protein 4 (Rbp4) [46], was not significantly differentially expressed on the microarrays between the $\mathrm{BC}$ supplemented and control diet fed mice. A changed $\mathrm{Rbp} 4-$ retinol complex has been associated with an increased delivery of retinol to different tissues $[46,47]$ and might possibly explain our retinol plasma and lung tissue concentrations. A second never reported interesting observation herein regarding $\mathrm{BC}$ metabolites in lung tissue was the more tight correlation of $\mathrm{BC}$ with retinyl esters than with retinol in lung tissue of $\mathrm{Bcmo1}^{+/+}$mice in the lung. This implies that BC accumulation tightly regulates the retinyl ester pool. Lung tissue has relatively high retinyl ester pools [48]. The main role for retinyl esters in the lung is to ensure a direct retinol deliv- 
ery when there is an increased retinol demand in the lung [49], especially during fetal development. We found a significant 6.5-fold decrease in slope in the correlation of lung $\mathrm{BC}$ with retinyl esters in $\mathrm{Bcmo1/-}$ mice compared to the $\mathrm{Bcmo1^{+/+ }}$ mice which implies decreased conversion efficiency in the Bcmo 1\% mice. This decreased efficiency was also found in people containing two snp's in the BCMO1 gene, resulting in a decreased BCMO1 activity and a 4-fold decreased conversion efficiency of BC as measured as the triglyceride-rich lipoprotein retinyl palmitate: $\mathrm{BC}$ ratio [18]. The surprising findings in $\mathrm{BC}$ metabolites in $\mathrm{Bcmo}^{+/+}$and $\mathrm{Bcmol}^{\%}$ mice and the understanding of these differences are especially important to understand effects of $\mathrm{BC}$ in human, in particular since downstream $\mathrm{BC}$ metabolism is different in mice and humans but also between humans.

Since we find inflammatory gene expression to be increased, the question may be raised whether there was an unintended infection present solely in the $\mathrm{Bcmo1 \%}$ control mice. There are some reasons to believe that this was not the case. First, we examined plasma levels of the cytokines; Mcp-1, Tnfa and Il-6 which are highly increased and detectable upon infection [50]. These levels were under the limit of detection, which is representative for an uninfected state. In addition, the $\mathrm{Bcmol}^{-}$- mice both on a control diet and on a BC supplemented diet were divided over two independent experiments. The significant up regulation of the inflammatory response in the Bcmo $1 \%$ control mice was similar in both experimental periods, making infection an unlikely explanation. Moreover, an increased inflammatory response in the lungs is often seen during vitamin A deficiency. An altered downstream $\mathrm{BC}$ metabolism in $\mathrm{Bcmo1 \%}$ mice, and thereby a higher vitamin $\mathrm{A}$ requirement in $\mathrm{Bcmo1}^{-}$- mice is therefore a likely explanation.

We initiated this study to identify possible pathways explaining possible harmful effects of $\mathrm{BC}$. Therefore we used $\mathrm{Bcmo1 \%}$ mice, able to accumulate $\mathrm{BC}$ as humans. In this study, $\mathrm{BC}$ supplementation was beneficial in $\mathrm{Bcmo1 \%}$ mice, since $\mathrm{BC}$ supplementation reduced the inflammatory response in these mice and generated a gene expression pattern more similar to $\mathrm{BCmo}^{+/+}$mice, as has been shown by cluster analysis. Although $\mathrm{BC}$ was beneficial in this model, these data also demonstrate that $\mathrm{BC}$ was able to influence the inflammatory response in the lungs. The harmful effects of $\mathrm{BC}$ have only been reported in smokers and asbestos exposed subjects (ATBC, CARET). An important difference between smokers and asbestos exposed subjects on one hand and non-smokers on the other hand, is that smoking causes an inflammatory response in the lungs which is shown to be involved in the onset and progression of carcinogenesis [51-54]. Since we find differences in downstream BC metabolizing enzymes, possible differences in these enzymes in smokers might give a clue in the adverse effects of BC in smokers. Microarray analysis of small airway epithelium of smokers has revealed that several downstream BC metabolizing enzymes are indeed differentially expressed. ALDH1A3 was 5-fold up regulated and $A D H 7$ was 6 -fold up regulated in smokers compared to non-smokers [55]. This paper implies that a proper retinoic acid synthesis is indispensable for a correct functioning of the immune system. It would be of interest to investi- 
gate whether polymorphisms in BC metabolizing enzymes in subjects of the ATBC and CARET study alter the lung cancer risk in smokers upon BC supplementation. Future studies using $\mathrm{Bcmo1}^{\%}$ mice as well as $\mathrm{Bcmo1}^{+/+}$mice in combination with $\mathrm{BC}$ and smoke or inflammation induction are necessary to further investigate and explain exact mechanisms. Since the $\mathrm{Bcmo1} \%$ mice seem to have a higher dietary need for vitamin A, this concentration should be increased to avoid effects of vitamin A deficiency.

All together, our results demonstrate that $\mathrm{Bcmo1 \%}$ mice on a control diet had an increased inflammation in their lungs, which was decreased to levels as observed in $\mathrm{BCmo1}^{+/+}$mice upon $\mathrm{BC}$ supplementation. We hypothesize that this was due to an increased vitamin A requirement in $\mathrm{Bcmol}^{-}$due to impaired retinoic acid synthesis. Since the $\mathrm{Bcmo1} \%$ control mice were most likely mildly vitamin A deficient, this study was unable to elucidate $\mathrm{BC}$ accumulation regulated gene expression. Nevertheless, these results might be important for the human population since individuals with polymorphisms in the BCMO1 gene, with a high population frequency, may have also a higher risk for vitamin A deficiency which is still a relatively frequently occurring state in developing countries as well as in certain groups of the Western society.

\section{Acknowledgements}

Yvonne van Helden was supported by a grant from NUTRIM/VLAG. This work is part of the research effort of the carotenoid focus team of the European Nutrigenomics Organization (Network of Excellence, EU Contract FOOD-CT-2004-506360) and has been sponsored in part by NuGO. We thank Sophie Alders for her contribution to the histological analysis. Jaap Keijer is a member of Mitofood (COST FA0602). CIBERobn is an initiative of the ISCIII (Spanish Government). Adrian Wyss is employed by DSM neutraceuticals and facilitated the use of $\mathrm{Bcmo1}^{-/}$mice, $\mathrm{BC}$ beadlets and helped in design of the study. None of the other authors declares any commercial interest. The study results and conclusions were derived independently of any commercial party (in particular DSM Nutritional Products) and were not amended. 


\section{References}

[1] R.G. Ziegler Vegetables, fruits, and carotenoids and the risk of cancer, Am J Clin Nutr 53 (1991) 251S259S.

[2] G. van Poppel Epidemiological evidence for beta-carotene in prevention of cancer and cardiovascular disease, Eur J Clin Nutr 50 Suppl 3 (1996) S57-61.

[3] R.G. Ziegler A review of epidemiologic evidence that carotenoids reduce the risk of cancer, J Nutr 119 (1989) 116-122.

[4] A. Sommer Vitamin a deficiency and clinical disease: an historical overview, J Nutr 138 (2008) 1835-1839.

[5] P.P. Glasziou and D.E. Mackerras Vitamin A supplementation in infectious diseases: a meta-analysis, Bmj 306 (1993) 366-370.

[6] T.E. Edes and D.S. Gysbers Carcinogen-induced tissue vitamin A depletion. Potential protective advantages of beta-carotene, Ann N Y Acad Sci 686 (1993) 203-211; discussion 211-202.

[7] C.A. Northrop-Clewes and D.I. Thurnham Monitoring micronutrients in cigarette smokers, Clin Chim Acta 377 (2007) 14-38.

[8] The alpha-tocopherol, beta-carotene lung cancer prevention study: design, methods, participant characteristics, and compliance. The ATBC Cancer Prevention Study Group, Ann Epidemiol 4 (1994) 1-10.

[9] G.S. Omenn, G.E. Goodman, M.D. Thornquist, J. Balmes, M.R. Cullen, A. Glass, J.P. Keogh, F.L. Meyskens, B. Valanis, J.H. Williams, S. Barnhart and S. Hammar Effects of a combination of beta carotene and vitamin A on lung cancer and cardiovascular disease, N Engl J Med 334 (1996) 1150-1155.

[10] C.H. Hennekens, J.E. Buring, J.E. Manson, M. Stampfer, B. Rosner, N.R. Cook, C. Belanger, F. LaMotte, J.M. Gaziano, P.M. Ridker, W. Willett and R. Peto Lack of effect of long-term supplementation with beta carotene on the incidence of malignant neoplasms and cardiovascular disease, N Engl J Med 334 (1996) 1145-1149.

[11] G.S. Omenn, G.E. Goodman, M.D. Thornquist, J. Balmes, M.R. Cullen, A. Glass, J.P. Keogh, F.L. Meyskens, Jr., B. Valanis, J.H. Williams, Jr., S. Barnhart, M.G. Cherniack, C.A. Brodkin and S. Hammar Risk factors for lung cancer and for intervention effects in CARET, the Beta-Carotene and Retinol Efficacy Trial, J Natl Cancer Inst 88 (1996) 1550-1559.

[12] G.E. Goodman, M.D. Thornquist, J. Balmes, M.R. Cullen, F.L. Meyskens, Jr., G.S. Omenn, B. Valanis and J.H. Williams, Jr. The Beta-Carotene and Retinol Efficacy Trial: incidence of lung cancer and cardiovascular disease mortality during 6-year follow-up after stopping beta-carotene and retinol supplements, J Natl Cancer Inst 96 (2004) 1743-1750.

[13] P. Palozza Prooxidant actions of carotenoids in biologic systems, Nutr Rev 56 (1998) 257-265.

[14] Y.G. van Helden, J. Keijer, A.M. Knaapen, S.G. Heil, J.J. Briede, F.J. van Schooten and R.W. Godschalk Beta-carotene metabolites enhance inflammation-induced oxidative DNA damage in lung epithelial cells, Free Radic Biol Med 46 (2009) 299-304.

[15] R.M. Russell The enigma of beta-carotene in carcinogenesis: what can be learned from animal studies, J Nutr 134 (2004) 262S-268S.

[16] S.J. Hickenbottom, J.R. Follett, Y. Lin, S.R. Dueker, B.J. Burri, T.R. Neidlinger and A.J. Clifford Variability in conversion of beta-carotene to vitamin A in men as measured by using a double-tracer study design, Am J Clin Nutr 75 (2002) 900-907.

[17] Y. Lin, S.R. Dueker, B.J. Burri, T.R. Neidlinger and A.J. Clifford Variability of the conversion of betacarotene to vitamin A in women measured by using a double-tracer study design, Am J Clin Nutr 71 (2000) 1545-1554.

[18] W.C. Leung, S. Hessel, C. Meplan, J. Flint, V. Oberhauser, F. Tourniaire, J.E. Hesketh, J. von Lintig and G. Lietz Two common single nucleotide polymorphisms in the gene encoding \{beta\}-carotene 15, 15'monoxygenase alter \{beta\}-carotene metabolism in female volunteers, Faseb J (2008).

[19] A. Lindqvist, J. Sharvill, D.E. Sharvill and S. Andersson Loss-of-function mutation in carotenoid 15,15'monooxygenase identified in a patient with hypercarotenemia and hypovitaminosis A, J Nutr 137 (2007) 2346-2350.

[20] J. von Lintig, S. Hessel, A. Isken, C. Kiefer, J.M. Lampert, O. Voolstra and K. Vogt Towards a better understanding of carotenoid metabolism in animals, Biochim Biophys Acta 1740 (2005) 122-131.

[21] S. Hessel, A. Eichinger, A. Isken, J. Amengual, S. Hunzelmann, U. Hoeller, V. Elste, W. Hunziker, R. Goralczyk, V. Oberhauser, J. von Lintig and A. Wyss CMO1 deficiency abolishes vitamin A production from beta-carotene and alters lipid metabolism in mice, J Biol Chem 282 (2007) 33553-33561.

[22] J. von Lintig and K. Vogt Filling the gap in vitamin A research. Molecular identification of an enzyme cleaving beta-carotene to retinal, J Biol Chem 275 (2000) 11915-11920. 


\section{Chapter 5}

[23] E.M. van Schothorst, V. Pagmantidis, V.C. de Boer, J. Hesketh and J. Keijer Assessment of reducing RNA input for Agilent oligo microarrays, Anal Biochem 363 (2007) 315-317.

[24] W. Rodenburg, J. Keijer, E. Kramer, C. Vink, R. van der Meer and I.M. Bovee-Oudenhoven Impaired barrier function by dietary fructo-oligosaccharides (FOS) in rats is accompanied by increased colonic mitochondrial gene expression, BMC Genomics 9 (2008) 144.

[25] J.M. Wettenhall and G.K. Smyth limmaGUI: a graphical user interface for linear modeling of microarray data, Bioinformatics 20 (2004) 3705-3706.

[26] L. Pellis, N.L. Franssen-van Hal, J. Burema and J. Keijer The intraclass correlation coefficient applied for evaluation of data correction, labeling methods, and rectal biopsy sampling in DNA microarray experiments, Physiol Genomics 16 (2003) 99-106.

[27] H.K. Lee, W. Braynen, K. Keshav and P. Pavlidis ErmineJ: tool for functional analysis of gene expression data sets, BMC Bioinformatics 6 (2005) 269.

[28] V.C. de Boer, E.M. van Schothorst, A.A. Dihal, H. van der Woude, I.C. Arts, I.M. Rietjens, P.C. Hollman and J. Keijer Chronic quercetin exposure affects fatty acid catabolism in rat lung, Cell Mol Life Sci 63 (2006) 2847-2858.

[29] C.T. Dao, J.K. Luo and D.E. Zhang Retinoic acid-induced protein ISGylation is dependent on interferon signal transduction, Blood Cells Mol Dis 36 (2006) 406-413.

[30] C. Stamme, D.S. Bundschuh, T. Hartung, U. Gebert, L. Wollin, R. Nusing, A. Wendel and S. Uhlig Temporal sequence of pulmonary and systemic inflammatory responses to graded polymicrobial peritonitis in mice, Infect Immun 67 (1999) 5642-5650.

[31] R.C. Baybutt and A. Molteni Vitamin A and emphysema, Vitam Horm 75 (2007) 385-401.

[32] A.C. Ross Retinoid production and catabolism: role of diet in regulating retinol esterification and retinoic Acid oxidation, J Nutr 133 (2003) 291S-296S.

[33] G. Duester Families of retinoid dehydrogenases regulating vitamin A function: production of visual pigment and retinoic acid, Eur J Biochem 267 (2000) 4315-4324.

[34] R.C. Baybutt, L. Hu and A. Molteni Vitamin A deficiency injures lung and liver parenchyma and impairs function of rat type II pneumocytes, J Nutr 130 (2000) 1159-1165.

[35] M. Iwata, Y. Eshima and H. Kagechika Retinoic acids exert direct effects on T cells to suppress Th1 development and enhance Th2 development via retinoic acid receptors, Int Immunol 15 (2003) 1017-1025.

[36] D. Mucida, Y. Park, G. Kim, O. Turovskaya, I. Scott, M. Kronenberg and H. Cheroutre Reciprocal TH17 and regulatory $T$ cell differentiation mediated by retinoic acid, Science 317 (2007) 256-260.

[37] M. Gianni, M. Terao, I. Fortino, M. LiCalzi, V. Viggiano, T. Barbui, A. Rambaldi and E. Garattini Stat1 is induced and activated by all-trans retinoic acid in acute promyelocytic leukemia cells, Blood 89 (1997) 1001-1012.

[38] Y. Shang, C.R. Baumrucker and M.H. Green The induction and activation of STAT1 by all-trans-retinoic acid are mediated by RAR beta signaling pathways in breast cancer cells, Oncogene 18 (1999) 6725-6732.

[39] Z.N. Yang, G.J. Davis, T.D. Hurley, C.L. Stone, T.K. Li and W.F. Bosron Catalytic efficiency of human alcohol dehydrogenases for retinol oxidation and retinal reduction, Alcohol Clin Exp Res 18 (1994) 587-591.

[40] M. Matsumoto, H. Yokoyama, H. Suzuki, H. Shiraishi-Yokoyama and T. Hibi Retinoic acid formation from retinol in the human gastric mucosa: role of class IV alcohol dehydrogenase and its relevance to morphological changes, Am J Physiol Gastrointest Liver Physiol 289 (2005) G429-433.

[41] L. Deltour, M.H. Foglio and G. Duester Impaired retinol utilization in Adh4 alcohol dehydrogenase mutant mice, Dev Genet 25 (1999) 1-10.

[42] C. Kiefer, S. Hessel, J.M. Lampert, K. Vogt, M.O. Lederer, D.E. Breithaupt and J. von Lintig Identification and characterization of a mammalian enzyme catalyzing the asymmetric oxidative cleavage of provitamin A, J Biol Chem 276 (2001) 14110-14116.

[43] X.D. Wang, R.M. Russell, C. Liu, F. Stickel, D.E. Smith and N.I. Krinsky Beta-oxidation in rabbit liver in vitro and in the perfused ferret liver contributes to retinoic acid biosynthesis from beta-apocarotenoic acids, J Biol Chem 271 (1996) 26490-26498.

[44] J.E. Thatcher and N. Isoherranen The role of CYP26 enzymes in retinoic acid clearance, Expert Opin Drug Metab Toxicol 5 (2009) 875-886.

[45] J.A. White, B. Beckett-Jones, Y.D. Guo, F.J. Dilworth, J. Bonasoro, G. Jones and M. Petkovich cDNA cloning of human retinoic acid-metabolizing enzyme (hP450RAI) identifies a novel family of cytochromes P450, J Biol Chem 272 (1997) 18538-18541.

[46] R. Kawaguchi, J. Yu, J. Honda, J. Hu, J. Whitelegge, P. Ping, P. Wiita, D. Bok and H. Sun A membrane receptor for retinol binding protein mediates cellular uptake of vitamin A, Science 315 (2007) 820-825.

[47] D.I. Thurnham and C.A. Northrop-Clewes Optimal nutrition: vitamin A and the carotenoids, Proc Nutr Soc 58 (1999) 449-457. 
[48] S.M. O'Byrne, N. Wongsiriroj, J. Libien, S. Vogel, I.J. Goldberg, W. Baehr, K. Palczewski and W.S. Blaner Retinoid absorption and storage is impaired in mice lacking lecithin:retinol acyltransferase (LRAT), J Biol Chem 280 (2005) 35647-35657.

[49] H.K. Biesalski and D. Nohr New aspects in vitamin a metabolism: the role of retinyl esters as systemic and local sources for retinol in mucous epithelia, J Nutr 134 (2004) 3453S-3457S.

[50] R. KuoLee, X. Zhao, J. Austin, G. Harris, J.W. Conlan and W. Chen Mouse model of oral infection with virulent type A Francisella tularensis, Infect Immun 75 (2007) 1651-1660.

[51] J.S. Brody and A. Spira State of the art. Chronic obstructive pulmonary disease, inflammation, and lung cancer, Proc Am Thorac Soc 3 (2006) 535-537.

[52] D. Pereg and M. Lishner Non-steroidal anti-inflammatory drugs for the prevention and treatment of cancer, J Intern Med 258 (2005) 115-123.

[53] A.G. Schwartz, G.M. Prysak, C.H. Bock and M.L. Cote The molecular epidemiology of lung cancer, Carcinogenesis 28 (2007) 507-518.

[54] M.J. Thun, S.J. Henley and C. Patrono Nonsteroidal anti-inflammatory drugs as anticancer agents: mechanistic, pharmacologic, and clinical issues, J Natl Cancer Inst 94 (2002) 252-266.

[55] B.G. Harvey, A. Heguy, P.L. Leopold, B.J. Carolan, B. Ferris and R.G. Crystal Modification of gene expression of the small airway epithelium in response to cigarette smoking, J Mol Med 85 (2007) 39-53. 
An ongoing controversy exists on beneficial versus harmful effects of high beta-carotene (BC) intake, especially for the lung. To elucidate potential mechanisms, we studied effects of BC on lung gene expression. We used a Beta-carotene 15,15'-monooxygenase 1 (Bcmo1) knockout mouse $\left(\mathrm{Bcmo1}^{-1}\right)$ model, unable to convert $\mathrm{BC}$ to retinoids, and wild type mice $\left(\mathrm{Bcmo}^{+/+}\right)$mice to dissect the effects of intact $\mathrm{BC}$ from effects of $\mathrm{BC}$ metabolites. As expected, $\mathrm{BC}$ supplementation resulted in a higher $\mathrm{BC}$ accumulation in lungs of $\mathrm{Bcmol}^{1 / 2}$ mice than in lungs of $\mathrm{Bcmo1}^{+/+}$mice. Whole mouse genome transcriptome analysis on lung tissue revealed that more genes were regulated in $\mathrm{Bcmo}^{-1}$ mice than $B \mathrm{Cmo}^{+/+}$mice upon BC supplementation. Frizzled homolog 6 (Fzd6) and Collagen triple helix repeat containing 1 (Cthrc1) were significantly downregulated (fold changes -2.99 and -2.60 respectively, $\mathrm{FDR}<0.05$ ) by $\mathrm{BC}$ in $\mathrm{Bcmo} 1 \%$. Moreover, many olfactory receptors and many members of the protocadherin family were upregulated. Since both olfactory receptors and protocadherins have an important function in sensory nerves and Fzd6 and Cthrc1 are important in stem cell development, we hypothesize that $\mathrm{BC}$ might have an effect on the highly innervated pulmonary neuroendocrine cell (PNEC) cluster. PNECs are highly associated with sensory nerves and are important cells in the control of stem cells. A role for BC in the innervated PNEC cluster might be of particular importance in smoke induced carcinogenesis, since PNEC derived lung cancer is highly associated with tobacco smoke. 


\section{Downregulation of Fzd6 and Cthre 1 and upregulation of olfactory recep- tors and protocadherins by dietary beta-carotene in lungs of BCmo $1 \%$ mice}

Carcinogenesis

Yvonne G.J. van Helden, Roger W. Godschalk, Sandra G. Heil, Annelies Bunschoten, Susanne Hessel, Jaume Amengual, M. Luisa Bonet, Johannes von Lintig, Frederik J. van Schooten, Jaap Keijer 


\section{Introduction}

Beta-carotene $(\mathrm{BC})$ is an orange colored phytochemical, present in for example dark green vegetables and oranged colored fruits and is widely used as a coloring agent. BC can be metabolized into vitamin A and is used in supplements to correct for vitamin A deficiency. BC is considered to be a health promoting agent because of its antioxidant properties, thereby preventing radical induced macromolecular damage. Indeed, many epidemiological studies showed that an increased intake of dietary BC, as well as increased BC plasma concentration, is associated with a decreased risk for cardiovascular diseases and several types of cancer, including lung cancer [1,2]. Because of this, two large scale human intervention trials were performed with the intention to decrease lung cancer risk by BC supplementation in male smokers (Alpha-Tocopherol and BetaCarotene study; ATBC) and in male and female smokers or asbestos exposed subjects (Carotenoid and Retinol efficacy Trial; CARET). Unexpectedly, both studies showed an increased lung cancer risk upon $\mathrm{BC}$ supplementation compared to placebo supplemented subjects $[3,4]$. At the same time a study performed mainly in non-smokers showed no effect of BC on lung cancer risk [5]. Together these studies indicate that BC has health promoting capacities, but high intakes can also result in adverse health effects such as an increased lung cancer risk in smokers and asbestos exposed subjects. The underlying mechanisms for the adverse effects of $\mathrm{BC}$ action are not precisely known, although several mechanisms have been suggested, e.g. BC or BC metabolites can become pro-oxidants at high concentrations [6] or in combination with oxidative stress [7]. There is also evidence that $\mathrm{BC}$ supplementation can result in different levels of the bioactive $\mathrm{BC}$ metabolites such as retinoic acid, which is able to bind to retinoic acid receptors (RAR) and retinoid X receptors (RXR) to activate these transcription factors. Additionally, retinoic acid-induced catabolism, can decrease RAR and RXR activity thereby specifically increasing cell proliferation [8]. However, the exact mechanism is unknown mainly because BC metabolism greatly differs between humans and mammalian model organisms such as mice.

In humans, an increased intake of $\mathrm{BC}$ results in an increase in plasma concentrations of $\mathrm{BC}$ and its metabolites. Beta-carotene 15,15'-monooxygenase 1 (Bcmo1) is a key enzyme in $\mathrm{BC}$ metabolism and cleaves $\mathrm{BC}$ symmetrically to form 2 molecules of retinal, which can be further metabolized into several other downstream BC metabolites [9]. Rodents, which are herbivores and therefore depend on the production of vitamin $\mathrm{A}$ from provitamin A carotenoids such as $\mathrm{BC}$, possess a more active Bcmol variant than man. While in humans a significant portion of $\mathrm{BC}$ is found intact in plasma, rodents cleave virtually all absorbed $\mathrm{BC}$ to facilitate their vitamin A requirements [10].

The aim of our study was to investigate $\mathrm{BC}$-induced gene expression changes in the lung. Therefore, male $\mathrm{Bcmo1}^{+/+}$mice and $\mathrm{Bcmo1/-}$ mice, were fed for 14 weeks with a 
vitamin A sufficient diet (1,500 IU $/ \mathrm{kg}$ ) without (control) or with supplementation of BC (BC, $150 \mathrm{mg} / \mathrm{kg}$ diet) and microarray analysis was performed (mouse whole genome arrays) on lung cRNA. We were mainly interested in effects of $\mathrm{BC}$ in the $\mathrm{Bcmo1} /$ - mice since $\mathrm{BC}$ is able to accumulate in tissues of these mice [11]. To dissociate effects induced by $\mathrm{BC}$ from effects induced by $\mathrm{BC}$ metabolites $\mathrm{Bcmo1^{+/+ }}$ mice were taken along.

\section{Material \& Methods}

\section{Animals and treatment}

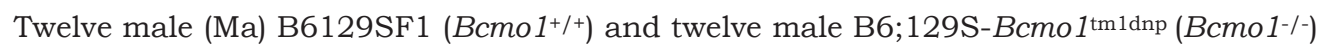
mice, previously described by Hessel et al. [11] were used for the experiment. The mouse experiment was conducted in accordance with the German animal protection laws by the guidelines of the local veterinary authorities. During the breeding and weaning periods of the mice, dams were maintained on KLIBA 3430 chow diet containing 14,000 IU vitamin A/kg (Provima Kliba AG, Kaiseraugst, Switzerland). Five-week-old $\mathrm{Bcmo1}^{+/+}$and $\mathrm{Bcmo1/-}$ mice were caged in groups containing 2 to 3 siblings per group and were maintained under environmentally controlled conditions (temperature $24{ }^{\circ} \mathrm{C}$, $12 \mathrm{~h} / 12 \mathrm{~h}$ light/dark cycle). Mice had ad libitum access to feed and water. Basic feed consisted of the palletized diet D12450B (Research Diets Inc, USA) with a fat content of $10 \%$. The diet was modified to contain 1,500 IU vitamin A per $\mathrm{kg}$ of diet, which is a vitamin A sufficient diet, and the control diet (control) was supplemented with water soluble vehicle beadlets (DSM Nutritional Products Ltd., Basel, Switzerland) containing DL-alpha-tocopherol and ascorbyl palmitate as stabilizers, as well as carriers such as gelatine, corn oil sucrose and starch. The BC diet (BC) was supplemented with identical water soluble beadlets containing BC (DSM Nutritional Products Ltd., Basel, Switzerland) to generate $150 \mathrm{mg} \mathrm{BC} / \mathrm{kg}$ diet. Beadlets were added by the manufacturer before low temperature pelletting. Feed pellets were color marked and stored at $4^{\circ} \mathrm{C}$ in the dark. After 14 weeks of dietary intervention, $6 \mathrm{Bcmo1^{+/+ }}$ mice on the control diet $\left(\mathrm{Bcmo1}^{+/+} \mathrm{Co}\right), 6 \mathrm{Bcmo1}^{+/+}$mice on the $\mathrm{BC} \operatorname{diet}\left(\mathrm{Bcmo1}^{+/+} \mathrm{BC}\right), 6 \mathrm{Bcmo1^{-/- }}$ on the control $\operatorname{diet}(\mathrm{Bcmo1} /-\mathrm{Co})$ and $6 \mathrm{Bcmo1} /-$ on the $\mathrm{BC} \operatorname{diet}\left(\mathrm{Bcmo1}^{-/-} \mathrm{BC}\right)$ were randomly sacrificed during 3 subsequent mornings. Blood was collected from the vena cava after isoflurane and ketamin anethesia. Blood was coagulated for at least 20 minutes at room temperature, cooled to $4^{\circ} \mathrm{C}$ and centrifuged. Lung tissue was removed, rinsed in phosphate buffered saline (PBS) and snap frozen in liquid nitrogen. The lung tissues were stored at $80^{\circ} \mathrm{C}$. 


\section{HPLC Separation of Retinoids and Carotenoids}

Retinoids and carotenoids were extracted from lung tissues and plasma under dim red safety light $(\lambda \geq 600 \mathrm{~nm})$. Briefly, tissues $(20-40 \mathrm{mg})$ were homogenized in $200 \mu 1$ of $2 \mathrm{M}$ hydroxylamine ( $\mathrm{pH}$ 6.8) and $200 \mu \mathrm{l}$ of methanol with a glass homogenizer. For determination of $\mathrm{BC}$ and retinol in serum, $180 \mu \mathrm{l}$ serum was added to $200 \mu \mathrm{l}$ methanol. Then $400 \mu 1$ acetone was added either to these plasma or tissue extracts. Extraction of carotenoids and retinoids was performed with petroleum ether. The extraction was repeated three times, and the collected organic phases were dried under nitrogen and dissolved in HPLC solvent (n-hexane/ethanol, 99.5:0.5). HPLC separation of BC and retinoids and quantification of peak integrals was performed as previously described [9]. Solvents for HPLC and extraction were purchased in HPLC grade from Merck (Darmstadt, Germany).

\section{Histology of the lung}

Small pieces of upper right lung tissue of 2 randomly selected animals per group were fixed by immersion in $0.1 \mathrm{M}$ sodium phosphate buffer containing $4 \%$ paraformaldehyde (pH 7.4) overnight at $4^{\circ} \mathrm{C}$, thereafter dehydrated, cleared and then paraffin-embedded. Three $\mu \mathrm{m}$-thick sections were cut and stained with Periodic Acid Schiff (PAS) and Mayer's hematoxylin for histological analysis.

\section{RNA Isolation}

Left lung lobes were homogenized in liquid nitrogen using a cooled mortar and pestle. Total RNA was isolated using TRIzol reagent (Invitrogen, Breda, The Netherlands) followed by purification using RNeasy columns (Qiagen, Venlo, The Netherlands) using the instructions of the manufacturer. RNA concentration and purity were measured using the Nanodrop system (IsoGen Life Science, Maarsen, The Netherlands). Approximately $30 \mu \mathrm{g}$ of total RNA was isolated with $\mathrm{A}_{260} / \mathrm{A}_{280}$ ratios above 2 and $\mathrm{A}_{260} / \mathrm{A}_{230}$ ratios above 1.9 for all samples, indicating good RNA purity. RNA degradation was checked on the Experion (Bio-Rad, Veenendaal, The Netherlands) using Experion StdSense chips (BioRad).

\section{Microarray hybridization procedure}

The 4x44k Agilent whole mouse genome microarrays (G4122F, Agilent Technologies, Inc. Santa Clara, CA) were used. Preparation of the sample and the microarray hybridization were carried out according to the manufacturer's protocol with a few exceptions as described previously [12,13]. In brief, cDNA was synthesized from $1 \mu \mathrm{g}$ lung RNA using the Agilent Low RNA Input Fluorescent Linear Amplification Kit for each animal without addition of spikes. Thereafter samples were split in 2 equal amounts, to synthesize Cyanine 3-CTP (Сy3) and Cyanine 5-CTP (Cy5) labeled cRNA using half the 
amounts per dye as indicated by the manufacturer (Agilent Technologies). Labeled cRNA was purified using RNeasy columns (Qiagen). Yield, $\mathrm{A}_{260} / \mathrm{A}_{280}$ ratio and $\mathrm{Cy} 3$ and $\mathrm{Cy} 5$ activity were examined for every sample using the nanodrop. All samples met the criteria of a cRNA yield higher than $825 \mathrm{ng}$ and a specific activity of at least 8.0 pmol Cy3 and Cy5. 1200 ng of every Cy3 labeled cRNA sample was pooled and used as a common reference pool. Individual $825 \mathrm{ng}$ Cy5-labeled cRNA and $825 \mathrm{ng}$ pooled Cy3-labeled cRNA were fragmented in $1 \mathrm{x}$ fragmentation and $1 \mathrm{x}$ blocking agent (Agilent Technologies) at $60^{\circ} \mathrm{C}$ for 30 minutes and thereafter mixed with GEx Hybridization Buffer HI-RPM (Agilent Technologies) and hybridized in a $1: 1$ ratio at $65^{\circ} \mathrm{C}$ for 17 hours in an Agilent Microarray hybridization Chamber rotating at $4 \mathrm{rpm}$. After hybridization, slides were washed according to the wash protocol with Stabilization and Drying solution (Agilent Technologies). Arrays were scanned with an Agilent scanner with 10\% and 100\% laser power intensities (Agilent Technologies).

\section{Data analyses of microarray results}

Signal intensities for each spot were quantified using Feature Extraction 9.1 (Agilent Technologies). Median density values and background values of each spot were extracted for both the experimental samples (Cy5) and the reference samples (Cy3). Quality control for every microarray was performed visually, by using Quality control graphs from Feature extraction and M-A plots and boxplots which were made using limmaGUI in R (Bioconductor) [14]. Data were imported into GeneMaths XT 2.0 (Applied Maths, Sint-Martens-Latem, Belgium). Spots with a Cy5 and Cy3 signal twice above background were selected and log transformed. The Cy5 signal was normalized against the Cy3 intensity as described before [15]. Supervised principal component analysis and self organizing map (SOM) analysis were performed using GeneMaths XT. Direct biological interaction analysis was performed using GO overrepresentation analysis (ErmineJ) [16] and literature mining.

\section{Analysis of mRNA expression by real-time quantitative PCR (Q-PCR)}

Differential gene expression of frizzled homolog 6 (Fzd6), collagen triple helix repeat containing 1 (Cthrc1), olfactory receptor 437 (Olfr437) and protocadherin beta 9 (Pcdhb9) were analyzed using Q-PCR to validate microarray results. $1 \mu \mathrm{g}$ RNA isolated from lung of individual animals was converted into cDNA using the iScript cDNA Synthesis Kit (Bio-Rad). One sample was taken along without reverse transcriptase to examine the presence of DNA (-RT reaction). An equal amount of cDNA of all individual samples was pooled and diluted (10x, 31.6x 100x, 316x 1000x, 3160x, 10000x) for the generation of a calibrationcurve. Each PCR reaction $(25 \mu \mathrm{l})$ contained $1 \mathrm{x}$ iQ SYBR green supermix (Bio-Rad), $10 \mu \mathrm{M}$ sense primer, $10 \mu \mathrm{M}$ antisense primer and $2 \mu 1100$ times diluted cDNA. Primers for Fzd6 were sense 5'-ACTCCCAGCGCCAAAGATCG-3' and antisense 5'GCAGAGATGTGGAGCCCTTGAG-3', for Cthrc1 sense 5'-TGGACCAAGGAAGCCCTGAGT- 
3' and antisense 5'-TGAACAGGTGCCGACCCAGA-3, for Olfr437 sense 5'TGGCCTGCGCCGACACTTTG and anti-sense: 5'-GGCCTTCCTGCGACCCTCCT and for Pcdh9 sense 5'- TGTTAGTGGATGGCTTCT and anti-sense 5'- ATGACCAGGTACAATGTAAG. For the amplification of the reference genes we used for Syntaxin $5 a$ ( Stx5a) sense 5'-TTAAAGAACAGGAGGAAACGATTCAGAG-3' and antisense 5'CAGGCAAGGAAGACCACAAAGATG-3', and for ring finger protein 130 (Rnf130) sense 5'ACAGGAACCAGCGTCGTCTTG-3' and antisense 5'ACCCGAACAACATCATTCTGCTTATAG-3', which showed equal gene expression levels for all individual animals on the microarray. These intron-spanning primers were designed using Beacon designer 7.00 (Premier Biosoft International, Palo Alto, CA) or using primer-BLAST (http://www.ncbi.nlm.nih.gov/). Amplification was performed in duplicate for Fzd6 and Cthrc1 and in quadruplets for Olfr437 and Pcdhb9, because of the relatively low absolute expression levels and relatively low fold changes, using the MyIQ single-color real-time PCR detection system (Bio-Rad) using the following temperature cycles: $1 \mathrm{x} 3 \mathrm{~min}$ at $95^{\circ} \mathrm{C}, 40 \mathrm{x} 2$-step amplification $\left(15 \mathrm{~s} 95^{\circ} \mathrm{C}, 45 \mathrm{~s} 60^{\circ} \mathrm{C}(\right.$ Fzd $6, C$ thrc 1 , Stx $5 a$ and Rnf130) or $54^{\circ} \mathrm{C}($ Olfr 437$)$ or $57.5^{\circ} \mathrm{C}\left(\right.$ Pcdhb9)), $1 \mathrm{x} 1 \mathrm{~min} 95^{\circ} \mathrm{C}, 1 \mathrm{x} 1 \mathrm{~min} 65^{\circ} \mathrm{C}$ followed by melting curve analysis $\left(60 \times 10 \mathrm{~s} 65^{\circ} \mathrm{C}\right.$ with an increase of $0.5^{\circ} \mathrm{C}$ per $\left.10 \mathrm{~s}\right)$. A negative control without cDNA template and the $-\mathrm{RT}$ sample were taken along with every assay. Using the standard curves for every gene, the relative level of expression of all genes was calculated. Normalized Gene Expression $(\Delta \Delta \mathrm{CT})$ analysis for Fzd6 and Cthrc1 was calculated using the IQ5 software version 2.0 (Bio-Rad).

\section{Statistical analysis}

Fold changes for both microarray gene expression and Q-PCR gene expression were calculated using mean log signal intensities. P-values for differential expressions were calculated between 2 groups using Student's $t$-test statistics on log intensity values (Excel version 2003). Changes were considered statistically significant at $\mathrm{p}<0.05$. To identify "marker regulated genes" from other regulated genes, the Benjamini Hochberg false discovery rate (FDR) testing method (Genemaths XT) was used. The effects of Diet (BC) and Genotype (knockout of Bcmo1) on concentrations of $\mathrm{BC}$, retinol and retinyl esters in lung and serum were analyzed using 2x2 factorial univariate ANOVA (SPSS version 15.0) and considered statistically significant when $\mathrm{p}<0.05$. A Student's $t$-test was used to test for the effect of a $\mathrm{BC}$ diet versus control diet and considered statistically significant when $\mathrm{p}<0.05$. Correlations and differences in correlations between BC concentration and $\mathrm{BC}$ metabolite concentrations in lung were tested (SPSS) and considered significant when $\mathrm{p}<0.05$. 


\section{Results}

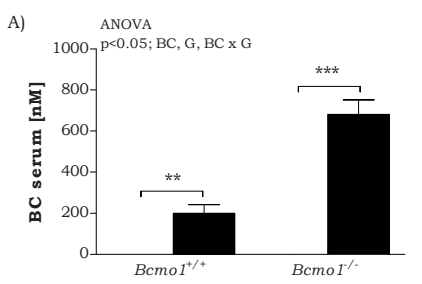

D)
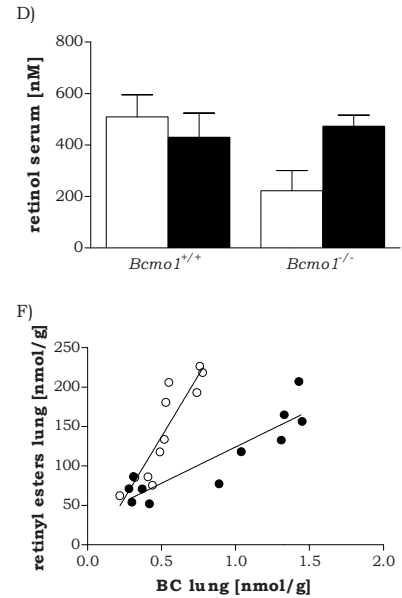
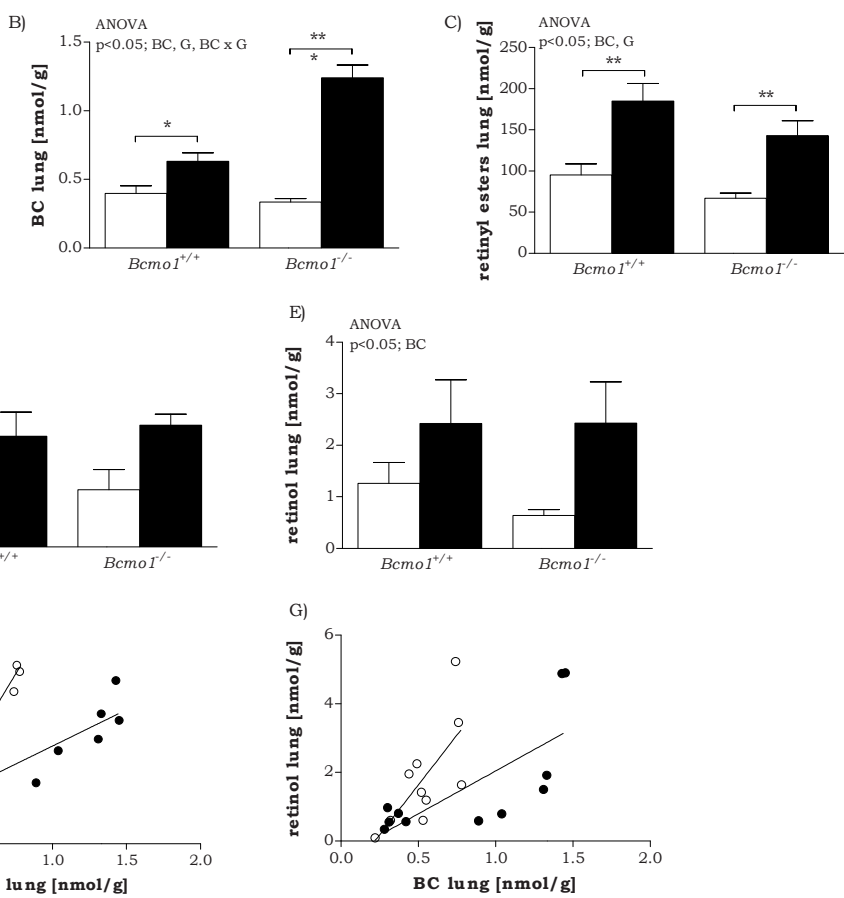

Figure 1: $\mathrm{BC}$ and $\mathrm{BC}$ metabolite concentrations in lungs of $\mathrm{Bcmo1}^{+/+}$and $\mathrm{Bcmo} \mathrm{1/-} \mathrm{mice.} \mathrm{Beta-carotene}$ (BC) concentration in serum (A) and lung tissue (B), retinyl ester concentration in lung tissue (C), retinol concentrations in serum (D) and in lung tissue (E) of male $\mathrm{Bcmo1}^{+/+}$mice and $\mathrm{Bcmo1/-}^{-/ \mathrm{ce}^{-}}$fed a control diet (white bars) or a $\mathrm{BC}$ diet (black bars). Correlation of $\mathrm{BC}$ concentration and retinyl ester concentration in lung $(\mathrm{F})\left(B c m o 1^{+/+}: \mathrm{R}=0.90, \mathrm{p}<0.001 ; B c m o 1^{-/-:} \mathrm{R}=0.89, \mathrm{p}<0.001\right)$ with significant different slopes $(\mathrm{p}<0.001)$ for $\mathrm{Bcmo1}^{+/+}($slope $=311.8)$ and Bcmo1/- $(91.94)$ and correlation of BC concentration and retinol concentration in lung $(\mathrm{G})\left(B c m o 1^{+/+}: \mathrm{R}=0.705, \mathrm{p}<0.05 ; B c m o 1^{-/-:} \mathrm{R}=0.746\right.$, $\mathrm{p}<0.01$ ) with non-significant different slopes measured in $\mathrm{Bcmo}^{+/+}$mice (open circles) and $\mathrm{Bcmo1/-}$ mice (closed circles). Concentrations (A-E) are expressed as mean \pm SEM, significance was tested for Diet $(B C)$ and Genotype $(G)$ using ANOVA and considered significant at $p<0.05$. Significant effects for the different factors; Diet $(\mathrm{BC})$, Genotype $(\mathrm{G})$ or an interaction $(\mathrm{BC} \times \mathrm{G})$ are displayed on top of each Figure. A Student's $t$-test was used between BC and control groups when there was a significant Diet effect using ANOVA, and considered significant when $\mathrm{p}<0.05$. Using t-test statistics: ${ }^{*} \mathrm{p}<0.05,{ }^{* *} \mathrm{p}<0.01$ and ${ }^{* * *} \mathrm{p}<0.001$.

\section{BC metabolism in Bcmo1-/- mice and $\mathrm{BCmo1}^{+/+}$mice}

$\mathrm{BC}$ supplementation resulted in increased $\mathrm{BC}$ concentrations in serum and lung tissue. $B \mathrm{cmo1}^{-1}$ - mice accumulated $\sim 3.5$ times more $\mathrm{BC}$ in serum and $\sim 2$ times more $\mathrm{BC}$ in lung 
tissue than $\mathrm{Bcmo1}^{+/+}$mice upon $\mathrm{BC}$ supplementation. $\mathrm{BC}$ supplementation also resulted in an increased lung retinol and retinyl ester concentration in both $\mathrm{Bcmo1}^{+/+}$ mice and $\mathrm{Bcmo1} / \mathrm{-}$ mice (Fig. $1 \mathrm{~A}-\mathrm{E}$ ). Correlations between concentrations of $\mathrm{BC}$ with retinol and $\mathrm{BC}$ with retinyl esters in mouse lung were made to investigate a possible dysregulation in $\mathrm{BC}$ metabolite accumulation. $\mathrm{BC}$ concentrations correlated significantly with retinol $(\mathrm{R}=0.705, \mathrm{p}<0.05)$ and retinyl ester $(\mathrm{R}=0.90, \mathrm{p}<0.001)$ concentrations in lungs of $\mathrm{Bcmol}^{+/+}$mice. In $\mathrm{Bcmo1/-}$ there was also a significant positive correlation between $B C$ and retinol $(R=0.74 p<0.01)$ or retinyl esters $(R=0.89, p<0.001)$ in the lung. The slope of the correlation between $\mathrm{BC}$ and retinyl ester concentration in lungs of $B \mathrm{cmo1}^{-/-}$compared to $\mathrm{Bcmo1}^{+/+}$mice were significantly different $(\mathrm{p}<0.001)$, a similar difference in slopes was shown in the correlation between $\mathrm{BC}$ and retinol, this was however not significant (Fig. $1 \mathrm{~F}$ and $1 \mathrm{G}$ ).

We also investigated whether gene expression differences were present in downstream $\mathrm{BC}$ metabolizing enzymes in $\mathrm{Bcmo1}^{-/}$mice as compared to $\mathrm{Bcmo1}^{+/+}$mice and in $\mathrm{BC}$ supplemented mice compared to control diet fed mice. We found: downregulation in gene expression of alcohol dehydrogenase 7 (class IV), mu or sigma polypeptide (Adh7); upregulation in gene expression of aldehyde dehydrogenase family 1, subfamily A2 (Aldh1a2); upregulation in gene expression of aldehyde dehydrogenase 2, mitochondrial (Aldh2); and an upregulation in gene expression of lecithin-retinol acyltransferase (phosphatidylcholine-retinol-O-acyltransferase) (Lrat) in Bcmo1/- mice (Table 1) as compared to $\mathrm{Bcmo1}^{+/+}$mice.

Table 1: Genes involved in downstream $\mathrm{BC}$ metabolism and retinoic acid catabolism that were regulated by BC supplementation or knockout of Bcmo1.

\begin{tabular}{|c|c|c|c|c|c|c|}
\hline \multirow[b]{3}{*}{$\begin{array}{l}\text { Gene } \\
\text { symbol }\end{array}$} & \multirow[b]{3}{*}{ Gene name } & \multirow[b]{3}{*}{ Probe name } & \multicolumn{4}{|c|}{ Gene expression* } \\
\hline & & & \multicolumn{2}{|c|}{ Bcmo1 1+/ $^{+}$} & \multicolumn{2}{|c|}{ Bcmo1 $/-$} \\
\hline & & & Co & BC & Co & BC \\
\hline Adh7 & $\begin{array}{l}\text { Alcohol dehydrogenase } 7 \text { (class IV), mu } \\
\text { or sigma polypeptide }\end{array}$ & A_51_P233797 & $1.00^{\mathrm{a}}$ & $1.01^{\mathrm{a}}$ & $-1.83^{b}$ & $-1.62^{b}$ \\
\hline Aldh1a2 & $\begin{array}{l}\text { Aldehyde dehydrogenase family } 1 \text {, sub- } \\
\text { family A2 }\end{array}$ & A_52_P58145 & $1.00^{\mathrm{a}}$ & $-1.02^{a}$ & $1.35^{\mathrm{b}}$ & $1.32^{\mathrm{b}}$ \\
\hline Aldh2 & $\begin{array}{l}\text { Aldehyde dehydrogenase 2, mitochon- } \\
\text { drial }\end{array}$ & A_52_P13109 & $1.00^{\mathrm{a}}$ & $-1.03^{a}$ & $1.49^{\mathrm{b}}$ & $1.49^{\mathrm{b}}$ \\
\hline Lrat & $\begin{array}{l}\text { Lecithin-retinol acyltransferase (phos- } \\
\text { phatidylcholine-retinol-O- } \\
\text { acyltransferase) }\end{array}$ & A_52_P669005 & $1.00^{\mathrm{a}}$ & $1.57^{\mathrm{b}}$ & $1.80^{\mathrm{bc}}$ & $2.67 \mathrm{c}$ \\
\hline
\end{tabular}

*gene expression relative to $\mathrm{Bcmol}^{+/+}$control mice, different letters indicate a significant difference $(\mathrm{p}<0.05)$

Altogether, these data show that $\mathrm{BC}$ accumulation was present in $\mathrm{BC}$ supplemented $B c m o 1^{-1}$ mice. The tight correlation between retinyl esters and $\mathrm{BC}$ supplementation in both $\mathrm{Bcmo1}^{+/+}$mice was still tightly correlated in $\mathrm{Bcmo1-/-}$, although the ratio BC:retinyl 
esters was much higher in $\mathrm{Bcmo1}^{-/-}$mice. Moreover, the knockout of the important BC metabolizing enzyme Bcmo1 resulted in a changed gene expression of other important downstream $\mathrm{BC}$ metabolizing enzymes.

\section{BC supplementation downregulates Fzd6 and Cthrc1 gene expression in Bcmo1/- mice}

Histology did not show any obvious difference in lung structure between mice of the four different groups (data not shown). We also analyzed gene expression changes in the lung of $\mathrm{Bcmo1}^{+/+}$mice and in $\mathrm{Bcmo1/-}$ mice after feeding a $\mathrm{BC}$ diet. Supervised principal component analysis showed that mice were clearly separated based on genotype (principal component 1) and that Bcmo1/- mice receiving the control diet were clearly separated from $\mathrm{Bcmo} 1^{-/}$mice receiving the $\mathrm{BC}$ supplemented diet (principal component 2) (Fig. 2A). From the 43379 probe sets (number of spots without control spots) present on the array, 33414 spots had an intensity of more than twice above the background. Of these spots, 326 were differentially expressed $(\mathrm{p}<0.05)$ in $\mathrm{Bcmol}^{+/+}$mice $($genes are listed in supplemental Table http://www.hap.wur.nl/UK/Publications/Supplemental+data/) and 1474 were differentially expressed $(\mathrm{p}<0.05)$ in $\mathrm{Bcmo1}^{-1}$ mice (genes are listed in supplemental Table 2, http:/ /www.hap.wur.nl/UK/Publications/Supplemental+data/) upon BC supplementation (Fig. 2B). Since BC accumulation was higher in Bcmo1/- mice and more genes were significantly differentially expressed in $\mathrm{Bcmo1} /$ mice, we further focused on effects of $\mathrm{BC}$ in this group. To identify key $\mathrm{BC}$ regulated genes, false discovery rate testing (FDR) was performed. Two genes were downregulated by $\mathrm{BC}$ with a FDR $<0.05$; frizzled homolog 6 (Fzd6) and collagen triple helix repeat containing 1 (Cthrc1) with a fold change of -2.99 and -2.60 , respectively, in BC supplemented $\mathrm{Bcmo1^{-/- }}$ compared to Bcmo $1^{-/}$control mice. These genes had also the lowest p-values in the data-set (Fig. 2C).

The significant downregulation of Fzd6 and Cthrc1 was confirmed by Q-PCR (Figure 3A and B). Nutritional intervention studies usually produce mild transcriptional effects and in many cases no genes pass FDR selection [17]. Therefore we consider the BC induced changes in Fzd6 and Cthrc1 gene expression as being important and further focused on these two genes, especially because these two genes may be involved in the same pathway. The expression of the genes Fzd6 and Cthrc1 was compared between all four groups; control Bcmo1 ${ }^{+/+}$, BC supplemented $\mathrm{Bcmo1}^{+/+}$, control $\mathrm{Bcmo1} 1^{-/}$and $\mathrm{BC}$ supplemented $\mathrm{Bcmo1^{+/+ }}$ to examine if effects were specific for $\mathrm{BC}$ supplementation in $\mathrm{Bcmo1}^{-/-}$mice. Indeed, $\mathrm{BC}$ supplementation resulted in a significant down regulation of Fzd6 and Cthrc1 only in Bcmo1/- mice and not in $\mathrm{Bcmo}^{1^{+/+}}$mice (Fig. 3C). 
A)

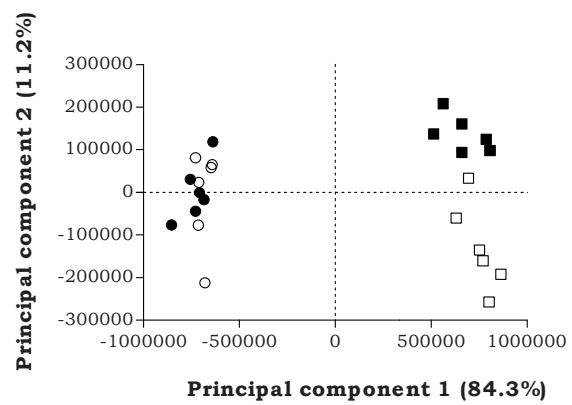

B)

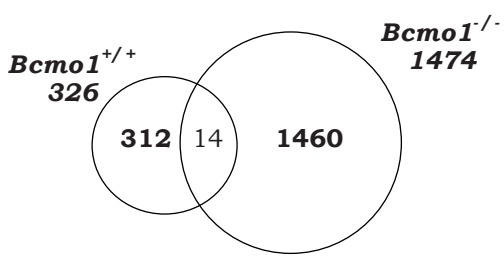

C)

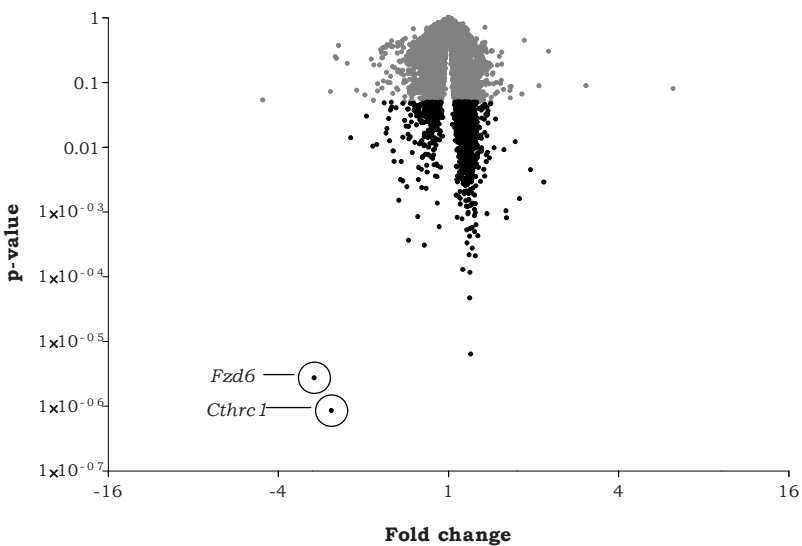

Figure 2: Presentation of $\mathrm{BC}$ induced gene expression effects in $\mathrm{Bcmo1^{-/ }}$ and $\mathrm{Bcmo1}^{+/+}$mice. (A) Supervised principal component analysis (SPCA) of Bcmo1+/+ mice (circles), Bcmo1/- mice (squares) receiving a control diet (open symbol) or BC diet (closed symbol). Mice are clearly separated based on genotype (x-axis) and $\mathrm{Bcmo1 \%}$ mice receiving the $\mathrm{BC}$ diet are clearly separated from $\mathrm{Bcmo1 \%}$ - control mice. (B) Venn diagram representing the number of regulated genes $(p<0.05)$ upon BC supplementation in $\mathrm{Bcmo}^{+/+}$mice (left circle) and $\mathrm{Bcmo1/-}$ mice (right circle) and the number of overlapping regulated genes in both groups. (C) Volcano plot representing the effect of BC supplementation on fold change gene expression difference in Bcmo 1/- mice compared to the control diet (x-axis) and the corresponding Student's $t$-test p-value on the y-axis. This plot clearly shows a similar low p-value and relatively high absolute fold change for both Cthrc1 and Fzd6. In grey are all genes with $\mathrm{p}>0.05$ and in black all genes with $\mathrm{p}<0.05$. 
A)

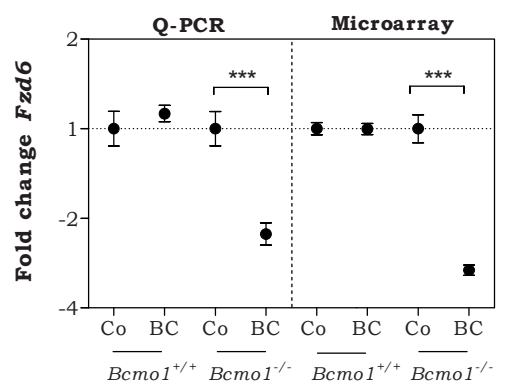

B)

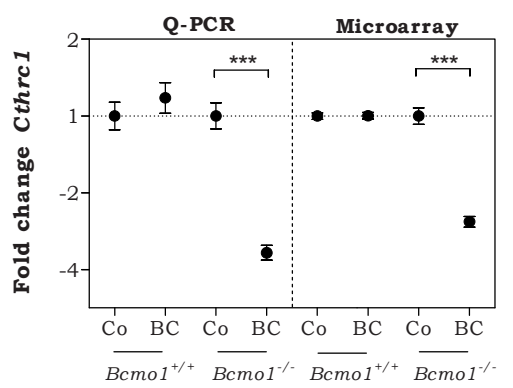

C)

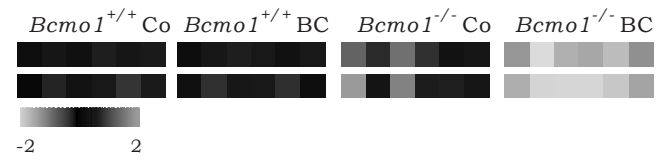

Gene name

Gene symbol

Collagen triple helix repeat containing 1 Cthrc1

Frizzled homolog 6

Fzd6

Fig. 3: The expression of the genes Fzd6 (A) and Cthrc1 (B) in the BC supplemented mice relative to the control diet fed mice were confirmed by Q-PCR using the stable reference genes Stx5a and Rnf130. Data represent the average gene expression \pm SEM compared to $B c m o 1^{+/+}$control mice. ${ }^{* * *} \mathrm{p}<0.001$ using a Student's $t$-test on the log transformed data. (C) Microarray based heatmap shows a low interindividual difference between the mice for the genes Cthrc1 and Fzd6 and a decreased gene expression of these genes in $\mathrm{BC}$ supplemented $\mathrm{Bcmo1} \%$ mice compared to $\mathrm{Bcmo1} 1^{+/+}$mice and $\mathrm{Bcmo1} \%$ control mice. For color figure see Color Figures section.

\section{Overrepresented gene-ontology (GO) processes by BC supplementation in Bcmo1\%-}

Self organizing map (SOM) analysis is a technique that groups genes with a similar inter-individual gene expression pattern in the same cluster. The distance between the clusters in the clustering profile represents the degree of difference in gene expression patterns [18]. We applied SOM analysis to identify genes regulated with similar interindividual variations in gene expression as Fzd6 and Cthrc1. The total number of SOM profiles was set to 144 , corresponding to an average of approximately 10 genes per profile [12]. SOM analysis clustered all genes into only 5 clusters from the 144 possible clusters. Moreover, clusters were relatively close together which indicates that all regulated genes $(\mathrm{p}<0.05)$ have a relatively similar variation in gene expression pattern between animals (Fig. 4). Knowledge is limited concerning the function of Cthrc1 and Fzd6 in lung. Overrepresented Gene Ontology (GO) processes might result in a hypothesis concerning the function of $\mathrm{BC}$ or $\mathrm{BC}$ induced Fzd6 and Cthrc1 regulation in lung tissue. Since significantly regulated genes had a relative similar gene expression pattern according to SOM analysis, we performed GO analysis using the bioinformatics tool ErmineJ, using all genes and their corresponding p-values, and not a subset of genes. 

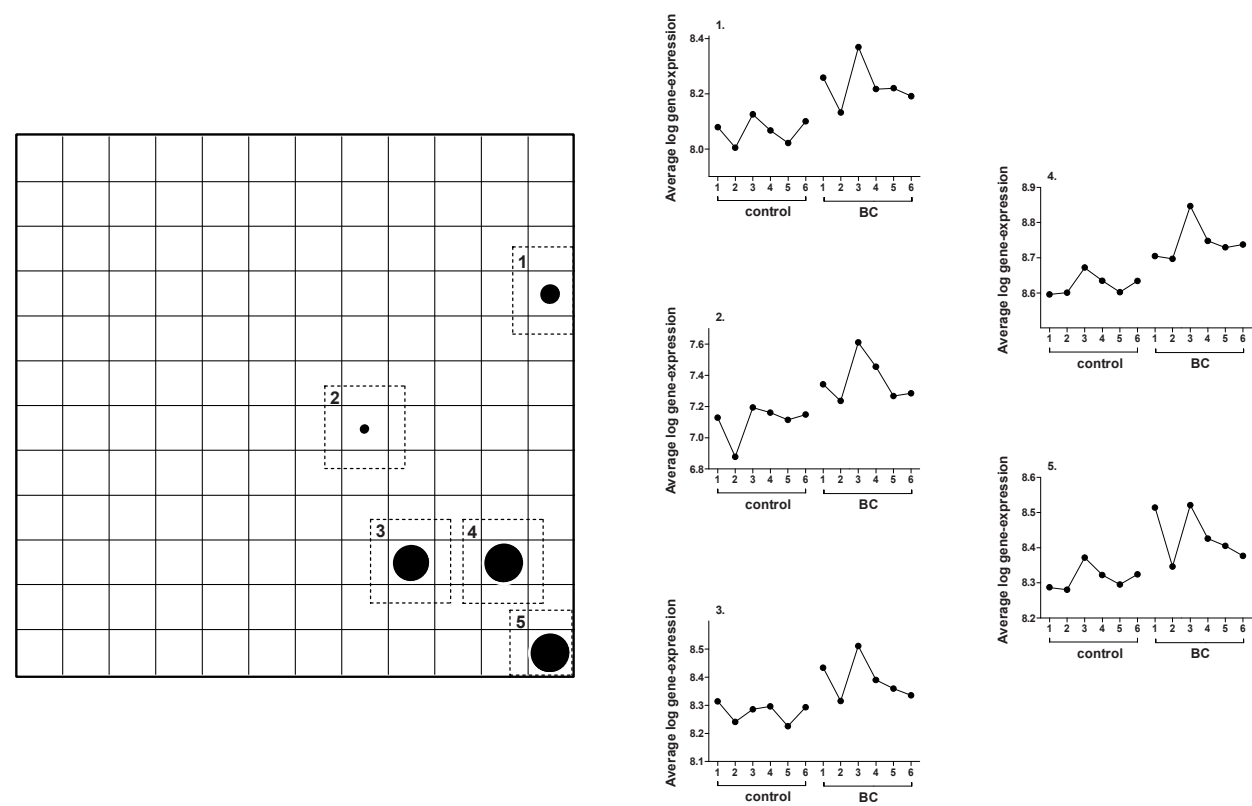

Figure 4: Self Organizing Maps (SOM) profile for BC regulated genes $(\mathrm{p}<0.05)$ in $\mathrm{Bcmo1} /$ - mice. SOM analysis presents all genes with a similar inter-individual gene expression within one group. The number of possible SOM profiles was set to 144, corresponding to an average of around 10 genes per profile [12]. The average gene expression pattern of every cluster is plotted with corresponding cluster numbers. Average log gene expression (y-axis) per cluster is plotted per animal (x-axis) with a rank of increasing animal number per group.

The four overrepresented GO processes with the lowest p-value were: GO:0007608; sensory perception of smell $\left(\mathrm{p}=1.89 \times 10^{-9}\right)$, GO:0007606; sensory perception of chemical stimulus $\left(\mathrm{p}=1.54 \times 10^{-8}\right)$ and GO:0007156; homophilic cell-adhesion ( $\left.\mathrm{p}=2.44 \times 10^{-08}\right)$ (Supplemental Table 3, http://www.hap.wur.nl/UK/Publications/Supplemental+data). The GO processes sensory perception of smell and sensory perception of chemical stimulus contained the same different olfactory receptors (Olfr) (26 different Olfr and cyclic nucleotide gated channel alpha 2 (Cnga2) $\mathrm{p}<0.05)$ (Table 2). The GO process homophilic celladhesion contained mainly different forms of the clustered cadherin family ( 9 different protocadherin beta's, 2 protocadherins, 2 different cadherins and desmoglein $\mathrm{p}<0.05$ ) (Table 2). Q-PCR confirmed the upregulation of Olfactory receptor 437 (Olfr437) and Protocadherin beta 9 (Pcdhb9) in Bcmo1\% mice after BC supplementation (Fig 5A and B). The significantly regulated olfactory receptors and protocadherins were present in all SOM profiles, which had relatively similar average gene expression patterns between the animals. 
Table 2: Genes present $(\mathrm{p}<0.05)$ in the three most significantly BC regulated GO processes as determined by ErmineJ in lung tissue of Bcmo 1/- mice.

\begin{tabular}{|c|c|c|c|c|c|c|}
\hline \multirow[b]{2}{*}{ Probe name } & \multirow[b]{2}{*}{$\begin{array}{l}\text { Gene } \\
\text { symbol }\end{array}$} & \multirow[b]{2}{*}{ Gene name } & \multicolumn{2}{|c|}{ Gene expression $^{a}$} & \multicolumn{2}{|c|}{ Gene expression $^{b}$} \\
\hline & & & $\begin{array}{l}\mathrm{Bcmo1}^{+/+} \\
\mathrm{Co}\end{array}$ & $\begin{array}{c}\mathrm{Bcmo1}^{+/+} \\
\mathrm{BC}\end{array}$ & $\begin{array}{l}\text { Bcmo1\% } \\
\text { Co }\end{array}$ & $\begin{array}{c}\text { Bcmo 1 }^{+/+} \\
\text {BC }\end{array}$ \\
\hline \multicolumn{7}{|c|}{ G0:0007608 sensory perception of smell and G0:0007606 sensory perception of chemical stimulus ${ }^{\#}$} \\
\hline A_51_P200249 & Olfr945 & olfactory receptor 945 & 1.00 & $\begin{array}{l}1.15 \\
\text { (n.s.) }\end{array}$ & 1.00 & $\begin{array}{c}1.21 \\
(0.004)\end{array}$ \\
\hline A_51_P423948 & Cnga2 & $\begin{array}{l}\text { cyclic nucleotide gated } \\
\text { channel alpha } 2\end{array}$ & 1.00 & $\begin{array}{l}1.05 \\
\text { (n.s.) }\end{array}$ & 1.00 & $\begin{array}{c}1.16 \\
(0.006)\end{array}$ \\
\hline A_51_P108555 & Olfr437 & olfactory receptor 437 & 1.00 & $\begin{array}{l}1.03 \\
\text { (n.s.) }\end{array}$ & 1.00 & $\begin{array}{c}1.23 \\
(0.011)\end{array}$ \\
\hline A_51_P113058 & Olfr1131 & olfactory receptor 1131 & 1.00 & $\begin{array}{l}1.00 \\
\text { (n.s.) }\end{array}$ & 1.00 & $\begin{array}{c}1.11 \\
(0.012)\end{array}$ \\
\hline A_51_P352864 & Olfr570 & olfactory receptor 570 & 1.00 & $\begin{array}{l}1.05 \\
\text { (n.s.) }\end{array}$ & 1.00 & $\begin{array}{c}1.14 \\
(0.013)\end{array}$ \\
\hline A_51_P191572 & Olfr411 & olfactory receptor 411 & 1.00 & $\begin{array}{l}1.01 \\
\text { (n.s.) }\end{array}$ & 1.00 & $\begin{array}{c}1.17 \\
(0.013)\end{array}$ \\
\hline A_51_P115139 & Olfr1417 & olfactory receptor 1417 & 1.00 & $\begin{array}{l}-1.02 \\
\text { (n.s.) }\end{array}$ & 1.00 & $\begin{array}{c}1.18 \\
(0.014)\end{array}$ \\
\hline A_51_P149531 & Olfr 126 & olfactory receptor 126 & 1.00 & $\begin{array}{l}1.03 \\
\text { (n.s.) }\end{array}$ & 1.00 & $\begin{array}{c}1.23 \\
(0.016)\end{array}$ \\
\hline A_52_P415047 & Olfr973 & olfactory receptor 973 & 1.00 & $\begin{array}{l}1.09 \\
\text { (n.s.) }\end{array}$ & 1.00 & $\begin{array}{c}1.10 \\
(0.020)\end{array}$ \\
\hline A_52_P133333 & Olfr 197 & olfactory receptor 197 & 1.00 & $\begin{array}{l}-1.01 \\
\text { (n.s.) }\end{array}$ & 1.00 & $\begin{array}{c}1.19 \\
(0.021)\end{array}$ \\
\hline A_51_P123314 & Olfr74 & olfactory receptor 74 & 1.00 & $\begin{array}{l}1.04 \\
\text { (n.s.) }\end{array}$ & 1.00 & $\begin{array}{c}1.14 \\
(0.024)\end{array}$ \\
\hline A_51_P347206 & Olfr569 & olfactory receptor 569 & 1.00 & $\begin{array}{l}-1.02 \\
\text { (n.s.) }\end{array}$ & 1.00 & $\begin{array}{c}1.12 \\
(0.027)\end{array}$ \\
\hline A_51_P373583 & Olfr1342 & olfactory receptor 1342 & 1.00 & $\begin{array}{l}1.07 \\
\text { (n.s.) }\end{array}$ & 1.00 & $\begin{array}{c}1.15 \\
(0.033)\end{array}$ \\
\hline A_51_P112682 & Olfr 159 & olfactory receptor 159 & 1.00 & $\begin{array}{l}1.04 \\
\text { (n.s.) }\end{array}$ & 1.00 & $\begin{array}{c}1.09 \\
(0.034)\end{array}$ \\
\hline A_51_P129972 & Olfr611 & olfactory receptor 611 & 1.00 & $\begin{array}{l}1.08 \\
\text { (n.s.) }\end{array}$ & 1.00 & $\begin{array}{c}1.13 \\
(0.034)\end{array}$ \\
\hline A_51_P514902 & Olfr446 & olfactory receptor 446 & 1.00 & $\begin{array}{l}1.05 \\
\text { (n.s.) }\end{array}$ & 1.00 & $\begin{array}{c}1.16 \\
(0.037)\end{array}$ \\
\hline A_51_P275365 & Olfr 1411 & olfactory receptor 1411 & 1.00 & $\begin{array}{l}-1.05 \\
\text { (n.s.) }\end{array}$ & 1.00 & $\begin{array}{c}1.17 \\
(0.039)\end{array}$ \\
\hline A_51_P276149 & Olfr1030 & olfactory receptor 1030 & 1.00 & $\begin{array}{l}1.03 \\
\text { (n.s.) }\end{array}$ & 1.00 & $\begin{array}{c}1.13 \\
(0.041)\end{array}$ \\
\hline A_51_P201751 & Olfr870 & olfactory receptor 870 & 1.00 & $\begin{array}{l}-1.00 \\
\text { (n.s.) }\end{array}$ & 1.00 & $\begin{array}{c}1.11 \\
(0.042)\end{array}$ \\
\hline A_51_P515949 & Olfr668 & olfactory receptor 668 & 1.00 & $\begin{array}{l}1.03 \\
\text { (n.s.) }\end{array}$ & 1.00 & $\begin{array}{c}1.09 \\
(0.042)\end{array}$ \\
\hline A_51_P352636 & Olfr397 & olfactory receptor 397 & 1.00 & $\begin{array}{l}1.04 \\
\text { (n.s.) }\end{array}$ & 1.00 & $\begin{array}{c}1.14 \\
(0.043)\end{array}$ \\
\hline A_52_P358720 & Olfr266 & olfactory receptor 266 & 1.00 & -1.02 & 1.00 & 1.08 \\
\hline
\end{tabular}




\begin{tabular}{|c|c|c|c|c|c|c|}
\hline & & & & (n.s.) & & $(0.044)$ \\
\hline A_51_P386280 & Olfr 187 & olfactory receptor 187 & 1.00 & $\begin{array}{c}-1.01 \\
\text { (n.s.) }\end{array}$ & 1.00 & $\begin{array}{c}1.16 \\
(0.045)\end{array}$ \\
\hline A_52_P313007 & Olfr469 & olfactory receptor 469 & 1.00 & $\begin{array}{l}1.08 \\
\text { (n.s.) }\end{array}$ & 1.00 & $\begin{array}{c}1.10 \\
(0.046)\end{array}$ \\
\hline A_51_P484279 & Olfr239 & olfactory receptor 239 & 1.00 & $\begin{array}{l}1.12 \\
\text { (n.s.) }\end{array}$ & 1.00 & $\begin{array}{c}1.20 \\
(0.047)\end{array}$ \\
\hline A_52_P232438 & Olfr 1419 & olfactory receptor 1419 & 1.00 & $\begin{array}{l}1.07 \\
\text { (n.s.) }\end{array}$ & 1.00 & $\begin{array}{c}1.16 \\
(0.047)\end{array}$ \\
\hline A_52_P390844 & Olfr740 & olfactory receptor 740 & 1.00 & $\begin{array}{c}1.04 \\
\text { (n.s.) }\end{array}$ & 1.00 & $\begin{array}{c}1.14 \\
(0.049)\end{array}$ \\
\hline \multicolumn{7}{|c|}{ GO:0007156: Homophilic cell adhesion } \\
\hline A_51_P191743 & Pcdhb16 & protocadherin beta 16 & 1.00 & $\begin{array}{r}-1.00 \\
\text { (n.s.) }\end{array}$ & 1.00 & $\begin{array}{c}1.24 \\
(0.000)\end{array}$ \\
\hline A_51_P483878 & Pcdhb9 & protocadherin beta 9 & 1.00 & $\begin{array}{c}-1.12 \\
\text { (n.s.) }\end{array}$ & 1.00 & $\begin{array}{c}1.23 \\
(0.007)\end{array}$ \\
\hline A_52_P515769 & Pcdh 12 & protocadherin 12 & 1.00 & $\begin{array}{l}1.01 \\
\text { (n.s.) }\end{array}$ & 1.00 & $\begin{array}{c}1.26 \\
(0.007)\end{array}$ \\
\hline A_51_P184223 & Pcdhb7 & protocadherin beta 7 & 1.00 & $\begin{array}{l}1.12 \\
\text { (n.s.) }\end{array}$ & 1.00 & $\begin{array}{c}1.40 \\
(0.007)\end{array}$ \\
\hline A_51_P511918 & Pcdhb 18 & protocadherin beta 18 & 1.00 & $\begin{array}{l}1.05 \\
\text { (n.s.) }\end{array}$ & 1.00 & $\begin{array}{c}1.15 \\
(0.011)\end{array}$ \\
\hline A_52_P529195 & Pcdhb4 & protocadherin beta 4 & 1.00 & $\begin{array}{c}-1.09 \\
\text { (n.s.) }\end{array}$ & 1.00 & $\begin{array}{c}1.72 \\
(0.012)\end{array}$ \\
\hline A_51_P159833 & Pcdhb15 & protocadherin beta 15 & 1.00 & $\begin{array}{l}1.02 \\
\text { (n.s.) }\end{array}$ & 1.00 & $\begin{array}{c}1.20 \\
(0.014)\end{array}$ \\
\hline A_52_P350148 & Celsr2 & $\begin{array}{l}\text { cadherin EGF LAG sev- } \\
\text { en-pass G-type receptor } \\
2\end{array}$ & 1.00 & $\begin{array}{l}1.10( \\
\text { n.s.) }\end{array}$ & 1.00 & $\begin{array}{c}1.12 \\
(0.015)\end{array}$ \\
\hline A_51_P257292 & Pcdhb5 & protocadherin beta 5 & 1.00 & $\begin{array}{l}-1.03 \\
\text { (n.s.) }\end{array}$ & 1.00 & $\begin{array}{c}1.11 \\
(0.017)\end{array}$ \\
\hline A_51_P373573 & $\operatorname{Cdh} 22$ & cadherin 22 & 1.00 & $\begin{array}{l}1.09 \\
\text { (n.s.) }\end{array}$ & 1.00 & $\begin{array}{c}1.18 \\
(0.022)\end{array}$ \\
\hline A_51_P239257 & Pcdh1 & protocadherin 1 & 1.00 & $\begin{array}{l}-1.03 \\
\text { (n.s.) }\end{array}$ & 1.00 & $\begin{array}{c}-1.13 \\
(0.030)\end{array}$ \\
\hline A_52_P88091 & Dsg2 & desmoglein 2 & 1.00 & $\begin{array}{l}1.03 \\
\text { (n.s.) }\end{array}$ & 1.00 & $\begin{array}{c}1.14 \\
(0.031)\end{array}$ \\
\hline A_51_P403413 & Pcdhb6 & protocadherin beta 6 & 1.00 & $\begin{array}{l}-1.01 \\
\text { (n.s.) }\end{array}$ & 1.00 & $\begin{array}{c}1.10 \\
(0.033)\end{array}$ \\
\hline A_51_P289066 & Pcdhb 10 & protocadherin beta 10 & 1.00 & $\begin{array}{l}-1.05 \\
\text { (n.s.) }\end{array}$ & 1.00 & $\begin{array}{c}1.13 \\
(0.035) \\
\end{array}$ \\
\hline
\end{tabular}

\#both GO processes contain the same genes, agene expression relative to average gene expression in $\mathrm{Bcmo1}^{+/+}$control mice (p-value), bgene expression relative to average gene expression in $\mathrm{Bcmo1} /$ control mice ( $\mathrm{p}$-value), n.s.: non-significant difference $(\mathrm{p}>0.05)$ between $\mathrm{BC}$ supplemented and control $\mathrm{BCmo1}^{+/+}$mice 
To validate the microarray results of the expression of genes involved in GO:0007608; sensory perception of smell, GO:0007606; sensory perception of chemical stimulus and GO:0007156: homophilic cell adhesion, we analyzed gene expression of Fzd6, Cthrc1, one olfactory receptor; olfactory receptor 437 (Olfr437) and one protocadherin beta; protocadherin beta 9 (Pcdhb9) using Q-PCR. Microarray analysis and Q-PCR showed similar expression patterns (Fig. 5) and fully confirmed the micorarray data, despite relatively low absolute expression levels and fold changes of Olfr437 and Pcdhb9.

A)

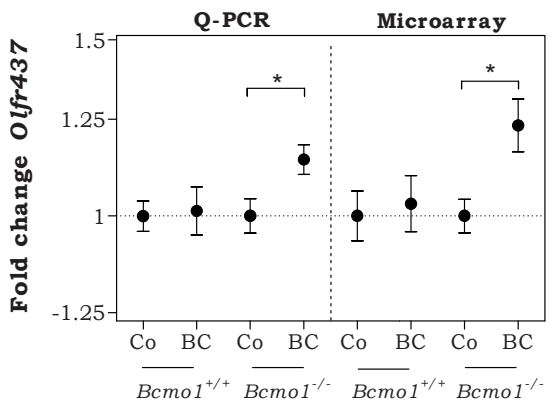

B)

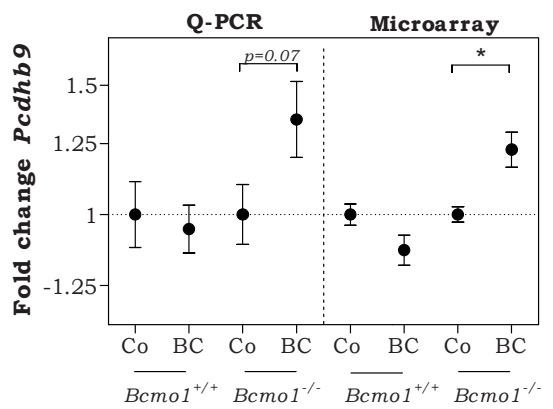

Fig. 5: The expression of the genes Olfr437 (A) and Pcdhb9 (B) in BC supplemented mice relative to control diet fed mice analyzed by microarray analysis and Q-PCR using the stable reference genes Stx5a and Rnf130. Data represent the average gene expression \pm SEM compared to control diet fed mice. ${ }^{*} \mathrm{p}<0.05$ using a Student's $t$-test on the log transformed data.

\section{Discussion}

In this study we assessed effects of $\mathrm{BC}$ supplementation in male wildtype $\left(\mathrm{Bcmo}^{+/+}\right)$ mice, which are able to metabolize $\mathrm{BC}$ to a high extent, and in male Bcmo1 knock-out $\left(\mathrm{Bcmo1}^{-/}\right)$mice, which are unable to symmetrically cleave BC. Indeed, the concentration of $\mathrm{BC}$ in serum and lung was increased to a higher level in $\mathrm{Bcmo1} /$ mice than in $\mathrm{BCmo1}^{+/+}$mice after BC supplementation. Genome-wide transcriptome analysis revealed that around two times more genes were regulated in $\mathrm{Bcmo1} /$ mice than in $\mathrm{Bcmo1}^{+/+}$ mice by $\mathrm{BC}$ supplementation. $\mathrm{BC}$ supplementation in $\mathrm{Bcmo1/-}$ mice resulted in three main, very significant findings. First, the genes Fzd6 and Cthrc1 were both very significantly downregulated (FDR<0.05) with a fold change of -2.99 and -2.60 , respectively. These genes are both involved in the Wnt-Fzd pathway which is important in the regulation of cell fate determination and development. Second, many olfactory receptors and members of the clustered protocadherin family were upregulated, and the presence of both groups of genes is mainly reported in neuronal cells. A third observation was that the interindividual gene expression patterns between the genes were highly similar. 
Pulmonary neuroendocrine cells (PNECs) are highly associated with sensory nerves and are involved in stem cell development during injury and repair. Since the BC regulated genes are involved in neuronal and developmental pathways, BC might specifically affect the highly innervated PNECs. A role for BC in the regulation of PNECs might be of particular importance in smoke induced lung carcinogenesis since PNEC-tumors comprise $\sim 20 \%$ of all lung cancers and are strongly associated with tobacco use.

In this study, we found a notable downregulation of Fzd6 and Cthrc1 by dietary BC in Bcmo1/- mice. Fzd6 encodes a member of the frizzled receptor family of transmembrane receptors for Wnt signals [19] and Cthrc1 encodes a secreted protein [20]. Both Fzd6 and Cthrc1 were downregulated to a similar degree and had a similar FDR suggesting that these genes were jointly regulated. This is in line with recent findings that Cthrc1 stabilizes the Wnt-Fzd complex [21]. The main known function of Fzd6 that emerges among the relatively limited number of studies on this protein is its involvement in developmental patterning during development [22]. But the precise functions of Fzd6 and Cthrc1 are, as yet, unknown for the lung. Fzd6 might have an important function in the lung since it is highly expressed in adult and fetal human lung tissue [23].

The highly significant BC induced downregulation of Fzd6 and Cthrc1 was observed in combination with an upregulation of many different olfactory receptors, protocadherins and cadherins in the $\mathrm{Bcmo1} \%$ mice. Clustered protocadherins are highly expressed in neurons and become highly enriched at synapses during development, and their expression decreases after neuronal maturation [24]. The main described function of olfactory receptors is that they bind odorant molecules in the olfactory bulb to result in a neuronal signal transduction through sensory nerves. Although the name "olfactory receptor" implicates a function only in olfaction, the presence and a function for olfactory receptors in tissues other than the olfactory bulb, has been described $[25,26]$. The function for olfactory receptors in the lung is unknown, but it is tempting to speculate that they might have a role in sensing the environment. In line with this, similar as in olfaction, sensory neurons are important in the lung to allow the lung to detect differences in the environment. The main function of sensory neurons in the lung is to allow the lung to react to differences in air composition, such as reduced oxygen tension (hypoxia) $[27,28]$ or differences in $\mathrm{CO}_{2}$ concentrations $[29,30]$. A possible function for olfactory receptors in the lung might thus be the detection of changes in the air composition.

There is one cell type which is highly associated and innervated with sensory nerves $[28,31,32]$, and that has the ability to react to changes in air composition. These cells are the pulmonary endocrine cells (PNECs) and it has been described that PNECs are able to detect for example hypoxia by the use of receptors which are highly similar to olfactory receptors $[27,28]$. PNECs can be present as solitary cells, or as clusters called the neuroepithelial bodies (NEBs) [33]. Besides a role for the highly innervated PNECs in airway chemoreception, it has been shown that the NEB microenvironment is highly important for lung stem cell development during injury and repair [34-36]. Wnt signal- 
ing has been proposed to be key regulator in stem cell control and development [37]. This dual function for the innervated PNECs in both chemodetection and in control of development are in correspondence with our findings; regulation of Fzd6, Cthrc1 and regulation of olfactory receptors and protocadherins. However, we cannot conclude that there is a general increase or decrease in the number of PNECs since Fzd6 and Cthrc1 were downregulated, while the olfactory receptors and the protocadherins were mainly upregulated. We can speculate on this. It is known that sensory nerves involved in olfaction are generated and regenerated from neuronal stem cells every 40 days throughout a lifetime [38], but the generation and regeneration of sensory nerves is, as far as we know, unknown for the lung. Generation and regeneration of sensory nerves might also be important in the lung and therefore, it is tempting to assume that there might be an important function of the stem cell developmental genes Fzd6 and Cthrc1 in sensory neurogenesis, resulting in an upregulation of olfactory receptors and protocadeherins. The Wnt-Fzd complex can activate the canonical pathway for cell differentiation, or alternatively, signals the noncanonical pathway for control of cell movement and tissue polarity $[39,40]$. The noncanonical pathway can be further subdivided into the wnt/ $\mathrm{Ca}^{2+}$ pathway, which is not very well characterized at this moment, and into the wnt/planar cell polarity (PCP) pathway which is typically involved in hair patterning and cell motility by the control of actin polymerization [41]. Although Cthrc1 and Fzd6 are both implicated in the wnt/PCP process and the main known function of Fzd6 is the control of developmental patterning, Fzd6 was also found to suppress the canonical pathway in Fzd6 transfected cells [21]. Indeed, in lung epithelial cells an increase in confluence resulted in an increase in Fzd6 and a decrease in activation of the canonical pathway [42]. Our findings in BC supplemented animals show the same correlation but in the opposite direction; a downregulation of Fzd6 in combination with an upregulation of olfactory receptors, protocadherins and cadherins (Supplemental Fig. 1).

The next question is whether our data might explain -part of- the mechanism underlying the increased lung cancer risk upon BC supplementation in smokers (ATBC, CARET). Small cell lung carcinoma (SCLC) and the most significant form of large cell lung carcinoma (LCLC), large cell neuroendocrine lung carcinoma, originate both from PNECs $[43,44]$. In total, PNECs are present in lung very sparsely with a frequency of 1 PNEC per 2500 epithelial cells [45], however, PNEC derived tumors account for $\sim 20 \%$ of all lung cancers and is highly associated with tobacco use [46]. In the CARET study, the risk for LCLC was significantly increased due to BC supplementation [4]. The control of stem cells is important to avoid undesired cell growth, which ultimately can result in cancer [47]. The Wnt pathway is one of the most important pathways involved in stem cell control and a dysregulation of these genes can result in uncontrolled growth of lung cancer cells $[48,49]$ and might be one of the explanations in the involvement of $\mathrm{BC}$ in the increased lung cancer risk in smokers of the ATBC and CARET study.

In our study, $\mathrm{BC}$ supplementation to $\mathrm{Bcmo1} /$ - mice resulted in a downregulation of Fzd6 and Cthrc1 in combination with an increase in the neuronal olfactory receptors 
and in members of the protocadherin family. BC itself was never associated with neuronal cell development, although its downstream metabolite, retinoic acid is. Retinoic acid is a ligand for the retinoic acid receptor (RARs) and the retinoid X receptors (RXRs). Depletion of vitamin A, a precursor for retinoic acid, or the knock-out of the RAR and/or RXR receptor results in defects of the nervous system [50], implicating that retinoic acid is of importance in neurogenesis. Moreover, Aldehyde dehydrogenase 1 family, member a3 (Aldh1a3), an important and rate-limiting enzyme in the synthesis of retinoic acid, has been shown to be present at high concentrations in the neuroepthelium and is therefore an important neuroepithelial marker. Mice without a functional Aldh1a3 enzyme show morphological defects in the nasal cavity, the most important site of the generation of olfactory neurons [51]. As can be seen in table I, we showed that several enzymes important in downstream $\mathrm{BC}$ metabolism were changed in $\mathrm{Bcmo1^{- }}$ /- mice compared to $\mathrm{Bcmo1}^{+/+}$mice. Although $\mathrm{BC}$ was especially high in the $\mathrm{Bcmo1^{-/ }}$ mice and $\mathrm{BC}$ metabolite concentrations were especially high in the $\mathrm{Bcmo1^{+/+ }}$ mice it is unknown at this moment whether high $\mathrm{BC}$ concentrations or for example alterations in the availability of retinoic acid caused the effects as we have described here for BC supplemention in male Bcmo1/- mice.

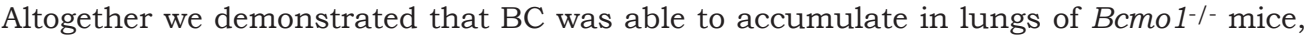
thereby decreasing Fzd6 and Cthrc1 gene expression with a fold change of -2.99 and 2.60 respectively. Moreover, many olfactory receptors and many members of the protocadherin family were upregulated. The inter-individual differences in gene expression of the significantly $(\mathrm{p}<0.05)$ regulated genes was low and therefore resulted in a high correlation of the expression of the genes as analyzed by SOM analysis. A specific role for the highly expressed Fzd6 gene and Cthrc1 in lung tissue has never been described. We hypothesize that BC decreases the regulation of both Fzd6 and Cthrc1, which possibly have a joint function and that by the downregulation of these two genes, olfactory receptors and protocadherins are increased. These processes might be of importance in smoke or asbestos induced lung carcinogenesis, and are possibly affected by BC.

\section{Acknowledgements}

Yvonne van Helden was supported by a grant from NUTRIM/VLAG. Jaap Keijer is a member of Mitofood (COST FA0602). We thank DSM neutraceuticals for the use of Bcmo1\% mice and the BC beadlets and the European Nutrigenomics Organization (Network of Excellence, EU Contract FOOD-CT-2004-506360) for support of the animal study. None of the authors declare any commercial interest. 


\section{References}

[1] G. van Poppel Epidemiological evidence for beta-carotene in prevention of cancer and cardiovascular disease, Eur J Clin Nutr 50 Suppl 3 (1996) S57-61.

[2] R.G. Ziegler A review of epidemiologic evidence that carotenoids reduce the risk of cancer, J Nutr 119 (1989) 116-122.

[3] D. Albanes, O.P. Heinonen, P.R. Taylor, J. Virtamo, B.K. Edwards, M. Rautalahti, A.M. Hartman, J. Palmgren, L.S. Freedman, J. Haapakoski, M.J. Barrett, P. Pietinen, N. Malila, E. Tala, K. Liippo, E.R. Salomaa, J.A. Tangrea, L. Teppo, F.B. Askin, E. Taskinen, Y. Erozan, P. Greenwald and J.K. Huttunen AlphaTocopherol and beta-carotene supplements and lung cancer incidence in the alpha-tocopherol, betacarotene cancer prevention study: effects of base-line characteristics and study compliance, J Natl Cancer Inst 88 (1996) 1560-1570.

[4] G.S. Omenn, G.E. Goodman, M.D. Thornquist, J. Balmes, M.R. Cullen, A. Glass, J.P. Keogh, F.L. Meyskens, Jr., B. Valanis, J.H. Williams, Jr., S. Barnhart, M.G. Cherniack, C.A. Brodkin and S. Hammar Risk factors for lung cancer and for intervention effects in CARET, the Beta-Carotene and Retinol Efficacy Trial, J Natl Cancer Inst 88 (1996) 1550-1559.

[5] C.H. Hennekens, J.E. Buring, J.E. Manson, M. Stampfer, B. Rosner, N.R. Cook, C. Belanger, F. LaMotte, J.M. Gaziano, P.M. Ridker, W. Willett and R. Peto Lack of effect of long-term supplementation with beta carotene on the incidence of malignant neoplasms and cardiovascular disease, N Engl J Med 334 (1996) 1145-1149.

[6] P. Palozza Prooxidant actions of carotenoids in biologic systems, Nutr Rev 56 (1998) 257-265.

[7] Y.G. van Helden, J. Keijer, A.M. Knaapen, S.G. Heil, J.J. Briede, F.J. van Schooten and R.W. Godschalk Beta-carotene metabolites enhance inflammation-induced oxidative DNA damage in lung epithelial cells, Free Radic Biol Med 46 (2009) 299-304.

[8] R.M. Russell The enigma of beta-carotene in carcinogenesis: what can be learned from animal studies, J Nutr 134 (2004) 262S-268S.

[9] J. von Lintig and K. Vogt Filling the gap in vitamin A research. Molecular identification of an enzyme cleaving beta-carotene to retinal, J Biol Chem 275 (2000) 11915-11920.

[10] J. von Lintig and A. Wyss Molecular analysis of vitamin A formation: cloning and characterization of betacarotene 15,15'-dioxygenases, Arch Biochem Biophys 385 (2001) 47-52.

[11] S. Hessel, A. Eichinger, A. Isken, J. Amengual, S. Hunzelmann, U. Hoeller, V. Elste, W. Hunziker, R. Goralczyk, V. Oberhauser, J. von Lintig and A. Wyss CMO1 deficiency abolishes vitamin A production from beta-carotene and alters lipid metabolism in mice, J Biol Chem 282 (2007) 33553-33561.

[12] W. Rodenburg, A.G. Heidema, J.M. Boer, I.M. Bovee-Oudenhoven, E.J. Feskens, E.C. Mariman and J. Keijer A framework to identify physiological responses in microarray-based gene expression studies: selection and interpretation of biologically relevant genes, Physiol Genomics 33 (2008) 78-90.

[13] E.M. van Schothorst, V. Pagmantidis, V.C. de Boer, J. Hesketh and J. Keijer Assessment of reducing RNA input for Agilent oligo microarrays, Anal Biochem 363 (2007) 315-317.

[14] J.M. Wettenhall and G.K. Smyth limmaGUI: a graphical user interface for linear modeling of microarray data, Bioinformatics 20 (2004) 3705-3706.

[15] L. Pellis, N.L. Franssen-van Hal, J. Burema and J. Keijer The intraclass correlation coefficient applied for evaluation of data correction, labeling methods, and rectal biopsy sampling in DNA microarray experiments, Physiol Genomics 16 (2003) 99-106.

[16] H.K. Lee, W. Braynen, K. Keshav and P. Pavlidis ErmineJ: tool for functional analysis of gene expression data sets, BMC Bioinformatics 6 (2005) 269.

[17] J. Keijer, Y.G.J. van Helden, A. Bunschoten and E.M. van Schothorst Transcriptome analysis in benefitrisk assessment of micronutrients and bioactive food components, Mol. Nutr. Food Res. in press (2009).

[18] P. Tamayo, D. Slonim, J. Mesirov, Q. Zhu, S. Kitareewan, E. Dmitrovsky, E.S. Lander and T.R. Golub Interpreting patterns of gene expression with self-organizing maps: methods and application to hematopoietic differentiation, Proc Natl Acad Sci U S A 96 (1999) 2907-2912.

[19] P. Bhanot, M. Brink, C.H. Samos, J.C. Hsieh, Y. Wang, J.P. Macke, D. Andrew, J. Nathans and R. Nusse A new member of the frizzled family from Drosophila functions as a Wingless receptor, Nature 382 (1996) 225-230.

[20] P. Pyagay, M. Heroult, Q. Wang, W. Lehnert, J. Belden, L. Liaw, R.E. Friesel and V. Lindner Collagen triple helix repeat containing 1 , a novel secreted protein in injured and diseased arteries, inhibits collagen expression and promotes cell migration, Circ Res 96 (2005) 261-268. 


\section{Chapter 6}

[21] S. Yamamoto, O. Nishimura, K. Misaki, M. Nishita, Y. Minami, S. Yonemura, H. Tarui and H. Sasaki Cthrc1 selectively activates the planar cell polarity pathway of Wnt signaling by stabilizing the Wntreceptor complex, Dev Cell 15 (2008) 23-36.

[22] N. Guo, C. Hawkins and J. Nathans Frizzled6 controls hair patterning in mice, Proc Natl Acad Sci U S A 101 (2004) 9277-9281.

[23] M. Tokuhara, M. Hirai, Y. Atomi, M. Terada and M. Katoh Molecular cloning of human Frizzled-6, Biochem Biophys Res Commun 243 (1998) 622-627.

[24] H. Morishita and T. Yagi Protocadherin family: diversity, structure, and function, Curr Opin Cell Biol 19 (2007) 584-592.

[25] M. Weber, U. Pehl, H. Breer and J. Strotmann Olfactory receptor expressed in ganglia of the autonomic nervous system, J Neurosci Res 68 (2002) 176-184.

[26] T. Yagi Clustered protocadherin family, Dev Growth Differ 50 Suppl 1 (2008) S131-140.

[27] D. Adriaensen, I. Brouns, J. Van Genechten and J.P. Timmermans Functional morphology of pulmonary neuroepithelial bodies: extremely complex airway receptors, Anat Rec A Discov Mol Cell Evol Biol 270 (2003) 25-40.

[28] R.I. Linnoila Functional facets of the pulmonary neuroendocrine system, Lab Invest 86 (2006) 425-444.

[29] J. Hu, C. Zhong, C. Ding, Q. Chi, A. Walz, P. Mombaerts, H. Matsunami and M. Luo Detection of nearatmospheric concentrations of CO2 by an olfactory subsystem in the mouse, Science 317 (2007) 953-957.

[30] S. Lahiri and R.E. Forster, 2nd $\mathrm{CO} 2 / \mathrm{H}(+)$ sensing: peripheral and central chemoreception, Int $\mathrm{J}$ Biochem Cell Biol 35 (2003) 1413-1435.

[31] J. Pan, H. Yeger and E. Cutz Innervation of pulmonary neuroendocrine cells and neuroepithelial bodies in developing rabbit lung, J Histochem Cytochem 52 (2004) 379-389.

[32] M. Weichselbaum, M.P. Sparrow, E.J. Hamilton, P.J. Thompson and D.A. Knight A confocal microscopic study of solitary pulmonary neuroendocrine cells in human airway epithelium, Respir Res 6 (2005) 115.

[33] A. Van Lommel, T. Bolle, W. Fannes and J.M. Lauweryns The pulmonary neuroendocrine system: the past decade, Arch Histol Cytol 62 (1999) 1-16.

[34] I. De Proost, I. Pintelon, W.J. Wilkinson, S. Goethals, I. Brouns, L. Van Nassauw, D. Riccardi, J.P. Timmermans, P.J. Kemp and D. Adriaensen Purinergic signaling in the pulmonary neuroepithelial body microenvironment unraveled by live cell imaging, Faseb J 23 (2009) 1153-1160.

[35] J.L. Peake, S.D. Reynolds, B.R. Stripp, K.E. Stephens and K.E. Pinkerton Alteration of pulmonary neuroendocrine cells during epithelial repair of naphthalene-induced airway injury, Am J Pathol 156 (2000) 279-286.

[36] S.D. Reynolds, A. Giangreco, J.H. Power and B.R. Stripp Neuroepithelial bodies of pulmonary airways serve as a reservoir of progenitor cells capable of epithelial regeneration, Am J Pathol 156 (2000) 269-278.

[37] T.M. Michaelidis and D.C. Lie Wnt signaling and neural stem cells: caught in the Wnt web, Cell Tissue Res 331 (2008) 193-210.

[38] C.L. Beites, S. Kawauchi, C.E. Crocker and A.L. Calof Identification and molecular regulation of neural stem cells in the olfactory epithelium, Exp Cell Res 306 (2005) 309-316.

[39] M. Katoh and M. Katoh WNT signaling pathway and stem cell signaling network, Clin Cancer Res 13 (2007) 4042-4045.

[40] T. Golan, A. Yaniv, A. Bafico, G. Liu and A. Gazit The human Frizzled 6 (HFz6) acts as a negative regulator of the canonical Wnt. beta-catenin signaling cascade, J Biol Chem 279 (2004) 14879-14888.

[41] D. Devenport and E. Fuchs Planar polarization in embryonic epidermis orchestrates global asymmetric morphogenesis of hair follicles, Nat Cell Biol 10 (2008) 1257-1268.

[42] M.D. Steel, S.M. Puddicombe, L.M. Hamilton, R.M. Powell, J.W. Holloway, S.T. Holgate, D.E. Davies and J.E. Collins Beta-catenin/T-cell factor-mediated transcription is modulated by cell density in human bronchial epithelial cells, Int J Biochem Cell Biol 37 (2005) 1281-1295.

[43] F.G. Fernandez and R.J. Battafarano Large-cell neuroendocrine carcinoma of the lung, Cancer Control 13 (2006) 270-275.

[44] W.D. Travis, L.B. Travis and S.S. Devesa Lung cancer, Cancer 75 (1995) 191-202.

[45] J.R. Gosney, M.C. Sissons and R.O. Allibone Neuroendocrine cell populations in normal human lungs: a quantitative study, Thorax 43 (1988) 878-882.

[46] B.I. Gustafsson, M. Kidd, A. Chan, M.V. Malfertheiner and I.M. Modlin Bronchopulmonary neuroendocrine tumors, Cancer 113 (2008) 5-21.

[47] T. Reya and H. Clevers Wnt signalling in stem cells and cancer, Nature 434 (2005) 843-850.

[48] J. Kim, L. You, Z. Xu, K. Kuchenbecker, D. Raz, B. He and D. Jablons Wnt inhibitory factor inhibits lung cancer cell growth, J Thorac Cardiovasc Surg 133 (2007) 733-737. 
[49] L. You, B. He, Z. Xu, K. Uematsu, J. Mazieres, I. Mikami, N. Reguart, T.W. Moody, J. Kitajewski, F. McCormick and D.M. Jablons Inhibition of Wnt-2-mediated signaling induces programmed cell death in non-small-cell lung cancer cells, Oncogene 23 (2004) 6170-6174.

[50] E.D. Dickman, C. Thaller and S.M. Smith Temporally-regulated retinoic acid depletion produces specific neural crest, ocular and nervous system defects, Development 124 (1997) 3111-3121.

[51] V. Dupe, N. Matt, J.M. Garnier, P. Chambon, M. Mark and N.B. Ghyselinck A newborn lethal defect due to inactivation of retinaldehyde dehydrogenase type 3 is prevented by maternal retinoic acid treatment, Proc Natl Acad Sci U S A 100 (2003) 14036-14041. 
The molecular mechanisms triggered in the lung by high dietary intakes of beta-carotene $(\mathrm{BC})$ are still largely unknown. We therefore performed whole genome microarray gene expression analysis of lung tissue of 14 weeks BC supplemented beta-carotene 15,15'- monooxygenase 1 knockout $\left(\mathrm{Bcmo}^{-}\right)$mice, that are -like humans-able to accumulate BC and wild type $\left(\mathrm{Bcmo1}^{+/+}\right)$mice as a control. We focused on genes that were altered in expression in both genders. As expected, BC supplementation resulted in larger BC accumulation in lungs of Bcmo $1 \%$ mice than in $\mathrm{Bcmol}^{+/+}$mice. Transcriptome analysis of Bcmo1-/- mice showed that genes regulated by BC in both genders were regulated in an opposite direction. This was not seen in $B \mathrm{cmo} 1^{+/+}$mice. Testosterone levels were as expected in $\mathrm{Bcmo}^{+/+}$mice, significantly higher in males than in females, but showed large variations in Bcmo1\% mice. Moreover, BC supplementation to male $B c m o 1^{1-}$ mice resulted in a significant overrepresentation of genes involved in steroid biosynthesis and a significantly altered gene expression of sex-hormone metabolizing enzymes. The effects of BC on hormone synthesis or metabolism could have contributed to the increased lung cancer risk observed in the ATBC and CARET studies, since sex-hormones influence lung cancer risk. Furthermore, these data implicate that effects of $\mathrm{BC}$ on hormone production or metabolism might depend on the presence of frequent human BCMO1 polymorphisms. 


\section{Beta-carotene affects gene expres- sion in lungs of male and female Bcmo 1\% mice in opposite directions}

Yvonne G.J. van Helden, Roger W.L. Godschalk, Hans Swarts, Peter C.H. Hollman, Frederik J. van Schooten, Jaap Keijer 


\section{Introduction}

Beta-carotene $(\mathrm{BC})$ is a lipid soluble provitamin, and a major dietary source of vitamin A. BC itself is thought to behave as a health promoting agent. This has been attributed to its ability to efficiently scavenge radicals and thereby preventing macromolecular damage [1]. Furthermore, epidemiological studies focusing on dietary intakes of BC indicated that high $\mathrm{BC}$ intake is associated with a reduced risk for the development of cardiovascular diseases and several types of cancer [2,3]. Moreover, $\mathrm{BC}$ is a provitamin A and therefore its consumption prevents vitamin A deficiency which is of importance even in the Western society. For example, pregnant and lactating woman are at risk for vitamin A deficiency in the Western society due to the discouragement of the consumption of food containing high amounts of vitamin A, this in combination with their increased requirements [4].

Although $\mathrm{BC}$ is mainly considered to be a health promoting agent, large scale intervention trials failed to confirm its beneficial properties. Two intervention trials even showed an increased lung cancer risk and increased mortality due to lung cancer in smokers by BC supplementation (CARET study and ATBC study) [5,6]. A 6-year follow up of the CARET study showed differences in lung cancer risk in response to BC supplementation between male and female volunteers, while the ATBC study was only executed in male volunteers. Male subjects had an increased lung cancer risk upon BC supplementation, but only for the duration of the $\mathrm{BC}$ intervention. On the other hand, $\mathrm{BC}$ supplemented females had an increased lung cancer risk that persisted even after the intervention had stopped and it took several years before the lung cancer risk in females reached the levels observed in non-supplemented controls [7]. The BC induced increase in lung cancer risk is thought to occur only in smokers or asbestos exposed subjects since one large-scale intervention trial with mainly non-smokers showed no effect of $\mathrm{BC}$ on lung cancer $[8,9]$. Although the effect of $\mathrm{BC}$ on lung carcinogenesis has been studied extensively, the mechanism how $\mathrm{BC}$ increases lung cancer risk, is still not precisely known. The main reason for this is that research on molecular pathways influenced by $\mathrm{BC}$ is hampered by the lack of an appropriate animal model that also allows for the use of state-of-the-art functional genomic tools, such as commercially available microarrays. Mice and rats are animal models for which these tools are commercially available, but they differ greatly in $\mathrm{BC}$ metabolizing activity, compared to humans. The main cause for this is the presence of a more active beta-carotene 15,15'-monooxygenase (Bcmo1) enzyme variant in rodents [10]. Bcmo1 is the key enzyme in BC metabolism and in rodents, Bcmo1 cleaves almost all absorbed BC. Since rodents metabolize BC to a high degree, $\mathrm{BC}$ supplementation results in an increase in $\mathrm{BC}$ metabolites rather than the accumulation of $\mathrm{BC}$ and rodents are therefore inadequate animals to study effects of $\mathrm{BC}$ in humans [10]. 
Not only inter-species differences in Bcmol activity have been described. Also large inter-individual differences in BCMO1 activity are present between humans. Around 25$45 \%$ of the volunteers participating in $\mathrm{BC}$ conversion studies have been classified as poor converters [11-13]. These inter-individual differences in BC metabolism are at least partly related to polymorphisms in the $B C M O 1$ gene, which results in a reduced $\mathrm{BCMO} 1$ activity $[14,15]$. Of the reported polymorphisms, there are two frequently occurring polymorphisms with variant allele frequencies of $42 \%$ and $24 \%$. As a result, individuals with these polymorphisms have relatively low vitamin A and high BC plasma concentrations, compared to their wildtype counterparts [14]. Differences in activity of BCMO1 might therefore have an effect on previously reported $\mathrm{BC}$ induced effects including the increased lung cancer risk.

The aim of our study was to investigate gene expression changes, induced by dietary BC to try to explain the previously found harmful effects of $\mathrm{BC}$ in the lung. For this purpose we used a recently described mouse model, which has no functional Bcmo1 (Bcmo $\left.1^{-/}\right)$ enzyme and which therefore displays increased BC plasma concentrations upon BC supplementation [16]. We performed whole genome microarray gene expression analysis on lung tissue of both female and male, $\mathrm{BCmo1}^{+/+}$and $\mathrm{Bcmo1} /$ - mice with or without 14weeks of $150 \mathrm{mg} / \mathrm{kg} \mathrm{BC}$ supplementation. We previously analyzed the effects of $\mathrm{BC}$ in lung tissue of female $\mathrm{Bcmo1} \%$ mice and the major effect observed was that BC supplementation counteracted inflammation associated gene expression effects, which were most like caused by an increased vitamin A demand in $\mathrm{Bcmo1} \%$ knockout mice (Chapter 5). This effect was not observed in lung tissue of male $\mathrm{Bcmo1} \%$ mice, where two genes, frizzled homolog 6 (Fzd6) and collagen triple helix receptor containing 1 (Cthrc1), were strongly downregulated by BC supplementation in combination with the up regulation of several olfactory receptors and protocadherins, which was not observed in female mice (Chapter 6). Thus, the major BC affected processes seemed different between both genders. However, both females and males displayed increased cancer risk after $\mathrm{BC}$ supplementation during the intervention of the CARET study. Therefore, we aimed to specifically focus on those genes that are commonly regulated by $\mathrm{BC}$ supplementation in both genders, i.e. in male as well as female $\mathrm{Bcmo1} \%$ mice.

\section{Materials \& Methods}

\section{Animals and treatment}

The experimental setup has been described previously (females [Chapter 5] and males [Chapter 6]). Twelve female (Fe) and twelve male (ma) B6129SF1 (Bcmo1 $\left.{ }^{+/+}\right)$and twelve female and twelve male B6;129S-Bcmo1tm1dnp (Bcmo1-/-) mice [16] were used for the dietary intervention, which was conducted in accordance with the German animal protection laws by the guidelines of the local veterinary authorities. During the breeding and 
weaning periods of the mice, mothers were maintained on KLIBA 3430 chow containing 14,000 IU vitamin A/kg diet (Provima Kliba AG, Kaiseraugst, Switzerland). Five-weekold female and male $\mathrm{Bcmo}^{+/+}$and $\mathrm{Bcmo1/-}$ mice were caged in groups containing 2 to 4 siblings per group and were maintained under environmentally controlled conditions (temperature $24^{\circ} \mathrm{C}, 12 \mathrm{~h} / 12 \mathrm{~h}$ light/dark cycle). Mice had ad libitum access to feed and water. Basic feed consisted of the pelletized diet D12450B (Research Diets Inc, USA) with a fat content of $10 \%$. The diet was modified to contain 1500 IU vitamin A per $\mathrm{kg}$ of diet, which is a vitamin A sufficient diet, and the control diet (control) was supplemented with water soluble vehicle beadlets (DSM Nutritional Products Ltd., Basel, Switzerland) containing DL-alpha-tocopherol and ascorbyl palmitate as stabilizers, as well as carriers such as gelatine, corn oil sucrose and starch. The BC diet (BC) was supplemented with identical water soluble beadlets containing BC (DSM Nutritional Products Ltd., Basel, Switzerland) to generate $150 \mathrm{mg} \mathrm{BC} / \mathrm{kg}$ diet. Beadlets were added by the manufacturer before low temperature pelletting. Feed pellets were color marked and stored at $4^{\circ} \mathrm{C}$ in the dark.

After 14 weeks of dietary intervention, 6 female and 6 male $\mathrm{Bcmo1}^{+/+}$mice on the control diet $\left(\mathrm{Bcmo1}^{+/+} \mathrm{Co}\right), 6$ female and 6 male $\mathrm{Bcmo1}^{+/+}$mice on the $\mathrm{BC} \operatorname{diet}\left(\mathrm{Bcmo1}^{+/+} \mathrm{BC}\right)$, 3 female and 6 male $B c m o 1^{\%}$ mice on the control diet $\left(B c m o 1^{\%} \mathrm{Co}\right)$ and 3 female and 6 male $\mathrm{Bcmo1 \%}$ mice on the $\mathrm{BC}$ diet $\left(\mathrm{Bcmo1}^{\%} \mathrm{BC}\right)$ were randomly sacrificed during 3 subsequent mornings. Due to an insufficient number of female $\mathrm{Bcmo1}^{-/-}$mice in the original breeding pool, 6 additional female $\mathrm{Bcmo1} /$ - mice were used that were born 2 weeks later from an identical experiment, with 3 mice receiving the control diet and 3 mice receiving the $B C$ diet to generate $n=6$ for each group. These mice were sacrificed 2 weeks after the first group of mice. Blood was collected from the vena cava after isoflurane and ketamin anethesia. Blood was coagulated for at least 20 minutes at room temperature, cooled to $4^{\circ} \mathrm{C}$ and centrifuged. Lung tissue was removed, rinsed in phosphate buffered saline (PBS) and snap frozen in liquid nitrogen. The lung tissues were stored at $-80^{\circ} \mathrm{C}$.

\section{RNA Isolation}

Left lung lobes were homogenized in liquid nitrogen using a cooled mortar and pestle. Total RNA was isolated using TRIzol reagent (Invitrogen, Breda, The Netherlands) followed by purification using RNeasy columns (Qiagen, Venlo, The Netherlands) using the instructions of the manufacturer. RNA concentration and purity were measured using the Nanodrop system (IsoGen Life Science, Maarsen, The Netherlands). Approximately $30 \mu \mathrm{g}$ of total RNA was isolated with $\mathrm{A}_{260} / \mathrm{A}_{280}$ ratios above 2 and $\mathrm{A}_{260} / \mathrm{A}_{230}$ ratios above 1.9 for all samples, indicating good RNA purity. RNA degradation was checked on the Experion (Bio-Rad, Veenendaal, The Netherlands) using Experion StdSense chips (BioRad). Two samples did not meet RNA quality (female $B c m o 1^{+/+}$mice, one on $\mathrm{BC}$ diet and one on control diet) and were omitted from the experiment. 


\section{Microarray hybridization procedure}

The 4x44k Agilent whole mouse genome microarrays (G4122F, Agilent Technologies, Inc. Santa Clara, CA) were used. Preparation of the sample and the microarray hybridization were carried out according to the manufacturer's protocol with a few exceptions as described previously $[17,18]$. In brief, cDNA was synthesized from $1 \mu \mathrm{g}$ lung RNA using the Agilent Low RNA Input Fluorescent Linear Amplification Kit for each animal without addition of spikes. Thereafter samples were split in 2 equal amounts, to synthesize Cyanine 3-CTP (Cy3) and Cyanine 5-CTP (Cy5) labeled cRNA using half the amounts per dye as indicated by the manufacturer (Agilent Technologies). Labeled cRNA was purified using RNeasy columns (Qiagen). Yield, $\mathrm{A}_{260} / \mathrm{A}_{280}$ ratio and Cy3 or Cy5 incorporation were examined for every sample using the nanodrop. All samples met the criteria of a cRNA yield higher than $825 \mathrm{ng}$ and a specific activity of at least 8.0 pmol Cy3 or Cy5. 1200 ng of every Cy3 labeled cRNA sample was pooled and used as a common reference pool. Individual 825 ng Cy5-labeled cRNA and 825 ng pooled Cy3-labeled cRNA were fragmented in $1 \mathrm{x}$ fragmentation and $1 \mathrm{x}$ blocking agent (Agilent Technologies) at $60^{\circ} \mathrm{C}$ for 30 minutes and thereafter mixed with GEx Hybridization Buffer HI-RPM (Agilent Technologies) and hybridized in a $1: 1$ ratio at $65^{\circ} \mathrm{C}$ for 17 hours in an Agilent Microarray hybridization Chamber rotating at $4 \mathrm{rpm}$. After hybridization, slides were washed according to the wash protocol with Stabilization and Drying solution (Agilent Technologies). Arrays were scanned with an Agilent scanner with $10 \%$ and $100 \%$ laser power intensities (Agilent Technologies).

\section{Data analyses of microarray results}

Signal intensities for each spot were quantified using Feature Extraction 9.1 (Agilent Technologies). Median density values and background values of each spot were extracted for both the experimental samples (Cy5) and the reference samples (Cy3). Quality control for every microarray was performed visually, by using Quality control graphs from Feature extraction, M-A plots and boxplots which were made using limmaGUI in $\mathrm{R}$ (Bioconductor) [19]. Data were imported into GeneMaths XT 2.0 (Applied Maths, SintMartens-Latem, Belgium). Spots with a Cy5 and Cy3 signal twice above background were selected and log transformed. The Cy5 signal was normalized against the Cy3 intensity as described before [20]. Pathway analysis was performed using GO overrepresentation analysis (ErmineJ) [21] and data mining.

\section{Analysis of mRNA expression by real-time quantitative PCR (Q-PCR)}

Differential gene expression of lecithin-retinol acyltransferase (phosphatidylcholineretinol-O-acyltransferase) (Lrat), glutamate receptor, ionotropic, AMPA1 (alpha 1) (Gria1) and endothelin 1 (Edn1) was analyzed using Q-PCR to validate microarray results. $1 \mathrm{\mu g}$ RNA isolated from lung of individual animals was converted into cDNA using the iScript 
cDNA Synthesis Kit (Bio-Rad). One sample was taken along without reverse transcriptase to examine the presence of DNA (without RT reaction). An equal amount of cDNA of all individual samples was pooled and diluted (10x, 31.6x 100x, 316x 1000x, 3160x, 10000x) for the generation of a calibration curve to test the efficiency of the Q-PCR reaction. Each PCR reaction $(25 \mu$ l) contained $1 x$ iQ SYBR green supermix (Bio-Rad), $10 \mu \mathrm{M}$ sense primer, $10 \mu \mathrm{M}$ antisense primer and $2 \mu 1100$ times diluted cDNA. Primers for Lrat were sense 5'-GCTCTCGGATCAGTCCACAGGC-3' and antisense 5'TCCCAAGACAGCCGAAGCAAGA-3', for Gria1 sense 5'-TGGTGGTGGTGGACTGTGAATC3' and antisense 5'- CAGGTTGGCGAGGATGTAGTGG-3 and for Edn1 sense 5'- AGACCAGGCAGTTAGATGTCAGTG and antisense 5'- TCGTAGTTTCCTTCCTTCCACCAG. For the amplification of the reference genes we used syntaxin $5 a(\operatorname{Stx} 5 a)$ with sense 5'TTAAAGAACAGGAGGAAACGATTCAGAG-3' and antisense 5' CAGGCAAGGAAGACCACAAAGATG-3', and ring finger protein 130 (Rnf130) with sense 5'-ACAGGAACCAGCGTCGTCTTG-3' and antisense 5'ACCCGAACAACATCATTCTGCTTATAG-3', which showed equal gene expression levels for all individual animals on the microarray. These intron-spanning primers were designed using Beacon designer 7.00 (Premier Biosoft International, Palo Alto, CA) or using primer-BLAST (http://www.ncbi.nlm.nih.gov/). Amplification was performed in duplicate using the MyIQ single-color real-time PCR detection system (Bio-Rad) using the following temperature cycles: $1 \times 3$ min at $95^{\circ} \mathrm{C}, 40 \mathrm{x} 2$-step amplification $\left(15 \mathrm{~s} 95^{\circ} \mathrm{C}, 45 \mathrm{~s}\right.$ $\left.60^{\circ} \mathrm{C}\right), 1 \times 1 \mathrm{~min} 95^{\circ} \mathrm{C}, 1 \times 1 \mathrm{~min} 65^{\circ} \mathrm{C}$ followed by melting curve analysis $\left(60 \times 10 \mathrm{~s} 65^{\circ} \mathrm{C}\right.$ with an increase of $0.5^{\circ} \mathrm{C}$ per $10 \mathrm{~s}$. A negative control without cDNA template and the minus reverse transcriptase sample were taken along with every assay. Using the standard curves for every gene, the relative level of expression of all genes was calculated. Normalized Gene Expression $(\triangle \triangle \mathrm{CT})$ analysis was calculated using the IQ5 software version 2.0 (Bio-Rad).

\section{Testosterone measurement}

Testosterone concentrations were measured using radio immunoassays (DSL 4100, Diagnostic Systems Laboratories, Beckman Coulter, Assendelft, The Netherlands) and were performed according to the manufacturer's protocol using quarters of all volumes as has been described previously [22]. Gamma-radiation was measured on a Wallac 1470 Wizard Gammacounter. The recovery of testosterone spikes and linearity of the dilution were tested before use.

\section{Statistical analysis}

General effects of diet, gender and genotype on concentrations of BC, retinol and retinyl esters in lung and serum were analyzed using $2 \times 2 \times 2$ factorial univariate ANOVA (SPSS version 15.0) and considered statistically significant when $\mathrm{p}<0.05$. Effects of $B C$ compared to control diet were tested using a Student's $t$-test and considered statistical sig- 
nificant at $\mathrm{p}$ 0.05). Fold changes for both microarray gene expression and Q-PCR gene expression were calculated using mean log signal intensities. P-values for differential expressions were calculated between two groups using two tailed Student's $t$-test statistics on $\log$ intensity values. Changes were considered statistically different at $p<0.05$.

\section{Results}
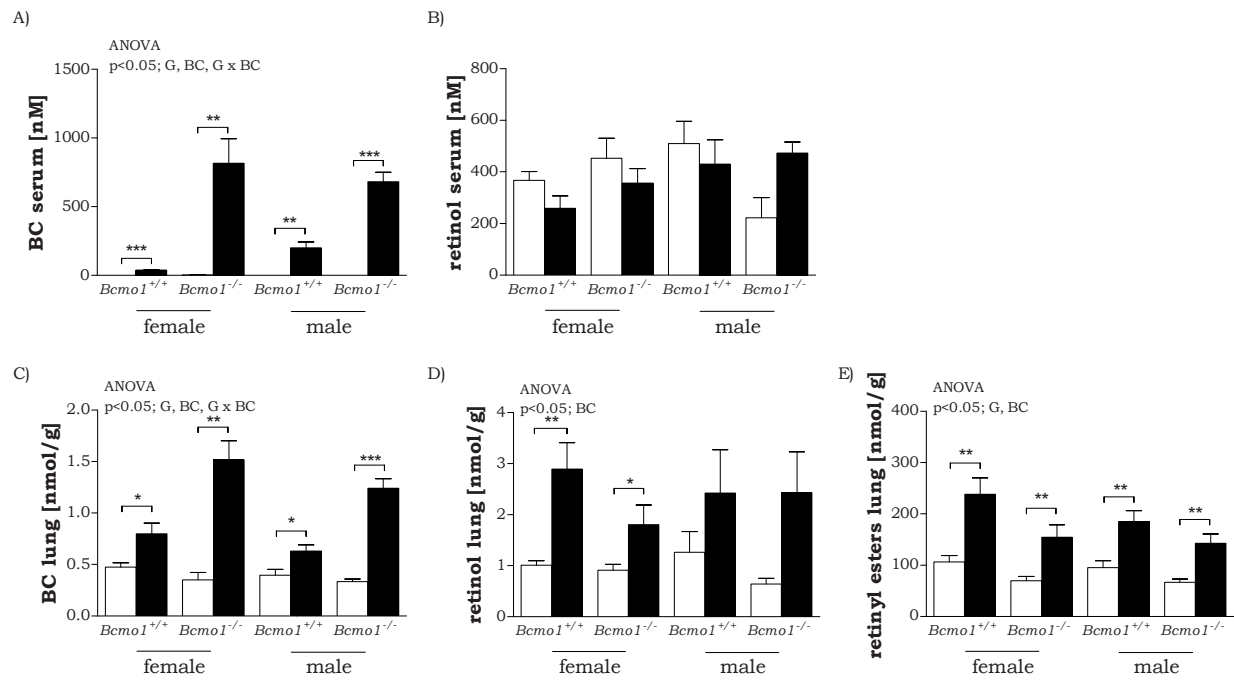

Figure 1: Beta-carotene $(B C)(A, C)$, retinol (B,D) concentrations in serum and lung tissue and retinyl ester concentrations in lung tissue $(\mathrm{E})$ of female and male $\mathrm{Bcmo1^{+/+ }}$ mice and $\mathrm{Bcmo1} \%$ mice fed a control diet (white bars) or a BC diet (black bars). Data are expressed as mean $\pm \mathrm{SEM}$, significance was tested for diet $(B C)$ and genotype $(G)$ using ANOVA and considered significant at $p<0.05$. Significant effects for the different factors; Diet (BC), Gender (S) and Genotype (G) or any interaction are displayed on top of each figure. A Student's $t$-test was used between BC and control groups when there was a significant Diet effect by ANOVA, and considered significant when $\mathrm{p}<0.05$. Using t-test statistics: ${ }^{*} \mathrm{p}<0.05,{ }^{* *} \mathrm{p}<0.01$ and ${ }^{* * *} \mathrm{p}<0.001$.

\section{$B C$ supplementation and knockout of Bcmo1 results in changes in $B C$ and BC metabolism}

$\mathrm{BC}$ concentrations in lung and serum were increased after 14 weeks of $\mathrm{BC}$ treatment compared to control diet fed mice, and as expected, to a higher level in Bcmo 1\%- mice as in $\mathrm{Bcmo1}^{+/+}$mice (as has been described separately for female [Chapter 5] and male [Chapter 6] mice). There were no significant differences in retinol serum concentrations between the different groups. In lung tissue, retinol and retinyl ester concentrations 


\section{Chapter 7}

were increased upon BC supplementation compared to the control diet fed mice (Fig. 1), but there was no interaction between $\mathrm{BC}$ and the $\mathrm{Bcmo} 1$ genotype concerning the concentration of these metabolites.

Gene expression of all groups was analyzed and of the 43,379 spots (number of spots minus control spots) on the whole genome microarrays, 31,128 spots had a signal twice above background and were regarded as positive spots and included in the analysis. We first analyzed the effect of $\mathrm{BC}$ or knockout of $\mathrm{Bcmo} 1$ on the expression of genes involved in $\mathrm{BC}$ metabolism. There were only three genes involved in downstream BC metabolism that were significantly regulated by $\mathrm{BC}$ (Table 1 ). The biggest fold change was found for lecithin-retinol acyltransferase (phosphatidylcholine-retinol-O-acyltransferase (Lrat; 1.57 fold increase after BC supplementation, only significantly regulated in $\mathrm{Bcmo1^{+/+ }}$ mice). Five genes involved in downstream $\mathrm{BC}$ metabolism were regulated due to the knock-out of $\mathrm{Bcmo1}$ with higher fold change differences than induced by $\mathrm{BC}$ supplementation. Most striking was the high fold change upregulation of Lrat (1.7-2.6 fold increase by knockout of Bcmo1), and the high fold change down regulation of alcohol dehydrogenase 7 (class IV), mu or sigma polypeptide (Adh7; 1.6-2.7 fold decrease by knockout of Bcmo1). 
BC oppositely affects males and females

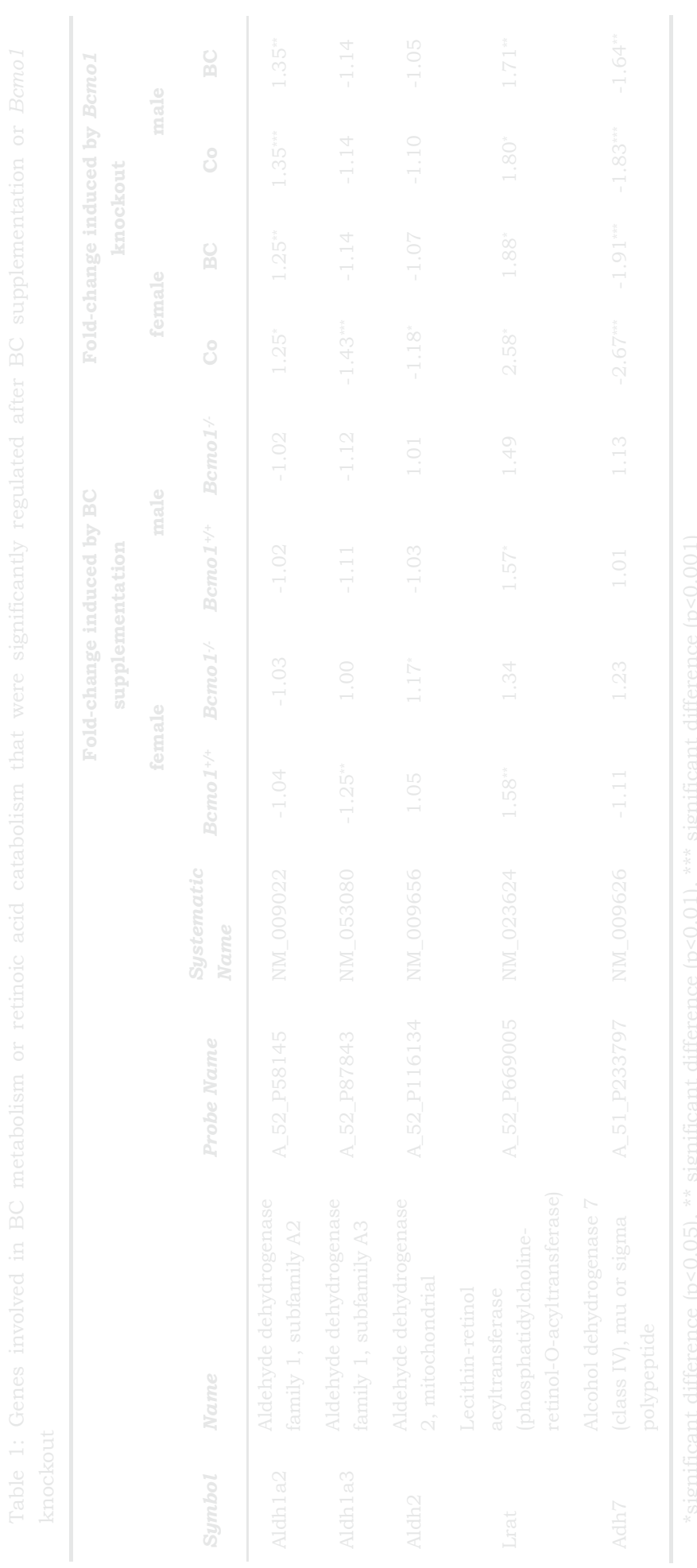




\section{Gene expression is changed in opposite direction by $\mathrm{BC}$ in male and female Bcmo1 $/$ mice}

BC supplementation resulted in a considerably higher number of significantly regulated spots in the $\mathrm{Bcmo1}^{-/-}$mice than in the $\mathrm{Bcmo1}^{+/+}$mice (Fig. 2A and 2B).

A)

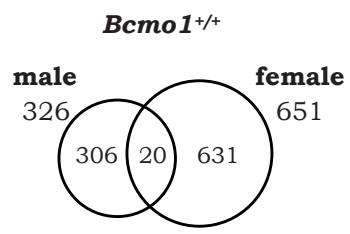

C)

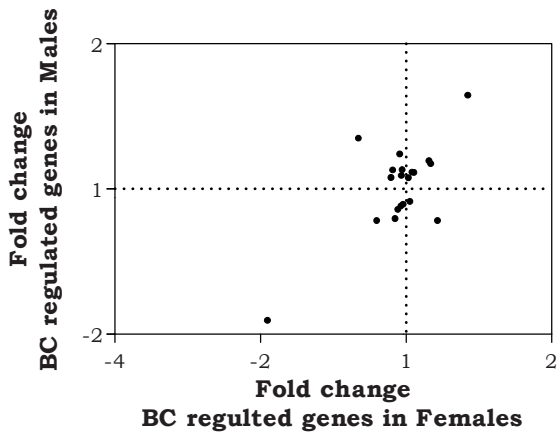

B)

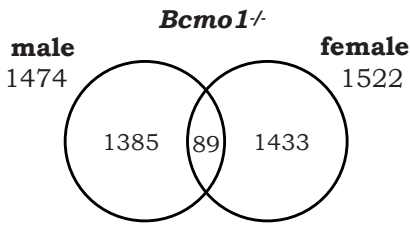

D)

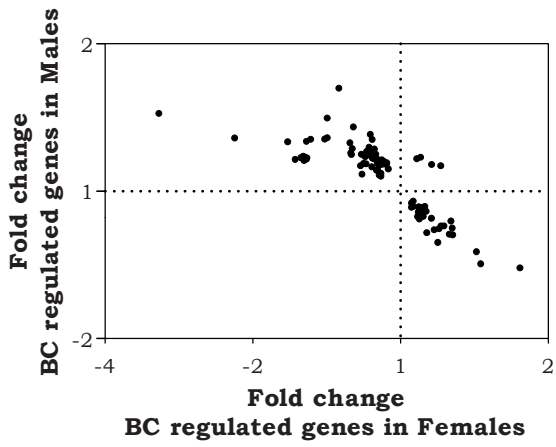

Figure 2: Venn diagrams representing the number of genes significantly regulated by BC in female and male mice and the number of genes regulated by $\mathrm{BC}$ in both females as well as males (overlap) in $\mathrm{Bcmo1}^{+++}$(A) and Bcmo1\% (B) mice. The scatter plots represent the gene expression fold changes of the genes regulated by $\mathrm{BC}$ independent of gender in females (x-axis) and males (y-axis) in $\mathrm{Bcmo1^{+/+ }}(\mathrm{C})$ and in $\mathrm{Bcmo1 \%}$ (D) mice.

Only 20 regulated genes overlapped in male and female $\mathrm{Bcmo1^{+/+ }}$ mice and 89 genes in Bcmo1\% mice. These two groups of regulated genes commonly affected in both genders showed no overlap between $\mathrm{Bcmo1}^{-}$and $\mathrm{Bcmol}^{+/+}$mice. To further determine whether these genes were similarly regulated by $\mathrm{BC}$ in both genders, fold changes of gender independent $\mathrm{BC}$ regulated genes were plotted for female mice against the fold changes in male mice. The $20 \mathrm{BC}$ regulated genes in male and female $\mathrm{Bcmo1}^{+/+}$mice were distributed in all four quadrants of the plot (Fig. 2C). 
BC oppositely affects males and females

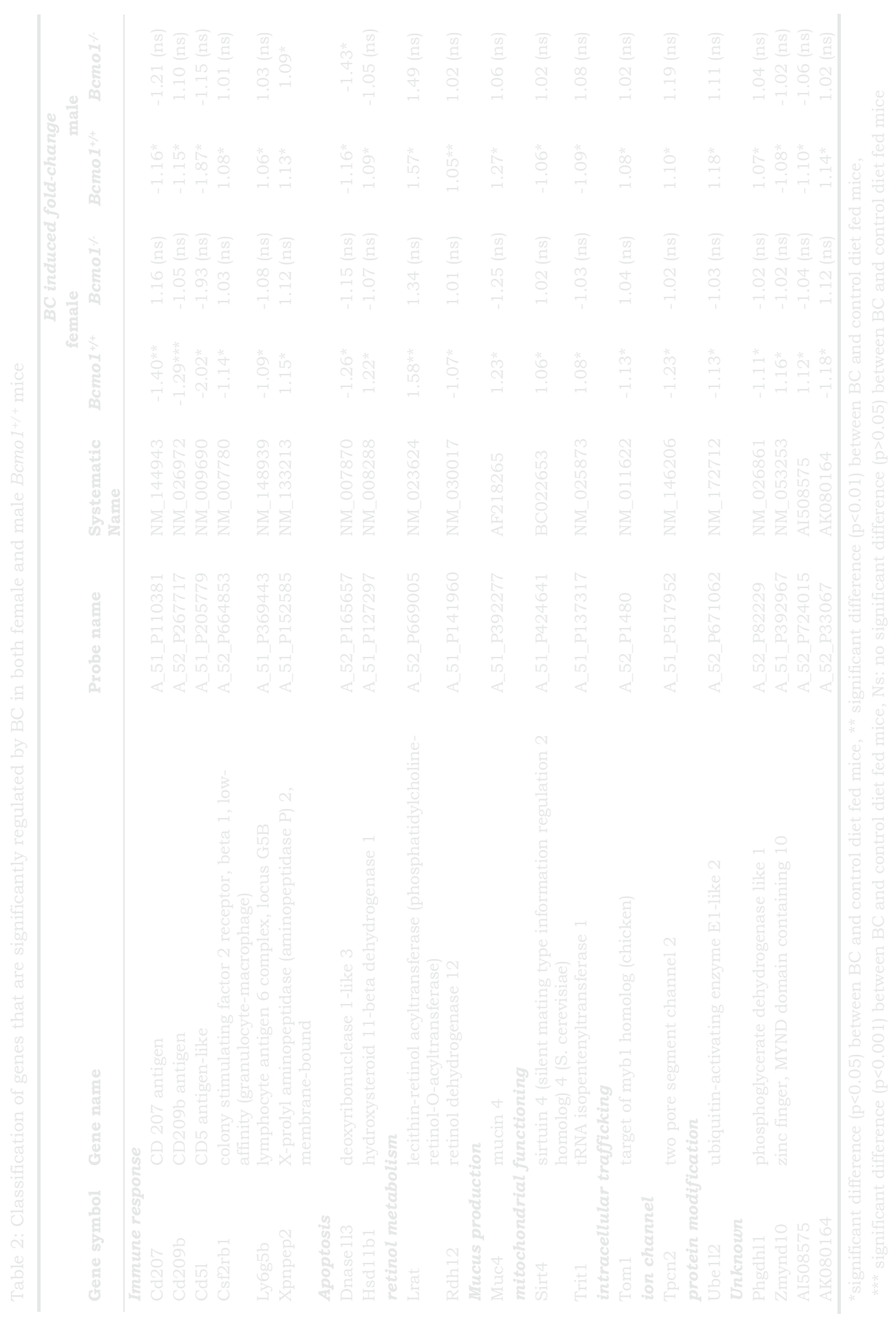




\section{Chapter 7}

To our surprise, genes regulated by $\mathrm{BC}$ in female $\mathrm{Bcmo1} /$ - were regulated in opposite directions compared to $\mathrm{BC}$ regulated genes in male $\mathrm{Bcmo1} \%$ mice (upwards regulated genes in males were down in females and vice versa, Fig.2D and Table 2), with only four out of the 89 probes being regulated in the same direction (in italics in Table 2).

We found $>95 \%$ of the probes being regulated in opposite direction by $\mathrm{BC}$ between males and females, suggesting that this is a real effect of BC. Randomly affected gene expression would theoretically result in $50 \%$ of the probes being regulated in a similar direction and $50 \%$ in opposite directions. Genes regulated by $\mathrm{BC}$ in both male and female $\mathrm{Bcmo1}^{+/+}$mice or Bcmo1/- mice were categorized into biological processes (table 2, table 3), with endothelial functioning, immune response and nervous response being most prominent (Fig. 3).

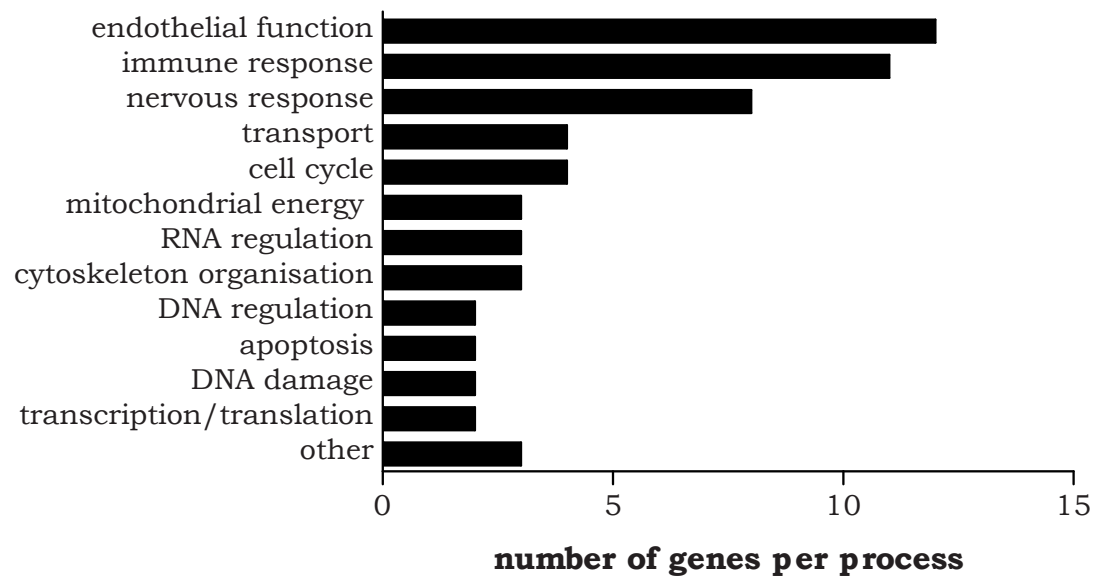

Figure 3: Classification of genes that are regulated by $\mathrm{BC}(\mathrm{p}<0.05)$ in male as well as in female $B c m o 1^{-}$ /- mice into different biological process categories.

We used Q-PCR to validate the microarray experiment. For validation of the effects in $\mathrm{Bcmo1}^{+/+}$mice, lecitin retinol acyltransferase (phosphatidylcholine-retinol $O$ acyltransferase) (Lrat), an enzyme involved in downstream BC metabolism, was selected. For validation of effects induced by $\mathrm{BC}$ supplementation in $\mathrm{Bcmo1} \%$ mice the genes glutamate receptor, ionotropic, AMPA1 (alpha 1) (Gria1) and endothelin 1 (Edn1), were chosen because of their relatively high expression level and relatively high fold changes. All three selected genes showed an identical expression using the microarray technique and Q-PCR (Fig. 4). 

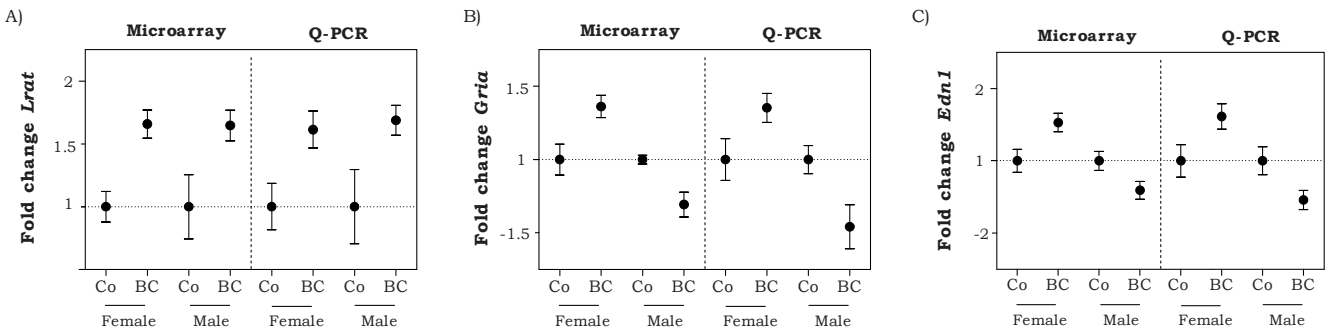

Figure 4: The expression of the genes Lrat in Bcmo1+/+ mice (A), Gria in Bcmo1\%- mice (B), and Edn1 in $B \mathrm{Cmo} 1 \%$ mice (C) in the $\mathrm{BC}$ supplemented mice relative to the control diet fed mice were validated by Q-PCR using the reference genes Stx5a and Rnf130. Data represent the average gene expression \pm SEM compared to control diet fed mice.

\section{BC supplementation results in the overrepresentation of the steroid bio- synthetic process in male Bcmo1\% mice}

Gene-Ontology (GO) processes affected by BC supplementation in male and in female $\mathrm{Bcmo1} \%$ mice were examined to further explain the opposite direction of gene expression induced by BC. This overrepresentation analysis was performed using ErmineJ overrepresentation analysis [21] on all genes and their corresponding p-value. We found a significant overrepresentation of the steroid biosynthetic process (GO:0006694) in male $\mathrm{Bcmo1} /$ mice by $\mathrm{BC}$ supplementation $\left(\mathrm{p}=4.6^{*} 10^{-6}\right)$, but not in female $\mathrm{Bcmo1} /$ mice $(p=0.17)$. Genes in the $B C$ induced overrepresented steroid biosynthetic process, in male $\mathrm{Bcmo1 \%}$ mice, are listed in Table 3 (genes presented until $\mathrm{p}=0.1$ ).

\section{Effect of BC on serum testosterone levels}

We determined serum concentrations only of the sex-hormone testosterone, since limited amounts of serum were still available. In addition, testosterone levels are relatively stable, whereas estradiol concentrations are much more sensitive to cyclic variation. As expected, testosterone levels were significantly higher in $\mathrm{Bcmo1}^{+/^{+}}$males than in $\mathrm{Bcmo1}^{+/+}$females (Figure 5A). In Bcmo1/- mice however, testosterone levels showed a high inter-individual variability (Figure $5 \mathrm{~B}$ ). Due to this large variation, there was no statistical significant difference in testosterone levels between male and female $\mathrm{Bcmo1/-}$ . However, BC increased testosterone levels in both $\mathrm{Bcmo1/-}$ female and male mice with a fold change of 4.7 and 4.0 respectively (Figure $5 \mathrm{C}$ ) although, due to the high variation in testosterone levels, differences did not reach statistical significance (ANOVA; effect of diet $\mathrm{p}=0.12$, and interaction effect of diet with $B c m o 1$ genotype $\mathrm{p}=0.14$ ) 
Table 3: Genes regulated by $\mathrm{BC}$ in male $\mathrm{Bcmo1 \%}$ mice resulting in a significant overrepresentation of the steroid biosynthetic process (GO: 0006694)\#.

\begin{tabular}{|c|c|c|c|c|c|c|}
\hline \multirow[b]{2}{*}{ Probe namer } & \multirow[b]{2}{*}{$\begin{array}{l}\text { Source } \\
\text { symbol }\end{array}$} & \multirow[b]{2}{*}{ Gene name } & \multicolumn{2}{|c|}{$\begin{array}{c}\text { gene expression } \\
\text { Female }\end{array}$} & \multicolumn{2}{|c|}{$\begin{array}{c}\text { gene expression } \\
\text { Male }\end{array}$} \\
\hline & & & $\begin{array}{l}\mathrm{Bcmo1}^{+/+} \\
\mathrm{Co}\end{array}$ & $\begin{array}{c}\mathrm{Bcmo1}^{+/+} \\
\mathrm{BC}\end{array}$ & $\begin{array}{l}\text { Bcmo1 } \% \\
\text { Co }\end{array}$ & $\begin{array}{l}\text { Bcmo1 } \% \\
\text { BC }\end{array}$ \\
\hline A_52_P137371 & Hmgcr & $\begin{array}{l}\text { 3-hydroxy-3- } \\
\text { methylglutaryl-Coenzyme } \\
\text { A reductase }\end{array}$ & 1.00 & $\begin{array}{l}-1.08 \\
(0.29)\end{array}$ & 1.00 & $\begin{array}{c}1.14 \\
(0.01)\end{array}$ \\
\hline A_51_P413238 & $\mathrm{Pbx} 1$ & $\begin{array}{l}\text { pre B-cell leukemia tran- } \\
\text { scription factor } 1\end{array}$ & 1.00 & $\begin{array}{c}1.02 \\
(0.68)\end{array}$ & 1.00 & $\begin{array}{l}-1.11 \\
(0.02)\end{array}$ \\
\hline A_51_P309733 & Cyp11a1 & $\begin{array}{l}\text { cytochrome } \mathrm{P} 450 \text {, family } \\
11 \text {, subfamily a, polypep- } \\
\text { tide } 1\end{array}$ & 1.00 & $\begin{array}{c}1.06 \\
(0.50)\end{array}$ & 1.00 & $\begin{array}{l}1.20 \\
(0.02)\end{array}$ \\
\hline A_51_P169527 & Mvk & mevalonate kinase & 1.00 & $\begin{array}{l}-1.05 \\
(0.48)\end{array}$ & 1.00 & $\begin{array}{c}1.11 \\
(0.03)\end{array}$ \\
\hline A_52_P165654 & Star & $\begin{array}{l}\text { steroidogenic acute regu- } \\
\text { latory protein }\end{array}$ & 1.00 & $\begin{array}{c}1.09 \\
(0.41)\end{array}$ & 1.00 & $\begin{array}{c}1.12 \\
(0.03)\end{array}$ \\
\hline A_52_P384574 & Stard4 & $\begin{array}{l}\text { StAR-related lipid transfer } \\
\text { (START) domain contain- } \\
\text { ing } 4\end{array}$ & 1.00 & $\begin{array}{c}1.07 \\
(0.54)\end{array}$ & 1.00 & $\begin{array}{l}-1.27 \\
(0.04)\end{array}$ \\
\hline A_52_P223224 & Dhrs8 & $\begin{array}{l}\text { dehydrogenase/reductase } \\
\text { (SDR family) member } 8\end{array}$ & 1.00 & $\begin{array}{l}-1.02 \\
(0.63)\end{array}$ & 1.00 & $\begin{array}{c}1.11 \\
(0.04)\end{array}$ \\
\hline A_51_P515446 & Cyp39a1 & $\begin{array}{l}\text { cytochrome } \mathrm{P} 450 \text {, family } \\
39 \text {, subfamily a, polypep- } \\
\text { tide } 1\end{array}$ & 1.00 & $\begin{array}{c}1.01 \\
(0.83)\end{array}$ & 1.00 & $\begin{array}{c}1.08 \\
(0.05)\end{array}$ \\
\hline A_52_P164570 & Hsd17b12 & $\begin{array}{l}\text { hydroxysteroid (17-beta) } \\
\text { dehydrogenase } 12\end{array}$ & 1.00 & $\begin{array}{l}1.00 \\
(0.95)\end{array}$ & 1.00 & $\begin{array}{l}-1.15 \\
(0.05)\end{array}$ \\
\hline A_52_P85765 & Stard6 & $\begin{array}{l}\text { StAR-related lipid transfer } \\
\text { (START) domain contain- } \\
\text { ing } 6\end{array}$ & 1.00 & $\begin{array}{l}-1.05 \\
(0.51)\end{array}$ & 1.00 & $\begin{array}{l}1.11 \\
(0.05)\end{array}$ \\
\hline A_51_P420415 & Srd5a 1 & $\begin{array}{l}\text { steroid } 5 \text { alpha-reductase } \\
1\end{array}$ & 1.00 & $\begin{array}{l}-1.00 \\
(0.98)\end{array}$ & 1.00 & $\begin{array}{c}1.12 \\
(0.06)\end{array}$ \\
\hline A_51_P485791 & Cyp51 & $\begin{array}{l}\text { cytochrome P450, family } \\
51\end{array}$ & 1.00 & $\begin{array}{l}-1.10 \\
(0.14)\end{array}$ & 1.00 & $\begin{array}{l}1.14 \\
(0.06)\end{array}$ \\
\hline A_52_P566605 & Hsd17b7 & $\begin{array}{l}\text { hydroxysteroid (17-beta) } \\
\text { dehydrogenase } 7\end{array}$ & 1.00 & $\begin{array}{l}-1.18 \\
(0.03)\end{array}$ & 1.00 & $\begin{array}{c}1.09 \\
(0.07)\end{array}$ \\
\hline A_52_P136138 & Fdft 1 & $\begin{array}{l}\text { farnesyl diphosphate far- } \\
\text { nesyl transferase } 1\end{array}$ & 1.00 & $\begin{array}{l}-1.08 \\
(0.33)\end{array}$ & 1.00 & $\begin{array}{c}1.18 \\
(0.07)\end{array}$ \\
\hline A_52_P388072 & Hmgcs 1 & $\begin{array}{l}\text { 3-hydroxy-3- } \\
\text { methylglutaryl-Coenzyme } \\
\text { A synthase } 1\end{array}$ & 1.00 & $\begin{array}{l}-1.10 \\
(0.22)\end{array}$ & 1.00 & $\begin{array}{c}1.16 \\
(0.08)\end{array}$ \\
\hline A_52_P636752 & Cyp51 & $\begin{array}{l}\text { cytochrome P450, family } \\
51\end{array}$ & 1.00 & $\begin{array}{l}-1.13 \\
(0.19)\end{array}$ & 1.00 & $\begin{array}{c}1.15 \\
(0.08)\end{array}$ \\
\hline A_51_P379798 & Fdps & $\begin{array}{l}\text { farnesyl diphosphate syn- } \\
\text { thetase }\end{array}$ & 1.00 & $\begin{array}{l}-1.04 \\
(0.65)\end{array}$ & 1.00 & $\begin{array}{c}1.14 \\
(0.08)\end{array}$ \\
\hline A_51_P485946 & Fdft1 & $\begin{array}{l}\text { farnesyl diphosphate far- } \\
\text { nesyl transferase } 1\end{array}$ & 1.00 & $\begin{array}{l}-1.15 \\
(0.20)\end{array}$ & 1.00 & $\begin{array}{l}1.07 \\
(0.10)\end{array}$ \\
\hline
\end{tabular}

\# genes presented: $\mathrm{BC}$ vs control in male $\mathrm{Bcmo1} /$ - mice $\mathrm{p}<0.1$; between brackets the actual $\mathrm{p}$-value 
A)

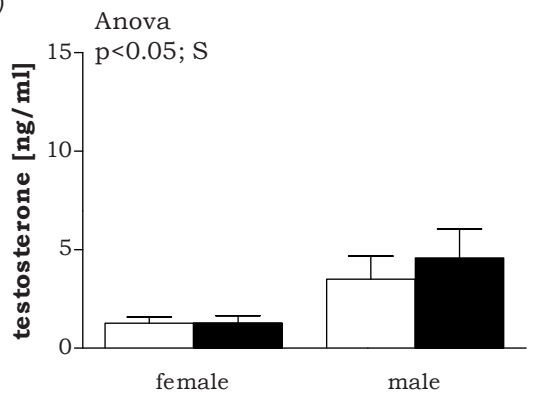

B)

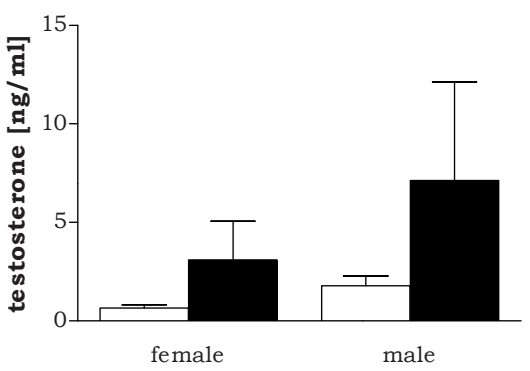

C)

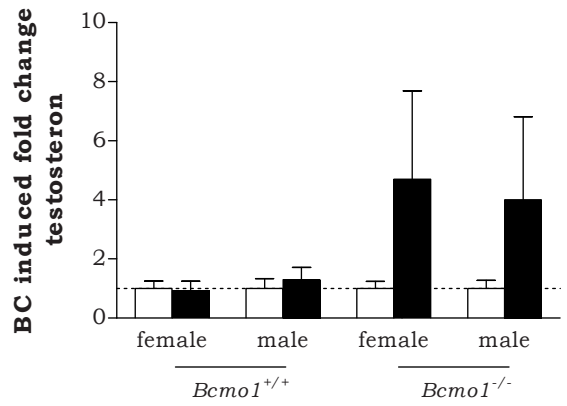

Figure 5: Testosterone levels in serum of $\mathrm{Bcmo1}^{+/+}$mice (A) and $\mathrm{Bcmo1}{ }^{-}$(B) mice, fed a control diet (white bars) or a BC diet (black bars) and fold change in testosterone concentration by BC supplementation $(\mathrm{C})$ as compared to control mice. Data are expressed as mean $\pm \mathrm{SEM}$, significance was tested for diet $(\mathrm{BC})$, Gender $(\mathrm{S})$ and Genotype $(\mathrm{G})$ using ANOVA and considered significant at $\mathrm{p}<0.05$. Significant effects are displayed on top of the Figure.

\section{Discussion}

We showed for the first time that $\mathrm{BC}$ supplementation to $\mathrm{Bcmo1} /$ - mice resulted in the regulation of gene expression in opposite directions for male and female mice. We hy- 
pothesize that $\mathrm{BC}$ alters systemic hormone production which was supported by the overrepresentation of the steroid biosynthetic process (GO:0006694) in male Bcmo1/mice upon a $B C$ diet $\left(p=4.6^{*} 10^{-6}\right)$. Moreover, testosterone concentrations were increased but highly variable after $\mathrm{BC}$ supplementation in $\mathrm{Bcmo} 1 \%$ mice. Alterations in hormone levels are thought to influence lung cancer risk and might therefore be, in part, an explanation for the $\mathrm{BC}$ induced increase in lung cancer risk in smokers and asbestos exposed subjects of the CARET and the ATBC studies. The presence of an active Bcmo1 enzyme is of importance in the observed opposite direction of gene expression by $\mathrm{BC}$ supplementation, since these effects were not observed in $\mathrm{Bcmo1}^{+/+}$mice. Therefore, the presence of previous reported BCMO1 polymorphisms in humans might influence the consequence of $\mathrm{BC}$ supplementation.

$\mathrm{BC}$ supplementation to $\mathrm{Bcmo1} \%$ mice resulted in an opposite direction of generegulation in males and females. Since testosterone levels seemed to be affected and the GO process for steroid synthesis was significantly regulated in male lung tissue, we hypothesize that $\mathrm{BC}$ increases systemic hormone synthesis in male and female $\mathrm{Bcmo1^{-/ }}$ mice. Interestingly, the biosynthetic pathway for BC production in plants partly overlaps with the sterol biosynthetic pathway in animals [23]. Therefore, the observed effects could be explained by this evolutionary conservation. Indeed, the rate limiting enzyme in the steroid synthesis pathway and in the carotenoid pathway in plants is HMGCoA reductase (Hmgcr), which gene expression was very significantly ( $p=0.005)$ upregulated by $\mathrm{BC}$ supplementation in lungs of male $\mathrm{Bcmo1 \%}$ mice. Also several related enzymes such as mevalonate kinase (Mvk), cytochrome P450, family 11 a1 (Cyp11a1) and others were significantly regulated in lung tissue of male $\mathrm{Bcmo1}^{-1-}$ mice, as can be seen in Table 3.

Although the number of studies that assessed effects of $\mathrm{BC}$ on hormone production is limited, these studies actually support a relation between BC and steroid hormone alterations. BC supplementation to female dogs resulted in increased plasma progesterone concentrations [24] and cats supplemented with BC had increased estradiol concentrations [25]. In addition, it has been reported that downstream BC metabolites, such as vitamin A and the bioactive metabolite retinoic acid, also have an effect on steroidogenesis and that these effects are, at least in part, due to an increased expression of enzymes involved in steroidogenesis [26,27], but it is not known whether this is regulated by binding of retinoid acid to the transcription factors retinoic acid receptor (RAR) or retinoid X receptor (RXR).

Our results suggest that the $\mathrm{BC}$ induced opposite direction of gene expression in the different genders of $\mathrm{Bcmo1}^{-}$mice are not due to $\mathrm{BC}$ metabolites such as retinoic acid, since this opposite direction of gene expression regulation was only observed in $\mathrm{Bcmo1} /$ mice. Compared to $\mathrm{BCmo1}^{-/-}$mice, male and female $\mathrm{Bcmo1}^{+/+}$mice had higher concentrations of the $\mathrm{BC}$ metabolites; retinol and retinyl esters accumulated in lung tissue after BC supplementation. Furthermore, although still not fully understood, it is gener- 
ally believed that retinoic acid concentrations are well regulated [28]. Nevertheless, it may be that the concentration of the bioactive metabolite retinoic acid, able to bind to RAR and RXR, is altered only in $\mathrm{Bcmo1} /$ mice and not in $\mathrm{Bcmo1}^{+/+}$mice. We previously reported that the $\mathrm{Bcmo} 1 \%$ mice were more prone to a phenotypic vitamin A deficiency than $\mathrm{Bcmo}^{+/+}$mice, due to alterations in the expression of downstream BC metabolizing enzymes important in the production of retinoic acid [Chapter 5]. Supplemental BC was able to restore this phenotype. We similarly show in this study that downstream $\mathrm{BC}$ metabolism was altered in Bcmo $1 \%$ mice. Most striking was the upregulation of Lrat combined with the downregulation of Adh7 in $B \mathrm{cmol}^{-/-}$mice. Lrat is involved in the storage of retinol by the formation of retinyl esters [29], while Adh7 is involved in the conversion of retinol into retinal which is the precursor for retinoic acid [30]. This therefore implicates a more vitamin A storing phenotype of $\mathrm{Bcmo1 \%}$ mice compared to $\mathrm{Bcmo1^{+/+ }}$ mice. Moreover, more enzymes involved in downstream BC metabolism were altered and altogether, these data indicate that also a change in retinoic acid, possibly due to a less tight regulation of retinoic acid stores in $\mathrm{Bcmo} 1 \%$ mice compared to $\mathrm{Bcmol}^{+/+}$mice, might explain the observed alterations in hormone production.

Another question is whether the processes that were regulated by BC supplementation

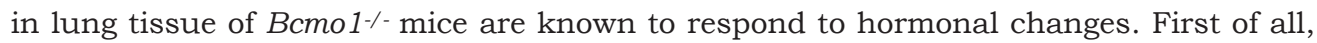
it is important to note that steroids have an effect on lung functioning and the lung contains necessary elements for sex hormone action, since it is active in androgen and estrogen metabolism and lung tissue contains estrogen and androgen receptors [31-33]. The $\mathrm{BC}$ regulated genes in lungs of $\mathrm{Bcmol}^{\%}$ in this study were mainly categorized in three biological categories; endothelial functioning, immune response and nervous response. Literature search revealed that these three categories are all affected by one gaseous mediator; nitric oxide (NO). NO is a radical and can be produced endogenously, by the iron containing enzyme nitric oxide synthase (Nos). Three distinct NOS isoforms have been characterized, neuronal NOS (nNOS or NOSI), inducible NOS (iNOS or NOSII) and endothelial NOS (eNOS or NOSIII) and all three NOS isoforms have been detected in the airway epithelium [34,35]. The functions of NO in the airway include neurotransmission, vascular tone homeostasis and regulation of immune functioning [36]. It is known that estrogen is able to increase NOS activity, whereas testosterone reduces NOS activity [37]. This may result in expression of genes involved in nerve signaling, vascular tone and inflammatory responses in opposite direction in male and female lung [38]. Thus, BC induced changes in hormone production possibly results in differences in NO synthesis and this could very well explain our results.

A last point which we would like to address is whether changes in hormone production induced by $\mathrm{BC}$ could possibly explain an increase in lung cancer risk as observed in the CARET and ATBC study. If this is the case, than hormones are a determining factor in lung carcinogenesis, resulting in gender related differences in lung cancer risk. Indeed, females are thought to be at a higher risk for the development of smoke induced lung cancer than males $[39,40]$ and lung cancer is more frequent in never-smoking females 
than in never-smoking males [41]. It has been hypothesized that especially estrogens might be an important contributor to the differences in lung cancer risk between the different genders. For example, estrogen replacement therapy increases lung cancer risk, and early menopause, which results in decreased estrogen levels, is associated with a reduced risk for lung cancer in women [42]. Although we unfortunately could not investigate differences in estrogen production in this study, we did measure testosterone, of which the production seemed to be affected by $\mathrm{BC}$ supplementation in $\mathrm{Bcmo1} \%$ mice. Testosterone can also be converted in estrogens by hormone converting enzymes, to exert an estrogen induced effect. Several enzymes involved in steroid conversion were shown to be significantly regulated in male $\mathrm{Bcmo1}^{-1-}$ mice (Table 3). For example, testosterone can be converted in the lung into estrone and $17 \beta$-estradiol. $17 \beta$-estradiol can bind to the estrogen receptor to induce estrogen related responses [43]. Interestingly, the gene expression of 17-beta-hydroxysteroid dehydrogenase 12 (Hsd17b12), which converts estrone into estradiol was significantly upregulated [44] and steroid 5 alphareductase 1 (Srd5a1), an important enzyme in the inactivation of testosterone [32] was down regulated $(\mathrm{p}=0.055)$, in lungs of male $\mathrm{Bcmo} 1 \%$ mice upon $\mathrm{BC}$ supplementation. Moreover, 17-beta-hydroxysteroid dehydrogenase 7 (Hsd17b7), which oxidizes or reduces estradiol, and thus decreases the estrogenic potency, was significantly downregulated by $\mathrm{BC}$ in female $\mathrm{Bcmo1} \%$ mice. Therefore, $\mathrm{BC}$ induced changes in hormone production could be an explanation for, part of, the increases in lung cancer risk in the CARET and ATBC study.

Altogether, we used $\mathrm{Bcmo1} \%$ mice to investigate $\mathrm{BC}$ induced alterations in gene expression in lung. We unexpectedly found that $\mathrm{BC}$ supplementation resulted in opposite direction of gene expression in male and female $\mathrm{Bcmo1} \%$ mice. We hypothesize that $\mathrm{BC}$ supplementation to $\mathrm{Bcmo1} \%$ mice resulted in changes in hormone production and metabolism, which would explain our opposite effects on lung gene expression. To fully understand and explain these effects, further research is needed specifically focusing on reproductive organs as potential target organ for $\mathrm{BC}$ and on quantitative measurements of sex hormones in response to BC supplementation in males and in females.

\section{Acknowledgements}

Yvonne van Helden was supported by a grant from NUTRIM/VLAG. We are grateful for the contribution of Johannes von Lintig and M. Luisa Bonet for their contribution in the animal experiment. We thank Evelien Kramer, Dini Venema and Annelies Bunschoten for their technical assistance. We also thank DSM neutraceuticals for the use of Bcmo1/- mice and the $\mathrm{BC}$ beadlets. None of the authors declare any commercial interest. 


\section{References}

[1] R.G. Ziegler Vegetables, fruits, and carotenoids and the risk of cancer, Am J Clin Nutr 53 (1991) 251S259S.

[2] G. van Poppel Epidemiological evidence for beta-carotene in prevention of cancer and cardiovascular disease, Eur J Clin Nutr 50 Suppl 3 (1996) S57-61.

[3] R.G. Ziegler A review of epidemiologic evidence that carotenoids reduce the risk of cancer, J Nutr 119 (1989) 116-122.

[4] M. Strobel, J. Tinz and H.K. Biesalski The importance of beta-carotene as a source of vitamin A with special regard to pregnant and breastfeeding women, Eur J Nutr 46 Suppl 1 (2007) I1-20.

[5] D. Albanes, O.P. Heinonen, P.R. Taylor, J. Virtamo, B.K. Edwards, M. Rautalahti, A.M. Hartman, J. Palmgren, L.S. Freedman, J. Haapakoski, M.J. Barrett, P. Pietinen, N. Malila, E. Tala, K. Liippo, E.R. Salomaa, J.A. Tangrea, L. Teppo, F.B. Askin, E. Taskinen, Y. Erozan, P. Greenwald and J.K. Huttunen AlphaTocopherol and beta-carotene supplements and lung cancer incidence in the alpha-tocopherol, betacarotene cancer prevention study: effects of base-line characteristics and study compliance, J Natl Cancer Inst 88 (1996) 1560-1570.

[6] G.S. Omenn, G.E. Goodman, M.D. Thornquist, J. Balmes, M.R. Cullen, A. Glass, J.P. Keogh, F.L. Meyskens, Jr., B. Valanis, J.H. Williams, Jr., S. Barnhart, M.G. Cherniack, C.A. Brodkin and S. Hammar Risk factors for lung cancer and for intervention effects in CARET, the Beta-Carotene and Retinol Efficacy Trial, J Natl Cancer Inst 88 (1996) 1550-1559.

[7] G.E. Goodman, M.D. Thornquist, J. Balmes, M.R. Cullen, F.L. Meyskens, Jr., G.S. Omenn, B. Valanis and J.H. Williams, Jr. The Beta-Carotene and Retinol Efficacy Trial: incidence of lung cancer and cardiovascular disease mortality during 6-year follow-up after stopping beta-carotene and retinol supplements, J Natl Cancer Inst 96 (2004) 1743-1750.

[8] N.R. Cook, I.M. Le, J.E. Manson, J.E. Buring and C.H. Hennekens Effects of beta-carotene supplementation on cancer incidence by baseline characteristics in the Physicians' Health Study (United States), Cancer Causes Control 11 (2000) 617-626.

[9] C.H. Hennekens, J.E. Buring, J.E. Manson, M. Stampfer, B. Rosner, N.R. Cook, C. Belanger, F. LaMotte, J.M. Gaziano, P.M. Ridker, W. Willett and R. Peto Lack of effect of long-term supplementation with beta carotene on the incidence of malignant neoplasms and cardiovascular disease, N Engl J Med 334 (1996) 1145-1149.

[10] J. von Lintig and A. Wyss Molecular analysis of vitamin A formation: cloning and characterization of betacarotene 15,15'-dioxygenases, Arch Biochem Biophys 385 (2001) 47-52.

[11] S.J. Hickenbottom, J.R. Follett, Y. Lin, S.R. Dueker, B.J. Burri, T.R. Neidlinger and A.J. Clifford Variability in conversion of beta-carotene to vitamin A in men as measured by using a double-tracer study design, Am J Clin Nutr 75 (2002) 900-907.

[12] Y. Lin, S.R. Dueker, B.J. Burri, T.R. Neidlinger and A.J. Clifford Variability of the conversion of betacarotene to vitamin A in women measured by using a double-tracer study design, Am J Clin Nutr 71 (2000) 1545-1554.

[13] Z. Wang, S. Yin, X. Zhao, R.M. Russell and G. Tang beta-Carotene-vitamin A equivalence in Chinese adults assessed by an isotope dilution technique, Br J Nutr 91 (2004) 121-131.

[14] W.C. Leung, S. Hessel, C. Meplan, J. Flint, V. Oberhauser, F. Tourniaire, J.E. Hesketh, J. von Lintig and G. Lietz Two common single nucleotide polymorphisms in the gene encoding beta-carotene 15,15'monoxygenase alter beta-carotene metabolism in female volunteers, Faseb J 23 (2009) 1041-1053.

[15] A. Lindqvist, J. Sharvill, D.E. Sharvill and S. Andersson Loss-of-function mutation in carotenoid 15,15'monooxygenase identified in a patient with hypercarotenemia and hypovitaminosis A, J Nutr 137 (2007) 2346-2350.

[16] S. Hessel, A. Eichinger, A. Isken, J. Amengual, S. Hunzelmann, U. Hoeller, V. Elste, W. Hunziker, R. Goralczyk, V. Oberhauser, J. von Lintig and A. Wyss CMO1 deficiency abolishes vitamin A production from beta-carotene and alters lipid metabolism in mice, J Biol Chem 282 (2007) 33553-33561.

[17] W. Rodenburg, J. Keijer, E. Kramer, C. Vink, R. van der Meer and I.M. Bovee-Oudenhoven Impaired barrier function by dietary fructo-oligosaccharides (FOS) in rats is accompanied by increased colonic mitochondrial gene expression, BMC Genomics 9 (2008) 144.

[18] E.M. van Schothorst, V. Pagmantidis, V.C. de Boer, J. Hesketh and J. Keijer Assessment of reducing RNA input for Agilent oligo microarrays, Anal Biochem 363 (2007) 315-317.

[19] J.M. Wettenhall and G.K. Smyth limmaGUI: a graphical user interface for linear modeling of microarray data, Bioinformatics 20 (2004) 3705-3706. 


\section{Chapter 7}

[20] L. Pellis, N.L. Franssen-van Hal, J. Burema and J. Keijer The intraclass correlation coefficient applied for evaluation of data correction, labeling methods, and rectal biopsy sampling in DNA microarray experiments, Physiol Genomics 16 (2003) 99-106.

[21] H.K. Lee, W. Braynen, K. Keshav and P. Pavlidis ErmineJ: tool for functional analysis of gene expression data sets, BMC Bioinformatics 6 (2005) 269.

[22] E. Rijntjes, A.T. Wientjes, H.J. Swarts, D.G. de Rooij and K.J. Teerds Dietary-induced hyperthyroidism marginally affects neonatal testicular development, J Androl 29 (2008) 643-653.

[23] A.M. Gawienowski Integration of the metabolic pathways of steroids, carotenoids, and retinoids, Crit Rev Biochem Mol Biol 34 (1999) 405-410.

[24] B.C. Weng, B.P. Chew, T.S. Wong, J.S. Park, H.W. Kim and A.J. Lepine Beta-carotene uptake and changes in ovarian steroids and uterine proteins during the estrous cycle in the canine, J Anim Sci 78 (2000) 12841290.

[25] B.P. Chew, B.B. Weng, H.W. Kim, T.S. Wong, J.S. Park and A.J. Lepine Uptake of beta-carotene by ovarian and uterine tissues and effects on steroidogenesis during the estrous cycle in cats, Am J Vet Res 62 (2001) 1063-1067.

[26] G. Livera, C. Pairault, R. Lambrot, M. Lelievre-Pegorier, J.M. Saez, R. Habert and V. Rouiller-Fabre Retinoid-sensitive steps in steroidogenesis in fetal and neonatal rat testes: in vitro and in vivo studies, Biol Reprod 70 (2004) 1814-1821.

[27] G. Livera, V. Rouiller-Fabre, C. Pairault, C. Levacher and R. Habert Regulation and perturbation of testicular functions by vitamin A, Reproduction 124 (2002) 173-180.

[28] J.E. Thatcher and N. Isoherranen The role of CYP26 enzymes in retinoic acid clearance, Expert Opin Drug Metab Toxicol 5 (2009) 875-886.

[29] Z.N. Yang, G.J. Davis, T.D. Hurley, C.L. Stone, T.K. Li and W.F. Bosron Catalytic efficiency of human alcohol dehydrogenases for retinol oxidation and retinal reduction, Alcohol Clin Exp Res 18 (1994) 587-591.

[30] A.C. Ross Retinoid production and catabolism: role of diet in regulating retinol esterification and retinoic Acid oxidation, J Nutr 133 (2003) 291S-296S.

[31] S. Mollerup, K. Jorgensen, G. Berge and A. Haugen Expression of estrogen receptors alpha and beta in human lung tissue and cell lines, Lung Cancer 37 (2002) 153-159.

[32] P.R. Provost, C.H. Blomquist, R. Drolet, N. Flamand and Y. Tremblay Androgen inactivation in human lung fibroblasts: variations in levels of 17 beta-hydroxysteroid dehydrogenase type 2 and 5 alpha-reductase activity compatible with androgen inactivation, J Clin Endocrinol Metab 87 (2002) 3883-3892.

[33] C.M. Wilson and M.J. McPhaul A and B forms of the androgen receptor are expressed in a variety of human tissues, Mol Cell Endocrinol 120 (1996) 51-57.

[34] K. Asano, C.B. Chee, B. Gaston, C.M. Lilly, C. Gerard, J.M. Drazen and J.S. Stamler Constitutive and inducible nitric oxide synthase gene expression, regulation, and activity in human lung epithelial cells, Proc Natl Acad Sci U S A 91 (1994) 10089-10093.

[35] A. Giaid and D. Saleh Reduced expression of endothelial nitric oxide synthase in the lungs of patients with pulmonary hypertension, N Engl J Med 333 (1995) 214-221.

[36] F.L. Ricciardolo, P.J. Sterk, B. Gaston and G. Folkerts Nitric oxide in health and disease of the respiratory system, Physiol Rev 84 (2004) 731-765.

[37] R. Singh, S. Pervin, J. Shryne, R. Gorski and G. Chaudhuri Castration increases and androgens decrease nitric oxide synthase activity in the brain: physiologic implications, Proc Natl Acad Sci U S A 97 (2000) 3672-3677.

[38] D.N. Krause, S.P. Duckles and D.A. Pelligrino Influence of sex steroid hormones on cerebrovascular function, J Appl Physiol 101 (2006) 1252-1261.

[39] S.K. Park, L.Y. Cho, J.J. Yang, B. Park, S.H. Chang, K.S. Lee, H. Kim, K.Y. Yoo and C.T. Lee Lung cancer risk and cigarette smoking, lung tuberculosis according to histologic type and gender in a population based case-control study, Lung Cancer (2009).

[40] H.A. Risch, G.R. Howe, M. Jain, J.D. Burch, E.J. Holowaty and A.B. Miller Are female smokers at higher risk for lung cancer than male smokers? A case-control analysis by histologic type, Am J Epidemiol 138 (1993) 281-293.

[41] J.M. Siegfried Women and lung cancer: does oestrogen play a role?, Lancet Oncol 2 (2001) 506-513.

[42] E. Taioli and E.L. Wynder Re: Endocrine factors and adenocarcinoma of the lung in women, J Natl Cancer Inst 86 (1994) 869-870.

[43] J. Gasperino and W.N. Rom Gender and lung cancer, Clin Lung Cancer 5 (2004) 353-359.

[44] V. Luu-The, P. Tremblay and F. Labrie Characterization of type 12 17beta-hydroxysteroid dehydrogenase, an isoform of type 3 17beta-hydroxysteroid dehydrogenase responsible for estradiol formation in women, Mol Endocrinol 20 (2006) 437-443. 
BC oppositely affects males and females 
Little information is available on differences, commonalities and especially interactions in overall gene expression responses as a result of diet, differences in gender (male and female) and effects induced by differences in metabolism. Moreover, it is unknown whether such effects are tissue specific. We used a previously performed BC study to analyze the magnitude of these effects and their importance for BC research. Therein we investigated the gene expression effects induced by betacarotene (BC) supplementation, knockout of beta-carotene 15,15'monooxygenase 1 (Bcmo 1), a key enzyme in BC metabolism, and differences between male and female mice in three tissues; lung, liver and inguinal white adipose tissue (iWAT). BC accumulation was highest in liver and iWAT of male and female Bcmol/-mice. Retinol concentrations were highest in liver. Unsupervised principal component analysis (PCA) showed that lung gene expression was most affected by knockout of Bcmo1. Liver was most affected by knockout of Bcmol and differences in gender. iWAT was most affected by differences in gender. Hardly any genes were commonly influenced by $\mathrm{BC}$ among the three tissues. The effect of BC supplementation and knockout of Bcmol were relatively gender specific, especially in iWAT. These data demonstrate that gene expression differences induced by BC are limited to the tissue and gender that is analyzed, and that differences in metabolism induced by for example single nucleotide polymorphisms, should be taken into account as much as possible. Moreover, our results indicate that gene expression differences obtained in surrogate tissues should be interpreted with caution for any nutritional intervention. 


\section{Global gene expression response of mouse lung, liver and white adipose tissue to beta-carotene supplemen- tation, knockout of Bcmol and gen- der}

Yvonne G.J. van Helden, Roger W.L. Godschalk, Johannes von Lintig, Georg Lietz, Jean-Francois Landrier, M. Luisa Bonet, Frederik J. van Schooten, Jaap Keijer 


\section{Introduction}

To test specific hypotheses in nutritional research, mechanistic studies are often performed in rodents and nutritional effects are usually assessed within one specified genetic background, tissue and gender. For this reason, little information is available on commonalities and differences in response to dietary interventions between different tissues, genetic backgrounds and genders. This type of information is necessary to interpret results and to generalize and extrapolate effects between tissues. This is for example of importance for benefit-risk assessment, since it is important to incorporate risks and benefits of a compound based on all tissues. Moreover, the use of surrogate tissues is increasingly used in human studies [1], but it is unknown whether mechanistic results obtained can be extrapolated with confidence to an effect in the tissue of interest. A comparison between gene expression in different tissues will give insight in the organ specificity of changes induced by an intervention. We will address three important questions in nutritional research in this paper; "how weigh gene expression responses of nutritional intake to effects induced by differences in genetic background or gender and do they interact", "do diverse tissues differ in response to an nutritional intervention", and finally "do female and male mice respond similar to a dietary intervention"? We used a previously performed study to analyze these questions. In this study we investigated the effects of beta-carotene (BC) in male or female mice with a knockout or not for beta-carotene 15,15'-monooxygenase 1 (Bcmo1), a key enzyme in BC metabolism, in male and female mice on gene expression changes in lung, liver and inguinal white adipose tissue (iWAT).

$\mathrm{BC}$ is a dietary compound which is present in colored fruits and dark green vegetables and is frequently used as a food coloring agent. After absorption and metabolism in the intestine, remainder intact $\mathrm{BC}$ is transported to the liver where $\mathrm{BC}$ is metabolized and, like in white adipose tissues, stored [2,3]. Increased BC intake has been associated with many health promoting activities, including antioxidant properties to prevent radical induced macromolecular damage [4]. It is associated with a decreased risk for cardiovascular diseases [5] and a decreased risk for several types of cancer [6]. Finally, BC can act as provitamin A, thereby preventing vitamin A deficiency. However, besides these health promoting effects, a high intake of $\mathrm{BC}$ has been associated with an increased lung cancer risk in smokers and asbestos exposed subjects $[7,8]$. Moreover, the increased lung cancer risk was higher in females than in males and was more persistent in female volunteers than in male volunteers after the intervention [9].

An important drawback in $\mathrm{BC}$ research is the lack of an appropriate animal model that resembles human $\mathrm{BC}$ metabolism and at the same time allows the application of stateof-the-art genetic and functional genomic knowledge and tools, such as commercial whole genome microarrays. Compared to humans, rodents differ tremendously in the 
activity of beta-carotene 15,15'-monooxygenase 1 (Bcmo1). Bcmo1 symmetrically cleaves BC to produce two molecules of retinal $[10,11]$ which can be further metabolized into several other downstream metabolites [12]. Due to the high activity of Bcmol in rodents, virtually all absorbed $\mathrm{BC}$ is metabolized, while humans accumulate intact beta-carotene [13], and consequently analysis of effects induced by $\mathrm{BC}$ is virtually impossible using rodents. However, a Bcmo1 knockout mouse (Bcmo1\%) model has become available. $\mathrm{BC}$ supplementation to these mice results in $\mathrm{BC}$ accumulation in several tissues [14].

We aimed to provide insight in the relative gene expression change induced by BC supplementation, knockout of $\mathrm{Bcmo1}^{-}$or gender in lung, liver and iWAT. Therefore we used whole genome microarray analyses to quantitatively assess gene expression changes in lung, liver and inguinal white adipose tissue of male and female betacarotene 15, 15'-monooxygenase 1 knockout (Bcmo1-/) and wildtype $\left(\mathrm{Bcmo1}^{+/+}\right)$mice given a diet with or without $\mathrm{BC}(150 \mathrm{mg} / \mathrm{kg}$ diet) for 14 weeks to contribute to questions of general importance to nutritional research as well as to $\mathrm{BC}$ research specifically.

\section{Materials \& Methods}

\section{Animals and treatment}

Twelve female (Fe) and twelve male (ma) B6129SF1 ( $\mathrm{Ccmo1}^{+/+}$) and twelve female and twelve male B6;129S-Bcmo1tm1dnp $\left(\mathrm{Bcmo1}^{-/-}\right)$mice [14], were used for the experiment. The mouse experiment was conducted in accordance with the German animal protection laws by the guidelines of the local veterinary authorities. During the breeding and weaning periods of the mice, mothers were maintained on KLIBA 3430 chow containing 14,000 IU vitamin A/kg diet (Provima Kliba AG, Kaiseraugst, Switzerland). Five-weekold female and male $\mathrm{Bcmo}^{+/+}$and $\mathrm{Bcmo1/-}$ mice were caged in groups containing 2 to 4 siblings per group and were maintained under environmentally controlled conditions (temperature $24^{\circ} \mathrm{C}, 12 \mathrm{~h} / 12 \mathrm{~h}$ light/dark cycle). Mice had ad libitum access to feed and water. Basic feed consisted of the palletized diet D12450B (Research Diets Inc, USA) with a fat content of $10 \%$ and a defined fatty acid composition. The diet was modified to contain 1500 IU vitamin A per kg of diet, which is a vitamin A sufficient diet, and the control diet (contol) was supplemented with water soluble vehicle beadlets (DSM Nutritional Products Ltd., Basel, Switzerland) containing DL-alpha-tocopherol and ascorbyl palmitate as stabilizers, as well as carriers such as gelatine, corn oil sucrose and starch. The BC diet (BC) was supplemented with identical water soluble beadlets containing BC (DSM Nutritional Products Ltd., Basel, Switzerland) to generate $150 \mathrm{mg}$ $\mathrm{BC} / \mathrm{kg}$ diet. Beadlets were added by the manufacturer before low temperature pelletting. Feed pellets were color marked and stored at $4^{\circ} \mathrm{C}$ in the dark. 
After 14 weeks of dietary intervention, 6 female and 6 male $B c m o 1^{+/+}$mice on the con-

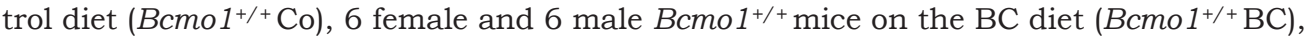
3 female and 6 male Bcmo $1 \%$ mice on the control diet (Bcmo1\% Co) and 3 female and 6 male $\mathrm{Bcmo1} \%$ mice on the $\mathrm{BC} \operatorname{diet}\left(\mathrm{Bcmo1}^{-\mathrm{BC}}\right)$ were randomly sacrificed during 3 subsequent mornings. Blood was collected from the vena cava after isoflurane and ketamin anethesia. Blood was coagulated for at least 20 minutes at room temperature, cooled to $4^{\circ} \mathrm{C}$ and centrifuged. Lung, inguinal white adipose (iWAT) and liver tissues were removed, lung and liver tissue were rinsed in phosphate buffered saline (PBS) and all tissues were snap frozen in liquid nitrogen. The tissues were stored at $-80^{\circ} \mathrm{C}$ until use. Due to an insufficient number of female $\mathrm{Bcmo1}^{-/}$mice in the original breeding pool, female $\mathrm{Bcmo1}^{-/-}$mice were used that were born 2 weeks later from an identical experiment, treated identically with 3 mice on the control diet and 3 mice on the BC diet to generate $n=6$ per group, and sacrificed 2 weeks after the first group of mice.

\section{RNA Isolation}

Lung, iWAT and liver were homogenized in liquid nitrogen using a cooled mortar and pestle. Total RNA was isolated using TRIzol reagent (Invitrogen, Breda, The Netherlands) followed by purification using RNeasy columns (Qiagen, Venlo, The Netherlands) using the instructions of the manufacturer. RNA concentration and purity were measured using the Nanodrop system (IsoGen Life Science, Maarsen, The Netherlands). RNA degradation was checked on the Experion (Bio-Rad, Veenendaal, The Netherlands) using Experion StdSense chips (Bio-Rad). Three RNA samples did not meet RNA quality (RNA from lung from one individual female $\mathrm{BCmo1}^{+/+}$control diet mouse, RNA from lung from one individual female $\mathrm{Bcmo1}^{+/+} \mathrm{BC}$ diet mouse and RNA from iWAT from one individual male $\mathrm{Bcmo1}^{+/+} \mathrm{BC}$ diet mouse) which were omitted from the experiment. Knockout of Bcmo1 was confirmed using quantitative RT-PCR analysis [unpublished results] and for several genes expression was checked using real-time quantitative Q-PCR and was found to be identical to the microarray results (Chapter 5, 6 and 7).

\section{Microarray hybridization procedure}

The 4x44k Agilent whole mouse genome microarrays (G4122F, Agilent Technologies, Inc. Santa Clara, CA) were used. Preparation of the sample and the microarray hybridization were carried out according to the manufacturer's protocol with a few exceptions as described previously [15,16]. In brief, cDNA was synthesized from $1 \mu \mathrm{g}$ RNA from individual samples using the Agilent Low RNA Input Fluorescent Linear Amplification Kit for each animal without addition of spikes. Thereafter samples were split in 2 equal amounts, to synthesize Cyanine 3-CTP (Cy3) and Cyanine 5-CTP (Cy5) labeled cRNA using half the amounts per dye as indicated by the manufacturer (Agilent Technologies). Labeled cRNA was purified using RNeasy columns (Qiagen). Yield, $\mathrm{A}_{260} / \mathrm{A}_{280}$ ratio and $\mathrm{Cy} 3$ or Cy5 activity were examined for every sample using the nanodrop. All samples 
met the criteria of a cRNA yield higher than $825 \mathrm{ng}$ and a specific activity of at least 8.0 pmol Cy3 or Cy5. 1200 ng of every Cy3 labeled cRNA sample was pooled and used as a common reference pool. Individual 825 ng Cy5-labeled cRNA and 825 ng pooled Cy3labeled cRNA were fragmented in $1 \mathrm{x}$ fragmentation and $1 \mathrm{x}$ blocking agent (Agilent Technologies) at $60^{\circ} \mathrm{C}$ for 30 minutes and thereafter mixed with GEx Hybridization Buffer HI-RPM (Agilent Technologies) and hybridized in a $1: 1$ ratio at $65^{\circ} \mathrm{C}$ for 17 hours in an Agilent Microarray hybridization Chamber rotating at $4 \mathrm{rpm}$. After hybridization, slides were washed according to the wash protocol with Stabilization and Drying solution (Agilent Technologies). Arrays were scanned with an Agilent scanner with $10 \%$ and 100\% laser power intensities (Agilent Technologies).

\section{Data analyses of microarray results}

Signal intensities for each spot were quantified using Feature Extraction 9.1 (Agilent Technologies). Median density values and background values of each spot were extracted for both the experimental samples (Cy5) and the reference samples (Cy3). Quality control for every microarray was performed visually, by using Quality control graphs from Feature extraction and M-A plots and boxplots which were made using limmaGUI in R (Bioconductor) [17]. Data were imported into GeneMaths XT 2.0 (Applied Maths, Sint-Martens-Latem, Belgium). Spots with a Cy5 and Cy3 signal twice above background were selected and log transformed. The Cy5 signal was normalized against the Cy3 intensity as described before [18]. Principal component analysis was performed using GeneMaths XT.

\section{Statistical analysis}

General effects of diet, gender and genotype on concentrations of BC, retinol and retinyl esters in lung, liver and iWAT were analyzed using $2 \times 2 \times 2$ factorial univariate ANOVA (SPSS version 15.0) and considered statistically significant when $\mathrm{p}<0.05$. Fold changes for microarray gene expression were calculated using mean log signal intensities. Pvalues for differential expressions were calculated between two groups using two tailed Student's $t$-test statistics on log intensity values. Changes were considered statistically significant at $\mathrm{p}<0.05$. 


\section{Results}

\section{Responses of $\mathrm{BC}$ supplementation related to Bcmo1 knockout and gender in lung, liver and iWAT}

$\mathrm{BC}$ accumulation was highest after $\mathrm{BC}$ supplementation in $\mathrm{Bcmo1 \%}$ mice and reached similar levels in iWAT and liver, while accumulation was lower in lung. Depending on the experimental group, retinol concentrations were between 5 and 10 fold higher in the liver compared to iWAT and lung tissue (Fig. 1).

Whole genome gene expression changes were analyzed using microarray technology. Spots with a signal twice above background were regarded as positive spots and included in the analysis. This resulted in $31,128,24,746$ and 25,139 spots with a signal twice above background in lung, liver and iWAT, respectively. Principal component analysis (PCA) was used as an unsupervised tool to plot the individual animals based on their overall gene expression profile. In lung, the individual animals were most discriminated based on the presence or absence of intact Bcmo1 (Fig. 2A). In liver the largest discriminating effect was observed for gender, followed by a clear discrimination based on the presence of an active Bcmol enzym. This resulted in a PCA plot displaying four separated groups (Fig. 2B). Gene expression effects in iWAT were strongest differentiated between male and female mice (Fig. 2C).

\section{Number of genes regulated by BC, Bcmo1 genotype and gender in lung, liv- er and adipose tissue}

As can be seen in Table 1, there were large differences in the number of significantly regulated genes $(\mathrm{p}<0.05)$ due to $B C$ supplementation $(B C$ diet versus control diet), knockout of $\mathrm{Bcmol}\left(\mathrm{Bcmo1}^{-/-}\right.$versus $\mathrm{BCmo1}^{+/+}$) or difference in gender (male versus female gene-expression). These effects also depended on the tissue.

BC supplementation resulted in the highest number of significantly regulated genes in iWAT of female $\mathrm{Bcmo1}^{+/+}$mice. These 4,970 significantly regulated genes were highly dependent on gender and on the presence of Bcmo1 since BC supplementation to female $\mathrm{Bcmo1} \%$ mice or to male $\mathrm{Bcmo1}^{+/+}$mice resulted in only 1,522 and 407 significantly regulated genes, respectively. At the same stringency, $\mathrm{BC}$ supplementation resulted in less (roughly 1,000) significantly regulated genes in lung and liver. 
A)

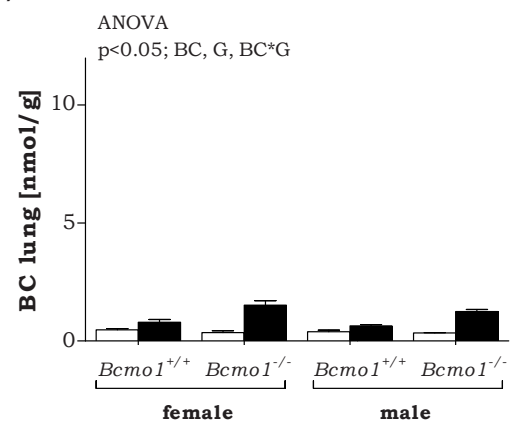

C)

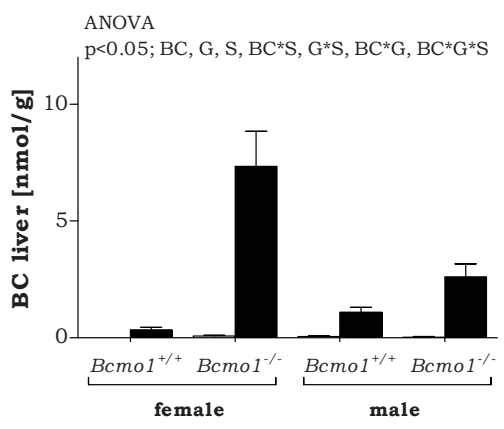

E)

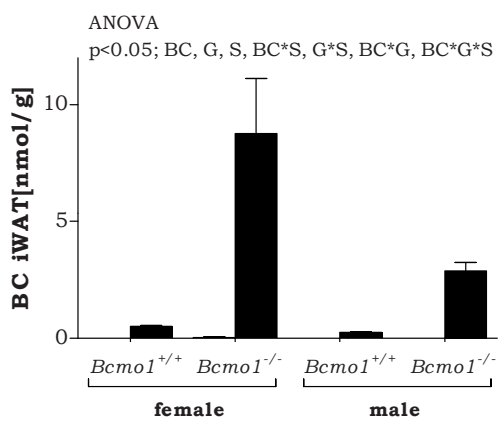

B)

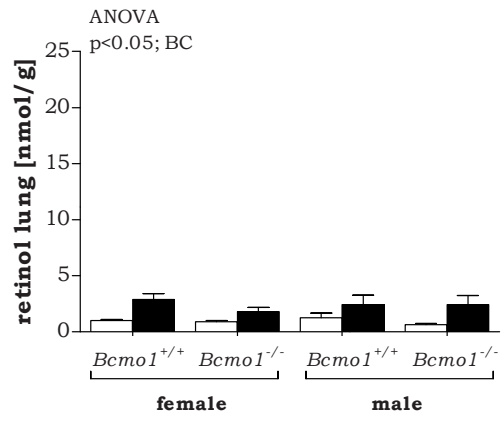

D)

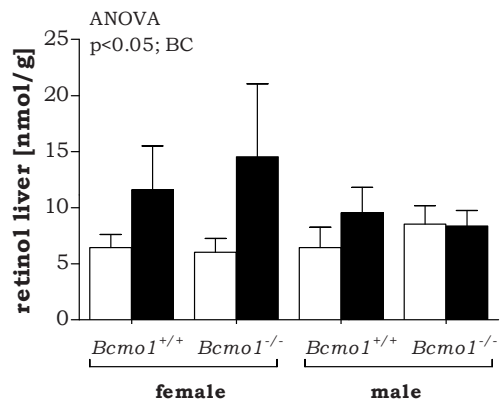

F)

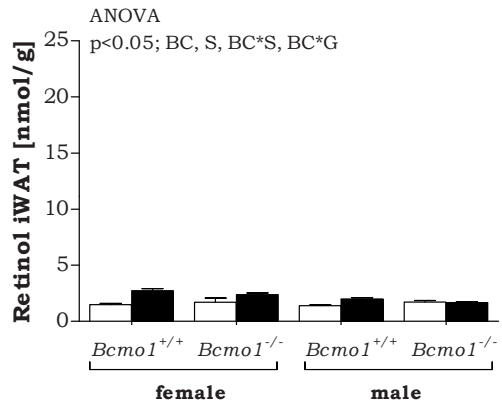

Figure 1: Beta-carotene $(\mathrm{BC})$ concentration in lung $(\mathrm{A})$, liver $(\mathrm{B})$ and inguinal white adipose tissue (iWAT; C) and concentrations of the BC metabolite retinol in lung (D), liver (E) and iWAT (F) in control mice (white bars) and in BC supplemented mice (black bars). Data are expressed as mean \pm SEM. Statistical differences were tested using ANOVA for effects of $\mathrm{BC}(\mathrm{BC})$, beta-carotene 15,15'monooxygenase $1(\mathrm{Bcmo})$ genotype $(\mathrm{G})$ and gender $(\mathrm{S})$ or any interaction, and considered statistically significant when $p<0.05$. Significant effects are displayed on top of each figure. 
A)

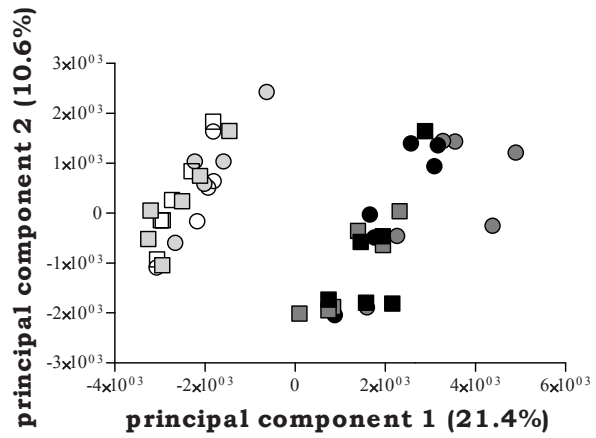

B)

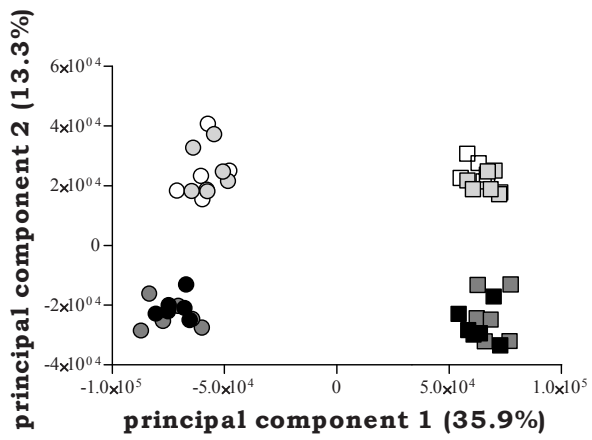

C)

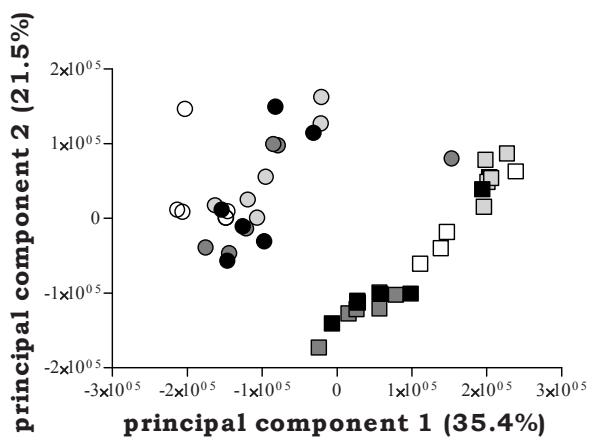

Figure 2: Unsupervised principal component analysis of all individual animals based on differences in gene expression in lung (A), liver (B) and inguinal white adipose tissue (iWAT; C). The $\mathrm{x}$-axis accounts for strongest variability in gene expression and the y-axis accounts thereafter for the strongest variability in gene expression of the data-set. Individual animals are presented; $\mathrm{Bcmo1} \%$ control diet (white) and $\mathrm{Bcmo1} 1^{\%-} \mathrm{BC}$ diet (light grey), $\mathrm{Bcmo1}^{+/+}$control diet (dark grey) and $\mathrm{Bcmo1}^{+/+} \mathrm{BC}$ diet (black) with females (squares) and males (circles). 
Relative effects of $\mathrm{BC}, \mathrm{Bcmo} 1$ genotype and gender in lung, liver and iWAT

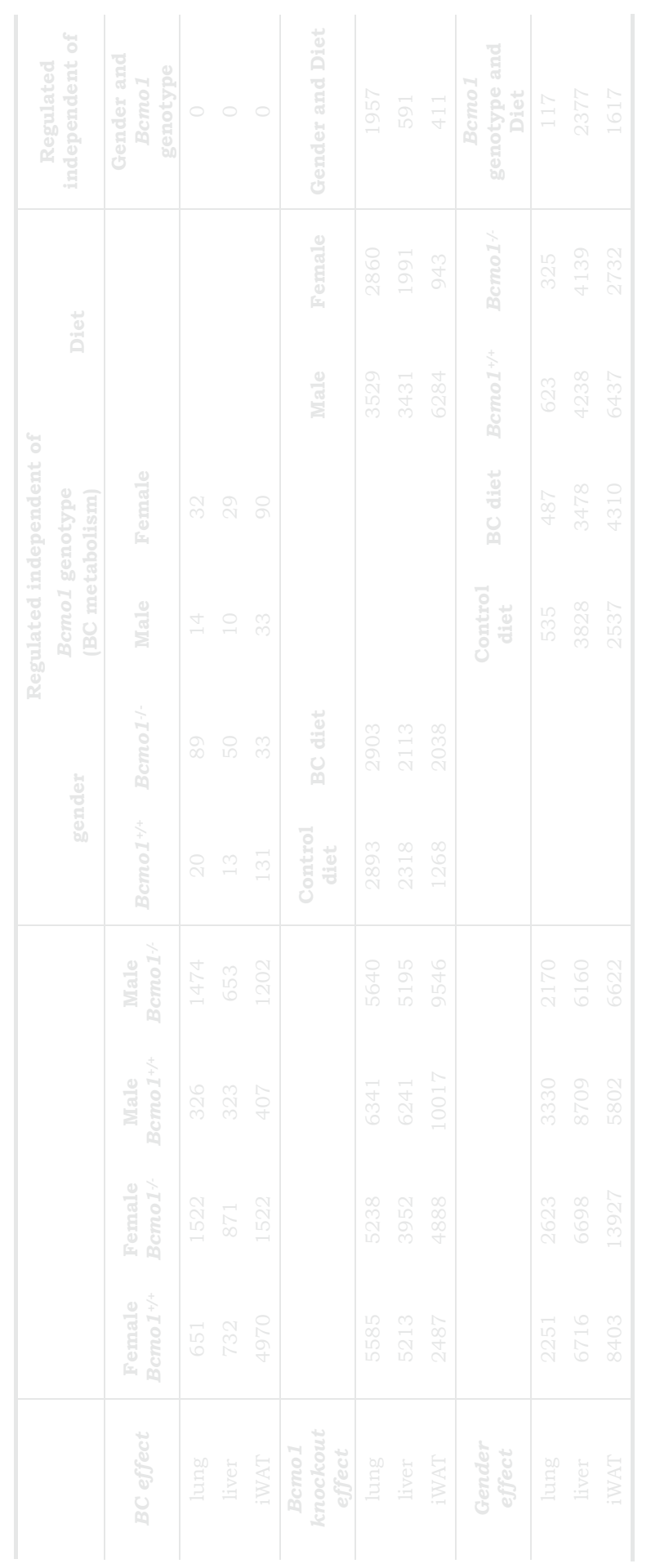


The effect of knocking-out Bcmo1, which affects BC metabolism, was most pronounced in iWAT of male mice, resulting in 10,017 and 9,546 genes significantly $(\mathrm{p}<0.05)$ differentially expressed in mice fed the control diet and mice fed the BC supplemented diet, respectively. The knockout of Bcmo1 in iWAT of female mice resulted in 2487 and 4888 regulated genes in mice fed the control diet or mice supplemented with $\mathrm{BC}$, respectively. The effect of knockout of Bcmo1 was therefore also dependent on gender. With 2487 significantly regulated genes in iWAT of control diet fed female mice, this group had the lowest response to the presence of Bcmo1.

Gene expression differences between male and female were highest in iWAT tissue. There were 13,927 genes differentially expressed between male and female BC supplemented $\mathrm{BCmo}^{+/+}$mice. Interestingly, BC supplementation had an effect on gene expression differences in male compared to female $\mathrm{Bcmo1}^{+/+}$mice since there were "only" 8403 genes significantly differentially expressed genes between male and female $\mathrm{Bcmo1^{+/+ }}$ mice receiving the control diet.

\section{Organ specificity of gene expression induced by BC, knockout of Bcmo1 or differences in gender}

We further focused on the organ specificity of significantly regulated genes induced by $\mathrm{BC}$ supplementation, knockout of Bcmo1 or difference in gender. As can be seen in Table 2, gene expression differences induced by $\mathrm{BC}$ had the highest organ specificity, and resulted in the lowest number of common significantly regulated genes in lung, liver and iWAT. There was even not a single common gene significantly regulated by $\mathrm{BC}$ in male $\mathrm{Bcmo1 \%}$ mice in all these three tissues. Effects induced by knockout of Bcmo1 had the lowest organ specificity, resulting in the regulation of at least 626 genes (female BC supplemented mice) in all three tissues and maximal 1,261 commonly regulated genes (control diet fed male mice). The effect of difference in gender was more tissue specific than effects induced by Bcmo1 knockout. 
Relative effects of $\mathrm{BC}, \mathrm{Bcmo} 1$ genotype and gender in lung, liver and iWAT

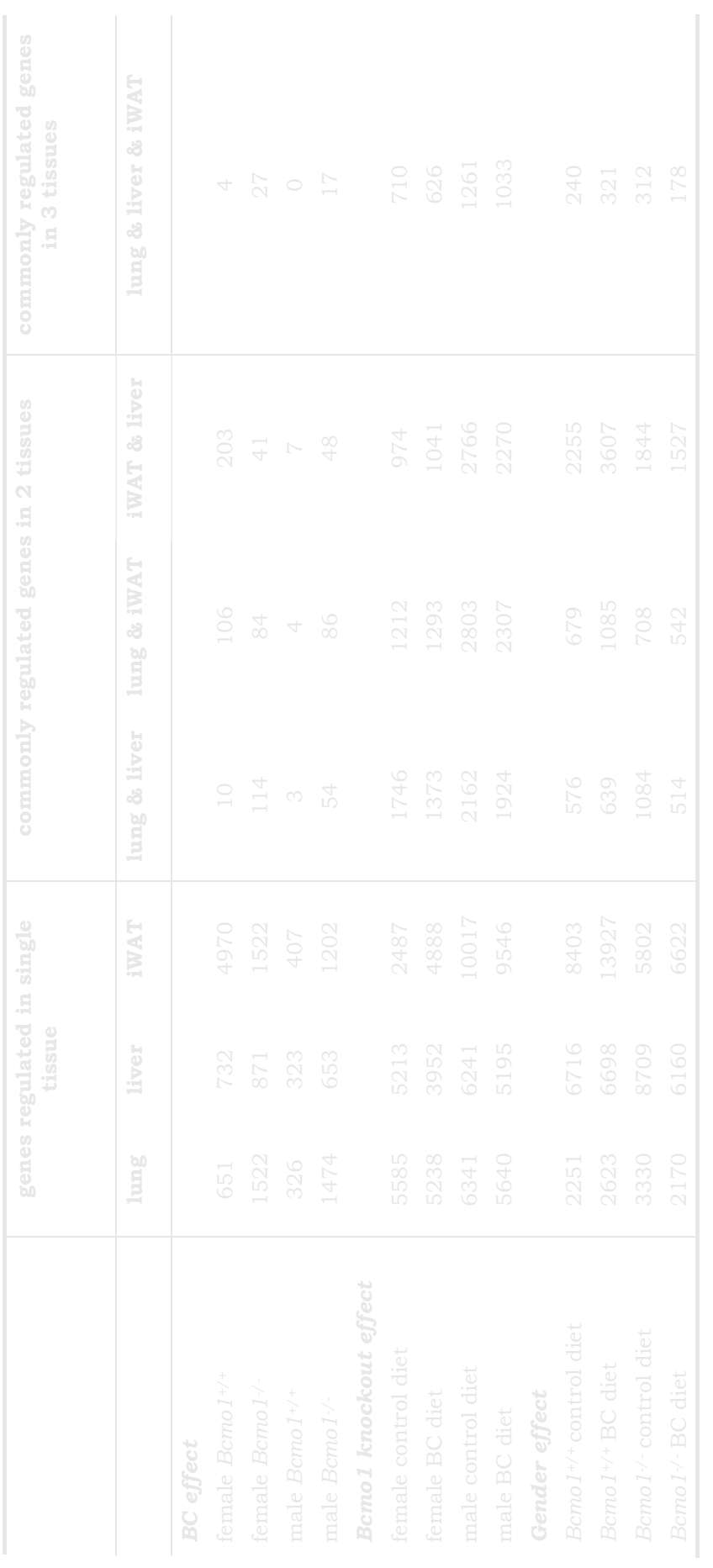




\section{Discussion}

In this study, we investigated the effect of $\mathrm{BC}$, knockout of Bcmo1, a key enzyme in $\mathrm{BC}$ metabolism, and gender on global gene expression changes in lung, liver and iWAT. We observed that BC supplementation, relative to Bcmo1 knockout and gender, resulted in the smallest number of significantly regulated genes in any tissue and that the effect of gender was surprisingly high, especially in iWAT. Moreover, the effect of BC supplementation on gene expression was highly organ specific. All together, our data demonstrate that effects of dietary intake should be interpreted in the context of genetic background and gender. In addition, effects should be interpreted in relation to the tissue under investigation and warn against the use of a "surrogate tissue" for mechanistic research, when not properly assessed and validated.

The first question that was addressed in this study: "how weigh gene expression responses induced by a dietary intervention to effects induced by differences in genetic background or gender and do they interact"? The number of genes changed by supplementation with the nutritional compound BC was relatively low, lower than the effects induced by knockout of Bcmol and by difference in gender, which implies the need of highly powered studies to analyze effects induced by BC. The effects of BC were highly dependent on gender and metabolic activity. This implies that results should be interpreted in the context of these modifiers, which should ideally be included in any study design, especially in $\mathrm{BC}$ research. This is exemplified for the results seen for the lung. PCA analysis showed that gene expression profiles in lung and liver were both highly affected by knockout of Bcmo1. Bcmo1 is suggested to be highly expressed in mouse liver tissue [13], and thus a discriminating effect between both genotypes might be expected for the liver. However, gene expression of Bcmol was not detected at all in lung tissue in that same study [13]. Interestingly, PCA analysis showed that the effect of genotype was the most discriminating factor in lung, and gene expression analysis showed that the effects were relatively independent of gender and diet. Taken together, this suggests that the lung is affected indirectly, but importantly, by knockout of $B c m o 1$. This also might have implications for $\mathrm{BC}$ research in humans. Effects found induced by $\mathrm{BC}$ might be highly dependent on human inter-individual differences in $\mathrm{BC}$ conversion ability $[19,20]$, which are thought to occur due to polymorphisms in Bcmo1 $[21,22]$.

Principal component analysis of microarray results and the number of significantly regulated genes revealed that the overall signature of gene expression patterns in all three tissues was different between genotypes. This variation might be caused either by Bcmo1-deficiency but part of this variation might also be caused by differences in the genetic background of mice. We tried to reduce the latter effect by using mixed background $\mathrm{BCmo}^{+/+}$mice and $\mathrm{Bcmo1} 1^{--}$mice, but effects due to differences in genetic back- 
ground cannot be excluded [23]. Moreover, it is generally known that retinoids influence many aspects of embryonic and fetal development [24], and a knockout of Bcmo1\%-during development might have caused part of the variation in the adult differences between both genotypes. To know whether this was the case more research is needed, but until then results concerning the $\mathrm{Bcmo} 1 \%$ have to be interpreted carefully.

The second question that was addressed in this study was: "Do diverse tissues differ in response to a nutritional intervention?" Effects induced by $\mathrm{BC}$ were highly organ specific and consequently analysis should focus on the individual target tissues, since there is limited translatability of effects to other tissues. Nevertheless, surrogate tissues are sometimes used in nutritional research. The concept of a surrogate tissue is that the question addressed is a determinant for "target" tissue, but the effects are determined by analyzing an accessible or "surrogate" tissue [1]. An often used easy accessible "surrogate tissue" are the human peripheral blood mononuclear cells (PBMC), present in blood. Although the use of for example PBMC's have been proven to be successful in profiling nutritional changes [25] and as a diagnostic marker for certain diseases $[26,27]$, its usefulness for mechanistic research is still illusive. Although we did not isolate PBMCs for microarray analysis, our study also implies that for functions that involve many different tissues, such as metabolism, faithful functional interpretation requires information for the tissues involved in these pathways. Nevertheless, these data also show that there are some genes which are organ independently affected by BC (except for male $\mathrm{Bcmo1}^{+/+}$mice). These genes might lead to markers in $\mathrm{BC}$ research, but this requires more detailed (functional) analysis.

The last question that was addressed in this study was: "Do female and male mice respond similar to a dietary intervention?" To our surprise, gene expression differences between male and female mice contributed most to the discrimination of individual animals in the PCA analysis in liver and iWAT, and resulted in the highest number of significantly regulated genes in iWAT. The differences in gender specific fat distribution, which reflect differences in gender dependent white adipose tissue gene-regulation, is extensively described and reviewed in literature [28]. These differences have been described to be caused by sex-hormones [28]. Also the liver transcriptome was highly affected by gender. The liver contains also estrogen and androgen receptors [29] and several studies show that fluctuations in sex-hormones result in differences in drug metabolizing cytochrome P450's [30]. The lung seemed to be somewhat less responsive to these gender effects but nevertheless, the gender effect was higher in lung tissue than effects induced by BC supplementation. A gender effect in lung is not illogical, since lung tissue contains androgen and estrogen receptors [31,32] and several sex-steroid metabolizing enzymes [33]. Moreover, many gender differences have been reported for the lung, such as differences in the development and susceptibility to different diseases, such as asthma and lung cancer [34]. Interestingly, BC had also a large effect on the gender dependent differences in iWAT of $\mathrm{BCmo1}^{+/+}$mice and therefore might actually influence gender specific effects. These results show that in $\mathrm{BC}$ research, but also in 
other molecular nutritional research, the interaction of gender and nutrition should not be neglected, especially in tissues such as iWAT and liver. It is therefore advisable to perform nutritional research, where differences are relatively small [35], in the gender of interest. Moreover, these data implicate that in vitro gene expression changes induced by nutrition are possibly difficult to correlate to effects in vivo. This because the number of significantly regulated genes seems to depend on gender and there are often no or no representative hormone signatures taken into account when analyzing gene expression responses in vitro.

Altogether, we aimed to answer three questions relevant for nutritional research; "how weigh gene expression responses of nutritional intake to effects induced by differences in genetic background or gender and do they interact", "do diverse tissues respond differently and how does this translate to the use surrogate tissues for mechanistic purposes", and finally "do female and male mice respond similar to differences in diets?". We demonstrate that the effect of $\mathrm{BC}$ was generally much smaller than the effect of the knockout of Bcmol and differences in gender, and that those effects were highly dependent on interactions with a functional Bcmo1 enzym and gender (Table 1). Moreover, the effects were highly organ specific (Table 2) and females and males responded differently to the effects induced by BC. We therefore conclude that mechanistic effects of BC should be investigated in the tissue of interest and that mechanistic effects in a specific gender can not be extrapolated, without evidence, to the opposite gender. Moreover, effort should be taken to make sure the "best possible" genetic phenotype is used to answer nutritional research questions. Of course, it remains to be seen to which extend this conclusion can be translated to other dietary compounds, but at least it poses a warning that these factors should be carefully considered.

\section{Acknowledgements}

The experiment described was performed in the framework of the Carotenoid focus team of the European Nutrigenomics Consortium (NuGO; CT2004-505944m) and the VLAG/Nutrim project that supported Yvonne van Helden. CIBER de Fisiopatología de la Obesidad y Nutrición is an initiative of the ISCIII. We thank Suzanne Hessel, Jaume Amengual, Erwan Gouranton, Joan Ribot, Evelien Kramer and Annelies Bunschoten for their contribution to different aspects of the overall project. 


\section{References}

[1] J.C. Rockett, M.E. Burczynski, A.J. Fornace, P.C. Herrmann, S.A. Krawetz and D.J. Dix Surrogate tissue analysis: monitoring toxicant exposure and health status of inaccessible tissues through the analysis of accessible tissues and cells, Toxicol Appl Pharmacol 194 (2004) 189-199.

[2] L.A. Kaplan, J.M. Lau and E.A. Stein Carotenoid composition, concentrations, and relationships in various human organs, Clin Physiol Biochem 8 (1990) 1-10.

[3] R.S. Parker Carotenoids in human blood and tissues, J Nutr 119 (1989) 101-104.

[4] L.J. Machlin and A. Bendich Free radical tissue damage: protective role of antioxidant nutrients, Faseb J 1 (1987) 441-445.

[5] G. van Poppel Epidemiological evidence for beta-carotene in prevention of cancer and cardiovascular disease, Eur J Clin Nutr 50 Suppl 3 (1996) S57-61.

[6] R.G. Ziegler A review of epidemiologic evidence that carotenoids reduce the risk of cancer, J Nutr 119 (1989) 116-122.

[7] D. Albanes, O.P. Heinonen, P.R. Taylor, J. Virtamo, B.K. Edwards, M. Rautalahti, A.M. Hartman, J. Palmgren, L.S. Freedman, J. Haapakoski, M.J. Barrett, P. Pietinen, N. Malila, E. Tala, K. Liippo, E.R. Salomaa, J.A. Tangrea, L. Teppo, F.B. Askin, E. Taskinen, Y. Erozan, P. Greenwald and J.K. Huttunen AlphaTocopherol and beta-carotene supplements and lung cancer incidence in the alpha-tocopherol, betacarotene cancer prevention study: effects of base-line characteristics and study compliance, J Natl Cancer Inst 88 (1996) 1560-1570.

[8] G.S. Omenn, G.E. Goodman, M.D. Thornquist, J. Balmes, M.R. Cullen, A. Glass, J.P. Keogh, F.L. Meyskens, Jr., B. Valanis, J.H. Williams, Jr., S. Barnhart, M.G. Cherniack, C.A. Brodkin and S. Hammar Risk factors for lung cancer and for intervention effects in CARET, the Beta-Carotene and Retinol Efficacy Trial, J Natl Cancer Inst 88 (1996) 1550-1559.

[9] G.E. Goodman, M.D. Thornquist, J. Balmes, M.R. Cullen, F.L. Meyskens, Jr., G.S. Omenn, B. Valanis and J.H. Williams, Jr. The Beta-Carotene and Retinol Efficacy Trial: incidence of lung cancer and cardiovascular disease mortality during 6-year follow-up after stopping beta-carotene and retinol supplements, J Natl Cancer Inst 96 (2004) 1743-1750.

[10] N.H. Fidge, F.R. Smith and D.S. Goodman Vitamin A and carotenoids. The enzymic conversion of betacarotene into retinal in hog intestinal mucosa, Biochem J 114 (1969) 689-694.

[11] J. von Lintig, S. Hessel, A. Isken, C. Kiefer, J.M. Lampert, O. Voolstra and K. Vogt Towards a better understanding of carotenoid metabolism in animals, Biochim Biophys Acta 1740 (2005) 122-131.

[12] D.S. Goodman and H.S. Huang Biosynthesis of Vitamin a with Rat Intestinal Enzymes, Science 149 (1965) 879-880.

[13] A. Wyss Carotene oxygenases: a new family of double bond cleavage enzymes, J Nutr 134 (2004) 246S$250 \mathrm{~S}$.

[14] S. Hessel, A. Eichinger, A. Isken, J. Amengual, S. Hunzelmann, U. Hoeller, V. Elste, W. Hunziker, R. Goralczyk, V. Oberhauser, J. von Lintig and A. Wyss CMO1 deficiency abolishes vitamin A production from beta-carotene and alters lipid metabolism in mice, J Biol Chem 282 (2007) 33553-33561.

[15] W. Rodenburg, J. Keijer, E. Kramer, C. Vink, R. van der Meer and I.M. Bovee-Oudenhoven Impaired barrier function by dietary fructo-oligosaccharides (FOS) in rats is accompanied by increased colonic mitochondrial gene expression, BMC Genomics 9 (2008) 144.

[16] E.M. van Schothorst, V. Pagmantidis, V.C. de Boer, J. Hesketh and J. Keijer Assessment of reducing RNA input for Agilent oligo microarrays, Anal Biochem 363 (2007) 315-317.

[17] J.M. Wettenhall and G.K. Smyth limmaGUI: a graphical user interface for linear modeling of microarray data, Bioinformatics 20 (2004) 3705-3706.

[18] L. Pellis, N.L. Franssen-van Hal, J. Burema and J. Keijer The intraclass correlation coefficient applied for evaluation of data correction, labeling methods, and rectal biopsy sampling in DNA microarray experiments, Physiol Genomics 16 (2003) 99-106.

[19] S.J. Hickenbottom, J.R. Follett, Y. Lin, S.R. Dueker, B.J. Burri, T.R. Neidlinger and A.J. Clifford Variability in conversion of beta-carotene to vitamin A in men as measured by using a double-tracer study design, Am J Clin Nutr 75 (2002) 900-907.

[20] Y. Lin, S.R. Dueker, B.J. Burri, T.R. Neidlinger and A.J. Clifford Variability of the conversion of betacarotene to vitamin A in women measured by using a double-tracer study design, Am J Clin Nutr 71 (2000) 1545-1554. 


\section{Chapter 8}

[21] W.C. Leung, S. Hessel, C. Meplan, J. Flint, V. Oberhauser, F. Tourniaire, J.E. Hesketh, J. von Lintig and G. Lietz Two common single nucleotide polymorphisms in the gene encoding beta-carotene 15,15'monoxygenase alter beta-carotene metabolism in female volunteers, Faseb J 23 (2009) 1041-1053.

[22] A. Lindqvist, J. Sharvill, D.E. Sharvill and S. Andersson Loss-of-function mutation in carotenoid 15,15'monooxygenase identified in a patient with hypercarotenemia and hypovitaminosis A, J Nutr 137 (2007) 2346-2350.

[23] N.J. Armstrong, T.C. Brodnicki and T.P. Speed Mind the gap: analysis of marker-assisted breeding strategies for inbred mouse strains, Mamm Genome 17 (2006) 273-287.

[24] M. Clagett-Dame and H.F. DeLuca The role of vitamin A in mammalian reproduction and embryonic development, Annu Rev Nutr 22 (2002) 347-381.

[25] M. Bouwens, O. van de Rest, N. Dellschaft, M.G. Bromhaar, L.C. de Groot, J.M. Geleijnse, M. Muller and L.A. Afman Fish-oil supplementation induces antiinflammatory gene expression profiles in human blood mononuclear cells, Am J Clin Nutr 90 (2009) 415-424.

[26] J. Hong, Y.C. Zang, G. Hutton, V.M. Rivera and J.Z. Zhang Gene expression profiling of relevant biomarkers for treatment evaluation in multiple sclerosis, J Neuroimmunol 152 (2004) 126-139.

[27] P.J. Valk, R.G. Verhaak, M.A. Beijen, C.A. Erpelinck, S. Barjesteh van Waalwijk van Doorn-Khosrovani, J.M. Boer, H.B. Beverloo, M.J. Moorhouse, P.J. van der Spek, B. Lowenberg and R. Delwel Prognostically useful gene expression profiles in acute myeloid leukemia, N Engl J Med 350 (2004) 1617-1628.

[28] E.B. Geer and W. Shen Gender differences in insulin resistance, body composition, and energy balance, Gend Med 6 Suppl 1 (2009) 60-75.

[29] M. Kalra, J. Mayes, S. Assefa, A.K. Kaul and R. Kaul Role of sex steroid receptors in pathobiology of hepatocellular carcinoma, World J Gastroenterol 14 (2008) 5945-5961.

[30] M. Kennedy Hormonal regulation of hepatic drug-metabolizing enzyme activity during adolescence, Clin Pharmacol Ther 84 (2008) 662-673.

[31] S. Mollerup, K. Jorgensen, G. Berge and A. Haugen Expression of estrogen receptors alpha and beta in human lung tissue and cell lines, Lung Cancer 37 (2002) 153-159.

[32] C.M. Wilson and M.J. McPhaul A and B forms of the androgen receptor are expressed in a variety of human tissues, Mol Cell Endocrinol 120 (1996) 51-57.

[33] M.A. Carey, J.W. Card, J.W. Voltz, D.R. Germolec, K.S. Korach and D.C. Zeldin The impact of sex and sex hormones on lung physiology and disease: lessons from animal studies, Am J Physiol Lung Cell Mol Physiol 293 (2007) L272-278.

[34] M.A. Carey, J.W. Card, J.W. Voltz, S.J. Arbes, Jr., D.R. Germolec, K.S. Korach and D.C. Zeldin It's all about sex: gender, lung development and lung disease, Trends Endocrinol Metab 18 (2007) 308-313.

[35] J. Keijer, Y.G.J. van Helden, A. Bunschoten and E.M. van Schothorst Transcriptome analysis in benefitrisk assessment of micronutrients and bioactive food components, Mol. Nutr. Food Res. in press (2009). 
Relative effects of BC, Bcmo1 genotype and gender in lung, liver and iWAT 
We previously investigated the effect of beta-carotene (BC) on lung tissue using Beta-carotene 15'15-monooxygenase knockout (Bcmo 1\%) mice which are, like humans and unlike WT $\left(\mathrm{Bcmol}^{+/+}\right)$mice, able to accumulate intact BC. In this study we investigated whether BC induced changes in lung gene expression also occur in other tissues. For this, we analyzed the transcriptome of lung, liver and iWAT of male and female, $\mathrm{Bcmol}^{+/+}$and $\mathrm{Bcmo}^{-1-}$ mice with or without 14 weeks of $\mathrm{BC}$ supplementation. A limited number of genes $(\sim 1 \%)$ regulated by $\mathrm{BC}$ in Bcmo 1\%-lung tissue were also regulated in liver and iWAT. However, the major effects identified in the lung were not specific for lung tissue. First, the increased inflammatory response in lungs of female control Bcmo 1\% mice was also seen in liver and iWAT. This is most likely because of a systemic mildly vitamin A deficient phenotype in control diet fed $\mathrm{Bcmo} 1 \%$ mice. In all three tissues, this effect is counteracted by supplemental BC. Second, BC supplementation to male Bcmo 1\% mice resulted in decreased expression of Frizzled homolog 6 (Fzd6) and upregulation of olfactory receptors and oxygen transport related gene expression in lung tissue, which was also found in iWAT. Third, BC supplementation resulted in an opposite direction of gene-regulation in male and female Bcmo $1 \%$ mice, in lung as well as liver and iWAT. These results contribute to understanding $\mathrm{BC}$ biology and are relevant to riskbenefit assessment of BC. 


\section{Organ specificity of beta-carotene induced lung gene expression changes in Bcmo 1\% mice}

Yvonne G.J. van Helden, Roger W.L. Godschalk, Frederik J. van Schooten, Jaap Keijer 


\section{Introduction}

A high intake of dietary beta-carotene has been associated with a wide variety of health promoting effects, such as; antioxidant properties to prevent radical induced macromolecular damage [1], a decreased risk for cardiovascular diseases [2], a decreased risk for several types of cancer [3] and the ability to act as provitamin A, thereby correcting for vitamin A deficiency. Based on these beneficial effects, two intervention trials were initiated; the Alpha-Tocopherol and Beta-Carotene Cancer prevention trial (ATBC study) and the Carotene and Retinol efficacy trial (CARET study), with the intention to decrease lung cancer risk in smokers or asbestos exposed subjects by BC supplementation in combination with or without vitamin E (ATBC study) or with vitamin A (CARET study). Unexpectedly, BC supplementation to these at risk subjects resulted in an increased lung cancer risk $[4,5]$. Another intervention trial with mainly non-smoking volunteers did not point to any detrimental effect of BC [6].

After these trials, mechanistic studies were initiated to answer questions regarding $\mathrm{BC}$ safety. This resulted in only a limited number of publications with regard to possible pathways changed by high $\mathrm{BC}$ intake, as an explanation for the previously found adverse effects. The main focus of these studies was the effect of $\mathrm{BC}$ on lung tissue. However, at present it is unknown if possible detrimental effects of $\mathrm{BC}$ are limited to the lung or whether other tissues are affected as well. One of the major factors contributing to the limited number of studies focusing on BC induced effects is the availability of an appropriate animal model for $\mathrm{BC}$ research. In humans, around $60-70 \%$ of the absorbed $\mathrm{BC}$ is metabolized in the enterocyte, while the remainder is distributed and stored in the human body as intact BC [7]. This in contrast to rodents, which metabolize virtually all of the absorbed $\mathrm{BC}$ in the intestine, and consequently lack the accumulation of intact $\mathrm{BC}$ in different tissues. Because of this, analysis of effects induced by high BC intake is practically impossible using rodents. Ferrets have been proposed as an animal model that behaves more similar to humans in BC metabolism. Ferrets are able to absorb intact $\mathrm{BC}$ and accumulate intact $\mathrm{BC}$ in several tissues such as the lung [8-10]. Unfortunately, only few tools are available to analyze molecular effects in ferrets. For example, whole genome microarrays are not available and hardly any antibodies are accessible. In fact, only few DNA sequences are known, making mechanistic molecular research a difficult exercise.

The key enzyme involved in the metabolism of $\mathrm{BC}$ is beta-carotene 15, 15'monooxygenase 1 (Bcmo1), which cleaves $\mathrm{BC}$ to produce two molecules of retinal [11] and the difference between $\mathrm{BC}$ metabolism in humans and rodents primarily lies in a different Bcmo1 activity [7]. Previously, a Bcmo1 knockout mouse (Bcmo1\%) has been established, and $\mathrm{BC}$ supplementation to these mice resulted in $\mathrm{BC}$ accumulation in 
several tissues including the lung [12]. This mouse model is therefore a unique model to investigate effects of $\mathrm{BC}$ with the advantage of the availability of mouse specific tools.

To assess the effects of $\mathrm{BC}$ on lung gene expression, we preformed a 14 week dietary $\mathrm{BC}$ $\left(150 \mathrm{mg} / \mathrm{kg}\right.$ diet) intervention study in female and male, wildtype $\left(\mathrm{Bcmo}^{+/+}\right)$mice and Bcmo1 knockout (Bcmo1/-) mice. We analyzed the gene expression responses in the lung of female mice [Chapter 5], male mice [Chapter 6] and the responses common to male and female mice [Chapter 7] after BC intake. These detailed analyses led to three outcomes. Firstly, gene expression responses indicated a mild increase in the inflammatory response in lungs of female control diet fed $\mathrm{Bcmo} \%$ mice. These mice had a mild vitamin A deficient phenotype resulting in an inflammatory response which was decreased by BC supplementation [Chapter 5]. Secondly, in male Bcmo1\% mice, BC supplementation decreased frizzled homolog 6 (Fzd6) and collagen triple helix receptor containing 1 (Cthrc1) expression tremendously (fold change -2.99 and -2.60 respectively), together with an increased expression of olfactory receptors and protocadherins [Chapter 6]. Thirdly, of the 89 genes that were commonly affected by BC in male and female Bcmo1\% mice, 85 genes ( $>95 \%$ ) were regulated in an opposite direction in male compared to female mice [Chapter 7]. We also assessed commonalities and differences in global gene expression responses to $\mathrm{BC}$ in $\mathrm{Bcmo1}^{+/+}$and $\mathrm{Bcmo1}^{1 /-}$ mice and concluded that lung, liver which is an important organ in BC metabolism and storage [13] and inguinal white adipose tissue (iWAT) which is an important BC storing organ [14], had only few genes commonly regulated between these three tissues and therefore differed substantially in global gene expression response to BC [Chapter 8].

Although only few genes that were regulated in lung tissue were also regulated in liver and iWAT, in this study we aimed to answer whether the major BC affected processes previously identified in the lung are specific for the lung. This information will contribute to the knowledge of the biology of $\mathrm{BC}$ and it is also of importance to properly assess whether benefits and risks of $\mathrm{BC}$ are limited to a specific tissue. For this analysis, BC induced changes in gene expression and biological processes in lung tissue were compared with gene expression changes in the liver, and in iWAT, and compared with the previously described effects for lung tissue.

\section{Materials \& Methods}

\section{Animals and treatment}

Twelve female $(\mathrm{Fe})$ and twelve male (Ma) B6129SF1 $\left(\mathrm{Bcmo1}^{+/+}\right)$and twelve female and twelve male B6;129S-Bcmo1tm1dnp (Bcmo1/-) mice, were used for the experiment. The mouse experiment was conducted in accordance with the German animal protection laws by the guidelines of the local veterinary authorities. During the breeding and 
weaning periods of the mice, mothers were maintained on KLIBA 3430 chow containing 14000 IU vitamin A/kg diet (Provima Kliba AG, Kaiseraugst, Switzerland). Five-week-old female and male $\mathrm{Bcmo1}^{+/+}$and $\mathrm{Bcmo1}^{-/-}$mice were caged in groups containing 2 to 4 siblings per group and were maintained under environmentally controlled conditions (temperature $24^{\circ} \mathrm{C}, 12 \mathrm{~h} / 12 \mathrm{~h}$ light/dark cycle). Mice had ad libitum access to feed and water. Basic feed consisted of the palletized diet D12450B (Research Diets Inc, USA). The diet was modified to contain 1500 IU vitamin A per $\mathrm{kg}$ of diet, which is a vitamin A sufficient diet, and the control diet (contol) was supplemented with water soluble vehicle beadlets (DSM Nutritional Products Ltd., Basel, Switzerland) containing DL-alphatocopherol and ascorbyl palmitate as stabilizers, as well as carriers such as gelatine, corn oil sucrose and starch. The BC diet (BC) was supplemented with identical water soluble beadlets containing BC (DSM Nutritional Products Ltd., Basel, Switzerland) to generate $150 \mathrm{mg} \mathrm{BC} / \mathrm{kg}$ diet. Beadlets were added by the manufacturer before low temperature pelletting. Feed pellets were color marked and stored at $4^{\circ} \mathrm{C}$ in the dark.

After 14 weeks of dietary intervention, 6 female and 6 male $\mathrm{Bcmo1}^{+/+}$mice on the control diet $\left(\mathrm{Bcmo1}^{+/+} \mathrm{Co}\right), 6$ female and 6 male $\mathrm{Bcmo1}^{+/+}$mice on the $\mathrm{BC} \operatorname{diet}\left(\mathrm{Bcmo1}^{+/+} \mathrm{BC}\right)$, 3 female and 6 male $\mathrm{Bcmo1} \%$ mice on the control diet $\left(\mathrm{Bcmo} 1^{-\mathrm{Co}}\right)$ and 3 female and 6 male $\mathrm{Bcmo1}^{-/}$mice on the $\mathrm{BC} \operatorname{diet}\left(\mathrm{Bcmo1}^{-1-\mathrm{BC}}\right)$ were randomly sacrificed during 3 subsequent mornings. Blood was collected from the vena cava after isoflurane and ketamin anethesia. Blood was coagulated for at least 20 minutes at room temperature, cooled to $4^{\circ} \mathrm{C}$ and centrifuged. Lung, inguinal white adipose (iWAT) and liver tissues were removed, lung and liver tissue were rinsed in phosphate buffered saline (PBS) and all tissues were snap frozen in liquid nitrogen. The tissues were stored at $-80^{\circ} \mathrm{C}$ until use. Due to an insufficient number of female $\mathrm{Bcmo1}^{-/}$mice in the original breeding pool, female $\mathrm{Bcmo1} /$ - mice were used that were born 2 weeks later from an identical experiment, treated identically with 3 mice on the control diet and 3 mice on the BC diet to generate $n=6$ per group, and sacrificed 2 weeks after the first group of mice.

\section{RNA Isolation}

Lung, iWAT and liver were homogenized in liquid nitrogen using a cooled mortar and pestle. Total RNA was isolated using TRIzol reagent (Invitrogen, Breda, The Netherlands) followed by purification using RNeasy columns (Qiagen, Venlo, The Netherlands) using the instructions of the manufacturer. RNA concentration and purity were measured using the Nanodrop system (IsoGen Life Science, Maarsen, The Netherlands). RNA degradation was checked on the Experion (Bio-Rad, Veenendaal, The Netherlands) using Experion StdSense chips (Bio-Rad). Three RNA samples did not meet RNA quality (RNA from lung from one individual female $\mathrm{BCmo1}^{+/+}$control diet mouse, RNA from lung from one individual female $\mathrm{BCmo1}^{+/+} \mathrm{BC}$ diet mouse and RNA from iWAT from one individual male $\mathrm{BCmo1}^{+/+} \mathrm{BC}$ diet mouse) which were omitted from the experiment. 


\section{Microarray hybridization procedure}

Microarray experiments were performed for each tissue separately. The $4 \mathrm{x} 44 \mathrm{k}$ Agilent whole mouse genome microarrays (G4122F, Agilent Technologies, Inc. Santa Clara, CA) were used. Preparation of the sample and the microarray hybridization were carried out according to the manufacturer's protocol with a few exceptions as described previously $[15,16]$. In brief, cDNA was synthesized from $1 \mu \mathrm{g}$ RNA from individual samples using the Agilent Low RNA Input Fluorescent Linear Amplification Kit for each animal without addition of spikes. Thereafter samples were split in 2 equal amounts, to synthesize Cyanine 3-CTP (Cy3) and Cyanine 5-CTP (Cy5) labeled cRNA using half the amounts per dye as indicated by the manufacturer (Agilent Technologies). Labeled cRNA was purified using RNeasy columns (Qiagen). Yield, $\mathrm{A}_{260} / \mathrm{A}_{280}$ ratio and Cy3 or Cy5 activity were examined for every sample using the nanodrop. All samples met the criteria of a cRNA yield higher than $825 \mathrm{ng}$ and a specific activity of at least 8.0 pmol Cy3 or Cy5. $1200 \mathrm{ng}$ of every Cy3 labeled cRNA sample was pooled and used as a common reference pool. Individual $825 \mathrm{ng}$ Cy5-labeled cRNA and $825 \mathrm{ng}$ pooled Cy3-labeled cRNA were fragmented in $1 \mathrm{x}$ fragmentation and $1 \mathrm{x}$ blocking agent (Agilent Technologies) at $60^{\circ} \mathrm{C}$ for 30 minutes and thereafter mixed with GEx Hybridization Buffer HI-RPM (Agilent Technologies) and hybridized in a $1: 1$ ratio at $65^{\circ} \mathrm{C}$ for 17 hours in an Agilent Microarray hybridization Chamber rotating at $4 \mathrm{rpm}$. After hybridization, slides were washed according to the wash protocol with Stabilization and Drying solution (Agilent Technologies). Arrays were scanned with an Agilent scanner with 10\% and 100\% laser power intensities (Agilent Technologies).

\section{Data analyses of microarray results}

Signal intensities for each spot were quantified using Feature Extraction 9.1 (Agilent Technologies). Median density values and background values of each spot were extracted for both the experimental samples (Cy5) and the reference samples (Cy3). Quality control for every microarray was performed visually, by using Quality control graphs from Feature extraction and M-A plots and boxplots which were made using limmaGUI in R (Bioconductor) [17]. Data were imported into GeneMaths XT 2.0 (Applied Maths, Sint-Martens-Latem, Belgium). Spots with a Cy5 and Cy3 signal twice above background were selected and log transformed. The Cy5 signal was normalized against the Cy3 intensity as described before [18]. Microarray analysis of lung, liver and iWAT resulted in $31,128,24,746$ and 25,139 spots above background respectively. Hierarchical cluster analysis was performed using GeneMaths XT. Pathway analysis was performed using GO overrepresentation analysis (ErmineJ) [19]. Comparison of the expression level of Fzd6 and Cthrc1 between the different tissues was performed by normalizing the individual log expression level of these genes against the average expression of all genes on that array $(100 \%)$. The average data per tissue were compared. 


\section{Statistical analysis}

Fold changes for both microarray gene expression were calculated using mean log signal intensities. P-values for differential expressions were calculated between two groups using two tailed Student's $t$-test statistics on log intensity values. Changes were considered statistically significant at $\mathrm{p}<0.05$. Differences in the fold change expression between commonly regulated genes in lung, liver and iWAT were tested using paired ANOVA with post-hoc Bonferroni correction.

Table 1: 27 genes significantly $(\mathrm{p}<0.05)$ regulated in lung, liver and iWAT after BC supplementation in female $\mathrm{Bcmol}^{\%}$ mice.

\begin{tabular}{|c|c|c|c|c|}
\hline \multirow[b]{2}{*}{ Gene name } & \multirow[b]{2}{*}{ abbreviation } & \multicolumn{3}{|c|}{ Fold change } \\
\hline & & lung & adipose & liver \\
\hline \multicolumn{5}{|l|}{ Inflammation } \\
\hline Interferon, alpha-inducible protein 27 & Ifi2 27 & -4.09 & -1.62 & -1.53 \\
\hline Interferon, alpha-inducible protein 27 & Ifi27 & -3.57 & -1.58 & -1.38 \\
\hline Interferon regulatory factor 7 & Irf7 & -1.87 & -1.43 & -1.28 \\
\hline Interferon induced with helicase $\mathrm{C}$ domain 1 & Ifih 1 & -1.63 & -1.32 & -1.19 \\
\hline Interferon-induced protein 44 & Ifi44 & -2.87 & -1.65 & -1.45 \\
\hline $\begin{array}{l}\text { Interferon dependent positive acting transcription factor } 3 \\
\text { gamma }\end{array}$ & Isgf3g & -1.50 & -1.25 & -1.30 \\
\hline Receptor transporter protein 4 & Rtp4 & -2.42 & -1.67 & -1.54 \\
\hline Radical S-adenosyl methionine domain containing 2 & Rsad2 & -2.33 & -1.29 & -1.38 \\
\hline Poly (ADP-ribose) polymerase family, member 12 & Parp12 & -1.40 & -1.25 & -1.23 \\
\hline 2'-5' oligoadenylate synthetase-like 2 & Oas12 & -2.55 & -1.51 & -1.77 \\
\hline 2'-5' oligoadenylate synthetase $1 \mathrm{~A}$ & Oas 1a & -2.16 & -1.52 & -1.33 \\
\hline $2 '-5$ ' oligoadenylate synthetase $1 \mathrm{~F}$ & Oas 1f & -2.61 & -1.55 & -1.34 \\
\hline Polymerase (DNA-directed), delta 3, accessory subunit & Pold3 & 1.78 & 1.84 & 1.94 \\
\hline Polymerase (DNA-directed), delta 3, accessory subunit & Pold3 & -1.68 & -1.47 & -1.35 \\
\hline Poly (ADP-ribose) polymerase family, member 14 & Parp14 & -1.53 & -1.23 & -1.24 \\
\hline \multicolumn{5}{|l|}{ Other } \\
\hline PHD finger protein 11 & Phf11 & -1.99 & -1.27 & -1.33 \\
\hline Lectin, galactoside-binding, soluble, 3 binding protein & Lgals3bp & -2.79 & -1.46 & -1.46 \\
\hline Guanylate nucleotide binding protein 3 & Gbp3 & -1.85 & -1.32 & -1.57 \\
\hline RAB6, member RAS oncogene family & Rab6 & 1.77 & 1.62 & 1.64 \\
\hline Tripartite motif protein 12 & Trim 12 & 8.75 & 8.09 & 7.23 \\
\hline Hemoglobin, beta adult major chain & $\mathrm{Hbb}-\mathrm{b} 1$ & -1.52 & -1.54 & -1.49 \\
\hline RIKEN cDNA $1810023 F 06$ gene & $\begin{array}{l}\text { 1810023F06 } \\
\text { Rik }\end{array}$ & -4.01 & -1.61 & -1.55 \\
\hline RIKEN cDNA 2310016 F22 gene & $\begin{array}{l}2310016 \mathrm{~F} 22 \\
\text { Rik }\end{array}$ & -2.49 & -1.57 & -1.39 \\
\hline Data not found & & -2.70 & -2.17 & -2.02 \\
\hline CDNA sequence $\mathrm{BC} 013672$ & $\mathrm{BC} 013672$ & -2.05 & -1.59 & -1.44 \\
\hline Data not found & & 1.72 & 1.51 & 1.38 \\
\hline CDNA sequence BC020489 & BC020489 & -3.71 & -1.86 & -1.56 \\
\hline
\end{tabular}




\section{Results}

\section{Organ specificity of $\mathrm{BC}$ induced gene-regulation in lungs of female $\mathrm{Bcmo1} \%$ mice}

$\mathrm{BC}$ supplementation resulted in 1522 significantly regulated genes in lung tissue of

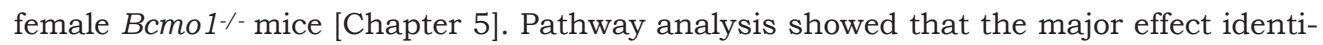
fied was a reduction of the inflammatory gene expression. Only 27 (1.8\%) of these 1522 genes were also regulated $(\mathrm{p}<0.05)$ by $\mathrm{BC}$ in liver tissue and in iWAT (Fig. 1A). Of these 27 genes, more than half (15 genes) are directly involved in the inflammatory response (Table 1).

We used ErmineJ, a bioinformatics tool to identify overrepresented Gene Ontology (GO) processes in a microarray dataset [19], to investigate if there was any overlap in the overrepresention of GO processes by BC supplementation in lung, liver and iWAT. We found two GO processes to be overrepresented in all three tissues by supplemental BC (Fig. 1B); GO:0009615 response to virus and GO:0032606 interferon type I production. Both processes are involved in the inflammatory response. We further evaluated the fold change gene expression of the 27 genes in all groups (control diet fed or BC supplemented $\mathrm{Bcmo1}^{+/+}$and $\mathrm{Bcmo1} \%$ mice) as compared to the expression of these genes in female control diet fed $\mathrm{BCmo1}^{+/+}$mice. In this analysis, we observed that these 27 genes were, similar to the previously described effects on the inflammatory response, mainly regulated in control diet fed $\mathrm{Bcmo1}^{-/}$mice and counteracted by dietary $\mathrm{BC}$ (Fig. 1C). The highest absolute fold changes were observed in lung tissue compared to liver and iWAT (Fig. 1D).

We further performed a hierarchical cluster analysis of these 27 genes to identify which group and tissue were most affected in gene expression. We clearly observed that control diet fed $\mathrm{Bcmo1}^{+/+}$mice, $\mathrm{BC}$ supplemented $\mathrm{Bcmo1}^{+/+}$mice and $\mathrm{BC}$ supplemented $\mathrm{Bcmo1} \%$ mice clustered together while the control diet fed $\mathrm{Bcmo} 1 \%$ mice clearly differed in gene expression of these 27 genes, with lung tissue being mostly affected resulting in a separation from liver and iWAT in this clustering (Fig. 2). Clearly the major BC in-

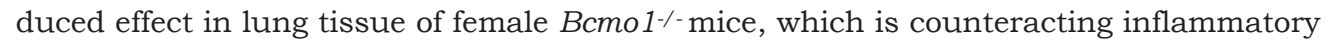
gene expression, also occurs in liver and iWAT. 
A)

Number of regulated genes

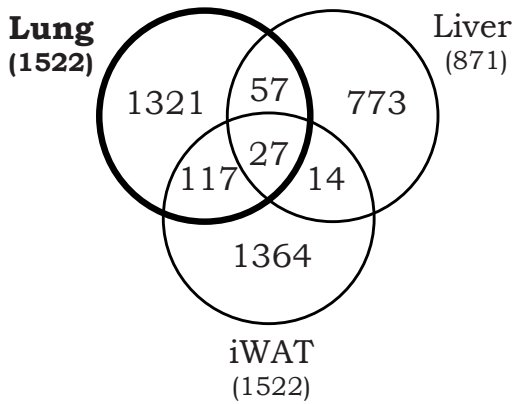

C)

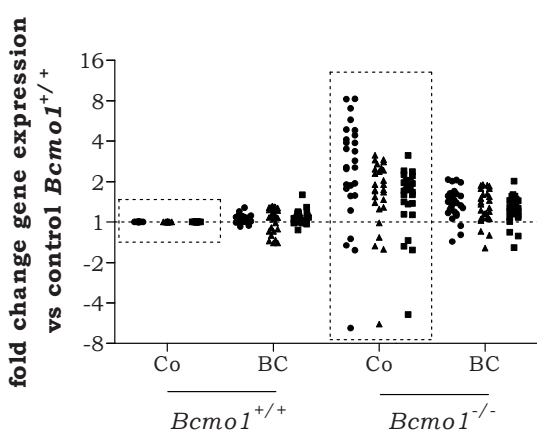

\section{Number of overrepresented GO}

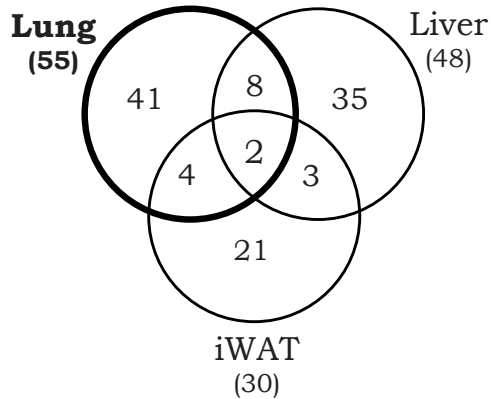

D)

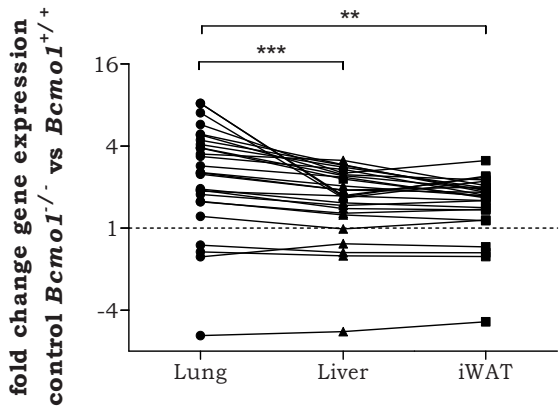

Figure 1: A) Venn diagram representing the number of significantly regulated genes $(\mathrm{p}<0.05)$ in lung, liver and iWAT after $\mathrm{BC}$ supplementation to female $\mathrm{Bcmo} 1 \%$ mice and the overlapping regulated genes. B) Venn diagram representing the number of GO processes which are significantly overrepresented after $\mathrm{BC}$ supplementation in lung, liver and iWAT of female $\mathrm{Bcmo} 1 \%$ mice when using ErmineJ overrepresentation analysis $(\mathrm{p}<0.001)$. C) Fold change expression of the 27 overlapping genes in lung, liver and iWAT after $\mathrm{BC}$ supplementation to female $\mathrm{Bcmo1}$ 1- mice. Fold changes in expression for every gene of the 27 genes that are regulated by $\mathrm{BC}$ supplementation in all three tissues are plotted for lung (circles), liver (triangles) and iWAT (squares) relative to the expression in control female $\mathrm{Bcmo1^{+/+ }}$ mice using log intensities. Dashed boxes indicate the comparison for Figure 1D. D). Fold change gene expression of the 27 genes commonly regulated by $\mathrm{BC}$ in lung (circles), liver (triangles) and iWAT (squares) in control $\mathrm{Bcmo1} \%$ mice relative to control $\mathrm{Bcmo1}^{+/+}$mice. Differences in the fold change expression between lung, liver and iWAT (circles) were tested using paired ANOVA with post-hoc Bonferroni correction. ${ }^{* * *} \mathrm{p}<0.001$ and ${ }^{* *} \mathrm{p}<0.01$

\section{Organ specificity of $\mathrm{BC}$ induced gene-regulation in lungs of male Bcmo1\% mice}

$\mathrm{BC}$ supplementation to male $\mathrm{Bcmo1} \%$ mice led to the regulation of 1474 genes in lung tissue, of which $17(1.2 \%)$ were also regulated in liver tissue and in iWAT (Fig. 3A). The genes are listed in Table 2. There were no $\mathrm{BC}$ regulated GO processes commonly over- 
represented in lung, liver and iWAT (Fig. 3B), as determined by ErmineJ overrepresentation analysis. In contrast to female $\mathrm{Bcmo1} /$ - mice, the 17 genes that were regulated by $\mathrm{BC}$ supplementation had an altered gene expression in the mice with the knockout for $B c m o 1$ and that were supplemented with BC (Fig. 3C). BC supplementation to male $\mathrm{Bcmo1} \%$ mice resulted in an equal fold change of these 17 genes in lung, liver and iWAT (Fig. 3D).

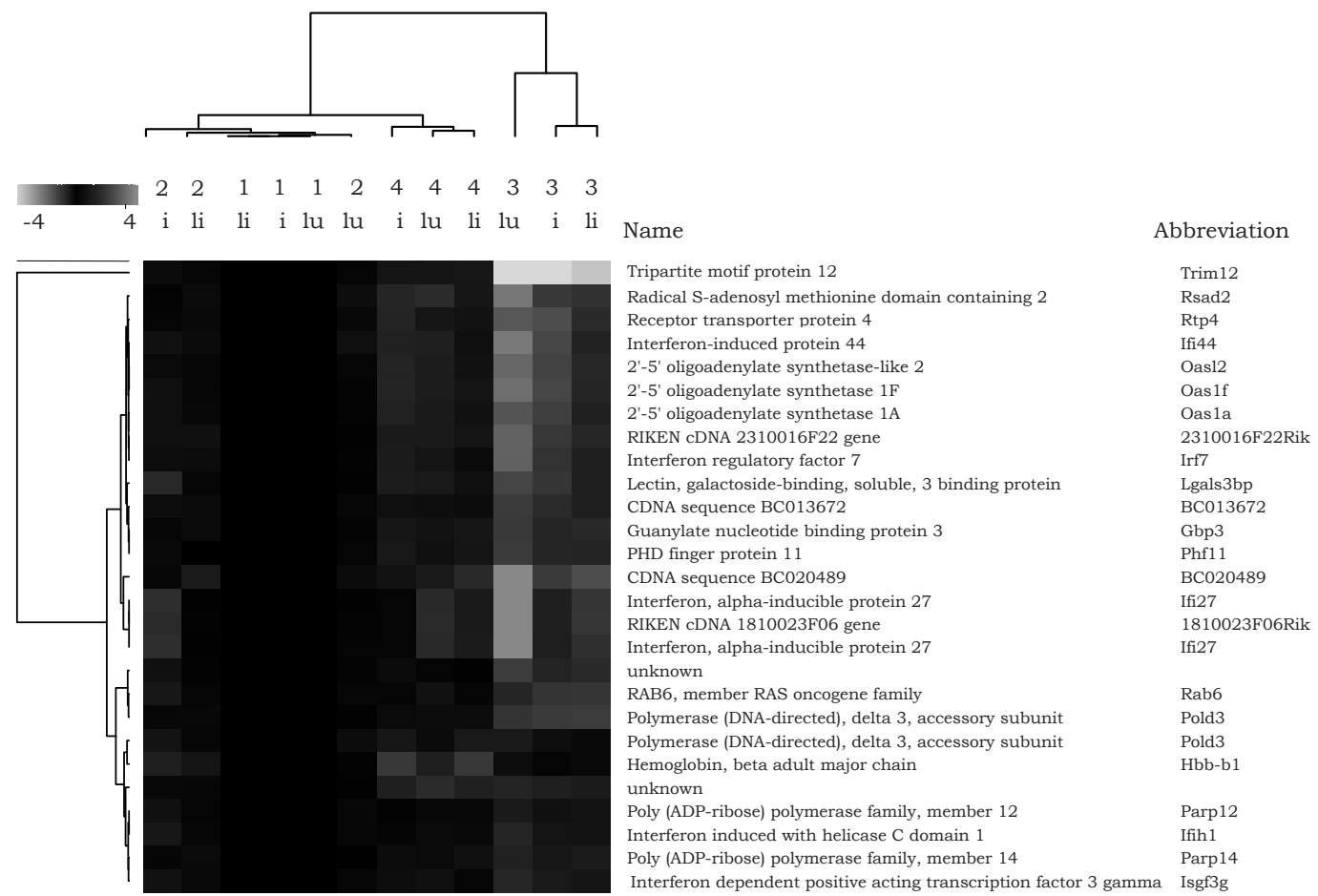

Figure 2: Hierarchical cluster analysis. Hierarchical cluster analysis of the 27 genes regulated by $\mathrm{BC}$ in the three tissues, lung, liver and iWAT of female Bcmo1\% mice, for all three tissues and the groups control Bcmo $1^{+/+}$mice, BC supplemented $\mathrm{Bcmo1}^{+/+}$mice, control Bcmo1/- mice and BC supplemented $\mathrm{Bcmo1} \%$ mice. The fold change gene expression is relative to the gene expression in control $\mathrm{Bcmo1^{+/+ }}$ mice for every tissue. The different groups are displayed with 1 : $\mathrm{Bcmol}^{+/+}$control mice, $2: \mathrm{Bcmo1}^{+/+} \mathrm{BC}$ mice, 3: Bcmo1\% control mice and 4: Bcmo1\% BC mice and the tissues with lu: lung, li: liver and i: iWAT. For color figure see Color Figures section. 
Table 2: 17 genes significantly $(\mathrm{p}<0.05)$ regulated in lung, liver and iWAT after BC supplementation in male $\mathrm{Bcmo1 \%}$ mice.

\begin{tabular}{|c|c|c|c|c|}
\hline \multirow[b]{2}{*}{ Gene Name } & \multirow[b]{2}{*}{ Abbreviation } & \multicolumn{3}{|c|}{ Fold change } \\
\hline & & Lung & Liver & IWAT \\
\hline \multicolumn{5}{|l|}{ Development } \\
\hline Placenta specific 9 & Plac9 & 2.17 & 1.77 & 1.66 \\
\hline Frizzled homolog 6 (Drosophila) & Fzd6 & -2.99 & -2.02 & -2.42 \\
\hline Actin-binding LIM protein 1 & Ablim 1 & -1.11 & -1.14 & -1.22 \\
\hline Enhancer of yellow 2 homolog (Drosophila) & Eny2 & 1.31 & 1.43 & 1.49 \\
\hline \multicolumn{5}{|l|}{ Gene transcription } \\
\hline Histidyl-tRNA synthetase & Hars & -1.56 & -1.50 & -1.54 \\
\hline $\begin{array}{l}\text { Eukaryotic translation initiation factor } 2 \text {, subunit } \\
1 \text { alpha }\end{array}$ & Eif2s 1 & 1.27 & 1.16 & 1.24 \\
\hline Ribonuclease P 14 subunit (human) & Rpp14 & 1.37 & 1.49 & 1.59 \\
\hline Bromodomain containing 8 & $\operatorname{Brd} 8$ & -1.21 & -1.22 & -1.19 \\
\hline \multicolumn{5}{|l|}{ other } \\
\hline $\begin{array}{l}\text { GTPase activating protein (SH3 domain) binding } \\
\text { protein } 2\end{array}$ & G3bp2 & 1.09 & 1.12 & 1.23 \\
\hline PRELI domain containing 2 & Prelid2 & -1.12 & -1.21 & -2.35 \\
\hline Transmembrane and coiled-coil domains 6 & Tmco6 & -1.47 & -1.80 & -1.43 \\
\hline Data not found & & -1.85 & -1.95 & -1.66 \\
\hline Predicted gene, ENSMUSG00000057445 & $\begin{array}{l}\text { ENS- } \\
\text { MUSG00000057445 }\end{array}$ & -2.22 & -1.45 & -1.38 \\
\hline RIKEN cDNA 2700038N03 gene & 2700038N03Rik & 1.15 & 1.23 & 1.16 \\
\hline DNA segment, Chr 14, ERATO Doi 449, expressed & D14Ertd449e & 1.95 & 2.01 & 1.87 \\
\hline Predicted gene, ENSMUSG00000057445 & $\begin{array}{l}\text { ENS- } \\
\text { MUSG00000057445 }\end{array}$ & -1.65 & -1.46 & -1.35 \\
\hline Hypothetical protein LOC544988 & LOC544988 & -1.53 & -1.40 & -1.30 \\
\hline
\end{tabular}

We previously described that $\mathrm{BC}$ supplementation to male $\mathrm{Bcmo} 1 \%$ mice led to a significant downregulation of frizzled 6 (Fzd6) and collagen triple helix repeat containing 1 (Cthrc1) and a significant upregulation of several olfactory receptors in the lung, which resulted in the overrepresentation of the GO processes; GO:0007608: sensory perception of smell and GO:0007606: sensory perception of chemical stimulus, and of several protocadherins which led to the overrepresentation of GO:0007156: Homophilic cell adhesion [Chapter 6]. We further focused on the expression level of Fzd6 and Cthrc1. The relative gene expression of Fzd6 was much higher ( 4 times) in lung tissue than in liver and iWAT (Fig. 4A). The gene expression of Cthrc1 was also highest in lung tissue followed by iWAT and was below the detection limit in liver (Fig. 4B). The fold change of Fzd6 in Bcmo1/- mice after BC supplementation was also highest in lung tissue compared to liver and iWAT, although this was not significantly different (Fig. 4C). Cthrc1 however was only regulated in lung tissue (Fig. 4D). 
A)

Number of regulated genes

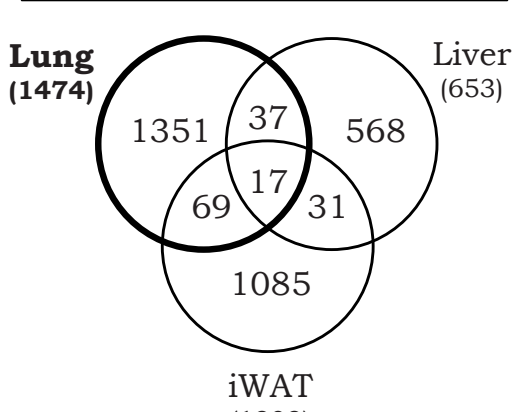

(1202)
B)

\section{Number of overrepresented GO}

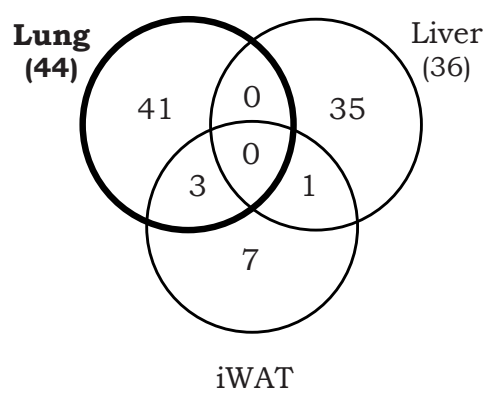

(11)
C)

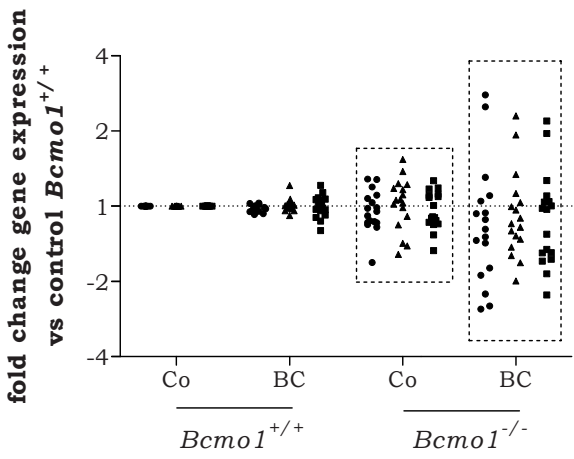

D)

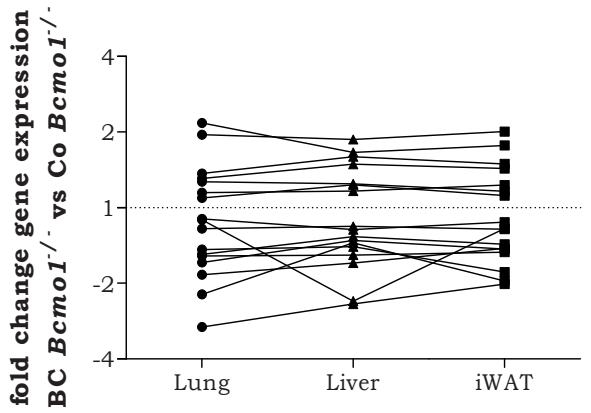

Figure 3: The effect of $\mathrm{BC}$ supplementation to male mice. A) Venn diagram representing the number of significantly regulated genes $(\mathrm{p}<0.05)$ in lung, liver and iWAT after BC supplementation to male Bcmo1-/- mice and the overlapping regulated genes. B) Venn diagram representing the number of GO processes which are significantly overrepresented after BC supplementation in lung, liver and iWAT of male Bcmo1-/- mice when using ErmineJ overrepresentation analysis $(p<0.001)$. C) Fold change expression of the 17 overlapping genes in lung, liver and iWAT after BC supplementation to male Bcmo1/- mice. Fold changes in expression for every gene of the 17 genes that are regulated by BC supplementation in all three tissues are plotted for lung (cicles), liver (triangles) and iWAT (squares) relative to the expression in control female Bcmo1+/+ mice using log intensities. Dashed boxes indicate the comparison for Figure 3D. D) Fold change gene expression of the 17 genes commonly regulated by $\mathrm{BC}$ in lung (circles), liver (triangles) and iWAT (squares) in BC supplemented Bcmo1-/- mice relative to control Bcmo1-/-mice. Differences in the fold change expression between lung, liver and iWAT (circles) were tested using paired ANOVA with post-hoc Bonferroni correction.

There was no GO process regulated in lung tissue that was also regulated in liver tissue, while lung tissue and iWAT had 3 GO processes commonly regulated being; GO:0007608: sensory perception of smell and GO:0007606: sensory perception of chemical stimulus and GO: 0015671: Oxygen transport. Like in lung tissue, both GO proc- 
esses; sensory perception of smell and sensory perception of chemical stimulus were overrepresented due to the regulation of many olfactory receptors.

A)

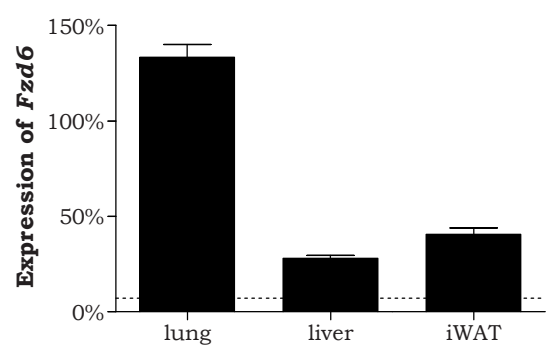

C)

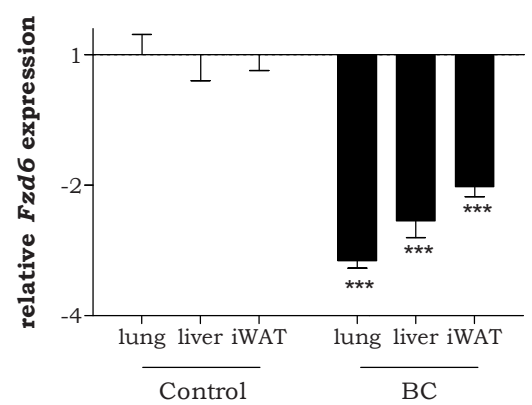

B)

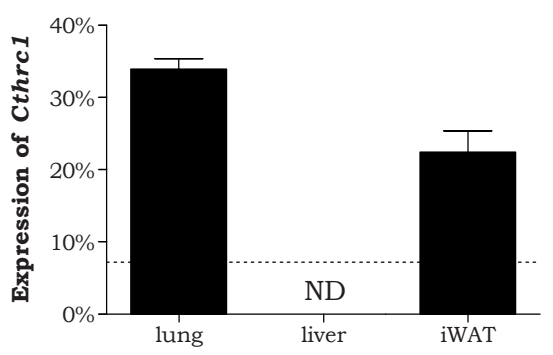

D)

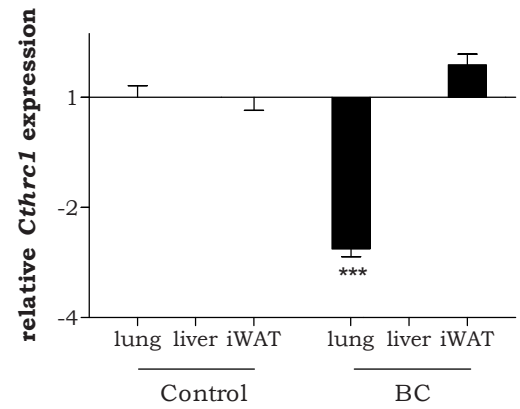

Figure 4: The log expression of Fzd6 A) and Cthrc1 B) were normalized to the average normalized log expression level for all genes of the microarray experiment conducted for lung, liver or iWAT and expressed as $\%$ of this average. The average normalized log expression of the lung, liver and iWAT was set to $100 \%$. The detection limit was $7.3 \%$ for lung tissue, $7.2 \%$ for liver (dashed line) and $5.4 \%$ for iWAT of the average expression on the array of all genes. C) The fold change gene expression of Fzd6 and D) Cthrc1 in lung, liver and iWAT induced by BC supplementation in male Bcmo $1 \%$ mice, relative to the expression in male control $\mathrm{Bcmo1}^{-1}$ mice ND: not above the detection limit.

\section{Organ specificity of BC induced opposite gene-regulation in male and fe- male mice}

We previously showed that genes which were regulated by $\mathrm{BC}$ in lungs of $\mathrm{Bcmo1} \%$ mice, were regulated in the opposite direction in males and females (Chapter 7). Thus when $\mathrm{BC}$ up-regulated the expression of a certain gene in females, the same gene was downregulated in males and vice versa. Moreover, we showed that these effects were not seen 
in $\mathrm{BCmo1}^{+/+}$mice. We also analyzed the effect of $\mathrm{BC}$ supplementation on the direction of gene-regulation in male and female mice in the other tissues. We found a similar opposite direction of gene-regulation induced by BC supplementation in liver and iWAT of male and female mice (Fig. 5).

We also analyzed whether this opposite direction of gene-regulation by BC supplemen-

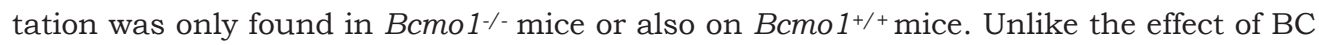
in lung tissue of $\mathrm{Bcmo1}^{+/+}$mice, iWAT of $\mathrm{Bcmo1}^{+/+}$mice showed also a very prominent opposite direction of gene-regulation induced by $\mathrm{BC}$ supplementation in male and female mice (Fig. 6).

\section{Discussion}

In this study, we analyzed the similarities in gene expression changes induced by $\mathrm{BC}$ in lung tissue with changes in liver and iWAT, two major BC storage organs. Although large quantitative differences in gene expression response between the tissues exist [Chapter 8] and only a few genes (around 1\%) are regulated in all three tissues, we found that the major responses observed in lung tissue were not organ-specific.

Firstly, we investigated whether the previously described effects of BC supplementation on the inflammatory response in lung tissue of female $\mathrm{Bcmo1} \%$ mice, were organ specific. Similar to the effects of $\mathrm{BC}$ on the immune response in lung tissue, we found that the overrepresented GO processes and the genes that were regulated by $\mathrm{BC}$ in lung, liver and iWAT of female $\mathrm{Bcmo1} /$ mice were involved in the general immune response. Also similar to lung tissue, these genes were actually a changed expression in control $\mathrm{Bcmo1}^{\%}$ and returned to control $\mathrm{Bcmol}^{+/+}$levels by $\mathrm{BC}$ supplementation. Based on transcriptome and immunohistochemical analysis of lung tissue in female $\mathrm{Bcmo1^{-/ } -}$ mice, we hypothesized that the increased inflammatory response in control $\mathrm{Bcmo1}$ mice, was induced by a higher vitamin A demand in female $\mathrm{Bcmo1} \%$ mice resulting in a mildly vitamin A deficient phenotype [Chapter 5]. This indicates that a vitamin A deficient phenotype will result in a systemic increased inflammatory state. Vitamin A deficiency has been linked to inflammation in the lung and has also been associated with inflammation in liver [20]. 
A)

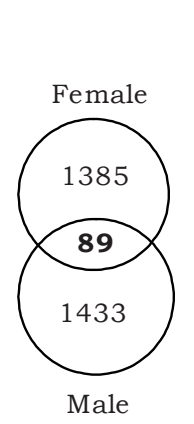

B)

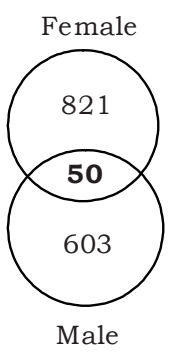

C)

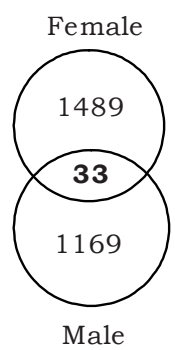

\section{Lung}

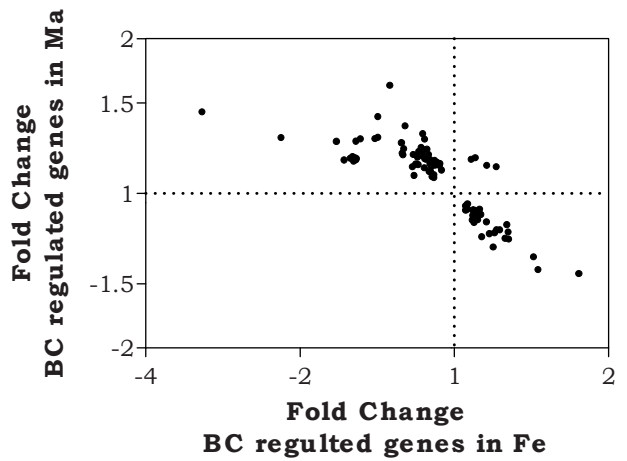

Liver

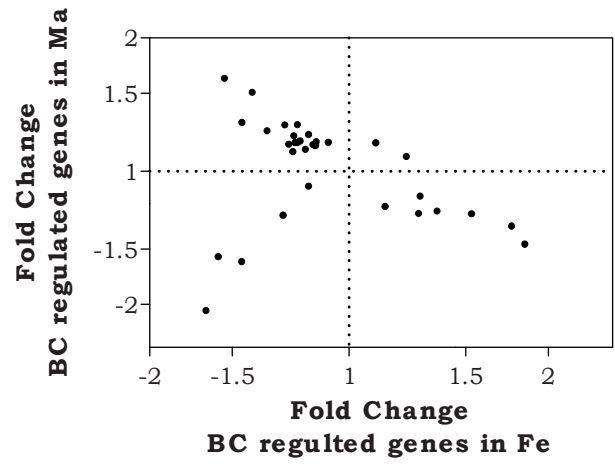

iWAT

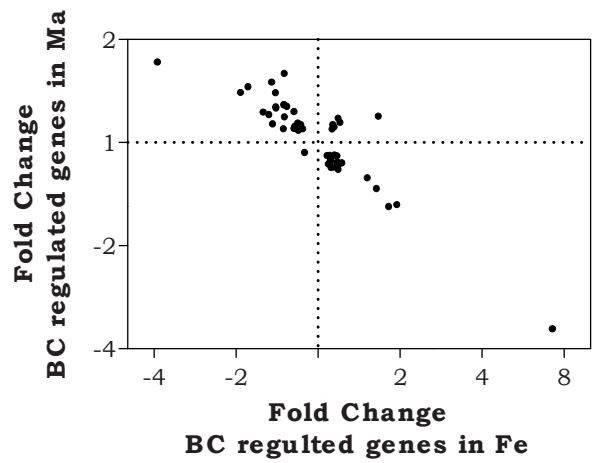

Figure 5: Number of genes regulated by $\mathrm{BC}$ in male and female $\mathrm{Bcmo1} \%$ mice and the overlap in genes in lung tissue (A), in liver tissue (B) and in iWAT (C). The scatter plots represent the gene expression fold changes of the genes regulated by $\mathrm{BC}$ independent of gender in females ( $\mathrm{x}$-axis) and males (y-axis) Bcmo1\% mice. 
A)

Lung
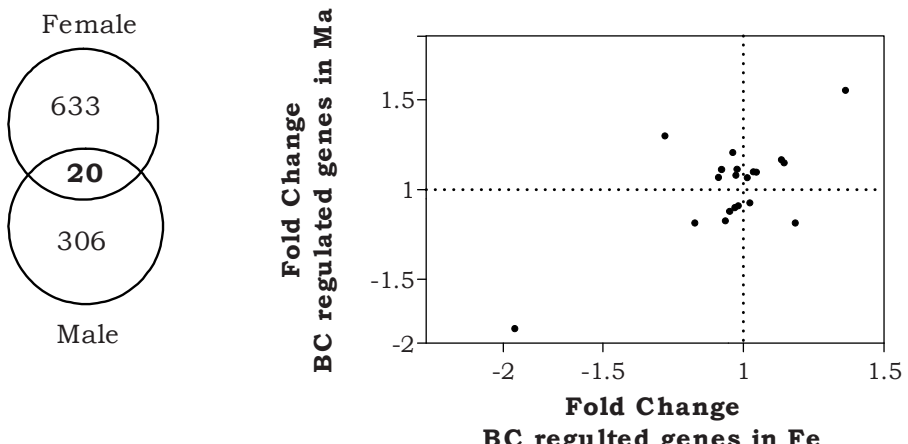

B)

Liver
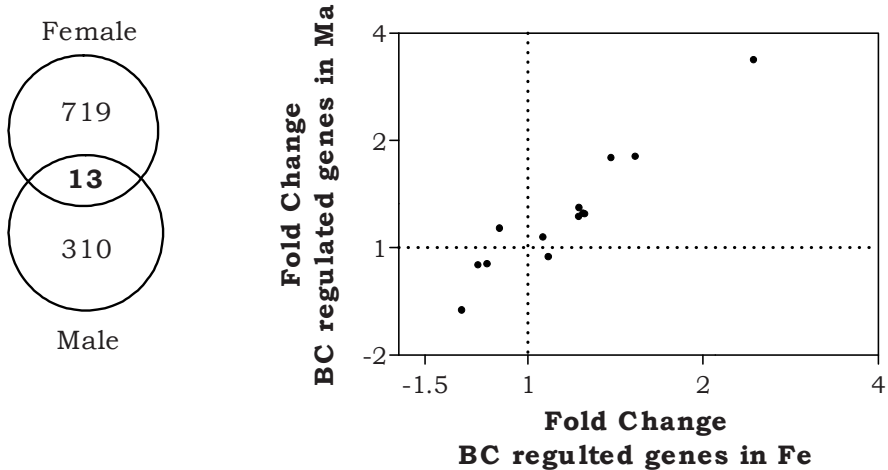

C)

iWAT
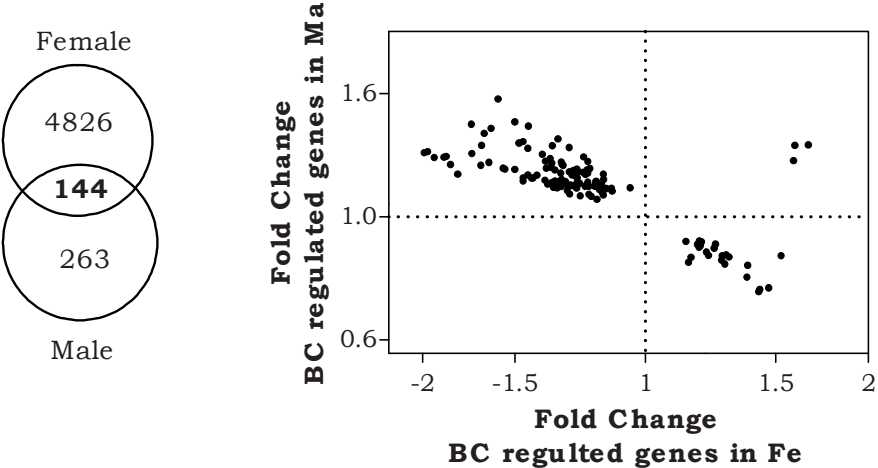

Figure 6: Number of genes regulated by $\mathrm{BC}$ in male and female $\mathrm{Bcmo1^{+/+ }}$ mice and the overlap in genes in lung tissue (A), in liver tissue (B) and in iWAT (C). The scatter plots represent the gene expression fold changes of the genes regulated by $\mathrm{BC}$ independent of gender in females ( $\mathrm{x}$-axis) and males ( $\mathrm{y}$-axis) in $\mathrm{Bcmo}^{+/+}$mice. 
For adipose tissue this is less well known. It is known that in diabetes, which is associated with inflammation of adipose tissue [21], significantly lower levels of retinol binding protein 4 (RBP4, which is a carrier protein for retinol) and vitamin A were found [2224], but it is unknown whether this is a cause or a consequence. Since we found that this inflammatory response was not limited to lung tissue, these data therefore strengthen our hypothesis that female $\mathrm{Bcmo1}^{\%}$ mice have a higher vitamin A demand and were mildly vitamin A deficient, rather than a local inflammation, when given the control diet.

A second analysis focused on the organ specificity of the previously described reduced expressions of Fzd6 and Cthrc1 in lung tissue in combination with increased expressions of olfactory receptors and protocadherins induced by BC supplementation in male Bcmo $1 \%$ mice [Chapter 6]. We show in this study that Fzd6 was significantly down regulated by $\mathrm{BC}$ supplementation in all three tissues. Expression of Fzd6 in lung has been reported before by us [Chapter 6] and others [25], and we now show expression and similar regulation in iWAT and liver. We only found a significant regulation of Cthrc1 after BC supplementation in lung tissue of male Bcmo1\%-mice, while it was expressed but not regulated in iWAT. In liver, Cthrc1 was not above the detection limit. For lung tissue the presence of Cthrc1 has been demonstrated before by us [Chapter 6] and others [26]. The expression levels of Fzd6 and of Cthrc1 were highest in lung, followed by iWAT and liver, with Cthrc1 being below the cut-off of a signal intensity higher than twice above background. A similar order for the p-value of the overrepresentated GO processes GO:0007608 sensory perception of smell and GO:0007606 sensory perception of chemical stimulus, which contained many olfactory receptorswas observed. We previously hypothesized that Fzd6 and olfactory receptors in the lung might be involved in the sensing of differences in air composition such as in hypoxia. Interestingly, there was also a third overlapping process regulated by BC supplementation in iWAT and in lung tissue which was GO: 0015671 oxygen transport. Although the main molecular mechanism involved in hypoxia signaling are though to be regulated through hypoxia inducible factors (HIF) [27], there might be other mechanisms involved. Confirming our results, another microarray study focusing on the effects of hypoxia showed that the more systemic regulated enzyme Fzd6 was significantly regulated by chronic constant hypoxia and chronic intermittent hypoxia in mouse brain [28]. We think that these observations strengthen our hypothesis that Fzd6 and olfactory receptors might be involved in oxygen sensing. Cthrc1 might contribute to this effect since it was previously observed that Cthrc1 stabilizes the Wnt-Fzd complex [29], and we found a highly similar fold change and corresponding p-value in lung tissue of both Fzd6 and Cthrc1. This fold change in Cthrc1 was not observed in the other tissues examined. The potential role of Cthrc1 in BC mediated regulation of Fzd6 signaling in the different tissues remains to be elucidated.

A third analysis focused on genes regulated by BC supplementation in lung tissue of both male and female $\mathrm{Bcmo1} \%$ mice and demonstrated that these genes were regulated 
in opposite direction in both genders. We speculated that BC supplementation potentially increases hormone synthesis, resulting in an opposite direction of gene expression changes induced by supplementary BC. A general regulation of $\mathrm{BC}$ on hormone production could be evolutionary programmed, since the pathways involved in BC synthesis in plants partly overlap with pathways involved in steroid synthesis [30]. This opposite regulation was only present in lung tissue of $\mathrm{Bcmol}^{\%}$ mice and not in lung tissue of $\mathrm{BCmo1}^{+/+}$mice, and therefore we hypothesized that this effect was induced by intact $\mathrm{BC}$ rather than by $\mathrm{BC}$ metabolites. Nevertheless, we also stated that we previously observed that retinoic acid levels were less well regulated in $\mathrm{Bcmo1 \%}$ mice than in $\mathrm{Bcmo1}^{1 /+}$ mice and that BC supplementation to these mice could possibly result in altered retinoic acid levels [Chapter 5]. We showed here, that opposite direction of gene expression regulation by $\mathrm{BC}$ in male and female $\mathrm{Bcmo1} \%$ mice was present in all three tissues; lung, liver and iWAT. However, we also found a prominent opposite direction of genes regulated by $\mathrm{BC}$ in iWAT of female and male $\mathrm{Bcmo1}^{+/+}$mice, while this was not observed for the lung. This opposite direction of regulation was even more prominent in iWAT of $\mathrm{Bcmo1}^{+/+}$ mice than in $\mathrm{Bcmo1} \%$ mice. Although retinoic acid levels are normally thought to be tightly regulated [31], this might differ between different tissues causing local effects. It has been shown that retinoic acid supplementation to wildtype mice, alters white adipose tissue weights and adipokines [32], and therefore white adipose tissue seems highly responsive to alterations in retinoic acid levels rather than being well regulated. Therefore, we assume now that the opposite regulation of gene expression induced by $\mathrm{BC}$ in male and female $\mathrm{Bcmo1} \%$ mice is caused by less tightly regulated retinoic acid levels in $\mathrm{Bcmo1 \%}$ mice than in $\mathrm{Bcmo1}^{+/+}$mice. Because of this, $\mathrm{Bcmo1 \%}$ mice might be more vulnerable for systemic changes in retinoic acid levels resulting possibly in altered hormone levels.

The main question that was addressed in this study was whether the major BC affected processes previously identified in the lung are specific to the lung or whether they occur in other organs as well. Although we previously described that only few genes $(\sim 1 \%)$ that were regulated in lung tissue were also regulated in liver and iWAT, we find that the major effects on a pathway level that were found in lung tissue are not limited to the lung. This information strengthens our previously described effects of BC. Moreover, these data are also of importance for the assessment of the organ specificity of benefits and risks of $\mathrm{BC}$. Furthermore these data indicate that the assessment of effects induced by $\mathrm{BC}$ can be investigated using surrogate tissue, but then analyses have to be assessed on a whole process level. Nevertheless, these data also show that it is important to select more than one surrogate tissue to dissect tissue specific effects from systemic effects. 


\section{Acknowledgements}

Yvonne van Helden was supported by a grant from NUTRIM/VLAG. We are grateful to Johannes von Lintig, Georg Lietz, Jaume Amengual, Suzanne Hessel, Joan Ribot and M. Luisa Bonet for their contribution to the animal experiment, which was performed in the framework of the carotenoid focus team of the FP- 6 Network of Excellence NuGO. We also thank DSM neutraceuticals for the use of $\mathrm{Bcmo1}^{-/-}$mice and the $\mathrm{BC}$ beadlets. None of the authors declare any commercial interest.

\section{References}

[1] Machlin, L.J. and Bendich, A. (1987). Free radical tissue damage: protective role of antioxidant nutrients. Faseb J 1, 441-5.

[2] van Poppel, G. (1996). Epidemiological evidence for beta-carotene in prevention of cancer and cardiovascular disease. Eur J Clin Nutr 50 Suppl 3, S57-61.

[3] Ziegler, R.G. (1989). A review of epidemiologic evidence that carotenoids reduce the risk of cancer. J Nutr 119, 116-22.

[4] Albanes, D. et al. (1996). Alpha-Tocopherol and beta-carotene supplements and lung cancer incidence in the alpha-tocopherol, beta-carotene cancer prevention study: effects of base-line characteristics and study compliance. J Natl Cancer Inst 88, 1560-70.

[5] Omenn, G.S. et al. (1996). Risk factors for lung cancer and for intervention effects in CARET, the BetaCarotene and Retinol Efficacy Trial. J Natl Cancer Inst 88, 1550-9.

[6] Hennekens, C.H. et al. (1996). Lack of effect of long-term supplementation with beta carotene on the incidence of malignant neoplasms and cardiovascular disease. N Engl J Med 334, 1145-9.

[7] von Lintig, J. and Wyss, A. (2001). Molecular analysis of vitamin A formation: cloning and characterization of beta-carotene 15,15'-dioxygenases. Arch Biochem Biophys 385, 47-52.

[8] Gugger, E.T., Bierer, T.L., Henze, T.M., White, W.S. and Erdman, J.W., Jr. (1992). Beta-carotene uptake and tissue distribution in ferrets (Mustela putorius furo). J Nutr 122, 115-9.

[9] Wang, X.D., Krinsky, N.I., Marini, R.P., Tang, G., Yu, J., Hurley, R., Fox, J.G. and Russell, R.M. (1992). Intestinal uptake and lymphatic absorption of beta-carotene in ferrets: a model for human beta-carotene metabolism. Am J Physiol 263, G480-6.

[10] Wang, X.D., Liu, C., Bronson, R.T., Smith, D.E., Krinsky, N.I. and Russell, M. (1999). Retinoid signaling and activator protein-1 expression in ferrets given beta-carotene supplements and exposed to tobacco smoke. J Natl Cancer Inst 91, 60-6.

[11] Goodman, D.S. and Huang, H.S. (1965). Biosynthesis of Vitamin a with Rat Intestinal Enzymes. Science 149, 879-80.

[12] Hessel, S. et al. (2007). CMO1 deficiency abolishes vitamin A production from beta-carotene and alters lipid metabolism in mice. J Biol Chem 282, 33553-61.

[13] Parker, R.S. (1989). Carotenoids in human blood and tissues. J Nutr 119, 101-4.

[14] Kaplan, L.A., Lau, J.M. and Stein, E.A. (1990). Carotenoid composition, concentrations, and relationships in various human organs. Clin Physiol Biochem 8, 1-10.

[15] Rodenburg, W., Keijer, J., Kramer, E., Vink, C., van der Meer, R. and Bovee-Oudenhoven, I.M. (2008). Impaired barrier function by dietary fructo-oligosaccharides (FOS) in rats is accompanied by increased colonic mitochondrial gene expression. BMC Genomics 9, 144.

[16] van Schothorst, E.M., Pagmantidis, V., de Boer, V.C., Hesketh, J. and Keijer, J. (2007). Assessment of reducing RNA input for Agilent oligo microarrays. Anal Biochem 363, 315-7.

[17] Wettenhall, J.M. and Smyth, G.K. (2004). limmaGUI: a graphical user interface for linear modeling of microarray data. Bioinformatics 20, 3705-6.

[18] Pellis, L., Franssen-van Hal, N.L., Burema, J. and Keijer, J. (2003). The intraclass correlation coefficient applied for evaluation of data correction, labeling methods, and rectal biopsy sampling in DNA microarray experiments. Physiol Genomics 16, 99-106. 


\section{Organ specificity of $\mathrm{BC}$ changed gene expression}

[19] Lee, H.K., Braynen, W., Keshav, K. and Pavlidis, P. (2005). ErmineJ: tool for functional analysis of gene expression data sets. BMC Bioinformatics 6, 269.

[20] Baybutt, R.C., Hu, L. and Molteni, A. (2000). Vitamin A deficiency injures lung and liver parenchyma and impairs function of rat type II pneumocytes. J Nutr 130, 1159-65.

[21] Hajer, G.R., van Haeften, T.W. and Visseren, F.L. (2008). Adipose tissue dysfunction in obesity, diabetes, and vascular diseases. Eur Heart J 29, 2959-71.

[22] Baena, R.M., Campoy, C., Bayes, R., Blanca, E., Fernandez, J.M. and Molina-Font, J.A. (2002). Vitamin A, retinol binding protein and lipids in type 1 diabetes mellitus. Eur J Clin Nutr 56, 44-50.

[23] Graham, T.E. et al. (2006). Retinol-binding protein 4 and insulin resistance in lean, obese, and diabetic subjects. N Engl J Med 354, 2552-63.

[24] Erikstrup, C. et al. (2009). RBP-to-retinol ratio, but not total RBP, is elevated in patients with type 2 diabetes. Diabetes Obes Metab 11, 204-12.

[25] Tokuhara, M., Hirai, M., Atomi, Y., Terada, M. and Katoh, M. (1998). Molecular cloning of human Frizzled6. Biochem Biophys Res Commun 243, 622-7.

[26] Durmus, T., LeClair, R.J., Park, K.S., Terzic, A., Yoon, J.K. and Lindner, V. (2006). Expression analysis of the novel gene collagen triple helix repeat containing-1 (Cthrc1). Gene Expr Patterns 6, 935-40.

[27] Webb, J.D., Coleman, M.L. and Pugh, C.W. (2009). Hypoxia, hypoxia-inducible factors (HIF), HIF hydroxylases and oxygen sensing. Cell Mol Life Sci 66, 3539-54.

[28] Zhou, D., Wang, J., Zapala, M.A., Xue, J., Schork, N.J. and Haddad, G.G. (2008). Gene expression in mouse brain following chronic hypoxia: role of sarcospan in glial cell death. Physiol Genomics 32, 370-9.

[29] Yamamoto, S., Nishimura, O., Misaki, K., Nishita, M., Minami, Y., Yonemura, S., Tarui, H. and Sasaki, H. (2008). Cthrc1 selectively activates the planar cell polarity pathway of Wnt signaling by stabilizing the Wnt-receptor complex. Dev Cell 15, 23-36.

[30] Gawienowski, A.M. (1999). Integration of the metabolic pathways of steroids, carotenoids, and retinoids. Crit Rev Biochem Mol Biol 34, 405-10.

[31] Thatcher, J.E. and Isoherranen, N. (2009). The role of CYP26 enzymes in retinoic acid clearance. Expert Opin Drug Metab Toxicol 5, 875-86.

[32] Felipe, F., Mercader, J., Ribot, J., Palou, A. and Bonet, M.L. (2005). Effects of retinoic acid administration and dietary vitamin A supplementation on leptin expression in mice: lack of correlation with changes of adipose tissue mass and food intake. Biochim Biophys Acta 1740, 258-65.

[33] Baron, J.A. and Sandler, R.S. (2000). Nonsteroidal anti-inflammatory drugs and cancer prevention. Annu Rev Med 51, 511-23.

[34] Harris, R.E., Beebe-Donk, J. and Alshafie, G.A. (2007). Reduced risk of human lung cancer by selective cyclooxygenase 2 (COX-2) blockade: results of a case control study. Int J Biol Sci 3, 328-34.

[35] Harris, R.E., Beebe-Donk, J. and Schuller, H.M. (2002). Chemoprevention of lung cancer by non-steroidal anti-inflammatory drugs among cigarette smokers. Oncol Rep 9, 693-5.

[36] Muscat, J.E., Chen, S.Q., Richie, J.P., Jr., Altorki, N.K., Citron, M., Olson, S., Neugut, A.I. and Stellman, S.D. (2003). Risk of lung carcinoma among users of nonsteroidal antiinflammatory drugs. Cancer 97, 1732-6.

[37] Pereg, D. and Lishner, M. (2005). Non-steroidal anti-inflammatory drugs for the prevention and treatment of cancer. J Intern Med 258, 115-23.

[38] Schwartz, A.G., Prysak, G.M., Bock, C.H. and Cote, M.L. (2007). The molecular epidemiology of lung cancer. Carcinogenesis 28, 507-18.

[39] Thun, M.J., Henley, S.J. and Patrono, C. (2002). Nonsteroidal anti-inflammatory drugs as anticancer agents: mechanistic, pharmacologic, and clinical issues. J Natl Cancer Inst 94, 252-66. 
Q6.

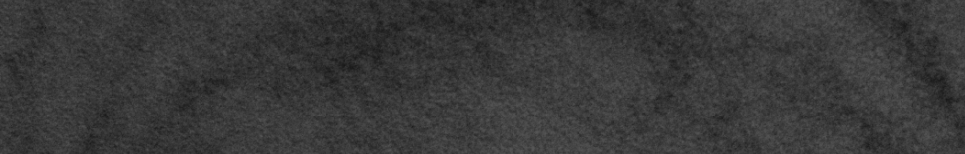

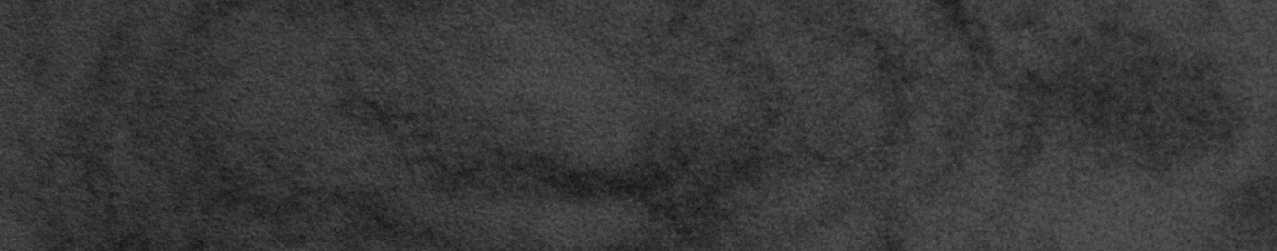

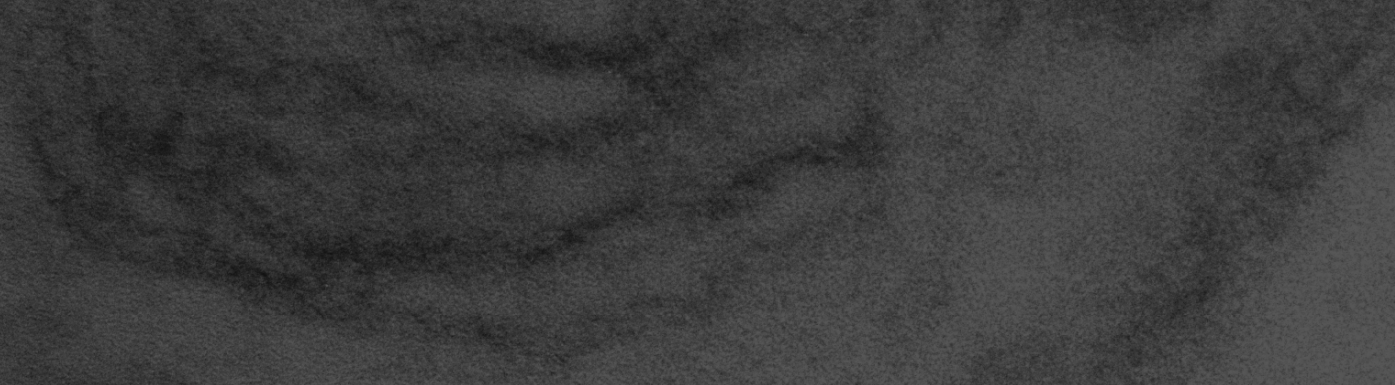

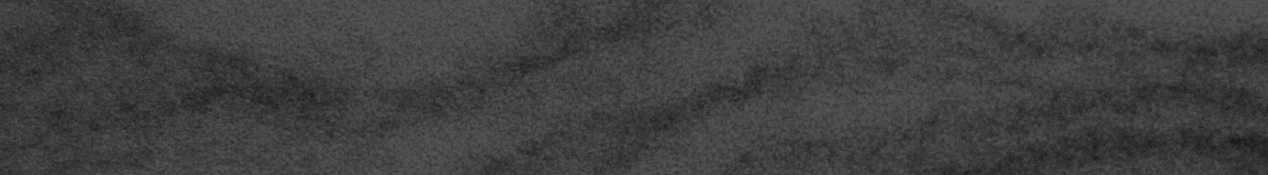

5.tres
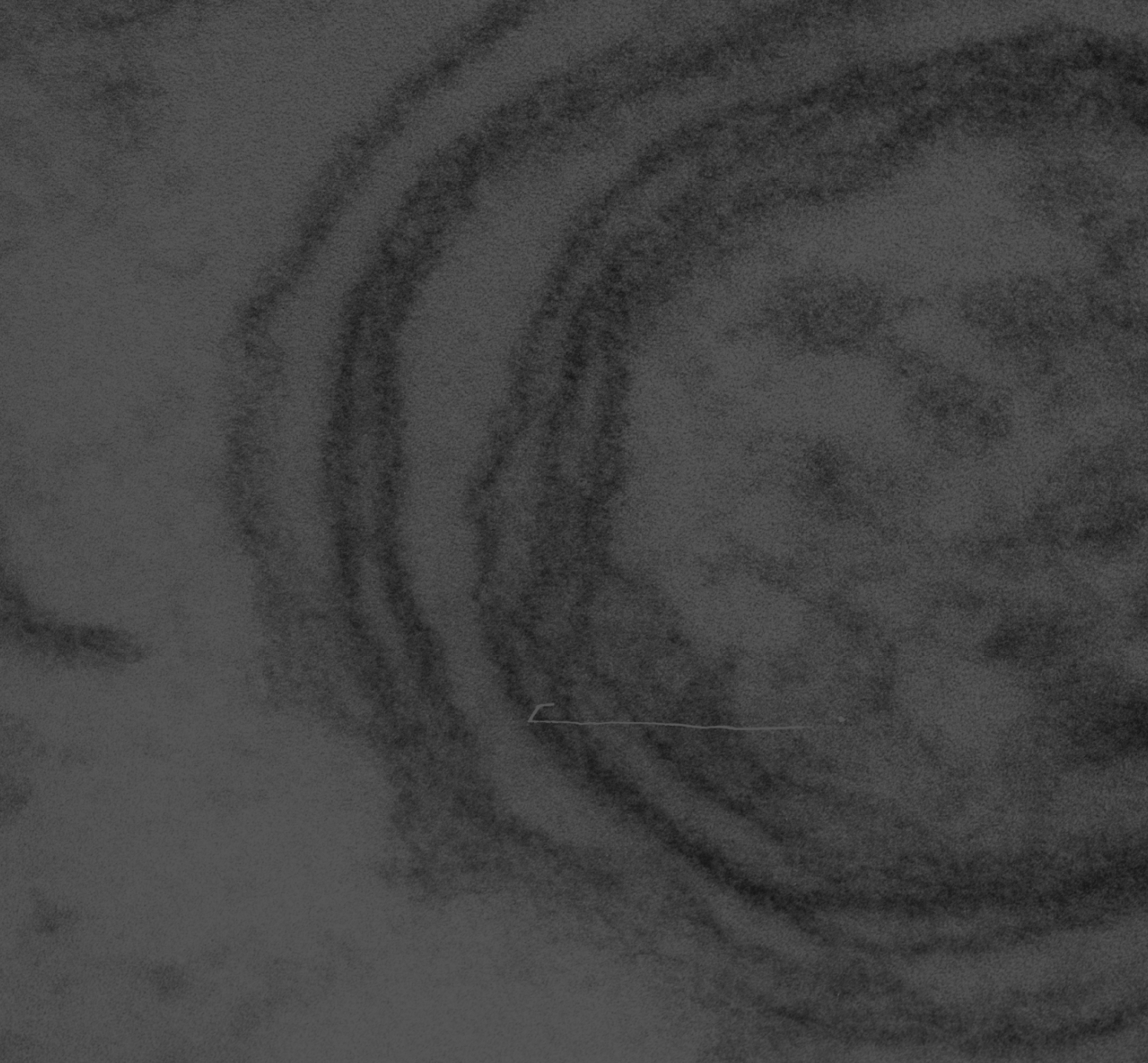


\section{Summary and}

\section{general discussion}

Yvonne G.J. van Helden

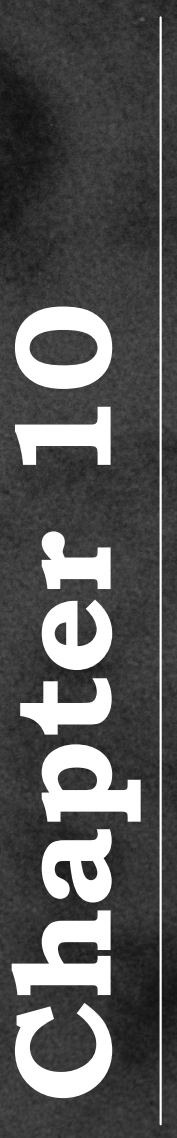




\section{Summary and general discussion}

\section{Main findings}

Beta-carotene $(\mathrm{BC})$ was previously shown to increase lung cancer risk in smokers and asbestos exposed subjects. Both types of exposure are typically associated with an inflammatory reaction in the lung, and a prolonged inflammation has indeed been shown to play an important role in the initiation and promotion of lung cancer. A chronic inflammation in the lungs is characterized by an influx of neutrophils and involves the generation of cell damaging free radicals. Since it has been reported that BC can act as an antioxidant as well as a pro-oxidant $[1,2]$, we aimed in the first part of this thesis to gain mechanistic knowledge on the circumstances in which $\mathrm{BC}$ acts as an antioxidant or pro-oxidant and how $\mathrm{BC}$ as such affects radical induced genotoxicity.

We demonstrate in Chapter 2 that the origin of the radical species to be scavenged affects pro- or antioxidant properties of $\mathrm{BC}$; we observed a protective role for $\mathrm{BC}$ against carbon centered radicals, but an enhancing effect of $\mathrm{BC}$ in hydroxyl radical induced damage. Indeed, $\mathrm{BC}$ supplemented ferrets had lower amounts of $\mathrm{M}_{1} \mathrm{dG}$, a DNA lesion resulting from the lipid peroxidation product MDA with carbon centered radical intermediates. However, the oxidative DNA lesion 8-oxo-dG, which directly results from DNA oxidation, was not changed in ferrets after BC supplementation, probably because $\mathrm{BC}$ supplementation also increased base excision repair (BER).

We subsequently focused on the effect of BC in neutrophil induced DNA damage. Smoke and asbestos both induce a chronic inflammation in the lungs [3-6] which is characterized by a neutrophilic influx [7]. Activated neutrophils generate high amounts of reactive oxygen species (ROS) which can cause oxidative DNA damage. Moreover, activated neurophils decrease cellular DNA repair capacity [8]. We demonstrated in Chapter 3 that the $\mathrm{BC}$ metabolites; retinoic acid and retinal specifically increased neutrophil induced oxidative DNA lesions by decreasing MPO activity, an enzyme active in the conversion of neutrophil generated hydrogenperoxide. Moreover, BC enhanced the formation of hydroxyl radicals from hydrogenperoxide. This ultimately resulted in an increased number of oxidative DNA lesions in neutrophil exposed lung epithelial cells when exposed to retinoic acid or retinal as measured with the FPG modified comet assay. This suggests that adverse effects of $\mathrm{BC}$ may be encountered under conditions of chronic inflammation.

$\mathrm{BC}$ or its metabolites might thus alter genotoxic effects of smoke or asbestos. Besides this effect, BC may also change general gene expression thereby altering the vulnerability of lung tissue for smoke or asbestos induced carcinogenesis. Gene expression changes induced by high $\mathrm{BC}$ intake are difficult to assess; for obvious ethical reasons, 
humans cannot be supplemented with high amounts of BC, neither is lung tissue easily accessible. Moreover, the frequently used in vivo models such as mice and rats highly differ in their BC metabolism compared to humans, since they almost completely convert $\mathrm{BC}$ into its metabolites, while humans only partly metabolize BC. Consequently, $\mathrm{BC}$ supplementation results in the accumulation of $\mathrm{BC}$ metabolites in rodents, while $\mathrm{BC}$ supplementation to humans results in accumulation of BC itself [9]. Other animal models that more resemble $\mathrm{BC}$ metabolism have been proposed for $\mathrm{BC}$ research. Examples are ferrets, gerbils and preruminant calves. However, these models have major disadvantages. When using ferrets or gerbils, there is not much knowledge on molecular mechanisms and a lack of commercially available molecular tools, which results in pioneering research focused on tool development, rather than resolving mechanistic questions regarding the molecular effects of $\mathrm{BC}$. There is more knowledge with regard to the use of calves, however, in that case research is expensive and the calves need special housing. We therefore used a "humanized" mouse model in the second part of this thesis. In this mouse model there is no functional beta-carotene 15,15'-monooxygenase 1 (Bcmo1) due to the knock-out of this gene [10]. Consequently, these mice lack the ability to cleave $\mathrm{BC}$ and are like man able to accumulate intact $\mathrm{BC}$. In the second part of this thesis we focused on gene expression changes induced by $\mathrm{BC}$ in this mouse model, to obtain more insights in functional effects of $\mathrm{BC}$ to contribute to the lack of knowledge of $\mathrm{BC}$ action in the lung. In Chapter 4 we explain and discuss the in-house knowledge with regard to functional genomics in nutritional studies.

For the assessment of gene expression effects induced by dietary $\mathrm{BC}$ in vivo, we performed a mouse experiment in which female and male, wild type $\left(\mathrm{Bcmo1}^{+/+}\right)$and $\mathrm{Bcmo1}$ knockout mice $\left(\mathrm{Bcmo1}^{-1}\right)$ were given a diet containing $1500 \mathrm{IU}$ vitamin A with vehicle beadlets $(\mathrm{Co})$ or a diet supplemented with beadlets containing $\mathrm{BC}$ to generate 150 $\mathrm{mg} / \mathrm{kg}$ diet $\mathrm{BC}(\mathrm{BC})$.

In Chapter 5 we focused on the effect of high BC consumption on gene expression changes in lung tissue of female Bcmo1\% mice. We observed a significant decrease in the expression of genes involved in the inflammatory response. After comparison of the gene expression with $\mathrm{Bcmo1}^{+/+}$mice, this decreased inflammatory response appeared to be an induced inflammatory response in the lungs of control diet fed female $\mathrm{Bcmo1}^{-/}$ mice, which was partly abolished by dietary BC. Histology of the lungs confirmed the gene expression results, showing inflammatory infiltrations in lung tissue, only in female control diet fed mice. These observations were explained by a higher dietary vitamin A demand in female $\mathrm{Bcmo1}^{-/}$mice due to an altered expression of downstream BC metabolizing enzymes, resulting in a gene expression more focused towards vitamin A storage rather than towards retinoic acid production, which is the actual bioactive metabolite. Indeed, a deficiency in retinoic acid is known to result in an inflammations.

In Chapter 6 we focused on gene expression changes induced in lung tissue of male $\mathrm{Bcmo1 \%}$ mice after BC supplementation. The higher inflammatory response in lungs of 
control diet fed Bcmo1\%-mice appeared specific for female mice and was not observed in male mice. In male Bcmo $1 \%$ mice however, frizzled homolog 6 (Fzd6) and collagen triple helix repeat containing 1 (Cthrc1) were significantly 2.60 and 2.99 fold down regulated after BC supplementation. Moreover, many olfactory receptors and protocadherins were up regulated. We hypothesized that these gene expression responses were related and may be involved in the detection of changes in air composition in the lung, such as hypoxia. Since pulmonary endocrine cells (PNECs) are important in the detection of hypoxia, particularly this cell type might be affected by BC supplementation. Although PNECs account for only 1 in 2500 lung cells [11], 20\% of all lung cancer types originate from these cells [12], and smoking particularly increases PNEC originated lung cancer risk. These findings warrant further research on the role of Fzd6 and Cthrc1 in PNECs.

The CARET study reported that BC supplementation in both male and female smoking and asbestos exposed volunteers resulted in an increased lung cancer risk. Therefore, we investigated pathways that were changed in lung tissue of male and female $\mathrm{Bcmo1}^{-1}$ mice after BC supplementation in Chapter 7. Interestingly, the genes that were altered in their expression by $\mathrm{BC}$ supplementation in male and female $\mathrm{Bcmo1} \%$ mice, had an opposite direction of the gene expression changes. This suggested a role for $\mathrm{BC}$ in the regulation of sex-hormones. These changes in lung gene expression were accompanied by a significant regulation of many enzymes involved in steroidogenesis and steroid conversion. Moreover, testosterone levels were highly variable in BC supplemented Bcmo1\%-mice, but not (as expected) in $\mathrm{Bcmo1}^{+/+}$mice. We therefore hypothesize that $\mathrm{BC}$ supplementation is able to alter systemic hormone production.

It is of importance for the risk-benefit assessment of $\mathrm{BC}$, to know whether $\mathrm{BC}$ effects are specific for lung. Therefore, we compared the $\mathrm{BC}$ induced gene expression effects in lung tissue with those induced in white adipose tissue, an important $\mathrm{BC}$ storage organ [13] and liver, important in both BC metabolism and storage [14].

In Chapter 8 we illustrate that only a few genes $(\sim 1 \%$ of the genes regulated by BC supplementation in lung), were also regulated in liver tissue and inguinal white adipose tissue (iWAT), and effects of BC on the expression of single genes is highly tissue specific. Moreover, the magnitude of changes induced by BC supplementation was much less than the differences induced by the knockout of Bcmol or differences in gender (females compared with males).

Although we found in Chapter 8 that only $1 \%$ of the genes regulated by BC in the lung were also regulated in liver and iWAT, we found that the pathways that were changed by $\mathrm{BC}$ in female $\mathrm{Bcmo1}^{\%}$ mice as describe in Chapter 5, or in male $\mathrm{Bcmo1} \%$ mice as described in Chapter 6 or the opposite change in gene expression in male and female Bcmo1\%- mice as described in Chapter 7, were not specific for lung tissue on pathway level which we describe in Chapter 9. 
Summary and general discussion

Altogether, we find that $\mathrm{BC}$ can change inflammation induced genotoxicity and gene expression in lung tissue, thereby altering processes that can be involved in lung carcinogenesis (Fig. 1). 


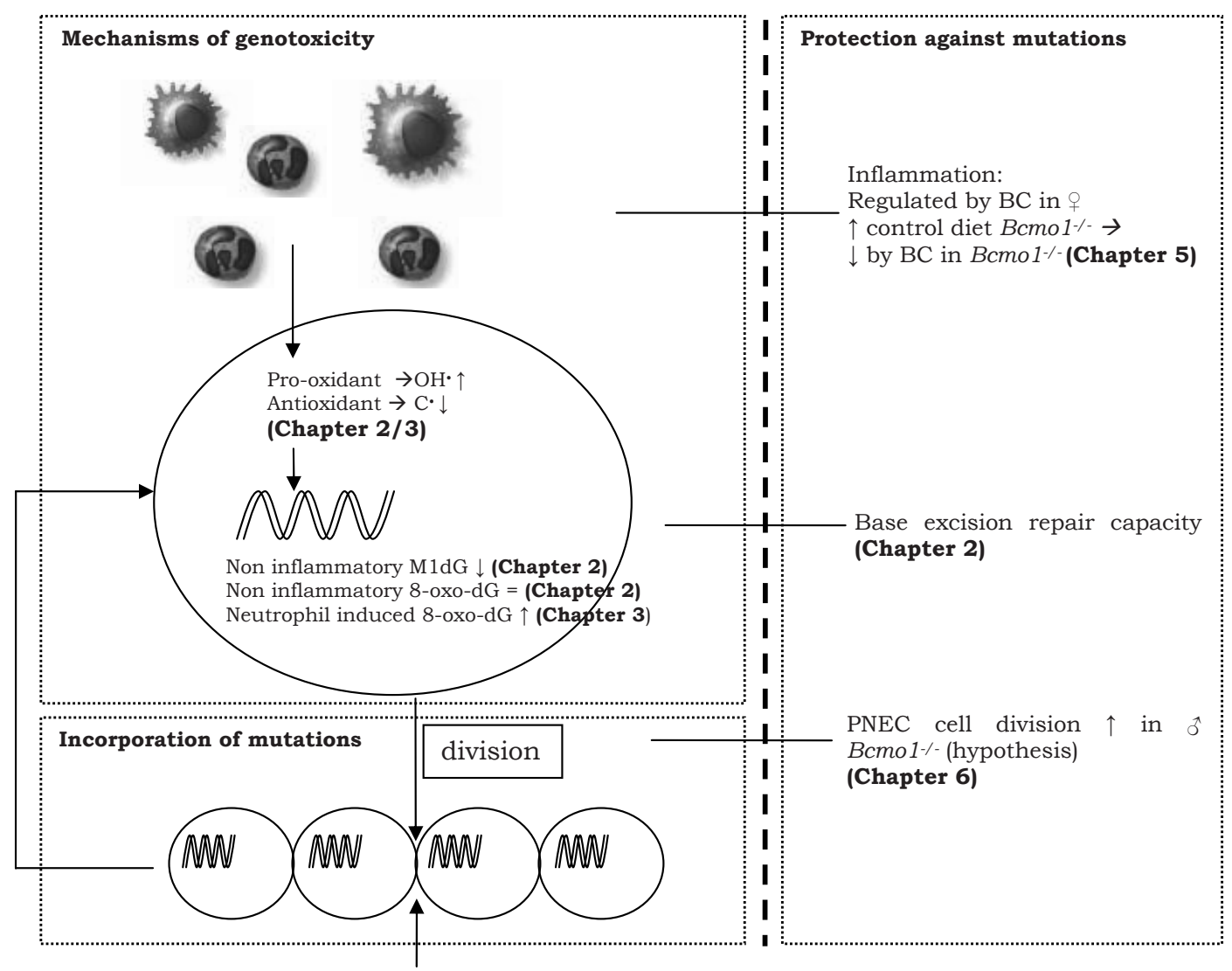

$\mathrm{BC}$ influences sex-hormones in $\mathrm{Bcmo1} \%$ mice (Chapter 7)

Effects of BC lung specific?

Effect of $\mathrm{BC} \ll$ effect gender or Bcmo1 genotype (Chapter 8)

high interaction with tissue, gender and genotype (Chapter 8)

Number of genes 1\% overlap with iWAT and liver (Chapter 8)

Effects on pathway level are not lung specific (Chapter 9)

Figure 1: Summary of main findings of $\mathrm{BC}$ action as described in this thesis with in bold the corresponding chapters 


\section{Discussion of main findings}

\section{In vitro study}

In our study, we used novel approaches to identify modes of action of BC that possibly contribute to an explanation for the previously found detrimental effects in the ATBC and CARET study. In the first part of this thesis we evaluated the role of $\mathrm{BC}$ in radical induced genotoxicity in cell lines. We therefore searched, within the limitations of the physiology of a cell line, good candidate cells for further in vitro experiments.

Human lung cancers are categorized into distinct classes, with adenocarcinoma currently being the most common type of lung cancer (also in non-smokers). It is generally believed that the tumor cells from this cancer originate from type II cells, which cover $\sim 5 \%$ of the alveolar surface [15]. It has indeed been shown that most of the tumor cells express surfactant protein-C, which is characteristic for type II cells and do not express the Clara cell specific protein (CCSP) [16]. The presence of lamellar bodies in lung carcinoma cells has also been demonstrated, in combination with electron dense granules and mitochondria, although this is a common characteristic for Clara cells [17].

Therefore, In order to find a suitable cell line for our in vitro studies, we used electron microscopy to characterize several lung cell lines to choose a cell type containing lamellar bodies and mitochondria as can be seen in Fig. 2 .

A)

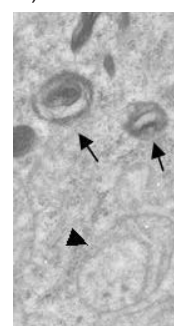

B)

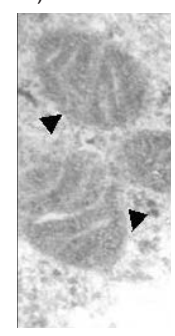

C)

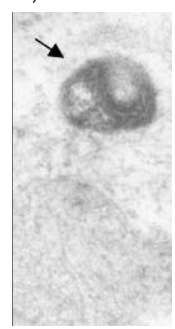

D)

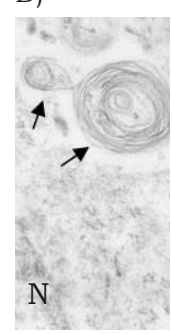

E)

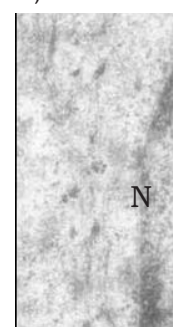

F)

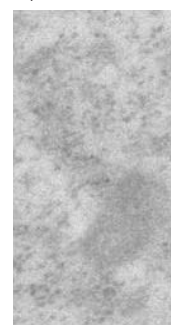

G)

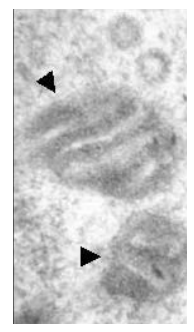

Figure 2. Electron photomicrographs of lung cell lines. A: A549 human type II cell line B: MLE-12 mouse type II epithelial cell line. C: L2 rat type II cell line D: BEAS-2B human bronchial epithelial cell line E: HBE-4 human bronchial epithelial cell line F: HBE-135, human bronchial epithelial cell line G: NL20, human bronchial epithelial cell line. Arrows indicate lamellar bodies, arrow heads indicate mitochondria, $\mathrm{N}$ : nucleus.

We also tried to identify the presence of CCSP and surfactant protein A and C, known markers of type II cells [18], to confirm the cell line histology. Unfortunately, we were not able to quantify these proteins due to low quality antibodies. 
On basis of these results, we specifically selected Beas-2B cells and A549 cells since they are human derived, and thereby having a $\mathrm{BC}$ metabolism probably more similar to that of humans. Moreover, these cells contain lamellar bodies, specific for carcinoma derived from type II cells. Of course one might question the physiological relevance of A549 cell, since they are of cancer origin. Since we were specifically interested in effects of $\mathrm{BC}$ and $\mathrm{BC}$ metabolites on genotoxicity, we think that the antioxidant properties of surfactant as stored in lamellar bodies, present in BEAS-2B and A549 cells, is more important than the characteristics of the immortalization.

From our gene expression studies, we suggest that pulmonary neuroendocrine cells (PNECs) would be an interesting additional cell type to study mechanisms of BC action in lung tissue $[19,20]$. However, at this moment no cell line is characterized as PNEC cell using the PNEC markers CGRP, Chromogranin A, peptide YY [18]. We expect that in future experiments, a PNEC cell line is the preferred choice to study the effect of BC on smoke or asbestos induced carcinogenesis.

Besides the use of immortal cell lines, we also used primary human neutrophils derived from several healthy volunteers to investigate the effect of BC metabolites on MPO activity and on the generation of oxidative DNA lesions.

\section{In vivo ferret studies}

To assess the effect of $\mathrm{BC}$ supplementation on changes in human lung tissue, ferrets are considered as a suitable model [21]. BC metabolism in ferrets and humans is highly similar while $\mathrm{BC}$ metabolism in rodents, such as rats or mice, differs greatly from $\mathrm{BC}$ metabolism in humans [9]. Therefore, we also attempted to assess the effect of $\mathrm{BC}$ on gene expression changes in lung tissue of ferrets. For that experiment, 6 ferrets per group were fed a) a control diet, b) supplemented with $0.8 \mathrm{mg} \mathrm{BC} / \mathrm{kg}$ body weight/day, c) supplemented with $3.2 \mathrm{mg} \mathrm{BC} / \mathrm{kg}$ body weight/day, d) fed the control diet and supplemented with $8 \mathrm{mg} \mathrm{B}[\mathrm{a}] \mathrm{P} / \mathrm{kg}$ three times a week or e) supplemented with $0.8 \mathrm{mg}$ $\mathrm{BC} / \mathrm{kg}$ body weight/day and supplemented with $8 \mathrm{mg} \mathrm{B}[\mathrm{a}] \mathrm{P} / \mathrm{kg}$ three times a week as described in Chapter 2. Since no ferret arrays were (and are) commercially available, the homology of ferret RNA to hybridize against in-house made human and mouse cDNA arrays was tested and resulted in $32 \%$ spots three times above background in the human array, and $23 \%$ spots three times above background in the mouse array, and thus we concluded that ferret lung RNA had the best hybridization quality with human microarrays compared to mouse microarrays. Thereafter, we embarked on a precarious enterprise and hybridized ferret lung RNA to a human cDNA array. Of course, it was of upmost importance to confirm effects found on the human array by ferret specific QPCR. Unfortunately, not many ferret specific sequences are present in publically available databases. Therefore, we sequenced parts of specific genes of ferret cDNAs to be able to design ferret specific primers for ferret specific Q-PCR. 
After sequencing these ferret specific cDNA fragments, the species canis lupus familiaris (i.e., the dog) appeared to have most sequence homology with ferrets, followed by human as can be seen in Table 1 . This is in agreement with the percentage of genes above background on the human and mouse microarrays. The effects of BC observed in the ferret experiment using microarrays designated for human could not be confirmed by Q-PCR, underlining the difficulties in molecular research using ferrets.

Table 1: percentage homology of ferret RNA sequence with human, mouse, rat or dog RNA sequence.

\begin{tabular}{|c|c|c|c|c|c|}
\hline Gene & Abbreviation & $\begin{array}{c}\text { Homo } \\
\text { Sapiens }\end{array}$ & $\begin{array}{l}\text { Mus Mus- } \\
\text { culus }\end{array}$ & $\begin{array}{c}\text { Rattus } \\
\text { Nervoricus }\end{array}$ & $\begin{array}{c}\text { Canis Lupus } \\
\text { Familiaris }\end{array}$ \\
\hline Tropomyosin 1; TPM1 & TPM1a & $95 \%$ & $92 \%$ & $90 \%$ & $96 \%$ \\
\hline Calnexin & CANX & $85 \%$ & \multirow{2}{*}{$\begin{array}{c}\text { Not found } \\
86 \%\end{array}$} & \multirow{2}{*}{$\begin{array}{c}\text { Not found } \\
89 \%\end{array}$} & Not found \\
\hline H3 Histone Family $3 A$ & H3F3 & $94 \%$ & & & $97 \%$ \\
\hline Histone $1,4 F$ & $H 4 F$ & $90 \%$ & $95 \%$ & $95 \%$ & $95 \%$ \\
\hline Histone deacetylase 1 & HDAC1 & $94 \%$ & $91 \%$ & $92 \%$ & $97 \%$ \\
\hline Nuclear receptor corepressor 1 & NCOR1 & $97 \%$ & $94 \%$ & $94 \%$ & $98 \%$ \\
\hline Retinoic Acid Receptor beta & $R A R \beta$ & $94 \%$ & $88 \%$ & $89 \%$ & $96 \%$ \\
\hline Thymosin beta 10 & TMSB10 & $89 \%$ & Not found & $88 \%$ & $94 \%$ \\
\hline Tight junction protein & $T J P$ & $97 \%$ & $95 \%$ & $96 \%$ & $98 \%$ \\
\hline Acetyl-CoA Acyltransferase 2 & $A C A A 2$ & $87 \%$ & $85 \%$ & $85 \%$ & Not found \\
\hline Actin beta & ACTB & $94 \%$ & $90 \%$ & $90 \%$ & $94 \%$ \\
\hline Creb binding protein & $C R E B B P$ & $88 \%$ & $87 \%$ & $88 \%$ & $94 \%$ \\
\hline H2A histone family & $H 2 A$ & $100 \%$ & $98 \%$ & $99 \%$ & $100 \%$ \\
\hline Histone acyltransferase 1 & $H A T$ & $96 \%$ & $94 \%$ & $96 \%$ & $99 \%$ \\
\hline E1A binding protein $p 300$ & EP300 & $95 \%$ & $92 \%$ & $92 \%$ & $79 \%$ \\
\hline P300/CBP-associated factor & $P C A F$ & $91 \%$ & $86 \%$ & Not found & $97 \%$ \\
\hline Prothymosin alpha & PTMA & $96 \%$ & $92 \%$ & $93 \%$ & $99 \%$ \\
\hline Histone deacetylase 2 & $H D A C 2$ & $92 \%$ & Not found & $85 \%$ & $94 \%$ \\
\hline Histone deacetylase 3 & $H D A C 3$ & $81 \%$ & Not found & $77 \%$ & $87 \%$ \\
\hline Ribosomal protein $L 17$ & RPL17 & $91 \%$ & $88 \%$ & $88 \%$ & $95 \%$ \\
\hline
\end{tabular}

Species with the most homology with ferret sequence in bold and grey

Ferrets are also a preferred animal model in influenza research [22]. Recently, gene expression changes induced by avian influenza H5N1 in lung tissue of ferrets were analyzed using Canine arrays [23]. Canine arrays were chosen since 30 publically available ferret sequences had the highest (89\%) homology with canine sequences. We found much higher homologies, which is probably caused by choosing highly conserved regions between human, mice, rats and dogs to increase the chance of a successful PCR. Overall, the results on ferret mRNA analysis on human microarrays could not be confirmed by Q-PCR, and therefore this approach was aborted. Since then the microarray quality is highly improved and continuously developed. Therefore microarray studies in ferrets may be possible in the near future. 


\section{In vivo Bcmo1\% mouse model}

We used $\mathrm{Bcmo1} \%$ mice to evaluate effects induced by $\mathrm{BC}$ in the second part of this thesis.
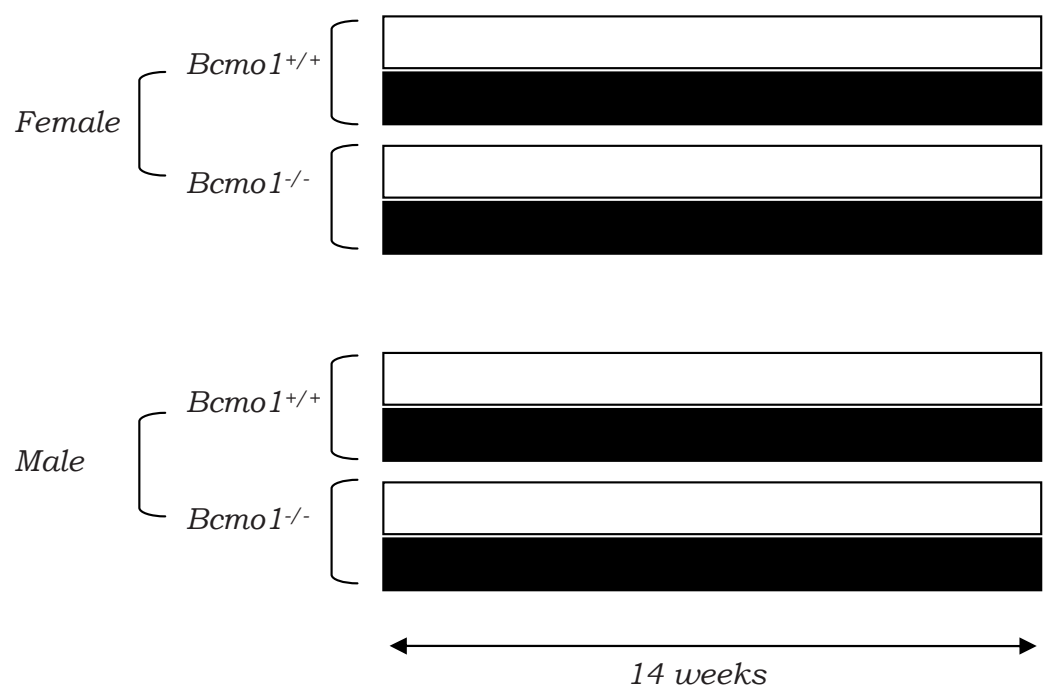

Figure 3: Experimental setup of the mouse experiment used in Chapter 5-9 of this thesis. Six animals per arm of the experiment.

The setup of the experiment is shown in Fig. 3 and appeared highly effective to dissect effects induced by $\mathrm{BC}$ supplementation in the $\mathrm{Bcmo1} \%$ mice from effects induced in $\mathrm{BCmo1}^{+/+}$, and effects induced in female mice from effects induced in male mice. The effect of $\mathrm{BC}$ decreasing the inflammatory response in female $\mathrm{Bcmo1 \%}$ mice as described in Chapter 5, would be interpreted as a decrease in inflammation when no $\mathrm{Bcmo1^{+/+ }}$ mice were taken along. We now assume that female Bcmo $1 \%$ mice are more vulnerable for vitamin A deficiency and that BC is able abolish this effect. Moreover, the effects of $\mathrm{BC}$ on transcription were different in male and female $\mathrm{Bcmo1} \%$ mice as described in Chapter 5 and Chapter $\mathbf{6}$ and resulted in opposite direction of gene-regulation of commonly regulated genes in $\mathrm{Bcmo} \mathrm{1 \%}$ mice as described in Chapter $\mathbf{7 .}$

We discussed in Chapter 4 that a good setup of an in vivo mouse experiment is an important prerequisite to obtain enough power to statistically significantly assign the small effects as are often observed by nutritional interventions. In contrast to the recommended $n=12$, in our experiment we used only 6 animals per group. This was done 
because this was the maximum capacity when taking breeding into account. Nevertheless, the differences that we have described are statistically significant, and thus enough power must have been obtained. The pathways that were significantly regulated in lung tissue after $\mathrm{BC}$ supplementation in $\mathrm{Bcmo1} \%$ mice were also differentially regulated by BC in iWAT and liver as has been described in Chapter 9, which can be taken as confirmation of the power of the experiment.

\section{Interpretation of main findings}

\section{The effect of BC on inflammation}

We showed in Chapter 2 that BC supplementation specifically decreased carbon centered radical formation, resulting in a decrease in the formation of $\mathrm{M}_{1} \mathrm{dG}$ in ferrets. However, hydroxyl radical formation was increased, especially in our in vitro experiments. Because BC supplementation also increased DNA repair capacity (BER), BC supplementation did not result in an increase in the oxidative DNA lesion 8-oxo-dG in vivo. Thus, sufficient $\mathrm{BC}$ normally has beneficial effects on genotoxicity. Since an inflammatory response in the lungs is mainly characterized by an increase in neutrophils [7], we investigated the effect of $\mathrm{BC}$ or its metabolites on neutrophil induced oxidative DNA lesions. We found that retinoic acid and retinol were able to increase neutrophil induced oxidative DNA lesions as described in Chapter 3. This results in a lower beneficial effect of BC in neutrophil exposed (smokers or asbestos exposed subjects) humans as compared to non-exposed subjects, as is displayed in Fig. 4.

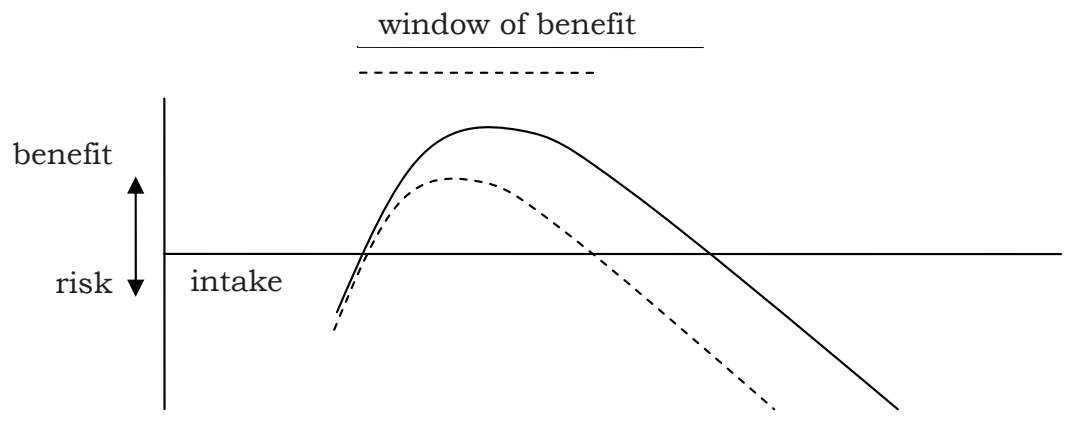

Figure 4: Hypothetical benefit-risk of $\mathrm{BC}$ on neutrophil induced genotoxicity in subjects that have a low neutrophilic influx in the lungs (solid line) and a high neutrophilic influx in the lungs (dashed lines). BC has beneficial effects towards radical centered radicals which results in a decrease in levels of the pro-mutagenic $\mathrm{M}_{1} \mathrm{dG}$. However, BC increases neutrophil induced levels of 8-oxo-dG. The presence of neutrophils is increased in smokers and asbestos exposed subjects and therefore results in a smaller window of benefit. 
Although we show that these BC metabolites have the ability to increase neutrophil induced oxidative DNA lesions, it must be emphasized that these results were obtained by using cell lines. Cell lines often display altered gene expression resulting in, for example, a non-physiological poor antioxidant enzyme or repair enzyme signature [24]. Nevertheless, these data show that $\mathrm{BC}$ metabolites have the potential to enhance neutrophil induced oxidative stress.

In Chapter 5 we also described that inactivation of Bcmo 1 resulted in inflammatory infiltrations in lungs of female $\mathrm{Bcmo1} \%$ mice, which was abolished by dietary $\mathrm{BC}$. We explained this effect by an altered downstream BC metabolism, resulting in a higher $\mathrm{BC}$ demand. $\mathrm{BC}$ supplementation resulted in a decrease of the inflammatory response, and results in a changed benefit-risk figure dependent on BCMO1 activity as is displayed in Fig. 5. A genetic polymorphism in $B C M O 1$ has been described in humans, which is associated with a lower BCMO1 activity. The vitamin A content in the control diet appeared, in contrast to females, physiologically sufficient for male $\mathrm{Bcmo} 1^{-1}$ mice, but we don't know the mechanism at this moment.

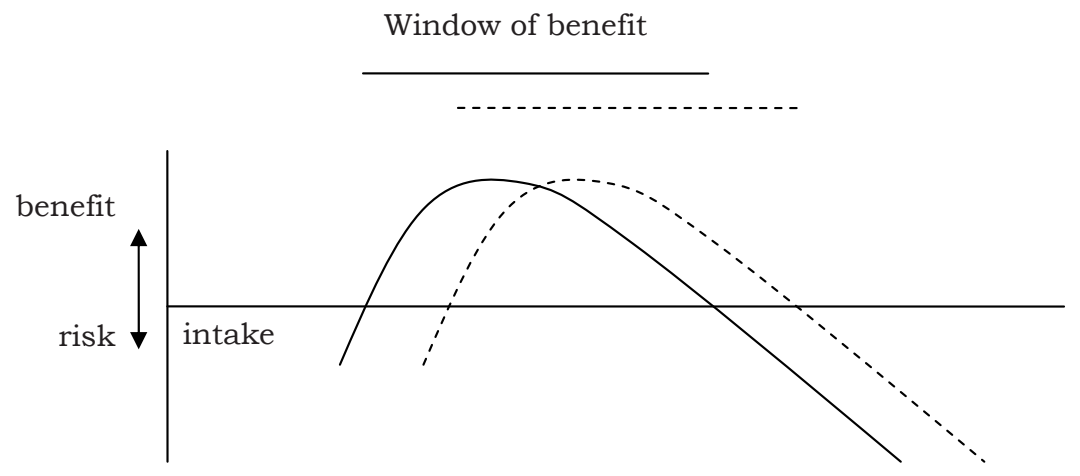

Figure 5: Hypothetical benefit-risk of BC in the female "low response" phenotype (solid line) and "low converter" phenotype. Females that have polymorphisms in the BCMO1 enzyme (associated with lower activity of BCMO1) might have a higher vitamin A demand, as was observed in female $\mathrm{Bcmo1} \%$ mice (Chapter 5). Vitamin A deficiency results in adverse effects such as an increase in inflammation. Because of the higher Vitamin A demand, the window of benefit of the low converter phenotype shifts to the right in the figure.

Thus, significantly decreased levels of $\mathrm{BC}$ or $\mathrm{BC}$ metabolites can increase inflammation. Interestingly, smokers have both an increased inflammatory response, and decreased 
vitamin A levels. An inverse correlation between the degree of inflammation and $\mathrm{BC}$ has been observed in several studies. For example there is an inverse correlation between white blood cell count and BC concentration in non-smokers [25] and smokers [26,27]. But, is the $\mathrm{BC}$ concentration modulating the inflammatory response, or does the inflammatory response alter BC levels? There is evidence for both theories. Increases in inflammation are usually associated with increased oxidative stress. BC is highly susceptible to oxidative degradation and several studies have shown that $\mathrm{BC}$ cleavage rapidly occurs after exposure to oxidative reagents such as hypochlorous acid $[28,29]$. This theory however, explains only part of the inverse correlation between $\mathrm{BC}$ concentration and the degree of inflammation. Studies that measured several carotenoids demonstrate that $\mathrm{BC}$ concentrations are decreased to a higher extent during inflammation than the more oxidative sensitive carotenoids such as lycopene and lutein [25,30]. This suggests that lower BC status increases inflammation. In agreement with this hypothesis, studies have shown that deficiency of the BC metabolite vitamin A is associated with an increased severity of infections and more deaths from infectious diseases; supplementation with vitamin A reduced these effects [31,32]. Supporting these data, vitamin A deficiency in rats resulted in inflammatory infiltrates in lungs [33]. To investigate the similarities between vitamin A deficiency and smoke induced histological changes in the lung, lungs of vitamin A deficient rats [33] were histologically compared to lungs of smoke exposed rats [34]. Remarkably, these lungs showed a similar structure, with emphysematous areas and inflammatory infiltrates [35].

The molecular mechanism underlying the vitamin A induced effects on the immune response are not well understood. As described in the introduction, RAR and RXR are transcription factors able to bind the retinoic acid responsive element in promoter regions of RAR-responsive genes. Retinoic acid binding to this receptor can consequently result in a gene expression response [36,37]. RARa and RARY are the predominant forms expressed in immunological cells, and RARy knockout results in a decrease in total white blood cell counts [38]. All-trans retinoic acid is, in contrast to its activating role for RAR, an effective repressor of ROR, and binding of retinoic acid has been shown to decrease immunological responses [39]. Altogether these observations lead to a hypothesis that a deficiency in the bioactive metabolite retinoic acid might lead to an increased inflammation in the lungs. In our study, supplemental BC was beneficial. Mechanistic knowledge on inflammatory responses during retinoic acid deficiency is of importance and might lead to mechanisms that explain the previously identified detrimental effects and might identify other vulnerable groups.

\section{Retinoic acid resistance?}

Thus negative effects of vitamin A deficiency on inflammation have been reported. Fig. 6 depicts that vitamin A deficiency results in an increased inflammatory response. This raises the question: "Is it possible that a chronic supplementation with BC eventually results in a decrease of the bioactive metabolite retinoic acid?" We investigated this possibility in literature. 


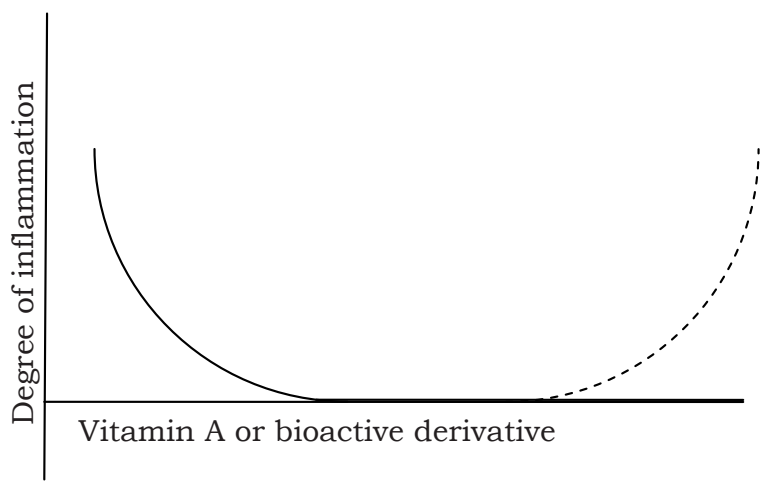

Figure 6: Vitamin A concentration can modulate the inflammatory response. During deficiency, inflammation is increased (solid line). High dose supplementation of the bioactive metabolite retinoic acid can increases inflammation in APL patients (dashed line) [40].

During illness, all-trans retinoic acid is frequently used as a therapeutic agent in patients suffering from acute promeyelocytic leukemia (APL). Without any other medication, around $25 \%$ of the patients develop the retinoic acid syndrome. Typical for the clinical manifestations of the retinoic acid syndrome are pulmonary effects (Table 2) and typical is that a large percentage of patients suffer from inflammatory infiltrates $[41,42]$. Although the exact mechanisms are unknown, these data indicate that an increase in retinoic acid might become detrimental under certain conditions.

Table 2: clinical manifestations of the retinoic acid syndrome [43].

\begin{tabular}{lc}
\hline Manifestation & \% of Patients \\
\hline Respiratory distress & 84 \\
Fever & 81 \\
Pulmonary edema & 54 \\
Pulmonary infiltrates & 52 \\
Pleural/pericardial effusion & 36 \\
Hypotension & 18 \\
Bone pain & 14 \\
Headache & 14 \\
Congestive heart failure & 11 \\
Acute renal failure & 11 \\
\hline
\end{tabular}


Retinoic acid levels are thought to be very well regulated [44]. Since the measurement of retinoic acid involves sophisticated equipment, the retinoic acid precursor retinol is measured in most studies that investigate effects of carotenoids. In contrast to the assumed stable retinoic acid levels, consumption of $\mathrm{BC}$ rich carrot juice resulted in stable retinol plasma concentrations, but almost doubled retinoic acid plasma concentrations [45]. This study was performed for the duration of only two weeks. What happens with retinoic acid levels after prolonged supplementation with beta-carotene is unknown, but for example, prolonged all trans retinoic acid treatment causes an increase in RA catabolism and can lead to retinoic acid resistance $[40,46]$. This is mainly caused by an increased Cytochrome P450 family 26 (CYP26) capacity. These studies indicate that RA levels may be altered after $\mathrm{BC}$ administration and that prolonged period of elevated RA levels induces an increase in RA catabolism. Moreover, we observed in Chapter $\mathbf{5}$ and Chapter 6 a positive correlation between BC concentrations in lung and retinyl ester concentrations in the lung. This indicates that there is a controlled balance between concentrations of $\mathrm{BC}$ and its stored form. When a more chronic $\mathrm{BC}$ supplementation is attenuated, $\mathrm{BC}$ might be stored at similar levels, while RA turnover is increased resulting in a physiological deficiency. This hypothesis is more or less strengthened by some adverse effects that have been observed in RA therapy. Administration of retinoic acid can induce RA hypercatabolism and patients cannot be actively treated with retinoic acid after a first therapy even when the dose is doubled $[47,48]$. Moreover, decreases in endogenous retinol stores down to $40 \%$ have been observed in patients with exogenous retinoid therapy and resulted in adverse effects on vision [49]. Moreover, the retinoic acid syndrome is characterized by weight gain (retinoic acid increase results in the opposite [41]) in association with pulmonary infiltrations.

Smokers have lower carotenoid levels, as we have described above and ferrets exposed to cigarette smoke have around half the retinoic acid concentration in their lungs compared to control ferrets [50]. Moreover smoke has been shown to induce RA catabolism in ferrets [51]. Therefore, smokers are probably already more vulnerable for a deficient state and decrease in retinoic acid might quickly result in an increase in the inflammatory response, which is similar to the observation of an increased inflammatory response in lungs of control diet fed female $\mathrm{Bcmo1}^{-}$- mice, which was abolished by dietary BC.

\section{BC metabolism: the important determinant in BC induced effects?}

Many of our described effects are possibly the effect of changes in retinoic acid concentration, induced by $\mathrm{BC}$ supplementation. We explained part of these effects by differ- 
ences in downstream BC metabolism (Chapter 5 and Chapter 6). This raises the question whether smoke or asbestos exposed subjects might have an altered downstream BC metabolism compared to healthy volunteers. Although this question was never directly addressed in human lung tissue, technology evolved and microarray data are usually publicly accessible with which this question could be answered (at least in part).

We used GEO Datasets (http://www.ncbi.nlm.nih.gov/gds) to analyze the effect of smoking on the gene expression of BC metabolizing enzymes, using 4 studies (Table 3). Unfortunately, no data were available from lung tissue of asbestos exposed subjects. The most remarkably changed downstream BC metabolizing enzyme is ADH7, the most important enzyme in the conversion of retinol into retinal [52].

Table 3: Enzymes involved in downstream BC metabolism that are significantly changed in smokers (based on publicly available microarray data at: http://www.ncbi.nlm.nih.gov/gds).

\begin{tabular}{|c|c|c|c|c|c|c|c|c|}
\hline $\begin{array}{l}\text { target } \\
\text { tissue }\end{array}$ & $\begin{array}{c}\text { smokers } \\
\text { (n) }\end{array}$ & $\begin{array}{c}\text { control } \\
\text { (n) }\end{array}$ & ADH7 & ADH1a3 & DHRS3 & BCMO1 & Aldh2 & $\begin{array}{l}\text { refer- } \\
\text { ence }\end{array}$ \\
\hline $\begin{array}{l}\text { large air- } \\
\text { way epithe- } \\
\text { lium }\end{array}$ & 26 & 17 & $\begin{array}{c}3.74 \\
(1.69 \mathrm{e}-9)\end{array}$ & $\begin{array}{c}1.736 \\
(0.0006)\end{array}$ & n.p. & n.p. & $\begin{array}{c}-1.09 \\
(0.270)\end{array}$ & [53] \\
\hline $\begin{array}{l}\text { small air- } \\
\text { way epithe- } \\
\text { lium }\end{array}$ & 10 & 12 & $\begin{array}{c}7.21 \\
(1.35 \mathrm{E}-7)\end{array}$ & $\begin{array}{c}1.368 \\
(0.001)\end{array}$ & $\begin{array}{c}1.237 \\
(0.058)\end{array}$ & $\begin{array}{c}-1.16 \\
(0.049)\end{array}$ & $\begin{array}{c}-1.099 \\
(0.16)\end{array}$ & [54] \\
\hline $\begin{array}{l}\text { small air- } \\
\text { way epithe- } \\
\text { lium }\end{array}$ & 6 & 5 & $\begin{array}{c}6.434 \\
(4.06 e-5)\end{array}$ & $\begin{array}{c}1.732 \\
(0.0748)\end{array}$ & $\begin{array}{c}1.099 \\
(0.2136)\end{array}$ & $\begin{array}{c}1.398 \\
(0.395)\end{array}$ & $\begin{array}{l}-1.177 \\
(0.299)\end{array}$ & [55] \\
\hline $\begin{array}{l}\text { general } \\
\text { airway }\end{array}$ & 33 & 22 & $\begin{array}{c}2.52 \\
(1.35 \mathrm{e}-08)\end{array}$ & $\begin{array}{c}1.44 \\
(0.0085)\end{array}$ & $\begin{array}{c}1.498 \\
(1.03 e-8)\end{array}$ & $\begin{array}{c}1.286 \\
(0.234)\end{array}$ & $\begin{array}{c}-1.23 \\
(0.002)\end{array}$ & [56] \\
\hline
\end{tabular}

n.p.: not present in database; p-value between brackets

We found in Chapter 5 that Adh7 was also significantly up regulated in female $B c m o 1^{-/}$mice after $\mathrm{BC}$ supplementation and non significantly in male $\mathrm{Bcmo} 1 \%$ mice after $\mathrm{BC}$ supplementation. These data suggest that $\mathrm{BC}$ supplementation to smokers, which have already increased ADH7 activity, might lead to an additive or even synergistic effect of $\mathrm{BC}$ on ADH7 expression. This might have important implications of BC on smoke induced carcinogenesis, since ADH7 has also been shown to have an increased activity in many types of cancer such as esophageal cancer [57] and gastric cancer [58].

\section{Gender effect}

Interestingly, the observed effects of $\mathrm{BC}$ in $\mathrm{Bcmo1/-}$ mice were gender specific. This resulted in an increase in inflammatory gene expression in control diet fed $\mathrm{Bcmo1} \%$ mice which was specific for female mice as described in Chapter 5, while the decrease in 
Fzd6 and Cthrc1 in combination with the increase in olfactory receptors and protocadherins after $\mathrm{BC}$ supplementation to $\mathrm{Bcmo1} /$ mice were specific for male mice as described in Chapter 6. Moreover, the effects induced by BC supplementation in both male and female mice were regulated in opposite direction as described in Chapter $\mathbf{7}$. These differences have also implications for differences in the benefit-risk figure. Females seem to have a higher vitamin A demand than males, which results in a shift to the right for the start of the hypothetical window of benefit in female as can be seen in Fig. 7.

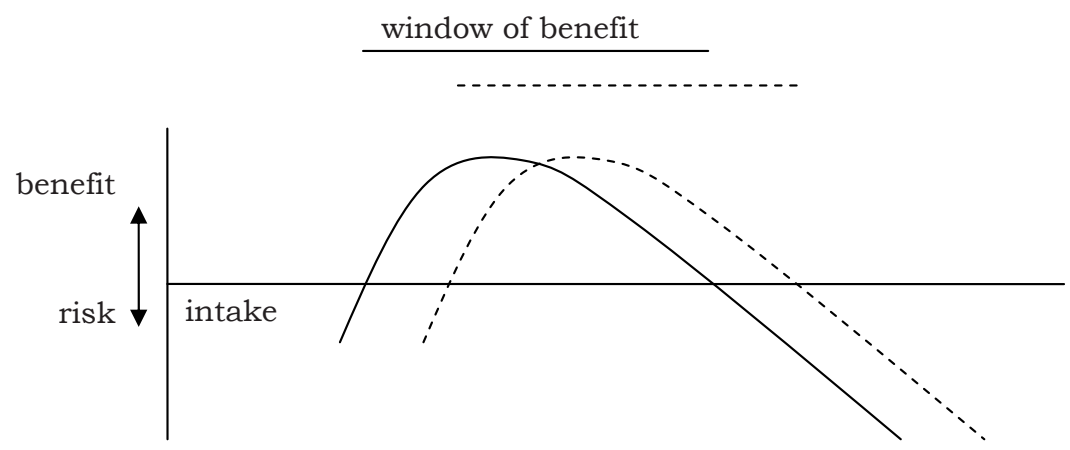

Figure 7: Hypothetical benefit-risk figure for male (solid) and female (dashed). Female Bcmo1/- mice seem to have a higher vitamin A demand than male mice.

We explained the opposing gene expression differences found in lung tissue, by a change in hormones or steroid biosynthesis due to an evolutionary conserved overlap in the production of $\mathrm{BC}$ in plants and the steroid synthesis in mammals [59]. We found a significant change in the GO process steroid biosynthesis in male $\mathrm{Bcmol} /$ mice after supplementation with $\mathrm{BC}$. This process might be the cause of the opposing gene expression differences in male and female mice or its consequences. In Chapter 9, we focused on the effect of BC supplementation in iWAT and liver and we also found an opposite direction of gene regulation in iWAT in male and female $\mathrm{Bcmo1}^{+/+}$mice after BC supplementation. Similar to lung tissue, the GO process steroid biosynthesis was significantly regulated in one of the two genders after BC supplementation (Table 4). There were a few genes commonly regulated in the steroid biosynthesis process between male $\mathrm{Bcmo1} \%$ mice and female $\mathrm{Bcmo1}^{+/+}$mice after $\mathrm{BC}$ supplementation, including MvK, Hmgcs1, Fdps and Cyp51 There are also two genes regulated in both iWAT of female $\mathrm{Bcmo1}^{+/+}$mice and lung tissue of male $\mathrm{Bcmo1}^{-/}$mice that play an important role in the conversion of steroids and thereby regulates the sex hormone bioactivity in the target tissue. Hsd17b12 converts estrone into the bioactive 17ß-estradiol [60] and Hsd $17 \mathrm{~b} 7$ has been shown to have a dual role: activation of estrogens by converting estrone into $17 \beta$-estradiol, while Hsd17b7 inactivates dihydrotestosterone (DHT) by trans- 
forming this into 5alpha -androstane-3beta,17beta-diol (3beta-diol) [61]. Changes in hormone production or activity normally results in physiological effects in adiposity. Sex steroids play a key role in the distribution of adipose tissue $[62,63]$. This is for example exemplified by a reduced degree of central obesity by hormone replacement therapy in postmenopausal woman and testosterone replacement therapy in older man [63]. Similarly, we found that adiposity was significantly decreased in female $\mathrm{Bcmo1}^{+/+}$mice, while not in male $\mathrm{Bcmo1}^{+/+}$mice as can be seen in Fig. 8 .

Table 4: Genes present (until $\mathrm{p}=0.05$ ) in the significantly regulated GO process steroid biosynthesis in iWAT of female $\mathrm{Bcmo1}^{+/+}$mice after BC supplementation.

\begin{tabular}{|c|c|c|c|}
\hline Probe & Score & Symbol & Name \\
\hline A_52_P67637 & $4.56 \mathrm{E}-04$ & $S c 5 d$ & $\begin{array}{l}\text { sterol-C5-desaturase (fungal ERG3, delta-5-desaturase) ho- } \\
\text { molog (S. cerevisae) }\end{array}$ \\
\hline A_51_P153170 & $5.25 \mathrm{E}-04$ & Cyb5r3 & cytochrome b5 reductase 3 \\
\hline A_51_P418056 & $9.51 \mathrm{E}-04$ & $S c 5 d$ & $\begin{array}{l}\text { sterol-C5-desaturase (fungal ERG3, delta-5-desaturase) ho- } \\
\text { molog (S. cerevisae) }\end{array}$ \\
\hline A_52_P118161 & 0.001033 & Lss & lanosterol synthase \\
\hline A_52_P35064 & 0.001037 & $\operatorname{Tm} 7 \mathrm{sf2}$ & transmembrane 7 superfamily member 2 \\
\hline A_51_P482711 & 0.001257 & Dhcr24 & 24-dehydrocholesterol reductase \\
\hline A_51_P209372 & 0.002543 & Sc4mol & sterol-C4-methyl oxidase-like \\
\hline A_51_P329711 & 0.004309 & Idi1 & isopentenyl-diphosphate delta isomerase \\
\hline A_51_P492408 & 0.005526 & Pmvk & phosphomevalonate kinase \\
\hline A_51_P290986 & 0.006027 & Dhcr7 & 7-dehydrocholesterol reductase \\
\hline A_51_P492410 & 0.006296 & Pmvk & phosphomevalonate kinase \\
\hline A_51_P146941 & 0.007138 & Hmgcs 1 & 3-hydroxy-3-methylglutaryl-Coenzyme A synthase 1 \\
\hline A_51_P158922 & 0.009218 & Prkaa1 & protein kinase, AMP-activated, alpha 1 catalytic subunit \\
\hline A_52_P164161 & 0.009666 & Cyp51 & cytochrome P450, family 51 \\
\hline A_51_P379798 & 0.0128 & $F d p s$ & farnesyl diphosphate synthetase \\
\hline A_52_P58006 & 0.01367 & Acbd3 & acyl-Coenzyme A binding domain containing 3 \\
\hline A_52_P243599 & 0.01445 & Hsd17b12 & hydroxysteroid (17-beta) dehydrogenase 12 \\
\hline A_52_P636752 & 0.01622 & Cyp51 & cytochrome P450, family 51 \\
\hline A_51_P169527 & 0.02114 & $M v k$ & mevalonate kinase \\
\hline A_51_P355943 & 0.02238 & Mvd & mevalonate (diphospho) decarboxylase \\
\hline A_52_P1013551 & 0.02461 & $N s d h l$ & $N A D(P)$ dependent steroid dehydrogenase-like \\
\hline A_52_P566605 & 0.02528 & $H s d 17 b 7$ & hydroxysteroid (17-beta) dehydrogenase 7 \\
\hline A_51_P485791 & 0.02842 & Cyp51 & cytochrome P450, family 51 \\
\hline A_51_P326942 & 0.03472 & $N s d h l$ & $N A D(P)$ dependent steroid dehydrogenase-like \\
\hline A_52_P388072 & 0.0392 & Hmgcs 1 & 3-hydroxy-3-methylglutaryl-Coenzyme A synthase 1 \\
\hline A_52_P297803 & 0.04138 & Nsdhl & $N A D(P)$ dependent steroid dehydrogenase-like \\
\hline A_51_P296487 & 0.04157 & Lss & lanosterol synthase \\
\hline
\end{tabular}


Thus the adiposity index 'perfectly' corresponds to the changes in the biosynthesis process. There is however no effect seen in adiposity in males and certainly more research is needed to identify the specific effects and mechanisms of BC induced effects on hormone synthesis or bioactivity.

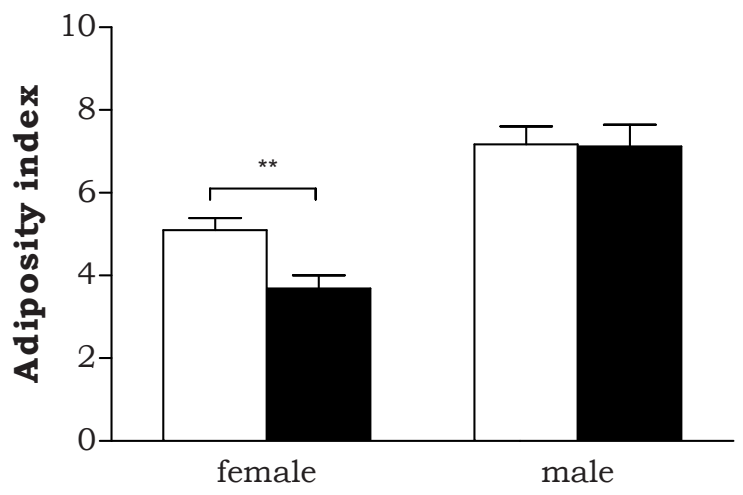

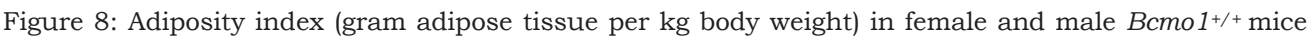
in control diet fed mice (white bars) and BC supplemented mice (black bars). ${ }^{* *} \mathrm{p}<0.01$ with Students' $t$-test. Error bars represent SEM.

\section{Interaction of $B C$ with xenobiotics?}

The effect of $\mathrm{BC}$ resulting in an increased lung cancer risk as described in the CARET and ATBC trials was observed in subjects that were exposed to either cigarette smoke or asbestos. In this thesis we tried to obtain more insight in molecular mechanisms changed by $\mathrm{BC}$ in lung tissue. There are some indications that xenobiotic exposure such as in smoking, alters lung biology, thereby additionally altering effects of BC. In Chapter 2, ferrets were exposed to $\mathrm{B}[\mathrm{a}] \mathrm{P}$ for 10 weeks. $\mathrm{B}[\mathrm{a}] \mathrm{P}$ is one of the best studied chemical pro-carcinogens and is present in cigarette smoke. $\mathrm{B}[\mathrm{a}] \mathrm{P}$ is metabolic activated into BPDE, a chemical carcinogen able to form adducts with the DNA [64]. Fourteen weeks after the B[a]P intervention had stopped, BPDE-DNA adducts were still detectable in the ferrets' lung. More remarkably, B[a]P exposed ferrets had significantly lower 8oxo-dG levels and had a significantly increased BER capacity. Previously a single dose of $\mathrm{B}[\mathrm{a}] \mathrm{P}$ was associated with an increased urinary excretion of 8-oxo-dG and a decrease in 8-oxo-dG in the DNA [65]. Although an exact mechanism was not tested, we found a significant increase in BER capacity after B[a]P exposure. Moreover, we found a significant negative correlation between 8-oxo-G and BPDE-DNA adducts as can be seen in 
Fig. 9, indicating that the presence of these BPDE adducts was possibly sufficient to increase BER capacity.

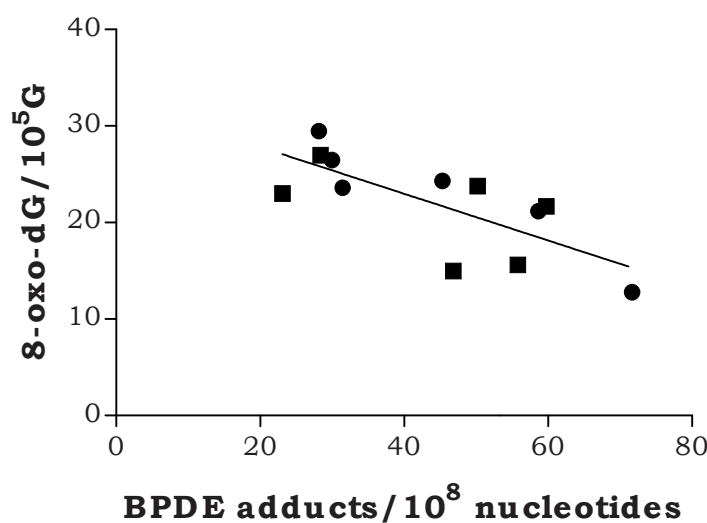

Figure 9: Correlation between BPDE-DNA adducts and 8-oxo-dG in ferrets fourteen weeks after the last $\mathrm{B}[\mathrm{a}] \mathrm{P}$ exposure in ferrets fed the control diet (circles) or fed $0.8 \mathrm{mg} / \mathrm{kg} \mathrm{BC}$ (squares) ( $\mathrm{R}=0.74$, $\mathrm{p}<0.01)$.

Although only smokers and not asbestos exposed subjects are exposed to high concentrations of $\mathrm{B}[\mathrm{a}] \mathrm{P}$, this example illustrates that xenobiotic exposures, are of importance in the ultimate result of the effect of $\mathrm{BC}$ on inflammation induced genotoxicity.

One xenobiotic that is present in both cigarette smoke as well as asbestos is iron. Cigarette smoke contains high amounts of iron (440-1150 $\mathrm{\mu g} / \mathrm{g}$ tobacco) [66] and also asbestos fibers are associated with high concentrations of iron. The amphibole fibers have a high iron content (27-33\%), while chrysotile asbestos has relatively small iron contents (6\%) [67], and epidemiological studies show that asbestos fibres that contain high amounts of iron are more carcinogenic than the low or non-iron containing counterparts [68]. Moreover, iron, mainly in the $\mathrm{Fe}^{3+}$ form, can bind and accumulates on asbestos fibres [69]. The main mechanism described for the possible detrimental effects of iron is the Fenton reaction:

$\mathrm{Fe}^{2+}+\mathrm{H}_{2} \mathrm{O}_{2} \rightarrow \mathrm{Fe}^{3+}+\cdot \mathrm{OH}+-\mathrm{OH}$

We proposed in Chapter 3 that $\mathrm{BC}$ and its metabolites are able to reduce $\mathrm{Fe}^{3+}$ into $\mathrm{Fe}^{2+}$, thereby increasing radical formation in the Fenton reaction. Besides this effect of $\mathrm{BC}$ on iron mediated radical formation, we actually found in Chapter $\mathbf{3}$ that BC was also able to reduce the activity of the iron containing enzyme MPO. 
Moreover, we found that $\mathrm{BC}$ was able to decrease the activity of the iron containing enzyme horse radish peroxidase 2 -fold (unpublished data). Altogether, these data implicate that $\mathrm{BC}$ might alter iron biology.

Besides the investigated effect of $\mathrm{BC}$ and its metabolites on the generation of oxidative stress, $\mathrm{BC}$ or its metabolites might also have a role in the uptake of iron. $\mathrm{Fe}^{3+}$ has very low solubility at neutral $\mathrm{pH}$ and accumulates onto the particle surfaces. It is known that reducing agents present in the lung, such as ascorbate, are able to reduce $\mathrm{Fe}^{3+}$ into $\mathrm{Fe}^{2+}$, thereby displacing the iron from the complexed surface [70]. Moreover, the uptake of iron under physiological conditions is probably also dependent on its valence. $\mathrm{Fe}^{3+}$ has very low solubility at neutral $\mathrm{pH}$ and reduction of $\mathrm{Fe}^{3+}$ into $\mathrm{Fe}^{2+}$ has been considered as essential in iron absorption [71]. There are only a few studies describing the effect of $\mathrm{BC}$ or $\mathrm{BC}$ metabolites on iron uptake, and they mainly focus on dietary iron absorption and distribution. It has been shown that vitamin $\mathrm{A}$ and $\mathrm{BC}$ were able to improve dietary nonheme iron absorption in colorectal cells of human subjects $[72,73]$ and changes from vitamin A deficiency towards sufficiency also resulted in organ specific alterations in iron content $[74,75]$. Moreover, RBP4, the main transporter of retinol, has been associated with increased concentration of ferritin, the main protein that complexes with iron, which indicates a relation between $\mathrm{BC}$ metabolite retinol and iron biology $[76,77]$. These data indicate that $\mathrm{BC}$ or its metabolites might be involved in the physiological effects of iron in lung tissue.

\section{How to continue to assess the risk of $\mathrm{BC}$ ?}

The aim of this thesis was to assess molecular mechanisms altered by $\mathrm{BC}$ action in the lung to contribute to an explanation for the previously observed adverse effects of $\mathrm{BC}$ on lung cancer risk. Novel observations have been made that a) contribute to explanations for the negative effects observed in the CARET and ATBC studies and at the same time agree with the many beneficial effects of $\mathrm{BC}$ and b) suggest novel roles of $\mathrm{BC} / \mathrm{RA}$ metabolism in cell biology and c) show that large gaps remain in our knowledge of $\mathrm{BC} / \mathrm{RA}$ biology.

With plenty new data, we would like to discuss questions resulting from this thesis that have to be addressed on the road towards benefit-risk assessment that will help to define a recommended daily intake and a upper limit of $\mathrm{BC}$. When questions are addressed regarding the effect of $\mathrm{BC}$ on lung tissue in humans, we are faced with (ethical) limitations since detrimental effects have been observed and lung tissue is difficult and too invasive to obtain. In vitro models are perfects tools to study molecular mechanisms in detail. We successfully used this approach in Chapter 2 and Chapter 3. In vitro studies however often fail when questions regarding the physiological response of a specific tissue to stimuli or compounds are tested in the context of the whole organism, taking absorption, distribution, metabolism and the effect on an organ due to interactions with other organs into account. We found that the response of lung tissue to oral 
$\mathrm{BC}$ administration was different for female and male, as has been discussed in Chapter 5 and Chapter 6, and that there is possibly even an interaction with other organs such as the steroid producing organs as has been described in Chapter $\mathbf{7}$ or with the immune system as has been described in Chapter $\mathbf{5}$.

As we discussed, there are still many gaps in the knowledge on the action of BC. Still many scientifically and socially relevant questions need to be addressed. We will discuss some of these questions below in combination with an suggested approach towards their answer.

\section{Are the effects found in Bcmo $1 \%$ mice induced by $B C$ or retinoic acid?}

In our study we used $\mathrm{Bcmo1 \%}$ mice, which were described previously [78]. Although Bcmo1 is the main BC metabolizing enzyme [79], we observed that in our studies $\mathrm{BC}$ was able to abolish a vitamin A deficient state. We assume that Bco2, implicated in BC metabolism [80] with a low affinity for BC, was involved in this conversion of $\mathrm{BC}$ to correct for retinoic acid needs (Chapter 5).

An appropriate animal model to investigate the effects of intact $\mathrm{BC}$ would therefore be a mouse model with a knockout for Bcmo1 and Bco2. When using this mouse model, WT controls have to be taken into account to correct for effects induced by possible alterations in downstream BC metabolism such as vitamin A deficiency, as we have observed for the female $\mathrm{Bcmo1}^{\%}$ mice in Chapter 5. An alternative to a $\mathrm{Bcmo1} / \mathrm{Bco} 2$ knockout mouse model might involve a bypass of the enterocytes. After absorption, most BC is cleaved in the enterocytes of mice and rats by Bcmo1 [81]. There are ways to bypass the most efficient cleavage sites, for example by injecting $\mathrm{BC}$ or by the use of implantable pumps, such as Alzet pumps. BC concentrations and accumulation have to be tested since these experiments have not been performed before, and other organs such as liver are known to metabolize $\mathrm{BC}$ in mice as well [9].

To investigate the effects induced by RA, wildtype mice are perfectly suitable. These mice can be supplemented with retinoic acid although these mice might induce RA hypercatabolism. To circumvent this, it might be better to supplement mice with retinoic acid metabolism blocking agents, which specifically block CYP26 and thereby preventing RA catabolism and increase RA concentrations [51].

When performing $\mathrm{BC}$ or retinoic acid research in these animal models, the diet of the F1 generation as well as the dams should be considered carefully. Most experimental (chow) diets contain high concentrations of vitamin A and BC. Dams are able to store these high concentrations of vitamin A, and will also deliver vitamin A to their offspring. Although generally vitamin A stores are low at birth in humans and rodents, because of a limited transplacental vitamin A transfer [82-84], lactating periods are crucial for the vitamin A stores in the neonates. As a consequence, the amount of vitamin A in the milk, which is dependent on maternal vitamin A stores and the amount of vitamin A present in maternal feed $[85,86]$, is an important determining factor in vitamin A stores 
of the offspring. The hepatic vitamin A stores at the start of the experiment will affect general $\mathrm{BC}$ and vitamin A physiology and thus can result in variations in the outcome of experiments investigating effects of $\mathrm{BC}$ or $\mathrm{BC}$ metabolites. For example Bcmol was shown to be not essential in the maintenance of vitamin A stores when $\mathrm{BC}$ is the main source of vitamin A [87]. However, in another study where dams were depleted of vitamin A, the enzyme played an important role and changed the conclusion of the role of Bcmo1 [10]. Our experiment carefully considered vitamin A concentration in diet fed to the dams. High hepatic vitamin A stores reduce dietary BC uptake and therefore the dams were fed a diet containing $1500 \mathrm{IU} / \mathrm{kg}$ feed which is considered a vitamin A sufficient diet [correspondence with Von Lintig/Wyss] in our study. The increased inflammation in female control diet fed $\mathrm{Bcmo1} \%$ mice however suggests that these mice were mildly vitamin A deficient, as discussed in Chapter 5.

\section{Are there differences between $a$ short and long BC intervention and can chronic $B C$ supplementation result in $B C$ or $R A$ resistance?}

The subjects in the ATBC and CARET study were supplemented with BC for medians of, respectively, 6.1 and 4 years with $20 \mathrm{mg}$ or $30 \mathrm{mg}$ of $\mathrm{BC}$, which resulted in an increased lung cancer risk in smokers and in asbestos exposed subjects [88-90]. To evaluate changes induced by $\mathrm{BC}$ supplementation, the effect of a short and chronic intervention has to be assessed. This might lead to insight about a possible BC or retinoic acid resistance.

\section{Is there a method to assay the bioactive potency induced by BC supplementa- tion?}

The bioactive potency of $\mathrm{BC}$ is mainly attributed to changes in RA as discussed in Chapter 1. Unfortunately we were not able to measure RA in the samples. At this moment it is also not completely known whether only RA has the ability to induce genetranscription. There might be a few ways to measure the bioactive potency in tissues or plasma after BC intervention.

A first method is the measurement of RA analytically, which unfortunately requires sophisticated equipment. This approach may not be sensitive enough and has the disadvantage that bioactivity is not simultaneously tested. This may be relevant since other $\mathrm{BC}$ metabolites may have a bioactive antagonistic or agonistic effect.

Another method is the use of reporter assays. A reporter gene assay contains recombinant DNA containing a responsive element in combination with a reporter gene, such as luciferase. The reporter gene expression is easily detectable and quantifies the potency of the "test" substance [91]. Such assays have been developed for retinoic acid isomers and their metabolite potency. In these assays cells were cotransfected with a reporter gene containing the RARE and with vectors expressing RARa, RAR $\beta$ or RARy [92]. Plasma or extractions of tissues can be tested on their ability to induce or inhibit RAR responsive transcription. Disadvantages of these assays include difficulties with the solu- 
bility or cellular uptake of the compounds of interest, or the components may be metabolized, resulting in a bias in the tested potency.

Another possibility is the (semi-) quantification of a biomarker. Biomarkers are any biological changes induced by alterations in BC or RA concentrations. In this case, a biomarker could be a gene which has a changed expression dependent on the concentration of $\mathrm{BC}$ or retinoic acid. A functional biomarker has often a high fold change in combination with a low p-value. As we demonstrated in Chapter 6, BC supplementation to male Bcmo 1\% mice resulted in a very significant down regulation of Fzd6 and Cthrc1, in combination with a high absolute fold change. These genes could thus be potential biomarkers for RA or BC status. A regulation of Fzd6 and Cthrc1 was only significantly observed in male $\mathrm{Bcmo1}^{\%}$ mice and not in $\mathrm{Bcmol}^{+/+}$mice or female mice. In Chapter 9, we observed that Fzd6 was down regulated in lung tissue, liver tissue and in iWAT, while Cthrc1 was only significantly down regulated in lung tissue. Although an effect of $\mathrm{BC}$ would be most logical, we think that retinoic acid levels in $\mathrm{Bcmo1}$ \% mice were less well controlled compared to $\mathrm{Bcmo1}^{+/+}$mice after $\mathrm{BC}$ supplementation, which probably corresponds with the human situation where $\mathrm{BC}$ supplementation results in increased RA plasma levels [45]. As can be seen in Fig. 10, Fzd6 expression was also altered in female $\mathrm{Bcmo1} \%$ mice, although just not significantly. Of course these data have to be interpreted very carefully, since this figure shows again opposite results in both genders, and thus this might be an effect of changes in hormone production. Further research would be needed to evaluate the exact role and response of Fzd6 in BC biology. to see whether it can be developed into a marker for RA or BC status.

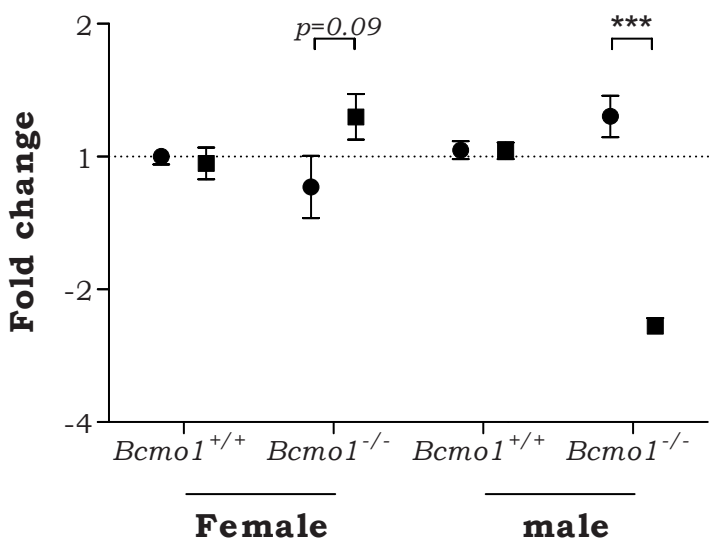

Figure 10: Fzd6 gene expression in mice fed the control diet (circles) or that were supplemented with

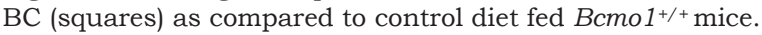




\section{Do mechanisms of $B C$ action in human lung tissue correspond to mechanisms investigated in lung tissue of animal models?}

The main difficulty when performing BC research in humans is the target tissue. It is virtually impossible to obtain lung tissue from volunteers since this is too invasive. When one is primarily interested in the immune response specifically in the lung, bronchioalveolar lavages can be obtained, although this is also considered as an invasive technique. When being interested in altered molecular mechanisms of $\mathrm{BC}$ action in the lung, the use of surrogate tissue is probably an unavoidable fact. The concept of a surrogate tissue is that the questions addressed for a "target" tissue is determined by analyzing an accessible or "surrogate" tissue [93]. An often used easily accessible "surrogate tissue" are the human peripheral blood mononuclear cells (PBMC). Although the use of for example PBMC's has been proven to be successful in profiling nutritional changes [94] and as a diagnostic marker for certain diseases [95,96], and for other mechanistic research [97], we did not isolate PBMCs for microarray analysis. Nevertheless, to get more insights in the tissue specificity of $\mathrm{BC}$ induced effects we compared the gene expression changes induced by BC in lung tissue with changes induced in liver and inguinal white adipose tissue. Interestingly, white adipose tissue can be used as an accessible tissue in human research $[98,99]$. As we showed in Chapter 8, only a minor number of genes $(\sim 1 \%)$ were similarly changed in all three tissues. However, on a pathway level as described in Chapter 9, all of the observed altered pathways by BC in lung tissue were also observed in white adipose tissue and almost all effects were also observed in liver tissue. This indicates that the use of surrogate tissue to investigate altered mechanisms on a transcriptional level after BC supplementation may be possible. Nevertheless, the research has to be conducted in preferably at least two surrogate tissues, to dissect surrogate tissue specific effects from the more systemic effects and has to be validated in, for example, animal models. Moreover, effects have to be carefully interpreted and validated.

\section{Are polymorphisms important in $B C$ metabolism altering relative risks for lung cancer incidence?}

As stated in Chapter 1, individuals have been classified as "low responders" and as "low converters", resulting in high inter-individual variations in $\mathrm{BC}$ or $\mathrm{BC}$ metabolite concentrations. polymorphisms in several genes have been demonstrated to be related to these phenotypes [100]. When material of the CARET or ATBC studies would be available, epidemiological analysis of lung cancer incidence in relation to the absence or presence of polymorphisms in the Bcmo1 gene would be relevant to study and might give answers to the questions regarding inter-individual differences in effects of BC.

Does smoking/inflammation in combination with $B C$ supplementation result in increased genotoxicity and are there differences in BC metabolism compared to BC supplementation to non-smokers?

We showed in Chapter 3, that the detrimental effects of BC might be observed in smokers and asbestos exposed subjects due to an increase in inflammation induced genotox- 
icity. We also showed in Chapter 2 that the effect in vivo might be different from the effect in vitro, and therefore it would be of importance to test whether BC increases neutrophil induced genotoxicity in vivo. To test this, lungs of animals can be exposed to lipopolysacchariden (LPS), which is a potent endotoxin recruiting circulating PMN to the lungs [101]. The effect of $\mathrm{BC}$ on for example 8-oxo-dG and $\mathrm{M}_{1} \mathrm{dG}$ can be tested. In this case ferrets might be an appropriate animal model, since BC metabolism is similar to the human situation, lung is physiologically comparable with respect to inflammation and, as we showed in Chapter 2, genotoxicity markers are measurable in ferrets.

Altogether, we identified many possible processes that are affected by BC. There is also still much research necessary to complete gaps in the knowledge of $\mathrm{BC}$ action, and also many new questions have risen, such as: Does BC or RA change hormone synthesis and is Fzd6 involved in carcinogenic processes? Altogether this thesis contributes to our understanding of the mechanisms of action of BC knowledge and is an important lead for future BC research.

\section{References}

[1] P. Palozza Prooxidant actions of carotenoids in biologic systems, Nutr Rev 56 (1998) 257-265.

[2] P. Palozza, S. Serini, F. Di Nicuolo, E. Piccioni and G. Calviello Prooxidant effects of beta-carotene in cultured cells, Mol Aspects Med 24 (2003) 353-362.

[3] J.S. Brody and A. Spira State of the art. Chronic obstructive pulmonary disease, inflammation, and lung cancer, Proc Am Thorac Soc 3 (2006) 535-537.

[4] G. Lee, T.C. Walser and S.M. Dubinett Chronic inflammation, chronic obstructive pulmonary disease, and lung cancer, Curr Opin Pulm Med 15 (2009) 303-307.

[5] R. Robledo and B. Mossman Cellular and molecular mechanisms of asbestos-induced fibrosis, J Cell Physiol 180 (1999) 158-166.

[6] A.G. Schwartz, G.M. Prysak, C.H. Bock and M.L. Cote The molecular epidemiology of lung cancer, Carcinogenesis 28 (2007) 507-518.

[7] C.M. Doerschuk Leukocyte trafficking in alveoli and airway passages, Respir Res 1 (2000) 136-140.

[8] N. Gungor, R.W. Godschalk, D.M. Pachen, F.J. Van Schooten and A.M. Knaapen Activated neutrophils inhibit nucleotide excision repair in human pulmonary epithelial cells: role of myeloperoxidase, Faseb $\mathrm{J}$ 21 (2007) 2359-2367.

[9] A. Wyss Carotene oxygenases: a new family of double bond cleavage enzymes, J Nutr 134 (2004) 246S$250 \mathrm{~S}$.

[10] S. Hessel, A. Eichinger, A. Isken, J. Amengual, S. Hunzelmann, U. Hoeller, V. Elste, W. Hunziker, R. Goralczyk, V. Oberhauser, J. von Lintig and A. Wyss CMO1 deficiency abolishes vitamin A production from beta-carotene and alters lipid metabolism in mice, J Biol Chem 282 (2007) 33553-33561. 
[11] B.I. Gustafsson, M. Kidd, A. Chan, M.V. Malfertheiner and I.M. Modlin Bronchopulmonary neuroendocrine tumors, Cancer 113 (2008) 5-21.

[12] W.D. Travis, L.B. Travis and S.S. Devesa Lung cancer, Cancer 75 (1995) 191-202.

[13] L.A. Kaplan, J.M. Lau and E.A. Stein Carotenoid composition, concentrations, and relationships in various human organs, Clin Physiol Biochem 8 (1990) 1-10.

[14] R.S. Parker Carotenoids in human blood and tissues, J Nutr 119 (1989) 101-104.

[15] R.E. Pattle and L.C. Thomas Lipoprotein composition of the film lining the lung, Nature 189 (1961) 844.

[16] E.L. Jackson, N. Willis, K. Mercer, R.T. Bronson, D. Crowley, R. Montoya, T. Jacks and D.A. Tuveson Analysis of lung tumor initiation and progression using conditional expression of oncogenic K-ras, Genes Dev 15 (2001) 3243-3248.

[17] H. Kitamura, Y. Kameda, T. Ito, H. Hayashi, N. Nakamura, Y. Nakatani, Y. Inayama and M. Kanisawa Cytodifferentiation of atypical adenomatous hyperplasia and bronchioloalveolar lung carcinoma: immunohistochemical and ultrastructural studies, Virchows Arch 431 (1997) 415-424.

[18] W.R. Otto Lung epithelial stem cells, J Pathol 197 (2002) 527-535.

[19] J.E. Muscat and E.L. Wynder Lung cancer pathology in smokers, ex-smokers and never smokers, Cancer Lett 88 (1995) 1-5.

[20] J.E. Tyczynski, F. Bray and D.M. Parkin Lung cancer in Europe in 2000: epidemiology, prevention, and early detection, Lancet Oncol 4 (2003) 45-55.

[21] C.M. Lee, A.C. Boileau, T.W. Boileau, A.W. Williams, K.S. Swanson, K.A. Heintz and J.W. Erdman, Jr. Review of animal models in carotenoid research, J Nutr 129 (1999) 2271-2277.

[22] R. Bodewes, G.F. Rimmelzwaan and A.D. Osterhaus Animal models for the preclinical evaluation of candidate influenza vaccines, Expert Rev Vaccines 9 59-72.

[23] C.M. Cameron, M.J. Cameron, J.F. Bermejo-Martin, L. Ran, L. Xu, P.V. Turner, R. Ran, A. Danesh, Y. Fang, P.K. Chan, N. Mytle, T.J. Sullivan, T.L. Collins, M.G. Johnson, J.C. Medina, T. Rowe and D.J. Kelvin Gene expression analysis of host innate immune responses during Lethal H5N1 infection in ferrets, $J$ Virol 82 (2008) 11308-11317.

[24] H. Greim, U. Andrae, U. Forster and L. Schwarz Application, limitations and research requirements of in vitro test systems in toxicology, Arch Toxicol Suppl 9 (1986) 225-236.

[25] S.B. Kritchevsky, A.J. Bush, M. Pahor and M.D. Gross Serum carotenoids and markers of inflammation in nonsmokers, Am J Epidemiol 152 (2000) 1065-1071.

[26] T.P. Erlinger, E. Guallar, E.R. Miller, 3rd, R. Stolzenberg-Solomon and L.J. Appel Relationship between systemic markers of inflammation and serum beta-carotene levels, Arch Intern Med 161 (2001) 19031908.

[27] V.L. Van Antwerpen, A.J. Theron, G.A. Richards, C.A. Van der Merwe, E. Viljoen, R. Van der Walt and R. Anderson Plasma levels of beta-carotene are inversely correlated with circulating neutrophil counts in young male cigarette smokers, Inflammation 19 (1995) 405-414.

[28] W.G. Siems, O. Sommerburg and F.J. van Kuijk Lycopene and beta-carotene decompose more rapidly than lutein and zeaxanthin upon exposure to various pro-oxidants in vitro, Biofactors 10 (1999) 105-113.

[29] O. Sommerburg, C.D. Langhans, J. Arnhold, M. Leichsenring, C. Salerno, C. Crifo, G.F. Hoffmann, K.M. Debatin and W.G. Siems Beta-carotene cleavage products after oxidation mediated by hypochlorous acid-a model for neutrophil-derived degradation, Free Radic Biol Med 35 (2003) 1480-1490.

[30] T. Quasim, D.C. McMillan, D. Talwar, N. Sattar, D.S. O'Reilly and J. Kinsella Lower concentrations of carotenoids in the critically ill patient are related to a systemic inflammatory response and increased lipid peroxidation, Clin Nutr 22 (2003) 459-462.

[31] P.P. Glasziou and D.E. Mackerras Vitamin A supplementation in infectious diseases: a meta-analysis, Bmj 306 (1993) 366-370.

[32] A. Sommer Vitamin a deficiency and clinical disease: an historical overview, J Nutr 138 (2008) 18351839.

[33] R.C. Baybutt, L. Hu and A. Molteni Vitamin A deficiency injures lung and liver parenchyma and impairs function of rat type II pneumocytes, J Nutr 130 (2000) 1159-1165.

[34] T. Li, A. Molteni, P. Latkovich, W. Castellani and R.C. Baybutt Vitamin A depletion induced by cigarette smoke is associated with the development of emphysema in rats, J Nutr 133 (2003) 2629-2634.

[35] R.C. Baybutt and A. Molteni Vitamin A and emphysema, Vitam Horm 75 (2007) 385-401.

[36] J. Bastien and C. Rochette-Egly Nuclear retinoid receptors and the transcription of retinoid-target genes, Gene 328 (2004) 1-16.

[37] B. Desvergne RXR: from partnership to leadership in metabolic regulations, Vitam Horm 75 (2007) 1-32. 
[38] L.E. Purton, S. Dworkin, G.H. Olsen, C.R. Walkley, S.A. Fabb, S.J. Collins and P. Chambon RARgamma is critical for maintaining a balance between hematopoietic stem cell self-renewal and differentiation, $\mathrm{J}$ Exp Med 203 (2006) 1283-1293.

[39] A.M. Jetten Retinoid-related orphan receptors (RORs): critical roles in development, immunity, circadian rhythm, and cellular metabolism, Nucl Recept Signal 7 (2009) e003.

[40] W.H. Miller, Jr. The emerging role of retinoids and retinoic acid metabolism blocking agents in the treatment of cancer, Cancer 83 (1998) 1471-1482.

[41] R.S. Larson and M.S. Tallman Retinoic acid syndrome: manifestations, pathogenesis, and treatment, Best Pract Res Clin Haematol 16 (2003) 453-461.

[42] E. Patatanian and D.F. Thompson Retinoic acid syndrome: a review, J Clin Pharm Ther 33 (2008) 331338.

[43] M.S. Tallman, J.W. Andersen, C.A. Schiffer, F.R. Appelbaum, J.H. Feusner, A. Ogden, L. Shepherd, J.M. Rowe, C. Francois, R.S. Larson and P.H. Wiernik Clinical description of 44 patients with acute promyelocytic leukemia who developed the retinoic acid syndrome, Blood 95 (2000) 90-95.

[44] O. Loudig, C. Babichuk, J. White, S. Abu-Abed, C. Mueller and M. Petkovich Cytochrome P450RAI(CYP26) promoter: a distinct composite retinoic acid response element underlies the complex regulation of retinoic acid metabolism, Mol Endocrinol 14 (2000) 1483-1497.

[45] R. Ruhl, A. Bub and B. Watzl Modulation of plasma all-trans retinoic acid concentrations by the consumption of carotenoid-rich vegetables, Nutrition 24 (2008) 1224-1226.

[46] V.C. Njar, L. Gediya, P. Purushottamachar, P. Chopra, T.S. Vasaitis, A. Khandelwal, J. Mehta, C. Huynh, A. Belosay and J. Patel Retinoic acid metabolism blocking agents (RAMBAs) for treatment of cancer and dermatological diseases, Bioorg Med Chem 14 (2006) 4323-4340.

[47] J. Muindi, S.R. Frankel, W.H. Miller, Jr., A. Jakubowski, D.A. Scheinberg, C.W. Young, E. Dmitrovsky and R.P. Warrell, Jr. Continuous treatment with all-trans retinoic acid causes a progressive reduction in plasma drug concentrations: implications for relapse and retinoid "resistance" in patients with acute promyelocytic leukemia, Blood 79 (1992) 299-303.

[48] J.R. Muindi, C.W. Young and R.P. Warrell, Jr. Clinical pharmacology of all-trans retinoic acid, Leukemia 8 Suppl 3 (1994) S16-21.

[49] Y.M. Peng, W.S. Dalton, D.S. Alberts, M.J. Xu, H. Lim and F.L. Meyskens, Jr. Pharmacokinetics of N-4hydroxyphenyl-retinamide and the effect of its oral administration on plasma retinol concentrations in cancer patients, Int J Cancer 43 (1989) 22-26.

[50] C. Liu, R.M. Russell and X.D. Wang Alpha-tocopherol and ascorbic acid decrease the production of betaapo-carotenals and increase the formation of retinoids from beta-carotene in the lung tissues of cigarette smoke-exposed ferrets in vitro, J Nutr 134 (2004) 426-430.

[51] C. Liu, R.M. Russell and X.D. Wang Exposing ferrets to cigarette smoke and a pharmacological dose of beta-carotene supplementation enhance in vitro retinoic acid catabolism in lungs via induction of cytochrome P450 enzymes, J Nutr 133 (2003) 173-179.

[52] Z.N. Yang, G.J. Davis, T.D. Hurley, C.L. Stone, T.K. Li and W.F. Bosron Catalytic efficiency of human alcohol dehydrogenases for retinol oxidation and retinal reduction, Alcohol Clin Exp Res 18 (1994) 587591 .

[53] B.J. Carolan, A. Heguy, B.G. Harvey, P.L. Leopold, B. Ferris and R.G. Crystal Up-regulation of expression of the ubiquitin carboxyl-terminal hydrolase L1 gene in human airway epithelium of cigarette smokers, Cancer Res 66 (2006) 10729-10740.

[54] A.E. Tilley, B.G. Harvey, A. Heguy, N.R. Hackett, R. Wang, T.P. O'Connor and R.G. Crystal Downregulation of the notch pathway in human airway epithelium in association with smoking and chronic obstructive pulmonary disease, Am J Respir Crit Care Med 179 (2009) 457-466.

[55] B.G. Harvey, A. Heguy, P.L. Leopold, B.J. Carolan, B. Ferris and R.G. Crystal Modification of gene expression of the small airway epithelium in response to cigarette smoking, J Mol Med 85 (2007) 39-53.

[56] A. Spira, J. Beane, V. Shah, G. Liu, F. Schembri, X. Yang, J. Palma and J.S. Brody Effects of cigarette smoke on the human airway epithelial cell transcriptome, Proc Natl Acad Sci U S A 101 (2004) 1014310148.

[57] W. Jelski, M. Kozlowski, J. Laudanski, J. Niklinski and M. Szmitkowski Alcohol dehydrogenase isoenzymes and aldehyde dehydrogenase activity in the sera of patients with esophageal cancer, Clin Exp Med 9 (2009) 131-137.

[58] W. Jelski, L. Chrostek, B. Zalewski and M. Szmitkowski Alcohol dehydrogenase (ADH) isoenzymes and aldehyde dehydrogenase (ALDH) activity in the sera of patients with gastric cancer, Dig Dis Sci 53 (2008) 2101-2105.

[59] A.M. Gawienowski Integration of the metabolic pathways of steroids, carotenoids, and retinoids, Crit Rev Biochem Mol Biol 34 (1999) 405-410. 
[60] V. Luu-The, P. Tremblay and F. Labrie Characterization of type 12 17beta-hydroxysteroid dehydrogenase, an isoform of type 3 17beta-hydroxysteroid dehydrogenase responsible for estradiol formation in women, Mol Endocrinol 20 (2006) 437-443.

[61] A. Lindqvist, Y.G. He and S. Andersson Cell type-specific expression of beta-carotene 9',10'monooxygenase in human tissues, J Histochem Cytochem 53 (2005) 1403-1412.

[62] A. Tchernof and J.P. Despres Sex steroid hormones, sex hormone-binding globulin, and obesity in men and women, Horm Metab Res 32 (2000) 526-536.

[63] J.S. Mayes and G.H. Watson Direct effects of sex steroid hormones on adipose tissues and obesity, Obes Rev 5 (2004) 197-216.

[64] G. Boysen and S.S. Hecht Analysis of DNA and protein adducts of benzo[a]pyrene in human tissues using structure-specific methods, Mutat Res 543 (2003) 17-30.

[65] J.J. Briede, R.W. Godschalk, M.T. Emans, T.M. De Kok, E. Van Agen, J. Van Maanen, F.J. Van Schooten and J.C. Kleinjans In vitro and in vivo studies on oxygen free radical and DNA adduct formation in rat lung and liver during benzo[a]pyrene metabolism, Free Radic Res 38 (2004) 995-1002.

[66] A.B. Thompson, T. Bohling, A. Heires, J. Linder and S.I. Rennard Lower respiratory tract iron burden is increased in association with cigarette smoking, J Lab Clin Med 117 (1991) 493-499.

[67] A.J. Ghio, J. Stonehuerner, M.P. Steele and A.L. Crumbliss Phagocyte-generated superoxide reduces $\mathrm{Fe} 3+$ to displace it from the surface of asbestos, Arch Biochem Biophys 315 (1994) 219-225.

[68] A.D. McDonald, J.C. McDonald and F.D. Pooley Mineral fibre content of lung in mesothelial tumours in North America, Ann Occup Hyg 26 (1982) 417-422.

[69] A.J. Ghio, A. Churg and V.L. Roggli Ferruginous bodies: implications in the mechanism of fiber and particle toxicity, Toxicol Pathol 32 (2004) 643-649.

[70] E.A. Leibold and H.N. Munro Cytoplasmic protein binds in vitro to a highly conserved sequence in the 5' untranslated region of ferritin heavy- and light-subunit mRNAs, Proc Natl Acad Sci U S A 85 (1988) 21712175.

[71] A. Dautry-Varsat, A. Ciechanover and H.F. Lodish pH and the recycling of transferrin during receptormediated endocytosis, Proc Natl Acad Sci U S A 80 (1983) 2258-2262.

[72] M.N. Garcia-Casal, M. Layrisse, L. Solano, M.A. Baron, F. Arguello, D. Llovera, J. Ramirez, I. Leets and E. Tropper Vitamin A and beta-carotene can improve nonheme iron absorption from rice, wheat and corn by humans, J Nutr 128 (1998) 646-650.

[73] M.N. Garcia-Casal, I. Leets and M. Layrisse Beta-carotene and inhibitors of iron absorption modify iron uptake by Caco-2 cells, J Nutr 130 (2000) 5-9.

[74] A.J. Roodenburg, C.E. West, R. Hovenier and A.C. Beynen Evaluation of a two-generation rat model for vitamin A deficiency and the interrelationship with iron metabolism, Br J Nutr 74 (1995) 689-700.

[75] A.J. Roodenburg, C.E. West, R. Hovenier and A.C. Beynen Supplemental vitamin A enhances the recovery from iron deficiency in rats with chronic vitamin A deficiency, Br J Nutr 75 (1996) 623-636.

[76] M. Broch, J. Vendrell, W. Ricart, C. Richart and J.M. Fernandez-Real Circulating retinol-binding protein4, insulin sensitivity, insulin secretion, and insulin disposition index in obese and nonobese subjects, Diabetes Care 30 (2007) 1802-1806.

[77] J.M. Fernandez-Real, J.M. Moreno and W. Ricart Circulating retinol-binding protein-4 concentration might reflect insulin resistance-associated iron overload, Diabetes 57 (2008) 1918-1925.

[78] W.C. Leung, S. Hessel, C. Meplan, J. Flint, V. Oberhauser, F. Tourniaire, J.E. Hesketh, J. von Lintig and G. Lietz Two common single nucleotide polymorphisms in the gene encoding beta-carotene 15, 15'monoxygenase alter beta-carotene metabolism in female volunteers, Faseb J 23 (2009) 1041-1053.

[79] C. Kiefer, S. Hessel, J.M. Lampert, K. Vogt, M.O. Lederer, D.E. Breithaupt and J. von Lintig Identification and characterization of a mammalian enzyme catalyzing the asymmetric oxidative cleavage of provitamin A, J Biol Chem 276 (2001) 14110-14116.

[80] K.Q. Hu, C. Liu, H. Ernst, N.I. Krinsky, R.M. Russell and X.D. Wang The biochemical characterization of ferret carotene-9',10'-monooxygenase catalyzing cleavage of carotenoids in vitro and in vivo, J Biol Chem 281 (2006) 19327-19338.

[81] R.S. Parker Absorption, metabolism, and transport of carotenoids, Faseb J 10 (1996) 542-551.

[82] C. Debier and Y. Larondelle Vitamins A and E: metabolism, roles and transfer to offspring, Br J Nutr 93 (2005) 153-174.

[83] J.A. Olson, D.B. Gunning and R.A. Tilton Liver concentrations of vitamin A and carotenoids, as a function of age and other parameters, of American children who died of various causes, Am J Clin Nutr 39 (1984) 903-910.

[84] J.E. Smith Preparation of vitamin A-deficient rats and mice, Methods Enzymol 190 (1990) 229-236. 


\section{Chapter 10}

[85] S.A. Akohoue, J.B. Green and M.H. Green Dietary vitamin A has both chronic and acute effects on vitamin A indices in lactating rats and their offspring, J Nutr 136 (2006) 128-132.

[86] M.H. Green, J.B. Green, S.A. Akohoue and S.K. Kelley Vitamin A intake affects the contribution of chylomicrons vs. retinol-binding protein to milk vitamin A in lactating rats, J Nutr 131 (2001) 1279-1282.

[87] Y. Fierce, M. de Morais Vieira, R. Piantedosi, A. Wyss, W.S. Blaner and J. Paik In vitro and in vivo characterization of retinoid synthesis from beta-carotene, Arch Biochem Biophys 472 (2008) 126-138.

[88] D. Albanes, O.P. Heinonen, P.R. Taylor, J. Virtamo, B.K. Edwards, M. Rautalahti, A.M. Hartman, J. Palmgren, L.S. Freedman, J. Haapakoski, M.J. Barrett, P. Pietinen, N. Malila, E. Tala, K. Liippo, E.R. Salomaa, J.A. Tangrea, L. Teppo, F.B. Askin, E. Taskinen, Y. Erozan, P. Greenwald and J.K. Huttunen Alpha-Tocopherol and beta-carotene supplements and lung cancer incidence in the alpha-tocopherol, betacarotene cancer prevention study: effects of base-line characteristics and study compliance, J Natl Cancer Inst 88 (1996) 1560-1570.

[89] G.S. Omenn, G.E. Goodman, M.D. Thornquist, J. Balmes, M.R. Cullen, A. Glass, J.P. Keogh, F.L. Meyskens, Jr., B. Valanis, J.H. Williams, Jr., S. Barnhart, M.G. Cherniack, C.A. Brodkin and S. Hammar Risk factors for lung cancer and for intervention effects in CARET, the Beta-Carotene and Retinol Efficacy Trial, J Natl Cancer Inst 88 (1996) 1550-1559.

[90] G.S. Omenn, G.E. Goodman, M.D. Thornquist, J. Balmes, M.R. Cullen, A. Glass, J.P. Keogh, F.L. Meyskens, B. Valanis, J.H. Williams, S. Barnhart and S. Hammar Effects of a combination of beta carotene and vitamin A on lung cancer and cardiovascular disease, N Engl J Med 334 (1996) 1150-1155.

[91] A. Meager Biological assays for interferons, J Immunol Methods 261 (2002) 21-36.

[92] N. Idres, J. Marill, M.A. Flexor and G.G. Chabot Activation of retinoic acid receptor-dependent transcription by all-trans-retinoic acid metabolites and isomers, J Biol Chem 277 (2002) 31491-31498.

[93] J.C. Rockett, M.E. Burczynski, A.J. Fornace, P.C. Herrmann, S.A. Krawetz and D.J. Dix Surrogate tissue analysis: monitoring toxicant exposure and health status of inaccessible tissues through the analysis of accessible tissues and cells, Toxicol Appl Pharmacol 194 (2004) 189-199.

[94] M. Bouwens, O. van de Rest, N. Dellschaft, M.G. Bromhaar, L.C. de Groot, J.M. Geleijnse, M. Muller and L.A. Afman Fish-oil supplementation induces antiinflammatory gene expression profiles in human blood mononuclear cells, Am J Clin Nutr 90 (2009) 415-424.

[95] J. Hong, Y.C. Zang, G. Hutton, V.M. Rivera and J.Z. Zhang Gene expression profiling of relevant biomarkers for treatment evaluation in multiple sclerosis, J Neuroimmunol 152 (2004) 126-139.

[96] P.J. Valk, R.G. Verhaak, M.A. Beijen, C.A. Erpelinck, S. Barjesteh van Waalwijk van Doorn-Khosrovani, J.M. Boer, H.B. Beverloo, M.J. Moorhouse, P.J. van der Spek, B. Lowenberg and R. Delwel Prognostically useful gene expression profiles in acute myeloid leukemia, N Engl J Med 350 (2004) 1617-1628.

[97] A. Caimari, P. Oliver, J. Keijer and A. Palou Peripheral Blood Mononuclear Cells as a Model to Study the Response of Energy Homeostasis-Related Genes to Acute Changes in Feeding Conditions, Omics.

[98] E.A. van Beek, A.H. Bakker, P.M. Kruyt, M.H. Hofker, W.H. Saris and J. Keijer Intra- and interindividual variation in gene expression in human adipose tissue, Pflugers Arch 453 (2007) 851-861.

[99] E.A. van Beek, A.H. Bakker, P.M. Kruyt, C. Vink, W.H. Saris, N.L. Franssen-van Hal and J. Keijer Comparative expression analysis of isolated human adipocytes and the human adipose cell lines LiSa-2 and PAZ6, Int J Obes (Lond) 32 (2008) 912-921.

[100] F. Tourniaire, E. Gouranton, J. von Lintig, J. Keijer, M. Luisa Bonet, J. Amengual, G. Lietz and J.F. Landrier beta-Carotene conversion products and their effects on adipose tissue, Genes Nutr 4 (2009) 179187.

[101] T.R. Martin Recognition of bacterial endotoxin in the lungs, Am J Respir Cell Mol Biol 23 (2000) 128-132. 


\section{Samenvatting}

\section{Proefschrift: Moleculaire Werkingsmechanimsen van Bètacaroteen in de Long}

In het verleden is gebleken dat hoge inname van bètacaroteen $(\mathrm{BC})$ het risico op het krijgen van longkanker in rokers en asbest blootgestelde mensen kan verhogen. Zowel roken als asbestblootstelling zijn geassocieerd met een ontsteking in de long, en een langdurige ontsteking lijkt een belangrijke rol te spelen in het ontstaan en uitgroeien van longkanker. Een chronische ontsteking in de longen wordt gekarakteriseerd door een toename van een aantal witte bloedcellen (onder andere neutrofielen), welke reactieve zuurstof radicalen kunnen vormen die de cel beschadigen. Omdat wetenschappelijke studies laten zien dat BC zowel zuurstofschade kan verminderen (antioxidant) als verergeren (pro-oxidant) [1,2], hadden wij ons in het eerste gedeelte van dit proefschrift als doel gesteld om te onderzoeken onder welke omstandigheden $\mathrm{BC}$ als een antioxidant of een pro-oxidant fungeerd. Vervolgens onderzochten wij het effect van BC op de door radicalen geïnduceerde DNA schade.

In Hoofdstuk 2 laten we zien dat de aard van het weg te vangen radicaal bepaald of $\mathrm{BC}$ een pro- of een antioxidant is; we zagen een beschermende werking van $\mathrm{BC}$ tegen koolstof gecentreerde radicalen, terwijl $\mathrm{BC}$ de hydroxyl radicaal geïnduceerde schade in cellen verhoogde. In lijn met deze bevindingen zorgde $\mathrm{BC}$ in fretten voor een verlaging van DNA schade veroorzaakt door het lipideperoxidatie product malondialdehyde (MDA), ook bekend als $\mathrm{M}_{1} \mathrm{dG}$. De oxidatieve DNA laesie 8-oxo-dG, welke direct resulteert uit DNA oxidatie, was echter onveranderd in fretten na toevoeging van $\mathrm{BC}$ aan het dieet, waarschijnlijk omdat BC gelijktijdig de DNA herstel capaciteit verhoogde.

Vervolgens testten we het effect van BC op neutrofiel geïnduceerde DNA schade. Geactiveerde neutrofielen genereren grote hoeveelheden reactieve zuurstof radicalen (reactive oxygen species; ROS) [3-6], welke oxidatieve DNA schade kunnen veroorzaken [7]. Bovendien verlagen geactiveerde neutrofielen de cellulaire DNA herstel capaciteit [8]. In Hoofdstuk 3 wordt beschreven dat de BC metabolieten; vitamine A zuur (retinoic acid) en retinal, neutrofiel geïnduceerd oxidatieve DNA laesies verhoogden. Dit was het resultaat van een verlaging van de activiteit van MPO, een enzym betrokken bij de omzetting van neutrofiel gegenereerd waterstofperoxide, in combinatie met een versterkte omzetting van waterstof peroxide resulterend in de toename van hydroxyl radicalen, door BC. Dit mechanisme leidde uiteindelijk tot een toename van de oxidatieve DNA schade in neutrofiel blootgestelde long epitheel cellen door retinoic acid en retinal. Dit wekt de suggestie dat negatieve effecten ten gevolge van BC inname kunnen worden verwacht tijdens een chronische ontsteking.

$\mathrm{BC}$ of een van zijn metabolieten kan dus de genotoxiciteit van rook of asbest veranderen. Behalve dit effect zou BC mogelijk ook de mate waarin een gen wordt afgeschreven (genexpressie) wat belangrijk is voor de regulatie van een cel, kunnen veranderen. Hier- 
door kan de vatbaarheid voor rook of asbest geïnduceerde carcinogenese verder worden beïnvloed. Genexpressie veranderingen die geïnduceerd worden door BC inname in de mens zijn moeilijk te bepalen omdat aan mensen op ethische gronden geen hoge dosis $\mathrm{BC}$ meer kan worden gegeven door de resultaten van interventie studies in rokers en asbest blootgestelde mensen. Bovendien is long weefsel nauwelijks toegankelijk in mensen. De vaak gebruikte in vivo modellen, zoals ratten en muizen, verschillen echter te sterk in hun $\mathrm{BC}$ metabolisme van de mens; knaagdieren zetten $\mathrm{BC}$ bijna geheel om, terwijl de mens BC slechts deels metaboliseerd. Als gevolg hiervan resulteert BC in het dieet bij knaagdieren in de accumulatie van $\mathrm{BC}$ metabolieten, terwijl dit bij mensen resulteert in de accumulatie van intact BC [9]. Hoewel andere diermodellen zoals de fret, de woestijnrat en kalveren, meer gelijkenis vertonen met het humane $\mathrm{BC}$ metabolisme en ook vaak gebruikt zijn voor onderzoek naar de effecten van $\mathrm{BC}$, hebben deze modellen grote nadelen. Voor wat betreft de fret of de woestijnrat als model voor de mens, is er weinig genetische kennis en zijn er nauwelijks commercieel verkrijgbare gereedschappen voor moleculair onderzoek. Gebruik van deze modellen voor BC onderzoek zou resulteren in pionierend onderzoek dat voornamelijk gericht is op het ontwikkelen van methoden, in plaats van onderzoek dat gericht is op het oplossen van mechanistische vragen. Er is meer kennis over kalveren, maar dit onderzoek is doorgaans duur en er is speciale huisvesting nodig. In ons onderzoek hebben we daarom gebruik gemaakt van een "gehumaniseerd" muizen model, welke beschreven wordt in het tweede gedeelte van dit proefschrift. In dit muizen model is geen functioneel beta-carotene 15,15'monooxygenase 1 (Bcmo1), omdat dit gen uitgeschakeld is (een zogenaamd knock-out model) [10]. Als gevolg hiervan kunnen deze muizen geen BC metaboliseren en zijn ze dus evenals mensen in staat om intact BC te accumuleren. In het tweede gedeelte van dit proefschrift hebben we door BC geïnduceerde veranderingen in gen expressie onderzocht in dit "gehumaniseerde" muizen model. Met dit onderzoek kunnen we meer inzicht in de functionele effecten van BC in de long krijgen. In Hoofdstuk 4 bediscussiëren we eerst de "in house" kennis op het gebied van functionele genomica in voeding interventie studies.

Voor de bepaling van gen expressie veranderingen in vivo veroorzaakt door BC hebben we een muizen experiment uitgevoerd waarbij mannetjes en vrouwtjes wildtype $(B c-$ $\mathrm{mol}^{+/+}$) en $\mathrm{Bcmo} 1$ knock-out muizen ( $\left.\mathrm{Ccmo1}^{-/}\right)$een dieet kregen dat 1500 IU vitamine A al dan niet met $150 \mathrm{mg} / \mathrm{kg} \mathrm{BC}$.

In Hoofdstuk 5 beschrijven we het effect van $\mathrm{BC}$ op genexpressie veranderingen in long weefsel van vrouwelijke $\mathrm{Bcmo1}^{\%}$ muizen. In eerste instantie vonden we een statistisch betrouwbare (significante) afname in de expressie van genen betrokken bij ontstekingsreacties in $\mathrm{Bcmo1 \%}$ muizen door BC. Echter, na vergelijking van deze genexpressie met de genexpressie in $\mathrm{Bcmo1}^{+/+}$muizen, bleek dat de afname in de ontstekingsresponse eigenlijk een inductie van de ontstekingsresponse in de longen van controle $\mathrm{Bcmo1}$ muizen. Deze inductie verdween wanneer er BC in het dieet aanwezig was. Histologie van de longen bevestigde de genexpressie resultaten, waarbij alleen ontstekingshaarden werden waargenomen bij controle Bcmo $1 \%$ muizen. We konden deze bevindingen verklaren door aan te nemen dat vrouwelijke $\mathrm{Bcmo} 1 \%$ muizen een grotere vitamine A behoefte hebben, mede doordat enzymen betrokken bij het BC metabolisme in expressie waren 
veranderd. Dit resulteerde in een genexpressie die veranderd was in de richting van vitamine A opslag in plaats van de aanmaak van de bioactieve metaboliet retinoic acid. Dit is in overeenstemming met de wetenschappelijke literatuur, waarin het bekend is dat een deficiëntie in retinoic acid resulteert in ontstekingen.

In Hoofdstuk 6 hebben we ons gericht op BC geïnduceerde genexpressie veranderingen in long weefsel van mannelijke $\mathrm{Bcmo} 1 \%$ muizen. De toename van de ontstekingsrespons in longweefsel van controle $\mathrm{Bcmo1 \%}$ muizen bleek specifiek voor vrouwelijke $\mathrm{Bcmo1}$ muizen en werd niet waargenomen in mannelijke muizen. Echter, BC suppletie aan mannelijke $\mathrm{Bcmo} 1 \%$ muizen resulteerde in een sterk lagere expressie van frizzled homo$\log 6$ (Fzd6) ( $\mathrm{min} 2.6 \mathrm{keer}$ ) en collagen triple helix repeat containing 1 (Cthrc1) (min 3 keer). Tegelijk hadden verschillende 'olfactory' receptoren (geurreceptoren) en protocadherines een hogere genexpressie. Wij hypothetiseren dat deze BC effecten specifiek plaats vinden in cellen die betrokken zijn bij de detectie van veranderingen in de lucht samenstelling in de long. 'Pulmonary endocrine cells' (PNECs) zijn specifiek betrokken bij de detectie van luchtsamenstelling en het is dus goed mogelijk dat dit specifieke celtype door BC beïnvloed wordt. Ondanks dat slechts 1 op de 2500 long cellen een PNEC cel is [11], ontstaat $20 \%$ van alle long kanker types uit PNEC en verhoogd in het bijzonder roken long kanker die is ontstaan uit PNEC cellen [12]. Het is belangrijk om deze bevindingen verder te onderzoeken en specifiek de rol van Fzd6 en Cthrc1 in PNECs en in relatie tot longkanker.

BC leidde in zowel mannelijke als vrouwelijke rokers en asbest blootgestelde mensen in de CARET studie tot een verhoging van het longkanker risico. Daarom onderzochten we de gezamenlijke processen die veranderd waren in long weefsel van zowel mannelijke als vrouwelijke $\mathrm{Bcmo1 \%}$ muizen door BC in Hoofdstuk 7. De genen die zowel in vrouwelijke als mannelijke muizen door BC veranderd tot expressie kwamen waren tegengesteld veranderd in $\mathrm{Bcmo1} \%$ muizen (significante toename in het ene geslacht ging gepaard met een afname in het andere en vice versa). Dit suggereert een rol voor BC in de regulatie van geslachtshormonen. De tegengestelde genexpressie veranderingen in de long werden vergezeld door een significante regulatie van veel enzymen betrokken bij de steroïdenproductie en conversie maar alleen in de longen van mannelijke Bcmo $1 \%$ muizen. Bovendien bleken testosteron niveaus zeer variabel te zijn in $\mathrm{Bcmo1} \%$ muizen die $\mathrm{BC}$ in het dieet hadden, maar niet in de controle $\mathrm{Bcmo1} \%$ muizen of de $\mathrm{Bcmo1}^{+/+}$muizen. Wij hypothetiseren dan ook dat $\mathrm{BC}$ in staat is om hormoon productie of conversie te veranderen.

Om een goede risico-baten analyse van $\mathrm{BC}$ te maken is het belangrijk om te weten of effecten van BC specifiek zijn voor de long. Daarom hebben we BC geïnduceerde genexpressie veranderingen in long weefsel vergeleken met effecten in andere organen die van belang zijn in de $\mathrm{BC}$ biologie. We vergeleken effecten in de long met effecten in wit vetweefsel dat belangrijk is voor de BC opslag [13], en met effecten in de lever welke belangrijk is voor zowel het $\mathrm{BC}$ metabolisme als de BC opslag [14].

In Hoofdstuk 8 laten we zien dat slecht een paar genen ( $1 \%)$ die gereguleerd zijn door $\mathrm{BC}$ in de long, ook werden gereguleerd in lever en in het zogenaamde 'inguinal' wit vetweefsel. Hieruit blijkt dat effecten van BC op de expressie van genen zeer weefsel speci- 
fiek was. Bovendien was de hoeveelheid genen die van expressie veranderd waren door de $\mathrm{BC}$ interventie veel kleiner dan na knock-out van Bcmo1 of verschillen in geslacht (man versus vrouw). Ondanks dat we in Hoofdstuk 8 beschrijven dat slechts $1 \%$ van de genen die gereguleerd waren door BC in long weefsel ook gereguleerd waren in lever en vet weefsel, beschrijven we in Hoofdstuk 9 dat de processen die door BC gereguleerd waren in longweefsel van vrouwelijke $B c m o 1 \%$ muizen zoals beschreven in Hoofdstuk 5 of in mannelijke Bcmo 1\% muizen zoals beschreven in Hoofdstuk 6 of de tegengestelde verandering in gen expressie in mannelijke en vrouwelijke Bcmo1\% muizen zoals beschreven in Hoofdstuk 7, niet specifiek voor longweefsel waren wanneer we de analyse op proces niveau uitvoerden.

Samenvattend beschrijven we in dit proefschrift dat BC 1) ontstekingsgeïnduceerde genotoxiciteit en 2) genexpressie in de long kan veranderen, waarbij enkele processen beinvloedt worden die betrokken kunnen zijn bij long carcinogenese (Fig. 1). 


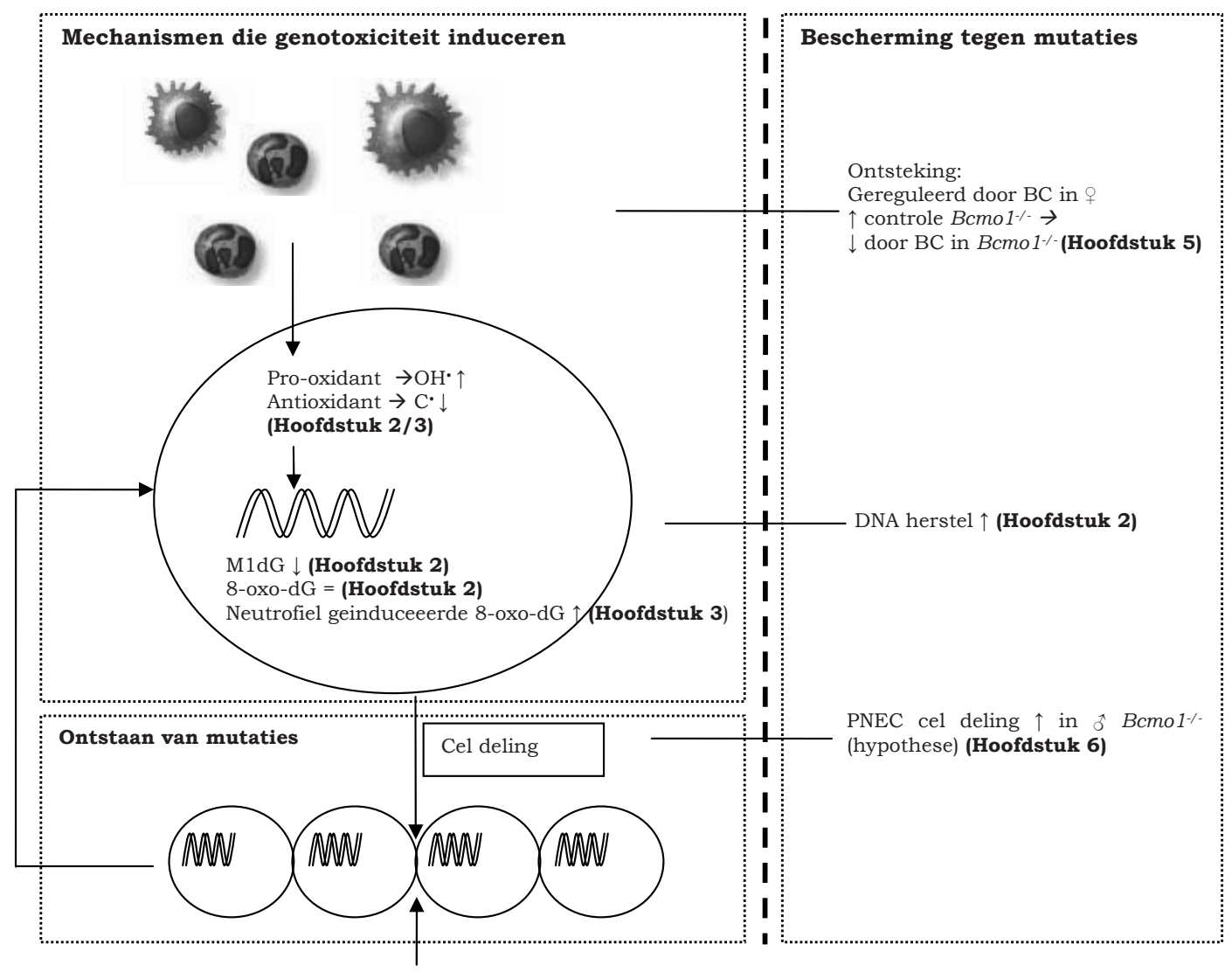

$\mathrm{BC}$ beïnvloed geslachtshormonen in $\mathrm{Bcmo1}^{1 /}$ muizen (Hoofdstuk 7)

Zijn de effecten van BC long specific?

Effect van $\mathrm{BC}<<$ effect van geslacht of Bcmo1 aanwezigheid (Hoofdstuk 8)

Hoge mate van interactie met weefsel, geslacht en aanwezigheid (Hoofdstuk 8)

Genen gereguleerd 1\% overlap met vet en lever (Hoofdstuk 8)

Effecten op process niveau zijn niet long specifiek (Hoofdstuk 9)

Figuur 1: Samenvatting van de belangrijkste bevindingen van de werking van BC in de long zoals beschreven in dit proefschrift, met de hoofdstukken die deze bevindingen beschrijven dik gedrukt. 


\section{Referenties}

[1] P. Palozza Prooxidant actions of carotenoids in biologic systems, Nutr Rev 56 (1998) 257-265.

[2] P. Palozza, S. Serini, F. Di Nicuolo, E. Piccioni and G. Calviello Prooxidant effects of beta-carotene in cultured cells, Mol Aspects Med 24 (2003) 353-362.

[3] J.S. Brody and A. Spira State of the art. Chronic obstructive pulmonary disease, inflammation, and lung cancer, Proc Am Thorac Soc 3 (2006) 535-537.

[4] G. Lee, T.C. Walser and S.M. Dubinett Chronic inflammation, chronic obstructive pulmonary disease, and lung cancer, Curr Opin Pulm Med 15 (2009) 303-307.

[5] R. Robledo and B. Mossman Cellular and molecular mechanisms of asbestos-induced fibrosis, J Cell Physiol 180 (1999) 158-166.

[6] A.G. Schwartz, G.M. Prysak, C.H. Bock and M.L. Cote The molecular epidemiology of lung cancer, Carcinogenesis 28 (2007) 507-518.

[7] C.M. Doerschuk Leukocyte trafficking in alveoli and airway passages, Respir Res 1 (2000) 136-140.

[8] N. Gungor, R.W. Godschalk, D.M. Pachen, F.J. Van Schooten and A.M. Knaapen Activated neutrophils inhibit nucleotide excision repair in human pulmonary epithelial cells: role of myeloperoxidase, Faseb J 21 (2007) 2359-2367.

[9] A. Wyss Carotene oxygenases: a new family of double bond cleavage enzymes, J Nutr 134 (2004) 246S$250 \mathrm{~S}$.

[10] S. Hessel, A. Eichinger, A. Isken, J. Amengual, S. Hunzelmann, U. Hoeller, V. Elste, W. Hunziker, R. Goralczyk, V. Oberhauser, J. von Lintig and A. Wyss CMO1 deficiency abolishes vitamin A production from beta-carotene and alters lipid metabolism in mice, J Biol Chem 282 (2007) 33553-33561.

[11] B.I. Gustafsson, M. Kidd, A. Chan, M.V. Malfertheiner and I.M. Modlin Bronchopulmonary neuroendocrine tumors, Cancer 113 (2008) 5-21.

[12] W.D. Travis, L.B. Travis and S.S. Devesa Lung cancer, Cancer 75 (1995) 191-202.

[13] L.A. Kaplan, J.M. Lau and E.A. Stein Carotenoid composition, concentrations, and relationships in various human organs, Clin Physiol Biochem 8 (1990) 1-10.

[14] R.S. Parker Carotenoids in human blood and tissues, J Nutr 119 (1989) 101-104. 


\section{Dankwoord}

Ruim 4 jaar en 200.000 kilometer verder ligt hier het resultaat: mijn proefschrift! Ik kan wel zeggen dat ik trots ben. Ik ben bevoorrecht geweest met de mensen om mij heen, die me allen veel steun en hulp hebben gegeven!

Allereerst wil ik mijn (co)-promotoren Jaap, Roger en Frederik-Jan bedanken! Jullie waren vanaf dag 1 van mijn promotie een goed team en jullie ogenschijnlijk onuitputtelijke enthousiasme heeft mij altijd enorm weten te motiveren.

Roger, bedankt voor al jouw geweldige hulp. Toen ik na een jaar RIKILT naar Maastricht kwam heb je mij enorm geholpen om een geweldig onderzoek bij GRAT neer te zetten. Door je enthousiasme en enorme nieuwsgierigheid was het erg motiverend om met je te werken. Aan creativiteit bij het zoeken naar mechanismen, hypotheses en verbanden was er geen gebrek waardoor het erg prettig was om met je over resultaten te filosoferen. En hoe zal ik je hulp bij het maken van 'sexy' artikelen ooit kunnen vergeten?

Roger, jij vormt een geweldig team samen met Frederik-Jan, waarbij jullie aan een half woord genoeg hebben. Dit is voor een AIO, die de wetenschap aan het ontdekken is op velerlei plekken in Nederland, een geweldige stabiele basis. Frederik-Jan, jij gaf me veel ruimte om mijn eigen creativiteit en inzichten te testen en te ontwikkelen, maar corrigeerde en discussieerde waar nodig.

Jaap, met recht nu gepromoveerd van co-promotor tot promotor van mijn proefschrift! Ik denk dat je voordat ik begon, niet had verwacht dat mijn 4-jarige AIO periode op deze manier zou verlopen en zou eindigen met jou als eerste aanspreekpunt (lees professor) bij Human and Animal Physiology (HAP). Jouw enthousiasme, kritische blik en wetenschappelijke kennis waren onmisbaar voor mijn 'wetenschappelijke opvoeding'. Deze zal in de toekomst nog zeker van pas gaan komen!

Nicole, zonder jou was dit project nooit gestart. Ik ben je enorm dankbaar voor je hulp en engelengeduld bij alle fretten PCR's aan de start van mijn AIO traject. Sandra, je was een waardige opvolger. Ik kon het erg goed met je vinden op zowel persoonlijk als wetenschappelijk vlak. Je hebt mij zeer goed geholpen om mijn horizon te verbreden. Bedankt!

Marjolein, tijdens de start van mijn project heb je mij erg goed geholpen, met het in kaart brengen van zowel wetenschappelijke als technische 'knowhow'. Ook de goede gesprekken die we nog vaak aan het eind van de dag op de verlaten kamer 1.53 hadden, zal ik niet gauw vergeten. Natuurlijk heb ik ook enorm veel van je goede organisatorische vaardigheden kunnen leren! Evelien, toen ik terug kwam van GRAT hebben we in een korte tijd erg veel samen gewerkt. Één woord en analyses werden uitgevoerd of technieken uitgezocht. Dank je voor al je hulp, en natuurlijk ook de gezellige tijd! Dini en Peter, wat was het fijn om met jullie samen te werken! Altijd waren we welkom voor onze NO-metingen, waarbij ook jullie engelengeduld hadden. Sophie en Katja, bedankt voor jullie hulp bij het analyseren van mijn longweefsel. Hans, jouw geweldige bek- 
waamheid bij het analyseren van hormoonprofielen heeft me enorm geholpen! Annelies, zonder jouw bijdrage had ik het eind volgens mij niet gered! De laatste loodjes wogen toch wel een behoorlijk stuk minder zwaar met jouw hulp. Net zoals bij Evelien, had ik bij jou aan een half woord genoeg en na even doorbikkelen lagen er weer geweldige resultaten (beiden hebben fold changes van 1.2, 1.3 bevestigd, voor insiders: een geweldig staaltje vakmanschap). Ook je enthousiasme bij het organiseren van team-verband stukjes en uitjes resulteert in een geweldig en gezellig team.

Buiten alle geweldige technische en vakinhoudelijke hulp, is er natuurlijk ook nog het fenomeen 'promoveren'. Maaike, Vincent en Wendy bedankt voor al jullie hulp, en leuke gesprekken. Soms is het erg fijn om eens met 'lotgenoten' te praten (zoals je het zo mooi omschrijft Maaike). Ook mijn kamergenoten Rolf en Evert mogen natuurlijk niet in het rijtje ontbreken. Ik heb het altijd enorm naar mijn zin gehad. En Rolf, het was wel gezellig (en natuurlijk ook handig) samen een kamer te delen in gemeenschap van goederen...' (ik heb er vaak genoeg van geprofiteerd).

Het leuke van promoveren is ook het samenwerken met studenten. Sonja, bedankt voor al je hulp en zonder jou waren de mooie 'hoofdstukplaatjes' nooit tot stand gekomen. Boukje, bedenkt voor je hulp met de NO-assays.

Eigenlijk was iedereen bij het RIKILT en later bij HAP enorm betrokken en was het op beide plekken enorm gezellig. Kortom: Annelies, Evelien, Wendy, Victor, Rolf, Gert-Jan, Katja, Arie, Sophie, Inge, Nicole, Evert, Erik, Sandra, Meryem, Anita, Annika, Hans, Melissa, Vincent, Harry, Marjolein, Marjorie, Maaike, Peter, Dini, Sonja, Boukje, Femke, Loes, Elise bedankt voor de geweldige tijd!

Na ongeveer een jaar was het zover, ik ging van het RIKILT als echte 'Mestreechse' AIO toch ook eens in Maastricht werken, en wel bij GRAT. Wat eerst een korte periode van 2 maanden zou worden, werd uiteindelijk een jaar. In tegenstelling tot het merendeel van de gevallen waarbij uitloop veroorzaakt wordt door tegenslagen, was het in mijn geval voornamelijk toe te schrijven aan successen. Ik ben dan ook veel mensen dank verschuldigd die ervoor gezorgd hebben dat ik er altijd met enorm veel plezier gewerkt heb. Allereerst natuurlijk mijn kamergenootjes Dennie en Joyce die van mijn begin bij GRAT tot mijn vertrek geweldig waren. Het was in het begin even wennen dat kamergesprekken toch weer in 'het plat' konden. Soms waren er nog wel eens lastige woorden, zoals 'vierst' (of zoiets Dennie), maar het kwam altijd goed! Karen B., zonder jou waren de pauzes nooit zo leuk geweest. Nicole en Sabine, het was geweldig om samen met jullie de NVT AIO/OIO dagen te organiseren. In het bijzonder wil ik ook nog de andere AIO's bedanken die tijdens mij GRAT-tijd aanwezig waren voor de gezelligheid: Nejla, Karen M., Pim, Yvonne, Anne, Joep, Marieke, Joost en Jonathan bedankt! Ad en Jacco, radicalen, radicaalmechanismen, neutrofielen.... ik kan wel zeggen dat ik enorm veel van jullie geleerd heb. Bedankt voor jullie hulp bij mijn hoofdstukken 2 en 3! Lou, bedankt voor al je hulp bij mijn 8-oxo-dG analyses, en wat zul je gevloekt hebben toen het DNA weggeblazen was. Edwin jij ook bedankt voor je hulp bij mijn ijzer-analyses. Verder heb ik bij GRAT een geweldige tijd gehad en hiervoor wil ik graag iedereen bedanken! Uiteindelijk natuurlijk ook een speciaal bedankje voor Marie-Claire. Bedankt voor je hulp wat soms resulteerde in enorme email uitwisselingen voor het regelen van mijn 
promotie. Je hebt toch enorm je best gedaan om uiteindelijk het onmogelijke mogelijk te maken!

Dan natuurlijk nog vrienden en familie. En dit is het dan... Het 'boekje'. Jullie hebben voor de nodige ontspanning gezorgd en hebben veelal geweldig meegeleefd als ik weer eens op het laatste moment een afspraak afzegde of even niets van mij liet horen. Pap en mam, bedankt dat jullie altijd klaar stonden indien er iets moest gebeuren, of als ik weer op het laatste moment iets geregeld wilde hebben. Marij, jij was natuurlijk bij uitstek dé persoon waarmee ik over het alles omvattende woord 'promoveren' en 'onderzoek' kon praten. Ik wens je ook alle succes met jouw laatste stuk van je promotie en je kunt nu dan toch alvast gaan proeven hoe het is om in de spotlight te staan!

Ralph, bedankt voor je eindeloze begrip en steun. Als ik weer eens een keer veel te laat thuiskwam stond jij altijd klaar en was jij altijd mijn luisterend oor. Zonder jou was dit eindresultaat zeker niet gelukt. Een mooi voorbeeldje van jouw toewijding en steun aan mijn onderzoek staat wel in hoofdstuk 4. Door jouw hulp is figuur 3 tot stand gekomen. Ikzelf had het nooit gered om 1000 random trekkingen uit een data-set te doen zonder jouw zelf geschreven programmaatje! Maar jij hebt de smaak van het begrip 'promoveren' geproefd, en kan dan natuurlijk niet achterblijven! Ralph, ik wens je ook alle succes met je promotie, en dan zijn de rollen natuurlijk omgedraaid!

Iedereen bedankt! 


\section{Curriculum Vitae Yvonne van Helden}

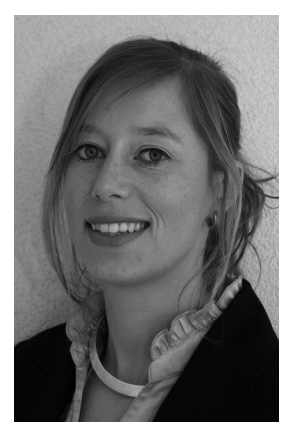

Yvonne Gerarda Jacoba van Helden was born on May 31 1981 in Grubbenvorst, The Netherlands. After graduation from the secondary education at the St. Thomascollege in Venlo in 1999, she started her study Molecular Sciences at Wageningen University. During this study she gained also much interest in Nutrition and Health in which she followed many extra subjects. After finishing her Molecular Biological thesis at the food and consumer product safety authority (VWA) in Eindhoven, the Toxicological thesis at Toxicology at Wageningen University, an internship at Numico in Wageningen, she received a scholarship (LEAFSE) to study at the University of Queensland in Australia for half a year. Thereafter she obtained two Master's degrees; one in Molecular Sciences and one in Nutrition \& Health. From September 2005 till December 2009 she was appointed as a PhD student at the department of Health Risk Analysis and Toxicology at Maastricht University. This research was conducted at RIKILT-Institute of Food Safety in Wageningen, Health Risk Analysis and Toxicology at Maastricht University and Human and Animal Physiology at Wageningen University. Part of this study was also conducted in collaboration with many international partners. Besides the conduct of her research project, she attended many courses which will result in the VLAG certificate. Moreover, several modules as part of the Postgraduate Education in Toxicology to become a European registered Toxicologist were fulfilled. From December 2009 onwards, Yvonne has been working as a postdoctoral fellow at Human and Animal Physiology at Wageningen University. 


\section{List of publications}

Yvonne G.J. van Helden, Jaap Keijer, Sandra G. Heil, Catalina Picó, Andreu Palou, Paula Oliver, Armelle Munnia, Jacob J. Briedé, Marco Peluso, Nicole Franssen-van Hal, Frederik J. van Schooten, Roger W. L. Godschalk. Beta-carotene affects oxidative stress-related DNA damage in lung epithelial cells and in ferret lung. Carcinogenesis. 2009 Dec;30(12):2070-6

Yvonne G.J. van Helden, Jaap Keijer, Ad M. Knaapen, Sandra G. Heil, Jacob J. Briedé, Frederik J. van Schooten, Roger W.L. Godschalk. Beta-carotene metabolites enhance inflammation-induced oxidative DNA damage in lung epithelial cells. Free Radical Biology \& Medicine. 2009 Jan 15;46(2):299-304

Jaap Keijer, Yvonne G. J. van Helden, Annelies Bunschoten, Evert M. van Schothorst. Transcriptome analysis in benefit-risk assessment of micronutrients and bioactive food components. Molecular Nutrition \& Food Research. 2010 Feb;54(2):240-8

Yvonne G.J. van Helden, Sandra. G. Heil, Frederik J. van Schooten, Evelien Kramer, Susanne Hessel, Jaume Amengual, Joan Ribot, Katja Teerds, Adrian Wyss, Georg Lietz, M. Luisa Bonet, Johannes von Lintig, Roger W.L. Godschalk, Jaap Keijer. Knockout of the Bcmo1 gene results in an inflammatory response in female lung, which is suppressed by dietary beta-carotene. Cellular and Molecular Life Sciences. 2010; doi: 10.1007/s00018-0100341-7

Yvonne G.J. van Helden, Roger W. Godschalk, Sandra G. Heil, Annelies Bunschoten, Susanne Hessel, Jaume Amengual, M. Luisa Bonet, Johannes von Lintig, Frederik J. van Schooten, Jaap Keijer. Downregulation of Fzd6 and Cthrc1 and upregulation of olfactory receptors and protocadherins by dietary beta-carotene in lungs of $\mathrm{Bcmo}^{1 /-}$ mice. Carcinogenesis. 2010; doi:10.1093/carcin/bgq083

Yvonne G.J. van Helden, Roger W.L. Godschalk, Hans Swarts, Peter C.H. Hollman, Frederik J. van Schooten, Jaap Keijer. Beta-carotene affects gene expression in lungs of male and female Bcmo 1\% mice in opposite directions. Submitted

Jaume Amengual*, Erwan Gouranton*, Yvonne G. J. van Helden*,Susanne Hessel, Joan Ribot, Evelien Kramer, Beata Kiec-Wilk, Ursula Razny, Georg Lietz, Adrian Wyss, Aldona Dembinska-Kiec, Andreu Palou, Jaap Keijer, Jean François Landrier, M. Luisa Bonet and Johannes von Lintig. Dietary Beta-carotene supplementation reduces adiposity in mice in a beta-carotene 15,15'-monooxygenase (Bcmo1)-dependent manner. Submitted * Joint first author

Yvonne G.J. van Helden, Roger W.L. Godschalk, Johannes von Lintig, Georg Lietz, JeanFrancois Landrier, M. Luisa Bonet, Frederik J. van Schooten, Jaap Keijer, Global gene expression response of mouse lung, liver and white adipose tissue to beta-carotene supplementation, knockout of Bcmo 1 and gender. Ready for submission

Yvonne G.J. van Helden, Roger W.L. Godschalk, Frederik J. van Schooten, Jaap Keijer. Organ specificity of beta-carotene induced lung gene expression changes in Bcmo1\% mice. Ready for submission 


\section{Color Figures}

\section{Chapter 2, Figure 4}

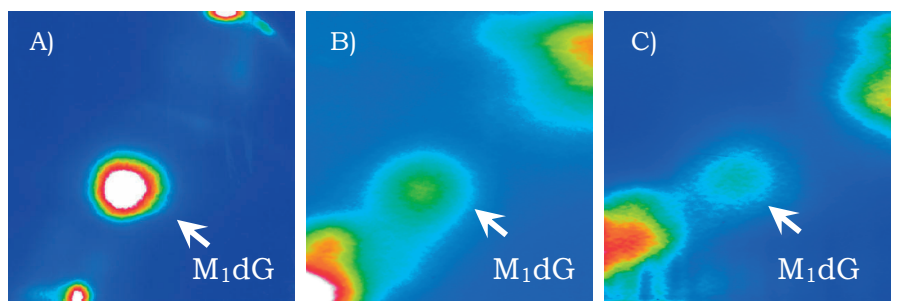

Figure 4: ${ }^{32} \mathrm{P}-\mathrm{DNA}$ post-labeling chromatograms. ${ }^{32} \mathrm{P}-\mathrm{DNA}$ post-labeling chromatograms showing patterns of $\mathrm{M}_{1} \mathrm{dG}$ in (A) MDA-treated CT-DNA, (B) $\mathrm{H}_{2} \mathrm{O}_{2}$-treated cells and (C) $\mathrm{H}_{2} \mathrm{O}_{2}$ in combination with BC-treated cells. 


\section{Chapter 5, Figure 3}

A)

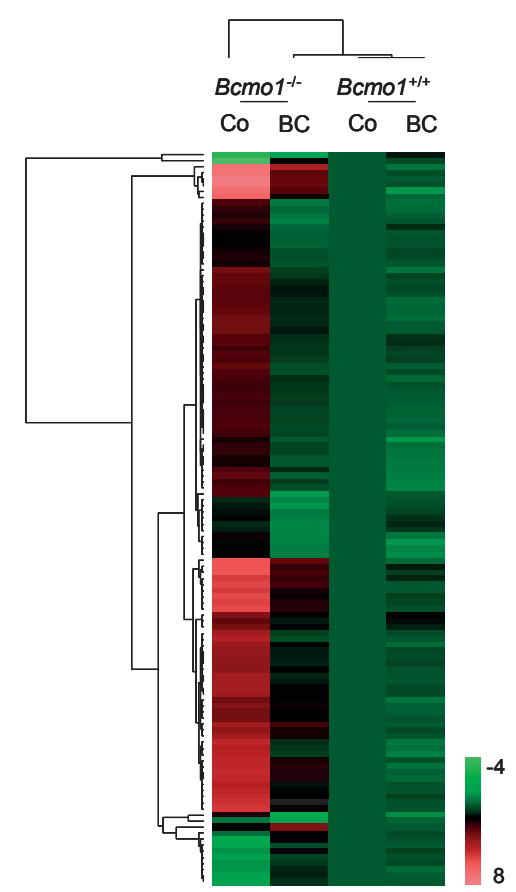

B)

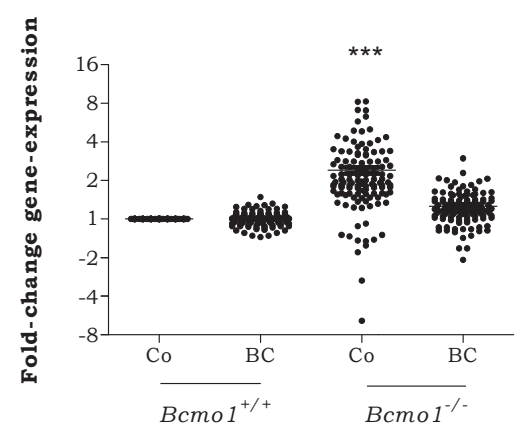

Figure 3: (A) Hierarchical clustering of all experimental groups based on the expression of all genes regulated by $\mathrm{BC}$ in the $\mathrm{Bcmo1} / \mathrm{-}$ mice with an absolute $\mathrm{FC}>1.5$ and $\mathrm{p}<0.05$. The expression of every gene is represented relative to the expression in $\mathrm{Bcmo1}^{+/+}$control mice, which was set to 1.0. Genes and groups were clustered using Euclidean distance (linear scaled) UPGMA. (B) Graph representing the expression level of all genes regulated by $\mathrm{BC}$ in the $\mathrm{Bcmo1} / \mathrm{-}$ mice with an absolute $\mathrm{FC}>1.5$ and $\mathrm{p}<0.05$, in all groups. The expression of every genes is represented relative to the expression in $\mathrm{BCmo1}^{+/+}$control mice, which was set to 1.0 . The absolute expression was significantly higher $(\mathrm{p}<0.001)$ in $\mathrm{Bcmo1}^{-}$- control mice compared to mice in the other groups. There was no significant difference in expression level between the other groups. ${ }^{* * *} \mathrm{p}<0.001$. 


\section{Chapter 5, Figure 6}
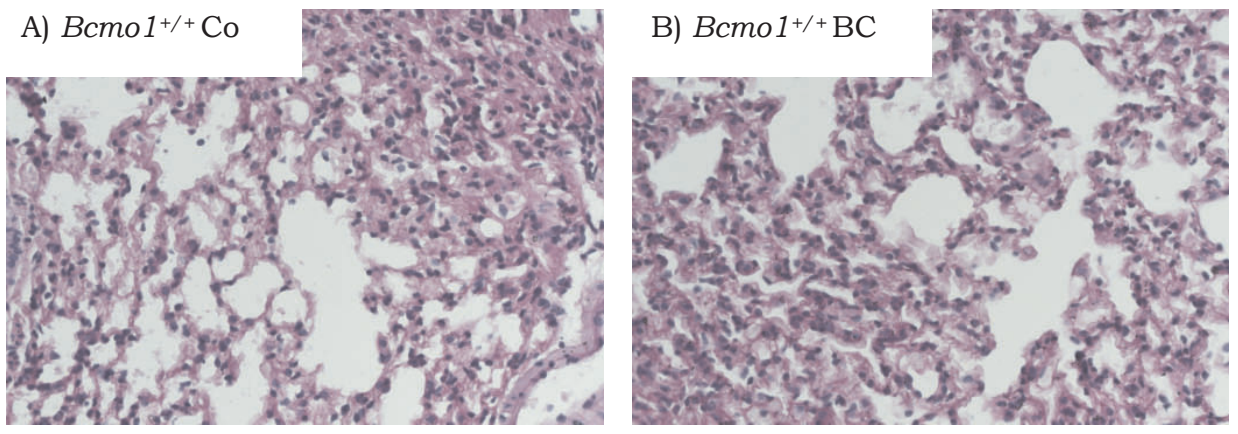

C) $\mathrm{Bcmo1 \%} \mathrm{Co}$
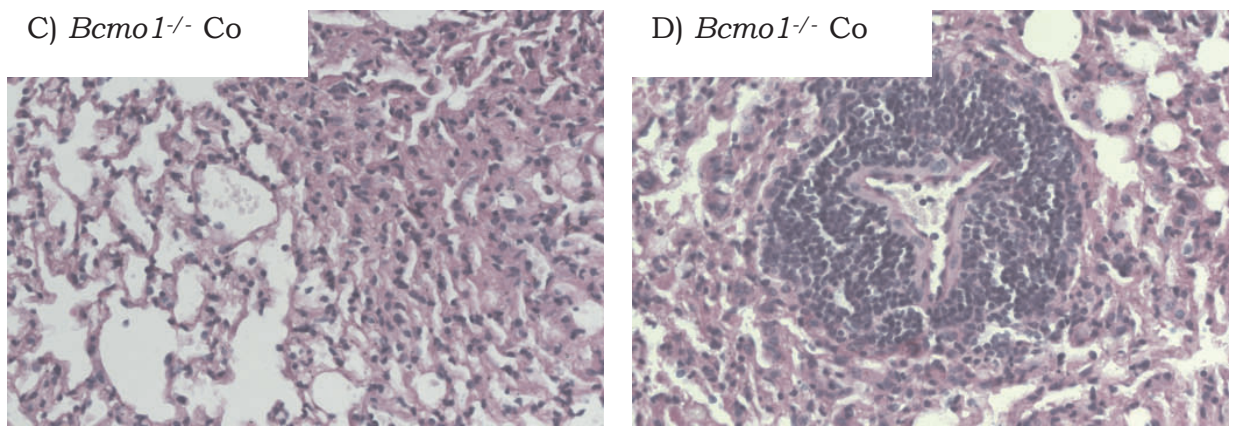

E) $\mathrm{Bcmo1 \%}$ BC

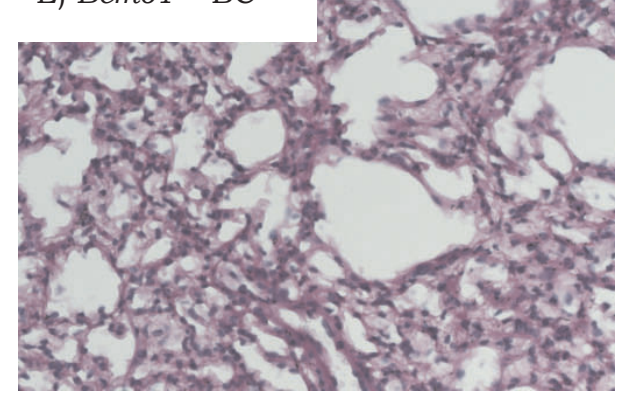

Figure 6: Histological analysis of lung tissue. Representative sections (right upper lobe) of the lung of $\mathrm{Bcmo1}^{+/+}$mice $(\mathrm{A}$ and $\mathrm{B})$ and $\mathrm{Bcmo1} \%$ mice $(\mathrm{C}, \mathrm{D}$ and $\mathrm{E})$ on a control diet $(\mathrm{A}, \mathrm{C}, \mathrm{D})$ or a $\mathrm{BC}$ enriched diet (B and E). The lungs of $B \mathrm{cmol}^{-} \%$ mice receiving the control diet $(\mathrm{C}, \mathrm{D})$ had a different appearance compared to the lungs of the other groups, with an increase in inflammatory cells and occasionally some inflamed area's (D). Magnification: 40 times. 


\section{Chapter 6, Figure 3}

A)

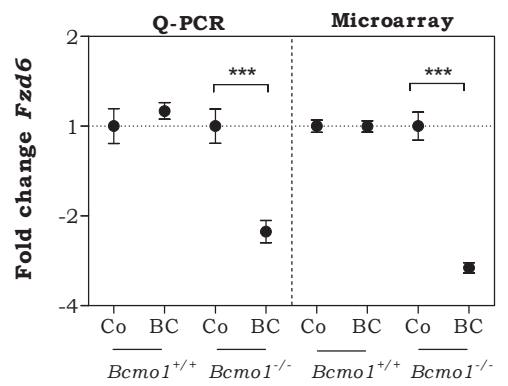

B)

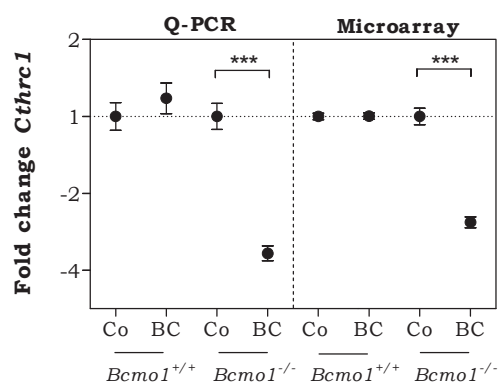

C)

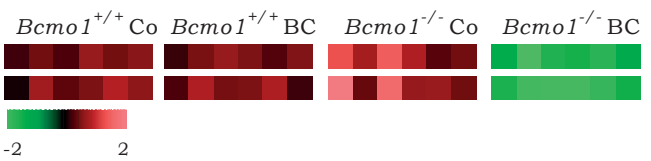

Gene name

Collagen triple helix repeat containing 1

Frizzled homolog 6

Gene symbol

Cthre 1

Fzd6

Fig. 3: The expression of the genes Fzd6 (A) and Cthrc1 (B) in the BC supplemented mice relative to the control diet fed mice were confirmed by Q-PCR using the stable reference genes Stx5a and Rnf130. Data represent the average gene expression \pm SEM compared to $B c m o 1^{+/+}$control mice. ${ }^{* * *} \mathrm{p}<0.001$ using a Student's $t$-test on the log transformed data. (C) Microarray based heatmap shows a low interindividual difference between the mice for the genes Cthrc1 and Fzd6 and a decreased gene expression of these genes in $\mathrm{BC}$ supplemented $\mathrm{Bcmo1} \%$ mice compared to $\mathrm{Bcmo} 1^{+/+}$mice and $\mathrm{Bcmo} 1^{\%}$ control mice. 


\section{Chapter 9, Figure 2}

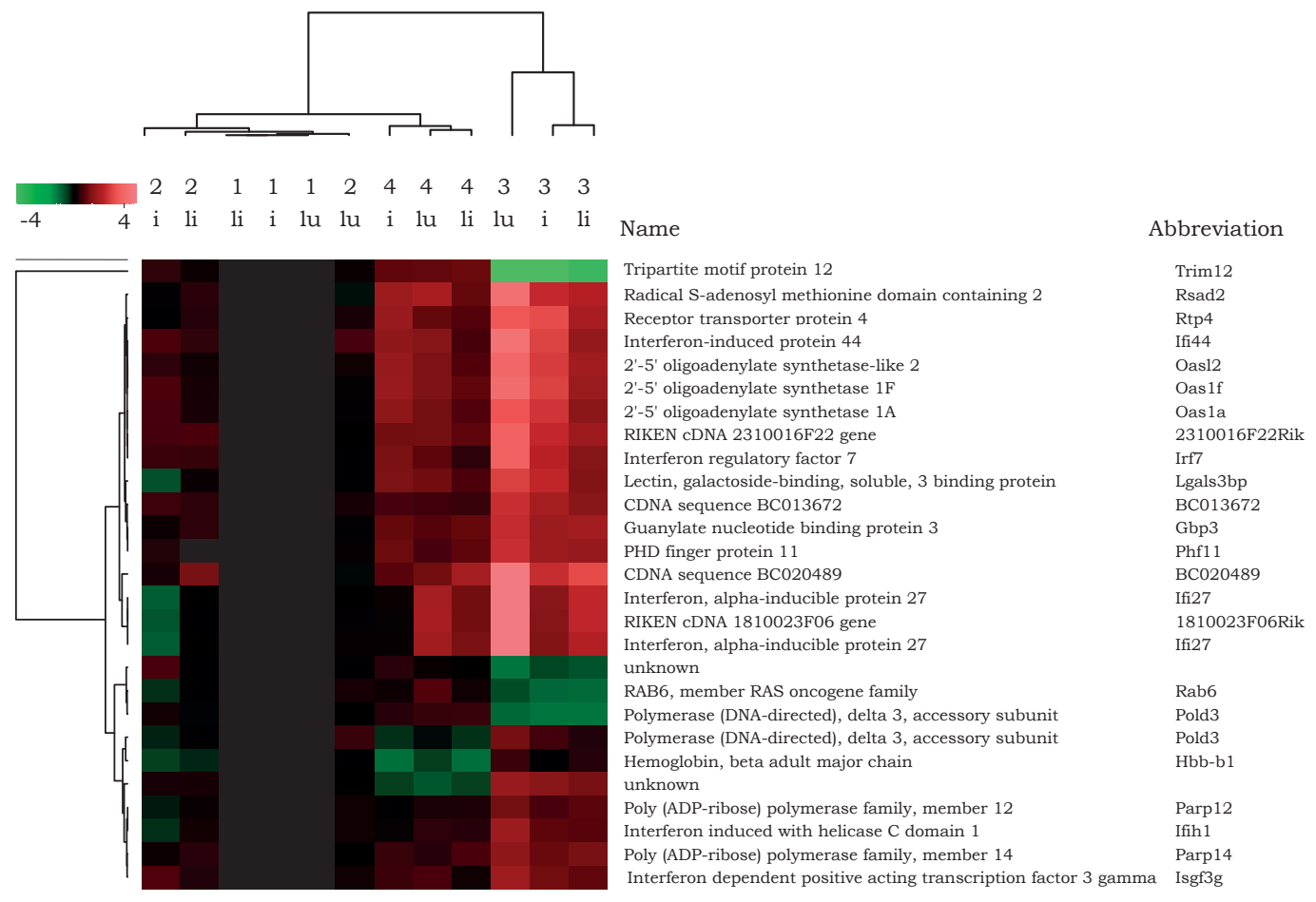

Figure 2: Hierarchical cluster analysis. Hierarchical cluster analysis of the 27 genes regulated by $\mathrm{BC}$ in the three tissues, lung, liver and iWAT of female $\mathrm{Bcmo1} \%$ mice, for all three tissues and the groups control $\mathrm{Bcmo1}^{+/+}$mice, BC supplemented $\mathrm{Bcmo1}^{+/+}$mice, control $\mathrm{Bcmo1} /$ mice and $\mathrm{BC}$ supplemented $\mathrm{Bcmo1} \%$ mice. The fold change gene expression is relative to the gene expression in control $\mathrm{Bcmo1^{+/+ }}$ mice for every tissue. The different groups are displayed with 1: $\mathrm{Bcmo} 1^{+/+}$control mice, 2: $\mathrm{Bcmo} 1^{+/+} \mathrm{BC}$ mice, 3: $\mathrm{Bcmo1}^{\%}$ control mice and 4: $\mathrm{Bcmo1}^{\%} \mathrm{BC}$ mice and the tissues with lu: lung, li: liver and i: iWAT. 